\title{
CONTROLS ON EARTHQUAKE RUPTURE AND TRIGGERING MECHANISMS IN SUBDUCTION ZONES
}

\author{
By \\ Andrea Lesley Llenos \\ Sc.B., Brown University, 2004 \\ Submitted in partial fulfillment of the requirements for the degree of \\ Doctor of Philosophy \\ at the \\ MASSACHUSETTS INSTITUTE OF TECHNOLOGY \\ and the \\ WOODS HOLE OCEANOGRAPHIC INSTITUTION
}

June 2010
(C) 2010 Andrea L. Llenos
All rights reserved.

The author hereby grants to MIT and WHOI permission to reproduce and to distribute publicly paper and electronic copies of this thesis document in whole or in part in any medium now known or hereafter created.

Author

Joint Program in Oceanography/Applied Ocean Science and Engineering Massachusetts Institute of Technology and Woods Hole Oceanographic Institution February 12, 2010

Certified by

Jeffrey J. McGuire Associate Scientist, Department of Geology and Geophysics, WHOI Thesis supervisor

Accepted by

Bradford H. Hager

Professor, Department of Earth, Atmospheric, and Planetary Science, MIT Co-chair, Joint Committee for Geology and Geophysics 


\title{
CONTROLS ON EARTHQUAKE RUPTURE AND TRIGGERING MECHANISMS IN SUBDUCTION ZONES
}

\author{
By \\ Andrea Lesley Llenos \\ Submitted to the MIT/WHOI Joint Program in Oceanography/Applied Ocean Science \\ and Engineering on February 12, 2010 in partial fulfillment of the requirements for the \\ degree of Doctor of Philosophy in Marine Geophysics
}

\begin{abstract}
Large earthquake rupture and triggering mechanisms that drive seismicity in subduction zones are investigated in this thesis using a combination of earthquake observations, statistical and physical modeling. A comparison of the rupture characteristics of $M \geq 7.5$ earthquakes with fore-arc geological structure suggests that long-lived frictional heterogeneities (asperities) are primary controls on the rupture extent of large earthquakes. To determine when and where stress is accumulating on the megathrust that could cause one of these asperities to rupture, this thesis develops a new method to invert earthquake catalogs to detect space-time variations in stressing rate. This algorithm is based on observations that strain transients due to aseismic processes such as fluid flow, slow slip, and afterslip trigger seismicity, often in the form of earthquake swarms. These swarms are modeled with two common approaches for investigating time-dependent driving mechanisms in earthquake catalogs: the stochastic Epidemic Type Aftershock Sequence model [Ogata, 1988] and the physically-based ratestate friction model [Dieterich, 1994]. These approaches are combined into a single model that accounts for both aftershock activity and variations in background seismicity rate due to aseismic processes, which is then implemented in a data assimilation algorithm to invert catalogs for space-time variations in stressing rate. The technique is evaluated with a synthetic test and applied to catalogs from the Salton Trough in southern California and the Hokkaido corner in northeastern Japan. The results demonstrate that the algorithm can successfully identify aseismic transients in a multi-decade earthquake catalog, and may also ultimately be useful for mapping spatial variations in frictional conditions on the plate interface.
\end{abstract}

Thesis supervisor: Dr. Jeffrey J. McGuire

Title: Associate Scientist with Tenure 


\section{Acknowledgments}

This thesis would not have been possible without the help and support of many, many people over the past six years, only a few of whom can be listed here. First and foremost, my deepest thanks go to my advisor Jeff McGuire, for all his time, support, confidence, patience, tolerance and nudging when I needed it. I have learned a tremendous amount from him and look forward to continuing to do so throughout the rest of my scientific career. I am also grateful for the help and insights provided by my thesis committee: Jian Lin, Rob Reves-Sohn, and Brad Hager, and thank Greg Hirth for chairing my defense. I would also like to thank current and former members of G\&G and the EAPS Geophysics group, especially Laurent Montési, Mark Behn, Dan Lizarralde, Stéphane Rondenay and Brian Evans. I learned a lot from my various interactions with them in seminars, classes, projects, casual chats, and field trips. I'm also grateful for my fellow JP G\&G and EAPS students, and in particular my group-mate, Emily Roland.

I have benefited a great deal from working with Yosihiko Ogata and Jiancang Zhuang at the Institute of Statistical Mathematics in Tokyo, Japan, who taught me a lot about the ETAS model and were gracious hosts during my two visits to the ISM. Thanks also go to Koichi Katsura, Akiko Kutsuna and the rest of the Statistical Seismology group at ISM.

I greatly appreciate the efforts of the WHOI Academic Programs Office, especially Julia and Marsha; the MIT Education Office, especially Ronni, Carol, and Jacqui; the WHOI G\&G Administrative staff, especially Christina and Maryanne; the EAPS Administrative staff, especially Beth and Kerin; and WHOI CIS, especially Jeff D. and Jonathan. Their assistance over the years has been invaluable. I'd also like to thank Andrew Daly for his organizational work on all the Geodynamics field trips I was able to participate in and our numerous talks about international travel, and Rose for the friendly and encouraging chats.

Staying sane in grad school would have been much harder without the support and friendships I have found in the various groups I've been involved in over the years, in particular FloodSafe Honduras, the Tech Catholic Community, the MIT Warehouse Music Program, and the MIT Women's Chorale. I'm extraordinarily grateful for my friends up in Boston, throughout New England and beyond, particularly Sunita, Linda, Gail, Joanne, and Wan, who were very good at making sure I left my computer from time to time. A special thank you goes to Elizabeth, friend, roommate, and all-around partnerin-crime over the last few years, for so many things that I will sum up simply as "being there." Grad school would have been significantly less fun and more difficult without her help and support. Finally, much thanks and love to my family, especially my sister Tracy and my mom, for supporting me even while wondering what exactly I was up to. Their constant love and support has made it possible for me to get this far.

Funding for this research was provided by a WHOI Hollister Research Fellowship, a National Defense Science and Engineering Graduate Fellowship, National Science Foundation Division of Earth Sciences (EAR) grant \#0738641, United States Geological Survey National Earthquake Hazards Reduction Program Award \#G10AP00004, and the WHOI Academic Programs Office. 


\section{Table of Contents}

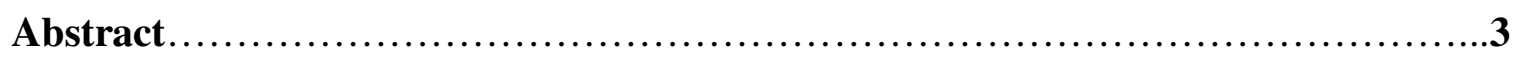

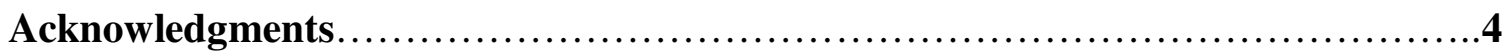

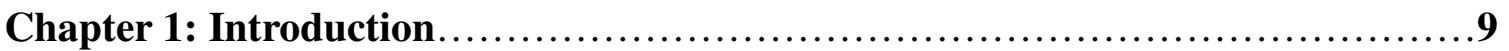

Chapter 2: Influence of fore-arc structure on the rupture extent of great subduction zone earthquakes...................................17

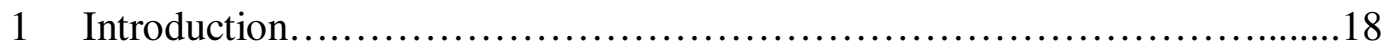

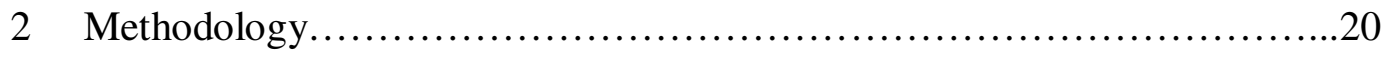

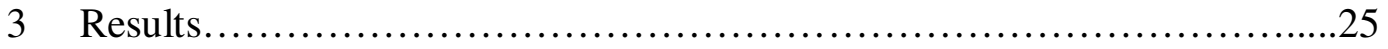

3.1 The 2003 Colima Mexico earthquake...............................25

3.2 The 2006 Java earthquake..........................................26

3.3 The 1995 Chile earthquake......................................27

3.4 Evaluation of bias from unmodeled propagation effects...............28

3.5 Summary of results................................................. 29

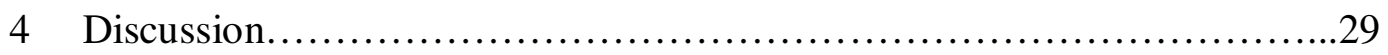

4.1 Fore-arc basin formation and wedge mechanics.......................30

4.2 How great earthquakes stop: Dynamic versus quenched heterogeneity ............................................... 31

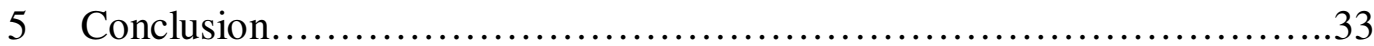

Appendix A: One-dimensional versus three-dimensional synthetics..............34

Appendix B: Results from additional events...............................47

Chapter 3: Modeling seismic swarms triggered by aseismic transients.............49

1 Introduction........................................................ 50

2 Models.................................................................

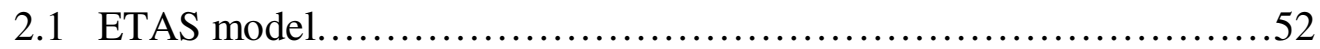


2.2 Rate- and state-dependent friction model........................52

2.3 Combining the ETAS and rate-state models.......................54

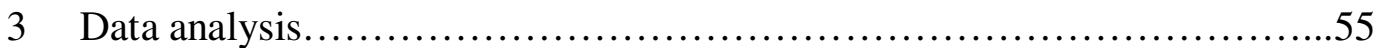

3.1 Detection of anomalous seismicity rates..........................55

3.1.1 2005 Obsidian Buttes swarm...............................55

3.1.2 2005 Kilauea swarm......................................56

3.1.3 2002 and 2007 Boso swarms..............................56

3.2 Fitting ETAS to earthquake swarms............................57

3.3 Comparison of rate-state predictions with observations................58

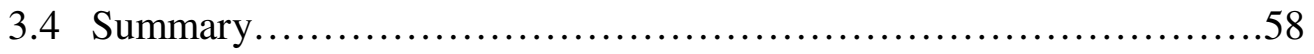

4 Discussion and conclusion......................................... 58

Chapter 4: Detecting aseismic strain transients from seismicity data.............61

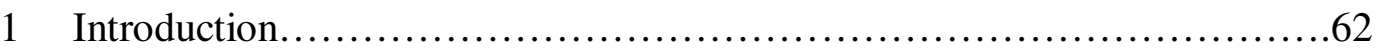

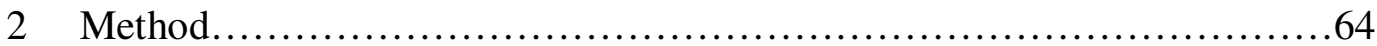

2.1 ETAS model...................................................65

2.2 Rate- and state-dependent friction model........................66

2.3 Combined ETAS/rate-state model.................................66

2.4 Extended Kalman Filter algorithm..............................67

2.5 Likelihood calculations.....................................69

2.6 Summary....................................................... 70

3 Synthetic test.......................................................... 71

3.1 Parameter estimation........................................ 71

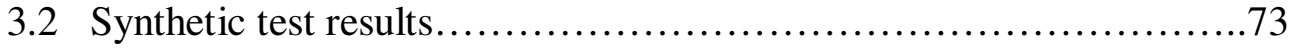

4 Data analysis: Salton Trough.........................................74

4.1 Data binning .............................................. 74

4.2 Parameter estimation.......................................... 75

4.3 Results..................................................... 76

$5 \quad$ Discussion......................................................... 76 
6 Conclusion..........................................................

Chapter 5: Detecting aseismic transients in the Hokkaido corner.....................95

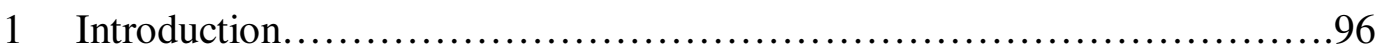

2 Method............................................................ 97

3 Data analysis and results........................................... 99

3.1 ETAS fitting to aftershock sequences.............................99

3.2 Filter results................................................ 101

3.2.1 Afterslip of the 1989 M7.1 and 1992 M6.9 Sanriku-oki earthquakes.......................................102

3.2.2 Afterslip of the 1994 M7.6 Sanriku-oki earthquake............102

3.2.3 Afterslip of the 2003 M8.0 Tokachi-oki earthquake...........103

3.2.4 Afterslip following moderate earthquakes...................104

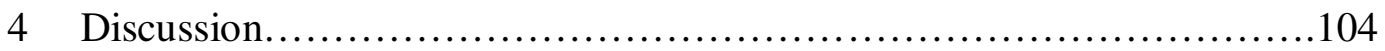

5 Conclusion.................................................... 106 


\section{Chapter 1: Introduction}

The largest earthquakes in the world occur on the megathrust of subduction zones, where almost $90 \%$ of the total seismic moment is released [Pacheco and Sykes, 1992]. Therefore, understanding the controls on large earthquake rupture and the triggering mechanisms that affect earthquake occurrence, in general, is critical in order to accurately assess both long-term and short-term seismic hazards in these regions. A wide spectrum of deformation occurs in subduction zones, ranging from the seismic (e.g., low frequency events, seismic tremor, microearthquakes, moderate-to-great interplate earthquakes) to the aseismic (e.g., stable slip, slow slip events, afterslip). All of these processes alter the regional stress state, but it is often difficult to monitor stress accumulation in subduction zones, as much of the seismogenic zone is located offshore.

The asperity model is commonly used to explain variations in large earthquake rupture and seismogenic behavior [Lay and Kanamori, 1981]. In this model, asperities, which may be related to frictional properties along the plate interface, lock during the interseismic period and then suddenly release the accumulated strain in an earthquake. This model predicts that long-lived (timescales of $\sim$ millions of years) frictional heterogeneity along the thrust controls rupture behavior. Recent studies by Song and Simons [2003] and Wells et al. [2003] based on correlating global and historical earthquake data with fore-arc geologic structure illuminated in the gravity field have provided evidence to support this model, suggesting that along-strike variations in frictional properties are important first-order controls on the rupture of great subduction zone earthquakes.

An alternative hypothesis is the seismic gap model [e.g., Thatcher, 1989], in which the occurrence of large earthquakes is controlled by short-lived (timescales of $\sim 100$ s of years) time-dependent stress heterogeneities. In this model, parts of the fault that have not ruptured in a long time have accumulated more stress and therefore are closer to failure than parts of the fault that have experienced recent earthquakes. Thus, large earthquakes tend to fill in the gaps where stress has not been released recently, and so rarely occur in the same place as the previous large earthquake. 
This thesis investigates the controls on large earthquake rupture and explores the triggering mechanisms that drive seismicity in subduction zones. Important questions that this thesis addresses include:

1) What factors influence where the largest earthquakes occur?

2) What controls how large these ruptures can grow?

3) How can we map spatial variations in frictional conditions on the plate interface that could potentially affect earthquake rupture?

4) How can we detect stress changes that could trigger these earthquakes, particularly offshore where land-based geodetic resolution is low?

To address the last two questions in particular, I develop a new technique that uses earthquake catalogs to identify space-time windows in which stressing rate changes due to transient aseismic processes are occurring. This novel way of producing estimates of stressing rate variations in space and time from seismicity data can be used in tectonic settings besides subduction zones and has other potential applications besides transient detection, including investigations of the physical processes that trigger earthquakes and improvements to short-term and real-time hazard assessment.

Chapter 2 sets the overall framework for this investigation by providing evidence to support the asperity model of large earthquake rupture. Following up on the hypothesis that gravity lows can be a proxy for seismogenic behavior [Song and Simons, 2003; Wells et al., 2003], I use a combination of $\mathrm{M} \geq 7.5$ earthquake observations and gravity anomaly data in subduction zones to examine the relationship between fore-arc geological structure revealed in the gravity field and the rupture extent of large subduction zone earthquakes. I demonstrate that large ruptures tend to stop in regions with positive gravity gradients by estimating a characteristic rupture length and directivity for each earthquake and comparing them with the local gravity field. This suggests that local increases in the gravity field can be related to physical conditions on the plate interface that favor rupture termination, such as a transition from velocityweakening (frictionally unstable) to velocity-strengthening (frictionally stable) behavior. As the gravity anomalies reflect geologic structure such as fore-arc basins that have 
formed over timescales on the order of millions of years [Fuller et al., 2006], this provides evidence that long-lived frictional heterogeneities (i.e., asperities) are responsible for controlling the rupture extent of large earthquakes.

This result raises several questions pertinent to estimating the seismic hazard in a subduction zone, including how to identify and map these frictional conditions on the plate interface, and how to determine when and where stress is accumulating that could cause an asperity to rupture. Transient aseismic deformation, such as slow slip events, fluid flow, or afterslip, may also alter the regional stress state, and their occurrence suggests the presence of velocity-strengthening conditions [e.g., Miyazaki et al., 2004]. Geodetic observations provide a way to monitor changes in deformation and estimate the degree of seismic coupling [e.g., Nishimura et al., 2004], but a large part of the seismogenic zone of a subduction zone is located offshore, where land-based geodetic instruments have little resolution and it is challenging to place seafloor instruments.

An alternative is to instead monitor spatial and temporal changes in seismicity rate. Strain transients due to aseismic processes, such as fluid flow [e.g., Hainzl and Ogata, 2005; Bourouis and Bernard, 2007], slow slip events [e.g., Segall et al., 2006; Ozawa et al., 2007; Lohman and McGuire, 2007; Delahaye et al., 2009], and afterslip [e.g., Matsubara et al., 2005; Hsu et al., 2006] have been shown to trigger variations in regional earthquake rates. Thus, seismicity rate variations in earthquake catalogs can potentially be used as a proxy to detect stressing rate variations in regions with limited geodetic data. Chapters 3-4 of my thesis are devoted to developing, testing, and applying this idea in a method to invert seismicity catalogs for stressing rate variations in space and time. Finally, in Chapter 5, I demonstrate how this new method can be applied to a subduction zone to detect aseismic strain transients and identify spatial variations in frictional conditions.

Chapter 3 begins by investigating the efficacy of two widely used approaches, the stochastic Epidemic Type Aftershock Sequence (ETAS) model [Ogata, 1988] and the physically-based rate- and state-dependent friction model [Dieterich, 1994], for modeling earthquake swarms, which are often triggered by aseismic transients. The ETAS model 
uses empirical aftershock triggering laws to model earthquake occurrence as a point process that can be described with optimizable parameters such as background seismicity rate and aftershock productivity, but it lacks a quantitative way of relating seismicity rate variations to stressing rate variations. The rate-state model, on the other hand, has been used to map seismicity rate variations to stressing rate variations [Dieterich et al., 2000; Toda et al., 2002], but the stressing rate changes estimated from this model will reflect a combination of variations due to the underlying aseismic process, as well as those due to aftershock sequences. In this chapter, I show that the rate-state model predicts a relationship between aftershock productivity and stressing rate that is not observed in real data. I also demonstrate that earthquake swarms in various tectonic settings appear as anomalies relative to the ETAS model [Ogata, 1988], because the heightened stressing rate during the swarms causes a significant increase in background seismicity rate while the other aftershock parameters remain relatively constant. These observations enable us to specify a combined ETAS/rate-state model of seismicity rate that models both aftershock activity as well as variations in background seismicity rate due to aseismic processes and provides a direct relationship to stressing rate.

In Chapter 4, I implement the seismicity rate model specified in Chapter 3 into a data assimilation algorithm to invert seismicity catalogs for estimates of space-time variations in stressing rate. I set up a state-space model that describes the system using an underlying state vector, consisting of background stressing rate, aseismic stressing rate, and rate-state variable $\gamma$, that evolves over time. I then use an extended Kalman filter to estimate the time history of the state variables in a given number of spatial boxes. I evaluate the algorithm using a synthetic catalog generated with known stressing rate histories including an aseismic transient, and show that it can successfully detect when and where the transient occurs. I then apply it to an earthquake catalog from the Salton Trough in southern California, where a number of aseismic transients such as afterslip and shallow creep events have been geodetically detected [e.g., Williams and Magistrale, 1989; Lohman and McGuire, 2007; Wei et al., 2009]. The algorithm successfully detects the largest geodetically-observed transient in the catalog (the 2005 Obsidian Buttes 
transient), and the filter estimate of the peak stressing rate during the transient is within a factor of 5 of the estimate from a geodetically-derived slip model [Lohman and McGuire, 2007]. This demonstrates that this approach can successfully identify space-time windows in which aseismic transients occurred from a multi-decade earthquake catalog.

Finally, in Chapter 5, I return to subduction zones and apply this new seismicitybased transient detection method to a catalog from northeastern Japan to identify spacetime windows where aseismic processes such as afterslip may be occurring. Afterslip was observed geodetically following the 4 major interplate thrust events that occurred in this catalog (1989 M7.1, 1992 M6.9, 1994 M7.6, and 2003 M8.0) [e.g., Miura et al., 1993; Kawasaki et al., 1995; Heki et al., 1997; Miyazaki et al., 2004]. I show that seismicity rate anomalies relative to ETAS following these events can be detected from the earthquake catalog alone. Several smaller seismicity rate anomalies are also detected that can be associated with postseismic slip following M6.3-6.5 earthquakes and precursory slip prior to the 1994 M7.6 Sanriku-oki earthquake. These transients were not observed geodetically but can be corroborated with repeating earthquake analyses [Uchida et al., 2003, 2004]. Moreover, analysis of the 2003 Tokachi-oki earthquake indicates that this method may be able to distinguish between velocity-weakening and velocity-strengthening patches on the fault. Aseismic slip can be associated with frictionally stable, velocity-strengthening behavior [e.g., Miyazaki et al., 2004], and the filter correctly identifies the spatial box where the peak afterslip occurred as opposed to where the coseismic rupture occurred (indicating frictionally unstable, velocityweakening behavior). These results indicate that with improvements in spatial resolution and offshore earthquake detection levels, this method can help map the frictional conditions on the plate interface that may control large earthquake ruptures, as well as enhance our ability to detect where and how stress is accumulating on the megathrust, especially in regions further offshore where geodetic resolution is limited. 


\section{References}

Bourouis, S., and P. Bernard (2007), Evidence for coupled seismic and aseismic fault slip during water injection in the geothermal site of Soultz (France), and implications for seismogenic transients, Geophys. J. Int., 169, 723-732, doi:10.1111/j.1365246X.2006.03325.x.

Delahaye, E. J., J. Townend, M. E. Reyners, and G. Rogers (2009), Microseismicity but no tremor accompanying slow slip in the Hikurangi subduction zone, New Zealand, Earth Planet. Sci. Lett., 277, 21-28, doi:10.1016/j.eps1.2008.09.038.

Dieterich, J. (1994), A constitutive law for rate of earthquake production and its application to earthquake clustering, J. Geophys. Res., 99, 2601-2618.

Dieterich, J., V. Cayol, and P. Okubo (2000), The use of earthquake rate changes as a stress meter at Kilauea volcano, Nature, 408, 457-460.

Fuller, C. W., S. D. Willet, and M. T. Brandon (2006), Formation of forearc basins and their influence on subduction zone earthquakes, Geology, 34, 65-68.

Hainzl, S., and Y. Ogata (2005), Detecting fluid signals in seismicity data through statistical earthquake modeling, J. Geophys. Res., 110, doi:10.1029/2004JB003247.

Lohman, R. B., and J. J. McGuire (2007), Earthquake swarms driven by aseismic creep in the Salton Trough, California, J. Geophys. Res., 112, B04405, doi:10.1029/2006JB004596.

Heki, K., S. Miyazaki, and H. Tsuji (1997), Silent fault slip following an interplate thrust earthquake at the Japan trench, Nature, 386, 595-598.

Hsu, Y.-J., M. Simons, J.-P. Avouac, J. Galetzka, K. Sieh, M. Chlieh, D. Natawidjaja, L. Prawirodirdjo, and Y. Bock (2006), Frictional afterslip following the 2005 Nias-Simeulue earthquakes, Sumatra, Science, 312, 1921-1926, doi:10.1126/science.1126960.

Kawasaki, I., Y. Asai, Y. Tamura, T. Sagiya, N. Mikami, Y. Okada, M. Sakata, and M. Kasahara (1995), The 1992 Sanriku-Oki, Japan, ultra-slow earthquake, J. Phys. Earth, 43, 105-116.

Lay, T., and H. Kanamori (1981), An asperity model of great earthquake sequences, in Earthquake Prediction: An International Review, Maurice Ewing Ser., vol. 4, ed. D. Simpson and P. Richards, pp. 579-592, AGU, Washington, D.C. 
Lohman, R. B., and J. J. McGuire (2007), Earthquake swarms driven by aseismic creep in the Salton Trough, California, J. Geophys. Res., 112, B04405, doi:10.1029/2006JB004596.

Matsubara, M., Y. Yagi, and K. Obara (2005), Plate boundary slip associated with the 2003 Off-Tokachi earthquake based on small repeating earthquake data, Geophys. Res. Lett., 32, L08316, doi:10.1029/2004GL022310.

Miura, S., K. Tachibana, T. Sato, K. Hashimoto, M. Mishina, N. Kato, and T. Hirasawa (1993). Postseismic slip events following interplate thrust earthquakes occurring in subduction zone, Proceedings of CRCM '93, Geodetic Society of Japan, 83-84.

Miyazaki, S., P. Segall, J. Fukuda and T. Kato (2004), Space time distribution of afterslip following the 2003 Tokachi-oki earthquake: Implications for variations in fault zone frictional properties, Geophys. Res. Lett., 31, L06623, doi: 10.1029/2003GL19410.

Nishimura, T., T. Hirasawa, S. Miyazaki, T. Sagiya, T. Tada, S. Miura, and K. Tanaka (2004), Temporal change of interplate coupling in northeastern Japan during 1995-2002 estimated from continuous GPS observations, Geophys. J. Int., 157, 901-916.

Ogata, Y. (1988), Statistical models for earthquake occurrences and residual analysis for point processes, J. Am. Stat. Assoc., 83, 9-27.

Ozawa, S., H. Suito, and M. Tobita (2007), Occurrence of quasi-periodic slow-slip off the east coast of the Boso peninsula, Central Japan, Earth Planets Space, 59, 1241-1245.

Pacheco, J. F., and L. R. Sykes (1992), Seismic moment catalog for large shallow earthquakes from 1900 to 1989, Bull. Seismol. Soc. Am., 82, 1306-1349.

Segall, P., E. K. Desmarais, D. Shelly, A. Miklius, and P. Cervelli (2006), Earthquakes triggered by silent slip events on Kilauea volcano, Hawaii, Nature, 442, doi:10.1038/nature04938.

Song, T. A., and M. Simons (2003), Large trench-parallel gravity variations predict seismogenic behavior in subduction zones, Science, 301, 630-633.

Thatcher, W. (1989), Earthquake recurrence and risk assessment in circum-Pacific seismic gaps, Nature, 341, 432-434.

Toda, S., R. S. Stein, and T. Sagiya (2002), Evidence from the AD 2000 Izu islands earthquake swarm that stressing rate governs seismicity, Nature, 419, 58-61. 
Uchida, N., T. Matsuzawa, and A. Hasegawa (2003), Interplate quasi-static slip off Sanriku, NE Japan, estimated from repeating earthquakes, Geophys. Res. Lett., 30(15), 1801, doi:10.1029/2003GL017452.

Uchida, N., A. Hasegawa, T. Matsuzawa, and T. Igarashi (2004), Pre- and post-seismic slow slip on the plate boundary off Sanriku, NE Japan associated with three interplate earthquakes as estimated from small repeating earthquake data, Tectonophysics, 385, 115, doi:10.1016/j.tecto.2004.04.015.

Wei, M., D. Sandwell, and Y. Fialko (2009), A silent $M_{w} 4.7$ slip event of October 2006 on the Superstition Hills fault, southern California, J. Geophys. Res., 114, B07402, doi:10.1029/2008JB006135.

Wells, R. E., R. J. Blakely, Y. Sugiyama, D. W. Scholl, and P. A. Dinterman (2003), Basin-centered asperities in great subduction zone earthquakes: A link between slip, subsidence, and subduction erosion?, J. Geophys. Res., 108, 1-30.

Williams, P. L., and H. W. Magistrale (1989), Slip along the Superstition Hills fault associated with the 24 November 1987 Superstition Hills, California, earthquake, Bull. Seis. Soc. Am., 79, 390-410. 


\title{
Chapter 2: Influence of fore-arc structure on the extent of great subduction earthquakes
}

\begin{abstract}
Structural features associated with fore-arc basins appear to strongly influence the rupture processes of large subduction zone earthquakes. Recent studies demonstrated that a significant percentage of the global seismic moment release on subduction zone thrust faults is concentrated beneath the gravity lows resulting from fore-arc basins. To better determine the nature of this correlation and to examine its effect on rupture directivity and termination, we estimated the rupture areas of a set of $M_{w}$ 7.5-8.7 earthquakes that occurred in circum-Pacific subduction zones. We compare synthetic and observed seismograms by measuring frequency-dependent amplitude and arrival time differences of the first orbit Rayleigh waves. At low frequencies, the amplitude anomalies primarily result from the spatial and temporal extent of the rupture. We then invert the amplitude and arrival time measurements to estimate the second moments of the slip distribution which describe the rupture length, width, duration, and propagation velocity of each earthquake. Comparing the rupture areas to the trench-parallel gravity anomaly (TPGA) above each rupture, we find that in 11 of the 15 events considered in this study the TPGA increases between the centroid and the limits of the rupture. Thus local increases in TPGA appear to be related to the physical conditions along the plate interface that favor rupture termination. Owing to the inherently long timescales required for fore-arc basin formation, the correlation between the TPGA field and rupture termination regions indicates that long-lived material heterogeneity rather than short timescale stress heterogeneities are responsible for arresting most great subduction zone ruptures.
\end{abstract}

Published as A. L. Llenos and J. J. McGuire, Influence of fore-arc structure on the extent of great subduction zone earthquakes, J. Geophys. Res., 112, B09301, doi:10.1029/2007JB004944, 2007. Reproduced by permission of American Geophysical Union. 


\title{
Influence of fore-arc structure on the extent of great subduction zone earthquakes
}

\author{
Andrea L. Llenos ${ }^{1}$ and Jeffrey J. McGuire ${ }^{2}$ \\ Received 19 January 2007; revised 3 May 2007; accepted 13 June 2007; published 6 September 2007.
}

[1] Structural features associated with fore-arc basins appear to strongly influence the rupture processes of large subduction zone earthquakes. Recent studies demonstrated that a significant percentage of the global seismic moment release on subduction zone thrust faults is concentrated beneath the gravity lows resulting from fore-arc basins. To better determine the nature of this correlation and to examine its effect on rupture directivity and termination, we estimated the rupture areas of a set of $\mathrm{M}_{\mathrm{w}}$ 7.5-8.7 earthquakes that occurred in circum-Pacific subduction zones. We compare synthetic and observed seismograms by measuring frequency-dependent amplitude and arrival time differences of the first orbit Rayleigh waves. At low frequencies, the amplitude anomalies primarily result from the spatial and temporal extent of the rupture. We then invert the amplitude and arrival time measurements to estimate the second moments of the slip distribution which describe the rupture length, width, duration, and propagation velocity of each earthquake. Comparing the rupture areas to the trench-parallel gravity anomaly (TPGA) above each rupture, we find that in 11 of the 15 events considered in this study the TPGA increases between the centroid and the limits of the rupture. Thus local increases in TPGA appear to be related to the physical conditions along the plate interface that favor rupture termination. Owing to the inherently long timescales required for forearc basin formation, the correlation between the TPGA field and rupture termination regions indicates that long-lived material heterogeneity rather than short timescale stress heterogeneities are responsible for arresting most great subduction zone ruptures.

Citation: Llenos, A. L., and J. J. McGuire (2007), Influence of fore-arc structure on the extent of great subduction zone earthquakes, J. Geophys. Res., 112, B09301, doi:10.1029/2007JB004944.

\section{Introduction}

[2] The largest earthquakes in the world occur in subduction zones, where almost $90 \%$ of the total global seismic moment is released [Lay and Bilek, 2007]. However, the amount of seismic coupling widely varies from one subduction zone to another, ranging from predominantly aseismic subduction in the Marianas to seismic subduction in Alaska [e.g., Scholz and Campos, 1995; Lay and Bilek, 2007]. Understanding this variation in earthquake occurrence in circum-Pacific subduction zones has been the subject of numerous studies. The correlations between earthquake occurrence and such factors as age of subducting oceanic lithosphere, amount of sediment, bathymetric features on the subducting slab, and convergence rate have been investigated [e.g., Mogi, 1969; Kelleher and McCann, 1976; Ruff and Kanamori, 1980; Pacheco et al., 1993; Scholz and Campos, 1995; Abercrombie et al., 2001]. However, wide variability in seismogenic behavior exists not only between

\footnotetext{
${ }^{1}$ MIT/WHOI Joint Program, Cambridge, Massachusetts, USA.

${ }^{2}$ Department of Geology and Geophysics, Woods Hole Oceanographic Institution, Woods Hole, Massachusetts, USA.

Copyright 2007 by the American Geophysical Union. 0148-0227/07/2007JB004944\$09.00
}

different subduction zones but within individual subduction zones themselves.

[3] The asperity model is commonly used to describe this variability in seismic behavior [Lay and Kanamori, 1981]. The moment release during great earthquakes is nonuniform, and the areas of high moment release are known as asperities. These asperities may occur because of variability in frictional properties on the plate interface, which may lock during the interseismic period and suddenly release slip in an earthquake [e.g., Lay et al., 1982]. An alternative view is that time-dependent stress heterogeneity is the dominant factor controlling the extent of great earthquakes. Numerical simulations demonstrated that even a fault with uniform frictional properties can generate a complex sequence of events that rupture different portions of the fault in each rupture rather than repeatedly at a fixed asperity [Shaw, 2000]. In this model, large earthquakes preferentially nucleate at the edge of a previous large rupture and propagate in the opposite direction providing a natural explanation for the observation that large subduction zone ruptures are predominantly unilateral along strike [McGuire et al., 2002]. Moreover, Thatcher [1989] used historical estimates of rupture area for great subduction zone earthquakes to argue that these events are rarely repeats of the previous big earthquake and instead fill in regions where stress accumulation has not been relieved recently (the 


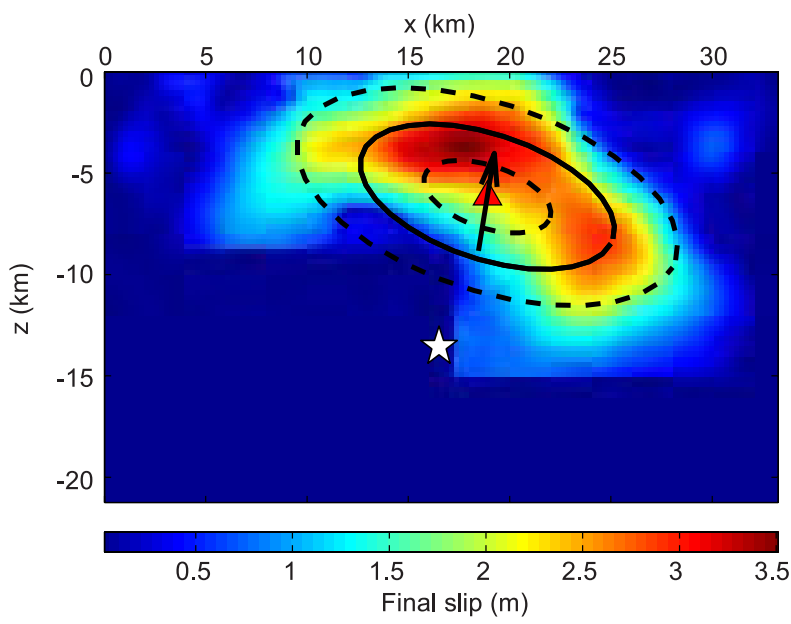

Figure 1. Characteristic rupture ellipse for the 2000 Tottori earthquake (solid black line), rupture directivity (arrow), centroid location (triangle), and hypocenter location (star) plotted on top of slip model of Iwata et al. [2000].

seismic gap hypothesis). While both "quenched heterogeneity" (the asperity model) and "dynamic heterogeneity" (the seismic gap hypothesis) likely influence the details of individual ruptures to some extent, it is very important to determine which is the dominant behavior in subduction zones as they have very different implications for the longterm seismic hazard at a particular location.
[4] In a given subduction zone, the trench-normal controls on earthquake rupture are relatively well understood. The fault width is constrained by the updip and downdip limits of the seismogenic zone, at depths of 5-10 km and 25-55 km, respectively [e.g., Byrne et al., 1988; Pacheco et al., 1993; Tichelaar and Ruff, 1993; Oleskevich et al., 1999; Lay and Bilek, 2007]. These limits result from transitions from velocity-strengthening to velocity-weakening behavior [Scholz, 2002]. These transitions likely occur because of changes in properties such as sediment strength and mineral composition due to changing pressure and temperature conditions [e.g., Byrne et al., 1988; Hyndman and Wang, 1993; Oleskevich et al., 1999].

[5] However, subduction zone earthquakes can release large amounts of seismic moment because extremely long fault lengths are possible along a subduction zone. An important question then becomes: what controls the alongstrike limits of these great earthquakes? What stops a $\mathrm{M}_{\mathrm{w}} 7.0$ earthquake from continuing to rupture along a subduction zone and becoming a $\mathrm{M}_{\mathrm{w}} 9.0$ earthquake? Some studies have shown that transverse structures such as ridges or seamounts in the subducting lithosphere often fragment the subduction zone and may provide natural barriers to rupture [e.g., Mogi, 1969; Kelleher and McCann, 1976; Cloos, 1992; Kodaira et al., 2000, 2002]. However, such structures can also prove to be asperities, as Abercrombie et al. [2001] found in the case of the 1994 Java tsunamigenic earthquake, where the majority of the seismic moment release was centered on a subducted seamount. Therefore the relationship between subducting geological structure and the extent of large individual ruptures remains unclear.
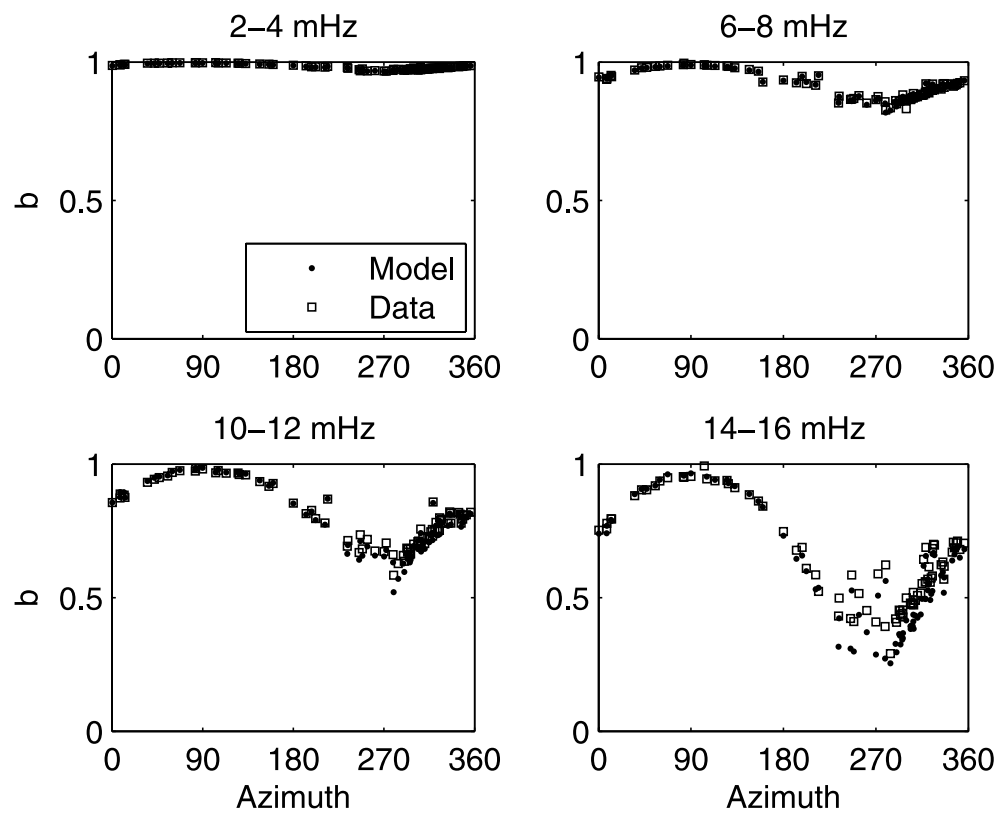

Figure 2. Amplitude measurements (square) and model (circle) from a synthetic line source test at different frequency bands. The 3-D point source synthetics were used to simulate a $70 \mathrm{~km}$ long unilateral rupture propagating to the east with a velocity of $2.5 \mathrm{~km} / \mathrm{s}$. Low-amplitude measurements at azimuths of 270 confirm that rupture propagated away from the west. The amplitude anomaly increases with frequency. In general, the model fits the measurements well at lower frequencies, but at the $14-16 \mathrm{mHz}$ band they begin to differ significantly. 


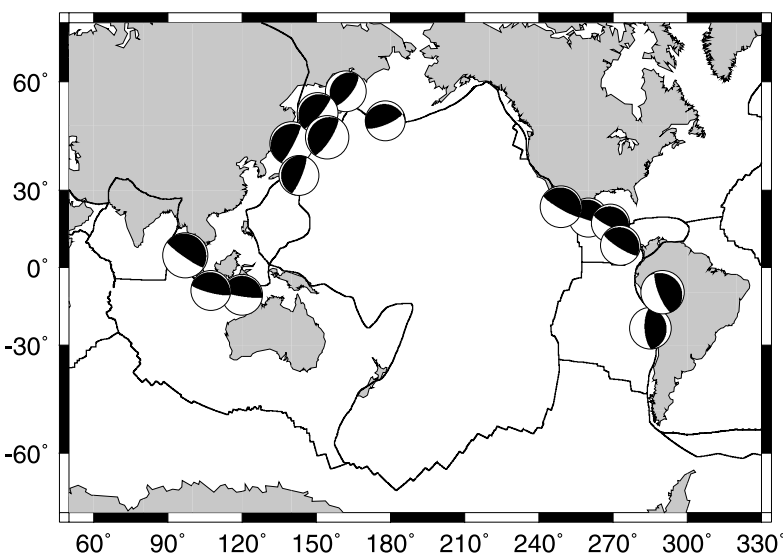

Figure 3. Location and focal mechanisms of the $15 \mathrm{M}_{\mathrm{w}}>$ 7.5 events in data set.

[6] The upper plate also plays an important role in earthquake rupture. McCaffrey [1993] emphasized the importance of fore-arc rheology in seismogenic behavior; strong fore arcs produce more large earthquakes because of their ability to store elastic strain energy. Recent studies by Song and Simons [2003] and Wells et al. [2003] have demonstrated that large subduction zone earthquakes occur preferentially in areas along the plate interface which are overlain by fore-arc basins. Song and Simons [2003] found that $80 \%$ of the cumulative seismic moment release in the 20 th century occurred in the $30 \%$ of the total area of subduction zone which exhibited strongly negative gravity anomalies, indicators of the presence of fore-arc basins. Fore-arc basins tend to form in strong, stable wedges and therefore reflect the mechanical and frictional properties along the plate interface over which they lay [Byrne et al., 1988; Fuller et al., 2006; Wang and Hu, 2006]. To what extent then can fore-arc structure influence the rupture of individual earthquakes?

[7] This study aims to investigate the relationship between earthquake rupture propagation and fore-arc structure in greater detail. Where do large events start and stop with respect to along-strike structures in the gravity field? To address this question, we estimated the finite source properties of a set of 15 subduction zone thrust events $\left(\mathrm{M}_{\mathrm{w}}>7.5\right)$ and compared them to fore-arc structure revealed by maps of trench-parallel gravity anomalies (TPGA) constructed by Song and Simons [2003]. We find that as a rupture approaches its eventual extent, the TPGA increases. This correlation, which reinforces the observations of Song and Simons [2003], suggests that the stress and frictional heterogeneities along the plate interface that control the rupture of large subduction zone earthquakes are expressed in the fore-arc gravity field.

\section{Methodology}

[8] To evaluate the relationships between fore-arc structure and individual ruptures, we require well constrained information on the spatial extent of rupture that can be determined in subduction zones worldwide. This is often a difficult observational problem because most subduction zone ruptures occur offshore and often with limited geodetic and near-field seismic data. Even for the best data sets, detailed finite fault inversions of great subduction zone earthquakes are highly sensitive to model parameterization and station coverage. An example of this is the $2003 \mathrm{M}_{\mathrm{w}} 8.3$ Tokachi-oki earthquake. Despite the abundance of quality seismic and geodetic data recorded during the event, by far the best data set ever for a $\mathrm{M}_{\mathrm{w}} 8$ subduction zone rupture, the finite fault models produced following the earthquake differ in characteristics such as number of asperities and orientation of rupture [Miyazaki et al., 2004a]. Some studies found that the rupture was oriented more along strike of the trench [Yamanaka and Kikuchi, 2003] while others found rupture areas that were half the size and oriented downdip [Yagi, 2004; Honda et al., 2004; Koketsu et al., 2004; Miyazaki et al., 2004a]. The differences between the slip models highlight the sensitivity of the results to the different fault parameterizations, constraints, and data sets used in each study. Even for the best combined seismic and geodetic data sets, the rupture area is only constrained to within a factor of two owing to the limited offshore coverage. Moreover, body wave based studies often have poor constraints on the seismic moment and slip distribution owing to their relatively high frequency band [Pritchard et al., 2007].

[9] An alternative approach is to utilize seismic surface waves to constrain only the gross features of the rupture,

Table 1. Characteristic Rupture Dimensions of the Events in This Study ${ }^{\mathrm{a}}$

\begin{tabular}{|c|c|c|c|c|c|c|}
\hline Event & Location & $M_{w}$ & $\mathrm{~L}_{\mathrm{c}}, \mathrm{km}$ & $\tau_{\mathrm{c}}, \mathrm{s}$ & $\left|v_{0}\right|, \mathrm{km} / \mathrm{s}$ & Directivity Ratio \\
\hline 19920902 & Nicaragua & 7.6 & $74 \pm 7$ & $40 \pm 1$ & $1.8 \pm 0.1$ & $0.97 \pm 0.10$ \\
\hline 19940602 & Java, Indonesia & 7.8 & $86 \pm 7$ & $16 \pm 2$ & $4.2 \pm 1.3$ & $0.78 \pm 0.19$ \\
\hline 19941228 & Sanriku-oki, Honshu, Japan & 7.7 & $161 \pm 14$ & $20 \pm 3$ & $6.1 \pm 1.9$ & $0.77 \pm 0.16$ \\
\hline 19950730 & Antofagasta, Chile & 8.0 & $121 \pm 10$ & $33 \pm 1$ & $1.3 \pm 0.1$ & $0.35 \pm 0.04$ \\
\hline 19950914 & Copala, Mexico & 7.3 & $74 \pm 4$ & $14 \pm 1$ & $3.2 \pm 0.3$ & $0.62 \pm 0.06$ \\
\hline 19951009 & Jalisco, Mexico & 8.0 & $77 \pm 6$ & $32 \pm 1$ & $2.1 \pm 0.1$ & $0.86 \pm 0.08$ \\
\hline 19951203 & Kurile Islands, Russia & 7.9 & $121 \pm 9$ & $36 \pm 1$ & $1.1 \pm 0.1$ & $0.32 \pm 0.03$ \\
\hline 19971205 & Kamchatka, Russia & 7.8 & $58 \pm 2$ & $34 \pm 1$ & $1.6 \pm 0.1$ & $0.95 \pm 0.02$ \\
\hline 20010623 & Arequipa, Peru & 8.4 & $167 \pm 2$ & $27 \pm 1$ & $1.1 \pm 0.2$ & $0.18 \pm 0.02$ \\
\hline 20030122 & Colima, Mexico & 7.5 & $92 \pm 6$ & $29 \pm 1$ & $1.4 \pm 0.1$ & $0.44 \pm 0.03$ \\
\hline 20030925 & Tokachi-oki, Hokkaido, Japan & 8.3 & $40 \pm 2$ & $45 \pm 1$ & $0.9 \pm 0.1$ & $0.96 \pm 0.02$ \\
\hline 20031117 & Rat Islands, Alaska & 7.8 & $70 \pm 21$ & $29 \pm 1$ & $2.2 \pm 0.4$ & $0.91 \pm 0.24$ \\
\hline 20050328 & Sumatra, Indonesia & 8.7 & $137 \pm 19$ & $47 \pm 3$ & $2.3 \pm 0.3$ & $0.79 \pm 0.15$ \\
\hline 20060717 & Java, Indonesia & 7.7 & $108 \pm 5$ & $55 \pm 1$ & $1.9 \pm 0.1$ & $0.98 \pm 0.05$ \\
\hline 20061115 & Kurile Islands, Russia & 8.3 & $93 \pm 3$ & $52 \pm 1$ & $1.8 \pm 0.1$ & $0.98 \pm 0.02$ \\
\hline
\end{tabular}

${ }^{\mathrm{a}}$ Event number is date as year, month, day. Errors are \pm 1 standard deviation. 
Table 2. Second Moments Inversion Results ${ }^{\mathrm{a}}$

\begin{tabular}{|c|c|c|c|c|c|c|c|c|c|c|}
\hline \multirow[b]{2}{*}{ Earthquake } & \multirow[b]{2}{*}{$\hat{\mu}^{(0,2)}$} & \multicolumn{3}{|c|}{$\hat{\boldsymbol{\mu}}^{(1,1)}$} & \multicolumn{6}{|c|}{$\hat{\boldsymbol{\mu}}^{(2,0)}$} \\
\hline & & $\mathrm{r}$ & $\theta$ & $\varphi$ & $\mathrm{rr}$ & $\mathrm{r} \theta$ & $\mathrm{r} \varphi$ & $\theta \theta$ & $\theta \varphi$ & $\varphi \varphi$ \\
\hline Nicaragua & $406 \pm 23$ & $-11 \pm 3$ & $374 \pm 19$ & $615 \pm 14$ & $6 \pm 1$ & $-10 \pm 6$ & $-18 \pm 7$ & $423 \pm 225$ & $586 \pm 131$ & $997 \pm 135$ \\
\hline Java & $65 \pm 19$ & $26 \pm 4$ & $-70 \pm 20$ & $262 \pm 19$ & $56 \pm 1$ & $214 \pm 46$ & $60 \pm 17$ & $1514 \pm 291$ & $-467 \pm 132$ & $1140 \pm 170$ \\
\hline Sanriku-oki & $103 \pm 29$ & $4 \pm 2$ & $-292 \pm 14$ & $-555 \pm 18$ & $0.3 \pm 0.3$ & $-4 \pm 3$ & $-26 \pm 9$ & $1093 \pm 231$ & $990 \pm 127$ & $6260 \pm 1089$ \\
\hline Antofagasta & $280 \pm 24$ & $22 \pm 2$ & $351 \pm 14$ & $-53 \pm 17$ & $4.7 \pm 0.4$ & $48 \pm 5$ & $-26 \pm 3$ & $1983 \pm 272$ & $-1682 \pm 271$ & $1963 \pm 381$ \\
\hline Copala & $51 \pm 5$ & $-10 \pm 1$ & $-145 \pm 4$ & $79 \pm 4$ & $3.1 \pm 0.4$ & $18 \pm 4$ & $-44 \pm 5$ & $601 \pm 63$ & $237 \pm 43$ & $1311 \pm 126$ \\
\hline Jalisco & $259 \pm 10$ & $12 \pm 3$ & $-379 \pm 14$ & $-373 \pm 11$ & $8 \pm 1$ & $-15 \pm 10$ & $-18 \pm 9$ & $842 \pm 135$ & $686 \pm 107$ & $730 \pm 109$ \\
\hline Kurile & $320 \pm 18$ & $-28 \pm 4$ & $-306 \pm 13$ & $164 \pm 16$ & $4 \pm 1$ & $29 \pm 2$ & $-46 \pm 5$ & $433 \pm 124$ & $-434 \pm 85$ & $3607 \pm 563$ \\
\hline Kamchatka & $289 \pm 6$ & $-41 \pm 2$ & $310 \pm 17$ & $-345 \pm 16$ & $91 \pm 13$ & $9 \pm 8$ & $93 \pm 8$ & $459 \pm 42$ & $-363 \pm 31$ & $486 \pm 42$ \\
\hline Arequipa & $187 \pm 16$ & $45 \pm 5$ & $81 \pm 11$ & $187 \pm 22$ & $206 \pm 2$ & $329 \pm 16$ & $192 \pm 45$ & $739 \pm 14$ & $-737 \pm 28$ & $6859 \pm 177$ \\
\hline Colima & $210 \pm 8$ & $0 \pm 4$ & $-264 \pm 12$ & $129 \pm 8$ & $2.0 \pm 0.4$ & $-7 \pm 5$ & $-6 \pm 3$ & $1726 \pm 229$ & $717 \pm 119$ & $725 \pm 102$ \\
\hline Tokachi-oki & $500 \pm 10$ & $-2 \pm 3$ & $-434 \pm 20$ & $-44 \pm 8$ & $0.4 \pm 0.2$ & $2 \pm 2$ & $-0.4 \pm 0.3$ & $406 \pm 30$ & $26 \pm 12$ & $178 \pm 32$ \\
\hline Rat Islands & $208 \pm 18$ & $-6 \pm 3$ & $-59 \pm 9$ & $-459 \pm 55$ & $0.8 \pm 0.1$ & $1 \pm 3$ & $12 \pm 3$ & $151 \pm 208$ & $-15 \pm 305$ & $1228 \pm 725$ \\
\hline Sumatra & $559 \pm 73$ & $15 \pm 5$ & $1200 \pm 42$ & $416 \pm 35$ & $2 \pm 1$ & $31 \pm 11$ & $14 \pm 5$ & $4503 \pm 1031$ & $-660 \pm 581$ & $2117 \pm 854$ \\
\hline Java & $761 \pm 31$ & $49 \pm 5$ & $1022 \pm 22$ & $1053 \pm 24$ & $5 \pm 1$ & $65 \pm 5$ & $68 \pm 7$ & $1435 \pm 112$ & $1402 \pm 61$ & $1613 \pm 321$ \\
\hline$\underline{\text { Kurile }}$ & $667 \pm 12$ & $-50 \pm 5$ & $-1077 \pm 38$ & $472 \pm 20$ & $41 \pm 1$ & $71 \pm 7$ & $-31 \pm 3$ & $1804 \pm 106$ & $-788 \pm 50$ & $431 \pm 26$ \\
\hline
\end{tabular}

${ }^{\mathrm{a}}$ Errors are \pm 1 standard deviation. Units of $\hat{\mu}^{(0,2)}$ are $\mathrm{s}^{2}$, units of $\hat{\boldsymbol{\mu}}^{(1,1)}$ are $\mathrm{km} \mathrm{s}$, and units of $\hat{\boldsymbol{\mu}}^{(2,0)}$ are $\mathrm{km}^{2}$.

such as its extent and directivity. Surface waves have the natural advantages of complete azimuthal coverage and of being inherently low-frequency such that they are sensitive to the entire moment release even for $\mathrm{M}_{\mathrm{w}} 8.5$ ruptures. Moreover, properties such as directivity and rupture extent can be estimated independent of any smoothing constraints or other a priori information [McGuire et al., 2001]. We quantify the extent and directivity of large ruptures using the second moments of a scalar source-space-time function describing the moment release distribution [Backus and Mulcahy, 1976a, 1976b; Backus, 1977a, 1977b; McGuire et al., 2001]. The second moments describe the length, width and duration of the area of greatest seismic moment release during an earthquake. They are defined as

$$
\begin{gathered}
\hat{\boldsymbol{\mu}}^{(\mathbf{2 , 0})}=\iint \dot{f}(\mathbf{r}, t)\left(\mathbf{r}-\mathbf{r}_{\mathbf{0}}\right)\left(\mathbf{r}-\mathbf{r}_{\mathbf{0}}\right)^{T} d V d t \\
\hat{\mu}^{(0,2)}=\iint \dot{f}(\mathbf{r}, t)\left(t-t_{0}\right)^{2} d V d t \\
\hat{\boldsymbol{\mu}}^{(\mathbf{1 , 1})}=\iint \dot{f}(\mathbf{r}, t)\left(\mathbf{r}-\mathbf{r}_{\mathbf{0}}\right)\left(t-t_{0}\right) d V d t
\end{gathered}
$$

where $\dot{f}$ is the source-space-time function and is proportional to slip rate at a point on the fault, $\mathbf{r}_{\mathbf{0}}$ and $t_{0}$ are the centroid location and time, $\hat{\boldsymbol{\mu}}^{(\mathbf{2 , 0 )}}$ is the second spatial moment, $\hat{\mu}^{(0,2)}$ is the second temporal moment, and $\hat{\boldsymbol{\mu}}^{(\mathbf{1}, \mathbf{1})}$ is the mixed moment which describes overall rupture directivity [McGuire et al., 2001].

[10] The second moments represent weighted averages of seismic moment release, and they define characteristic rupture dimensions that are somewhat smaller than the total rupture dimensions. These characteristic rupture dimensions are [Silver, 1983; Silver and Jordan, 1983; McGuire et al., 2001]

$$
x_{c}(\hat{\mathbf{n}})=2 \sqrt{\hat{\mathbf{n}}^{T}\left(\hat{\boldsymbol{\mu}}^{(\mathbf{2}, \mathbf{0})} / M_{0}\right) \hat{\mathbf{n}}}
$$

$$
\begin{gathered}
\tau_{c}=2 \sqrt{\hat{\mu}^{(0,2)} / M_{0}} \\
v_{c}=L_{c} / \tau_{c} \\
\mathbf{v}_{\mathbf{0}}=\hat{\boldsymbol{\mu}}^{(\mathbf{1}, \mathbf{1})} / \hat{\mu}^{(0,2)}
\end{gathered}
$$

where $M_{0}$ is the seismic moment and $x_{c}(\hat{\mathbf{n}})$ is the characteristic dimension of slip in the direction of $\hat{\mathbf{n}}$, which has its maximum value of $L_{c}$ when $\hat{\mathbf{n}}$ corresponds to the largest eigenvector associated with the largest eigenvalue of $\hat{\boldsymbol{\mu}}^{(\mathbf{2 , 0})}$. The characteristic duration is $\tau_{\mathrm{c}}$, the characteristic velocity is $v_{c}$ and the average velocity of the instantaneous spatial centroid is $\mathbf{v}_{\mathbf{0}}$. The velocity $v_{c}$ can range from 1 to 2 times the actual rupture velocity [McGuire et al., 2002]. A directivity ratio is defined by $\left|\mathbf{v}_{\mathbf{0}}\right| / v_{c}$, such that ruptures with directivity ratios $\leq 0.5$ are predominantly bilateral, while those greater than $\sim 0.5$ are predominantly unilateral.

[11] Figure 1 demonstrates the relationship between the characteristic rupture dimensions and the slip distribution of the 2000 western Tottori earthquake. The second moments were calculated directly from the slip model of Iwata et al. [2000]. The ellipse represents the area on the fault plane that released the majority of the seismic moment during the earthquake as measured by the second spatial moment. The arrow indicates the rupture directivity, which is described by the mixed moment.

[12] We estimate the second moments by comparing point source synthetic and observed seismograms. The data seismogram recorded at station/component $p$ can be expressed as

$$
s_{p}(\mathbf{x}, t)=\iint G_{i j}^{p}\left(\mathbf{x}, \mathbf{x}^{\prime}, t-t^{\prime}\right) \hat{\mathbf{M}}_{\mathbf{i j}} \dot{f}\left(\mathbf{x}^{\prime}, t^{\prime}\right) d x^{\prime} d t^{\prime}
$$

where $\hat{\mathbf{M}}_{\mathbf{i j}}$ is the moment tensor, assumed constant during the earthquake, that describes fault orientation; $\dot{f}$ is the source-space-time function; and $G_{i j}^{p}$ is the Green's function. 
(a)
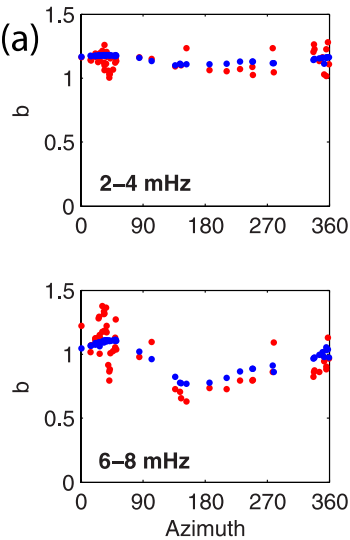

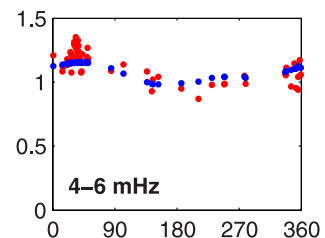

(c)
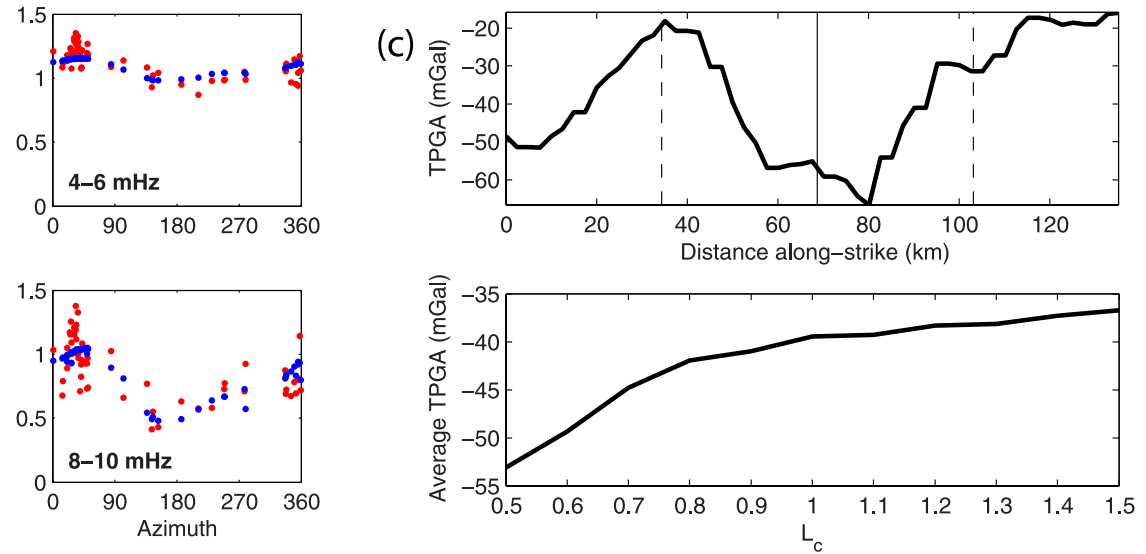

(b)

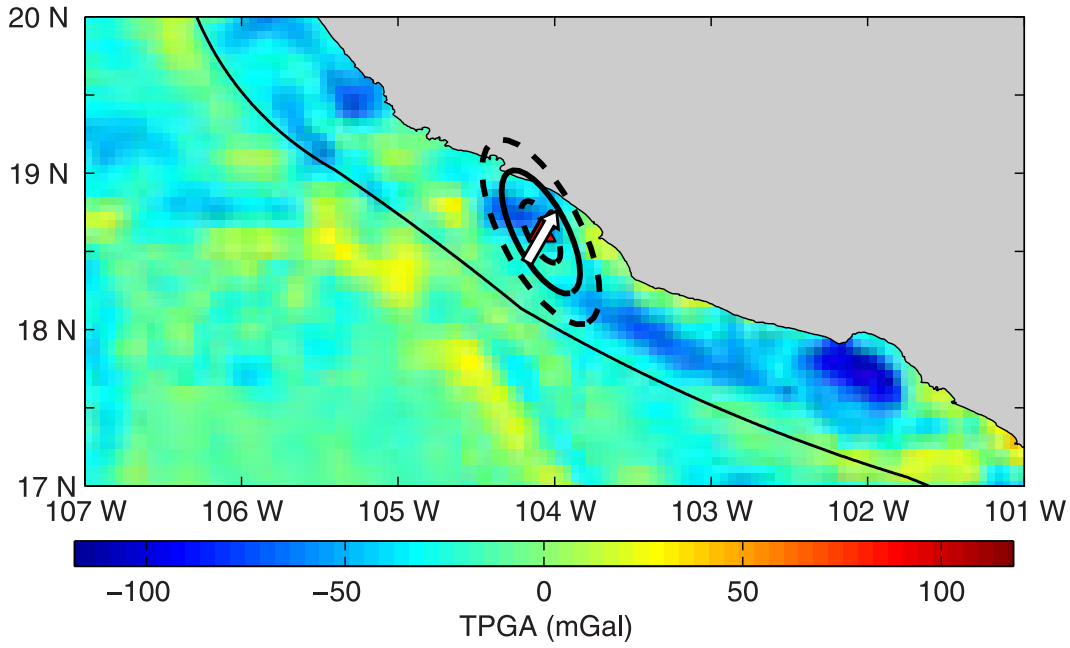

Figure 4. Results for bilateral event 20030122 in Mexico. (a) Amplitude measurements (red) and fit from inversion (blue) at different frequency bands. (b) Centroid (red triangle) and characteristic rupture ellipses with major axes of length $0.5 L_{c}$ (inner dashed ellipse), $1 L_{c}$ (solid black ellipse) and $1.5 L_{c}$ (outer dashed ellipse) plotted on a TPGA map. Directivity vector $\mathbf{v}_{\mathbf{0}}$ is shown by the white arrow. The trench is the thin black line. The area of high seismic moment release is largely contained in a negative TPGA region that corresponds with the Manzanillo fore-arc basin. (c) (top) TPGA values in a single profile along strike of the characteristic rupture ellipse. Rupture propagates from the centroid (solid black line) out to both the left and right. Dashed lines mark the extent of the $1 L_{c}$ rupture ellipse. The ends of the plot mark the extent of the $1.5 L_{c}$ rupture ellipse. (bottom) Average TPGA measured over rupture ellipses of varying $L_{c}$. TPGA is minimized near the centroid (shown by the $0.5 L_{c}$ rupture ellipse). Rupture extent (1 $L_{c}$ ) corresponds with increasing TPGA.

The Green's function can be expanded in a Taylor series about a point $\left(\mathbf{x}_{\mathbf{0}}^{\prime}, t_{0}^{\prime}\right)$ :

$$
\begin{aligned}
G_{i j}^{p}\left(\mathbf{x}, \mathbf{x}^{\prime}, t-t^{\prime}\right)= & {\left[1+\left(\mathbf{x}^{\prime}-\mathbf{x}_{\mathbf{0}}^{\prime}\right) \cdot \nabla_{s}+\left(t^{\prime}-t_{0}^{\prime}\right) \frac{\partial}{\partial t_{0}^{\prime}}\right.} \\
& +\frac{1}{2}\left(t^{\prime}-t_{0}^{\prime}\right)^{2} \frac{\partial^{2}}{\partial t_{0}^{\prime 2}}+\left(t^{\prime}-t_{0}^{\prime}\right)\left(\mathbf{x}^{\prime}-\mathbf{x}_{\mathbf{0}}^{\prime}\right) \cdot \nabla_{s} \frac{\partial}{\partial t_{0}^{\prime}} \\
& \left.+\frac{1}{2}\left(\mathbf{x}^{\prime}-\mathbf{x}_{\mathbf{0}}^{\prime}\right)^{T}\left(\mathbf{x}^{\prime}-\mathbf{x}_{\mathbf{0}}^{\prime}\right): \nabla_{s} \nabla_{x}+\ldots\right] \\
& \cdot G_{i j}^{p}\left(\mathbf{x}, \mathbf{x}_{\mathbf{0}}^{\prime}, t-t_{0}^{\prime}\right)
\end{aligned}
$$

At low frequencies, the Taylor series can be truncated after the second-order terms allowing the seismogram to be written in terms of the zeroth, first, and second moments:

$$
\begin{aligned}
s_{p}(\mathbf{x}, t)= & \mu^{(0,0)} G_{i j}^{p}\left(\mathbf{x}, \mathbf{x}_{\mathbf{0}}^{\prime}, t-t_{0}^{\prime}\right) \hat{\mathbf{M}}_{\mathbf{i j}}+\mu^{(1,0)} \\
& \cdot \nabla_{s} G_{i j}^{p}\left(\mathbf{x}, \mathbf{x}_{\mathbf{0}}^{\prime}, t-t_{0}^{\prime}\right) \hat{\mathbf{M}}_{\mathbf{i j}} \\
& +\mu^{(0,1)} \frac{\partial}{\partial t_{0}^{\prime}} G_{i j}^{p}\left(\mathbf{x}, \mathbf{x}_{\mathbf{0}}^{\prime}, t-t_{0}^{\prime}\right) \hat{\mathbf{M}}_{\mathbf{i j}}
\end{aligned}
$$


(a)
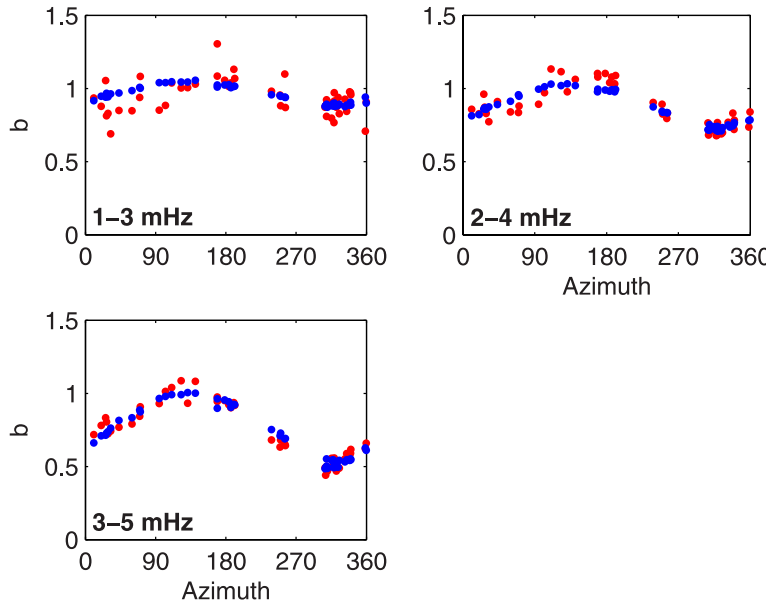

(c)
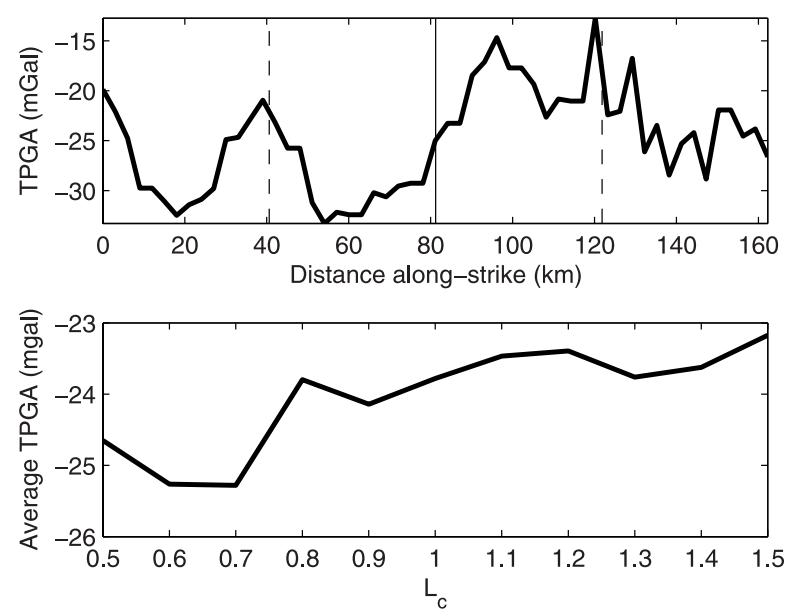

(b)

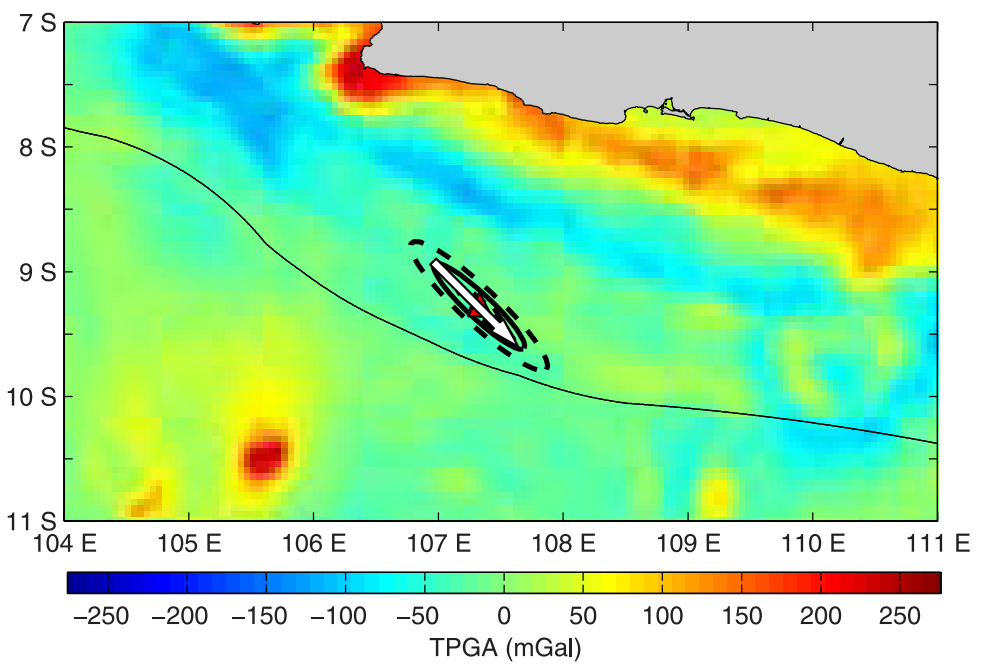

Figure 5. Results for unilateral event 20060717 in Java. (a) Amplitude measurements (red) and model (blue). (b) See Figure 4 for symbol explanation. The area of high seismic moment release shown by the characteristic rupture ellipse (solid black line) stops at a positive TPGA area. (c) (top) TPGA values along strike of the characteristic rupture ellipse. Rupture propagates from left to right. Solid black line denotes the centroid location; dashed lines mark the extent of the $1 L_{c}$ rupture ellipse, which occurs as the TPGA becomes more positive. The ends of the plot mark the extent of the $1.5 L_{c}$ rupture ellipse. (bottom) Average TPGA measured over rupture ellipses of varying $L_{c}$. TPGA is a local minimum at the centroid location $\left(0.5 L_{c}\right)$.

$$
\begin{aligned}
& +\frac{1}{2} \mu^{(0,2)} \frac{\partial^{2}}{\partial t_{0}^{\prime 2}} G_{i j}^{p}\left(\mathbf{x}, \mathbf{x}_{\mathbf{0}}^{\prime}, t-t_{0}^{\prime}\right) \hat{\mathbf{M}}_{\mathbf{i j}} \\
& +\mu^{(1,1)} \cdot \nabla_{s} \frac{\partial}{\partial t_{0}^{\prime}} G_{i j}^{p}\left(\mathbf{x}, \mathbf{x}_{\mathbf{0}}^{\prime}, t-t_{0}^{\prime}\right) \hat{\mathbf{M}}_{\mathbf{i j}} \\
& +\frac{1}{2} \boldsymbol{\mu}^{(\mathbf{2}, \mathbf{0})}: \nabla_{s} \nabla_{s} G_{i j}^{p}\left(\mathbf{x}, \mathbf{x}_{\mathbf{0}}^{\prime}, t-t_{0}^{\prime}\right) \hat{\mathbf{M}}_{\mathbf{i j}}
\end{aligned}
$$

The first term of the equation on the right-hand side is the point source synthetic seismogram, $\tilde{s}_{p}=\mu^{(0,0)} G_{i j}^{p}\left(\mathbf{x}, \mathbf{x}_{\mathbf{0}}^{\prime}\right.$, $\left.t-t_{0}^{\prime}\right) \hat{\mathbf{M}}_{\mathbf{i j}}$. Thus the observed seismogram is described by the contribution from the best fitting point source perturbed by finite source effects.
[13] The perturbations to the synthetic seismogram that describe the finite source can be estimated from the data using (10). To measure these anomalies, we rewrite (10) as $s_{p}(\mathbf{x}, t)=\sum m_{i} A_{p i}(t)$, where $\mathbf{m}$ is a vector containing the independenit elements of the zeroth, first, and second moments, and $A_{p i}(t)$ is the partial derivative of the Green's function specific to the $i$ th element of $\mathbf{m}$. Then the crosscorrelation function of $s$ and $\tilde{s}_{p}$ can be expressed as

$$
\begin{aligned}
C_{s \tilde{s}}(\tau) & =s_{p}(t) \otimes \tilde{s}_{p}(t-\tau) \approx \tilde{s}_{p}(t-\tau) \otimes \sum_{i} m_{i} A_{p i}(t) \\
& =\sum_{i} m_{i} \tilde{s}_{p}(t-\tau) \otimes A_{p i}(t)
\end{aligned}
$$




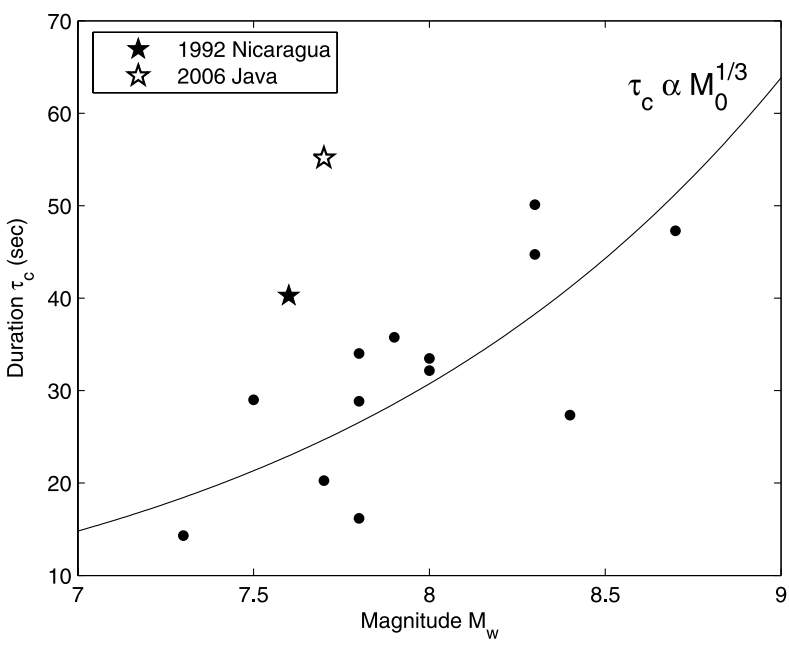

Figure 6. $M_{w}$ versus duration for events in the data set, with a least squares fit showing the scaling between moment and duration. The 1994 Nicaragua and 2006 Java tsunami earthquakes show anomalously long durations for events of their magnitudes.

A system of equations $\mathbf{A}_{\mathbf{p j}} \mathbf{m}_{\mathbf{j}}=b_{p}$ can then be defined, where the measurement $b_{p}$ is the peak of the crosscorrelogram $C_{s \tilde{s}}$ at station $p$, and $\mathbf{A}_{\mathbf{p j}}$ is the cross correlation of $A_{p j}(t)$ with synthetic seismogram $\tilde{s}_{p}\left(t-\tau_{p}\right)$. We weight both $b_{p}$ and $\mathbf{A}_{\mathbf{p j}}$ by the peak of the autocorrelogram of $\tilde{s}_{p}$ to account for arbitrary differences in amplitude between stations. Thus, in our measurement scheme $b<1$ implies that the observed seismogram has a lower amplitude than the point source synthetic, as would be expected if the arrival is sensitive to the destructive interference associated with finite source effects in the frequency band being considered. This measurement scheme provides a straightforward way to identify the directivity of an earthquake. Figure 2 shows the amplitude measurements made from a synthetic line source test simulating rupture propagating toward the east. Low amplitude measurements $(b<1)$ are found at azimuths of around 270, away from the direction of propagation.

[14] We measured frequency-dependent amplitude anomalies using fundamental mode Rayleigh wave data obtained from the GSN, GEOFON, GEOSCOPE, MEDNET, and China Digital seismic networks through the IRIS Data Management Center. The point source synthetics for an event were generated using the Global centroid moment tensor (CMT) solution for that event, available at http://www. globalcmt.org. We utilized two sets of point source synthetics: normal mode synthetics, using the one-dimensional (1-D) PREM Earth model [Dziewonski and Anderson, 1981] with phase velocity maps correcting for 3-D structure [Ekstrom et al., 1997]; and 3-D synthetics, calculated using the spectral element method of Komatitsch and Tromp [1999] with the 3-D velocity model CRUST2.0 [Bassin et al., 2000] and mantle velocity model S20RTS [Ritsema and van Heijst, 2000]. We used the 1-D normal mode synthetic seismograms to calculate $\mathbf{A}_{\mathbf{p j}}(\mathrm{t})$, the partial derivatives of the Green's functions. These derivatives depend primarily on sourcestation geometry and so the accuracy of the velocity model is not as important as it is for the amplitude measurements, which we therefore made using the 3-D synthetic seismograms. The improvement in Earth model allowed much more accurate amplitude predictions to be made for the Rayleigh wave, especially at the higher-frequency bands used in this study (see Appendix A for further discussion regarding the use of 1-D versus 3-D synthetics).

[15] For each event, we make measurements at a set of global stations with good azimuthal coverage and at a number of frequency bands ranging from 1 to $10 \mathrm{mHz}$. Waveforms are windowed around the peak of the Rayleigh wave using frequency-dependent window lengths prior to cross correlation. Stations with correlation coefficients less than 0.9 in any frequency band are discarded from all bands in the inversion to avoid errors from unmodeled heterogeneity. The magnitude of the amplitude anomaly increases with frequency, however, we can only use frequency bands where the amplitude reduction due to finite source effects is less than about $60 \%$ of the point source amplitude. Above this band, higher-order terms in (9) become important (Figure 2). The useable frequency range depends on the spatial extent and directivity of the rupture and hence is different for different sized earthquakes.

[16] The inverse problem for the second moments is nonunique but can be stabilized by incorporating the constraint that the 4-D source region must have a nonnegative volume [Das and Kostrov, 1997; McGuire et al., 2001]. Other constraints are used to limit changes to the centroid depth as well as ensure that rupture does not occur above the Earth's surface. These nonlinear constraints are expressed as linear matrix inequalities in the semidefinite programming approach of Vandenberghe and Boyd [1996]. The least squares objective function (11) is minimized subject to the various inequality constraints. The solution $\mathbf{m}$ is a 15 component vector containing the second moments as well as changes to the centroid time, location and seismic moment.

[17] We use a leave-one-out jackknife technique to estimate the error of the solution [Tukey, 1984]. We divide the data into $N$ subsets, where $N$ is the number of stations. For the $i$ th subset, the measurements at station $i$ in all frequency bands are left out, and the inversion is performed with the remaining data to produce an estimate of the model parameters. The $N$ estimates of the model parameters then provide a conservative estimate of the variance of the model parameters [Efron and Stein, 1981]. The variance of the model parameters can then be used in standard error propagation equations to estimate the variance in derived quantities such as $L_{c}$ and $\tau_{\mathrm{c}}$ [Bevington and Robinson, 1992].

[18] The characteristic rupture ellipses for each event are compared to the maps of trench- parallel gravity anomaly (TPGA) produced by Song and Simons [2003]. To construct these maps, an average trench normal gravity profile for each subduction zone is removed from the free air gravity data [Sandwell and Smith, 1997] along the length of the subduction zone. The resulting TPGA illuminates shorterwavelength features such as fore-arc basins. We compare the characteristic rupture dimensions with the spatial variations in TPGA to test the hypothesis that a correlation exists between variations in the TPGA field and earthquake 
(a)
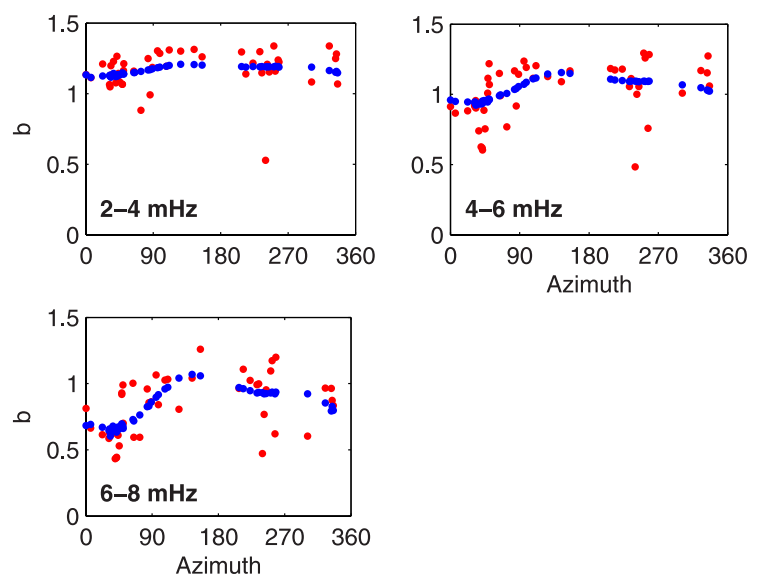

(c)
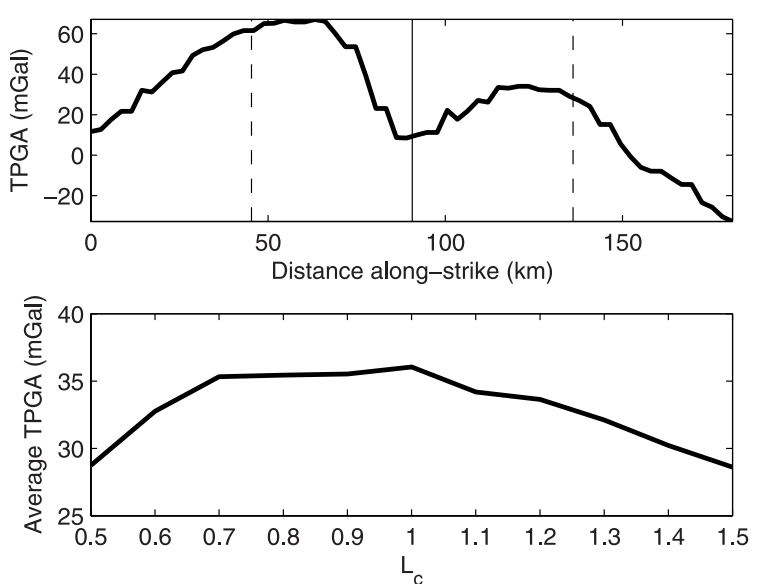

(b)

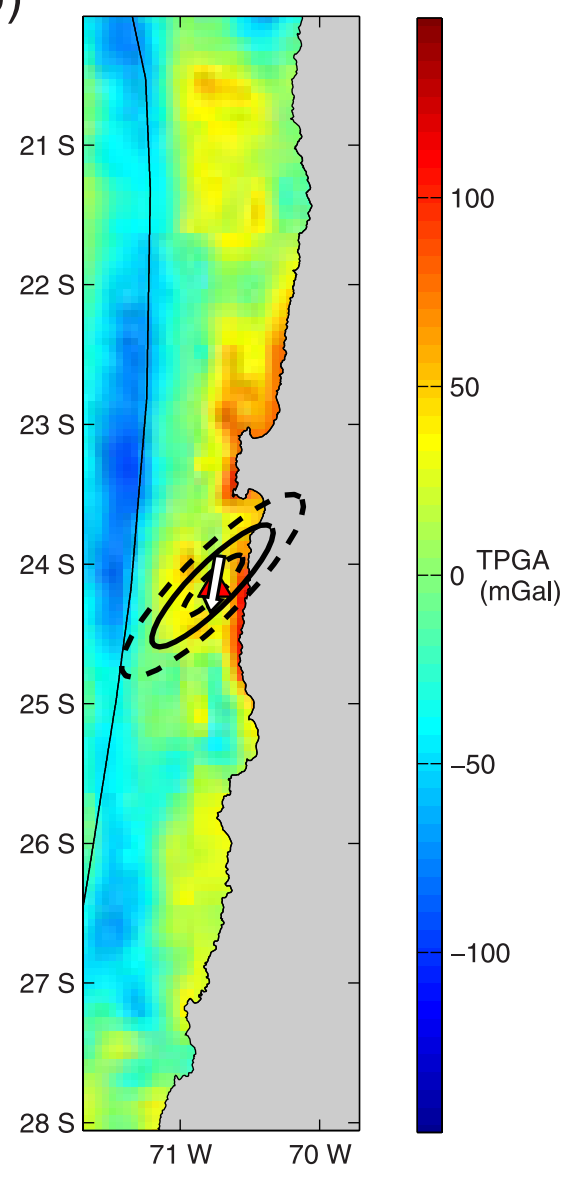

Figure 7. Results for event 19950730 in Chile. (a) Amplitude measurements (red) and model (blue). (b) See Figure 4 for symbol explanation. Although the majority of the seismic moment released in this event occurred in a high TPGA region, the centroid is located in a local TPGA minimum. (c) (top) TPGA values along strike of the characteristic rupture ellipse. Rupture propagates from the centroid (black line) out to the limits of the rupture ellipse (dashed line). The ends of the plot mark the extent of the $1.5 L_{c}$ rupture ellipse. TPGA values at along-strike distances of less than $50 \mathrm{~km}$ should be ignored because they occur inland, where the TPGA measurements are not as accurate. (bottom) Average TPGA measured over rupture ellipses of varying $L_{c}$. Inland TPGA values were masked out in calculating the average. Again a local minimum occurs near the centroid.

rupture characteristics such as centroid location, rupture extent and directivity.

\section{Results}

[19] We estimated the second moments for 15 shallow thrust earthquakes $\left(\mathrm{M}_{\mathrm{w}}>7.5\right)$ that occurred on the plate interface in circum-Pacific subduction zones from 1992 to 2006 (Figure 3). Because of the complex nature of the moment release during the 2004 Sumatra earthquake, this event was not included in our analysis. Table 1 summarizes the characteristic rupture dimensions of these events and Table 2 summarizes the second moment inversion results. Several representative events are discussed in greater detail below. Appendix B contains our Rayleigh wave measurements and comparisons with the TPGA field for each event.

\subsection{The 2003 Colima Mexico Earthquake}

[20] On 22 January 2003, a $M_{w} 7.5$ earthquake occurred near the state of Colima, Mexico. This event primarily ruptured bilaterally in the updip-downdip directions [Yagi et al., 2004]. Our second moment estimates (Table 1 and Figure 4a) support this conclusion. The inversion resulted in a characteristic rupture length $L_{c}$ of $92 \mathrm{~km}$, a duration $\tau_{c}$ of $29 \mathrm{~s}$, and a directivity ratio of 0.44 . This agrees well with the finite source model determined by Yagi et al. [2004] using a joint inversion of teleseismic body wave and strong motion data.

[21] The characteristic rupture ellipse representing the area of greatest moment release is compared to the TPGA field in Figure 4b. Although the measurements and directivity clearly indicate a downdip rupture, the ellipse is oriented more along strike. The centroid is located in a 
Unilateral events
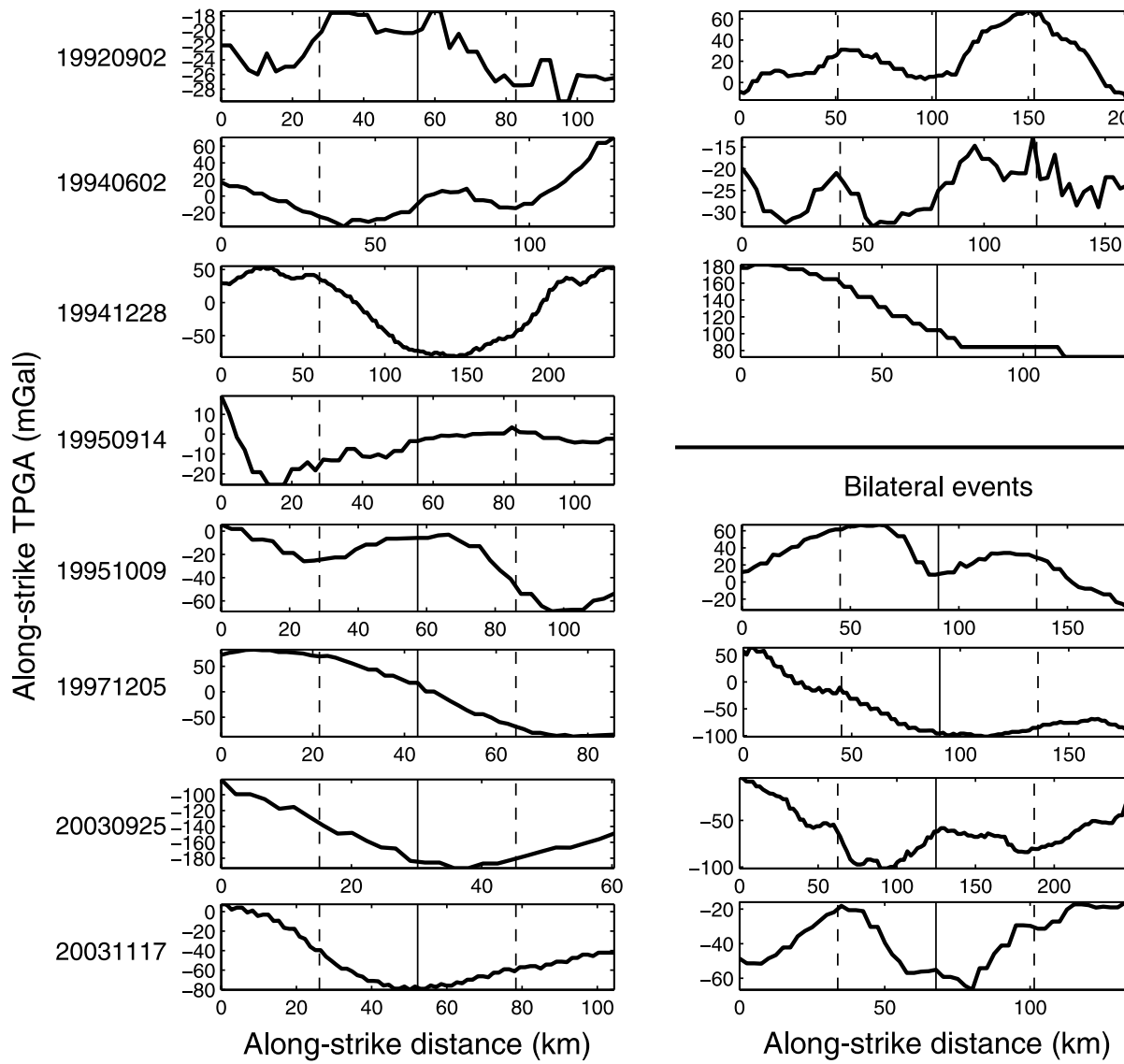

20050328

20060717

20061115

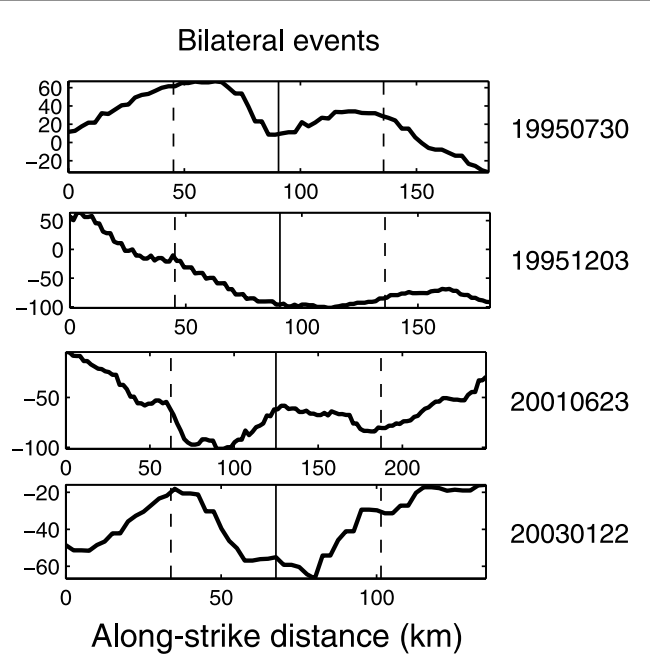

Figure 8. TPGA measured along strike of rupture ellipses for each event in the data set. The solid line marks the centroid location, and the dashed lines mark the extent of the best fitting $\left(1 L_{c}\right)$ rupture ellipse. Rupture propagates from left to right for unilateral events and from the centroid outward in both directions for bilateral events. In general, the rupture ellipse limits correspond with positive changes in TPGA. The profiles of 19950914 and 19950730 are not entirely accurate, as part of each profile occurs on land, where accurate TPGA measurements are unavailable.

highly negative TPGA region which corresponds to the Manzanillo basin [Wells et al., 2003]. This basin also overlies part of the rupture area of the $1995 \mathrm{M}_{\mathrm{w}} 8.0$ Jalisco event (Figure B7b in Appendix B). The along-strike limits of the rupture ellipse are characterized by local TPGA maxima (Figure $4 \mathrm{c}$ ). These results suggest that the main moment release filled the area underlying the Manzanillo basin. Figure 4c (bottom) shows the average TPGA over rupture ellipses of varying $L_{c}$ (with a constant aspect ratio), which illustrates how the TPGA changes within the rupture zone. The average TPGA is minimized near the centroid and increases as the region near the boundary of the actual rupture area is included (i.e., $1 L_{c}$ in Figure 4c). Therefore the limits of the significant moment release are characterized by increasing TPGA.

\subsection{The 2006 Java Earthquake}

[22] On 17 July 2006, a $\mathrm{M}_{\mathrm{w}} 7.7$ earthquake occurred in the fore arc of the Java trench. This earthquake generated a tsunami with a wave height of $1.8 \mathrm{~m}$ that struck the coast of Java, killing over 400 people. Preliminary results reported by the U.S. Geological Survey (USGS) (http://earthquake. usgs.gov/eqcenter/eqinthenews/2006/usqgaf) suggest that this event had a similar source mechanism as that of the $M_{w} 7.8$ shallow thrust earthquake (also in this study) that occurred off the coast of Java on 2 June 1994 which also generated a tsunami.

[23] For this event, we generated point source synthetics using the focal mechanism reported in the Global CMT catalog but the centroid location reported by the USGS. In their study of the 1994 Java earthquake, Abercrombie et al. [2001] found that the Global CMT locations for earthquakes in the Java trench appear to be systematically biased to the south and suggest that the $3-\mathrm{D}$ velocity models used in the CMT inversion are inadequate in this part of the globe.

[24] There is a very strong directivity signal at azimuths of around 300 (Figure 5a), indicating that rupture propagated unilaterally to the east-southeast. By the $3-5 \mathrm{mHz}$ band, the amplitude of the data has dropped to 0.5 of the amplitude of the synthetic. Such a strong signal in this low of a frequency band is more typical of $\mathrm{M}_{\mathrm{w}} 8.5$ events 

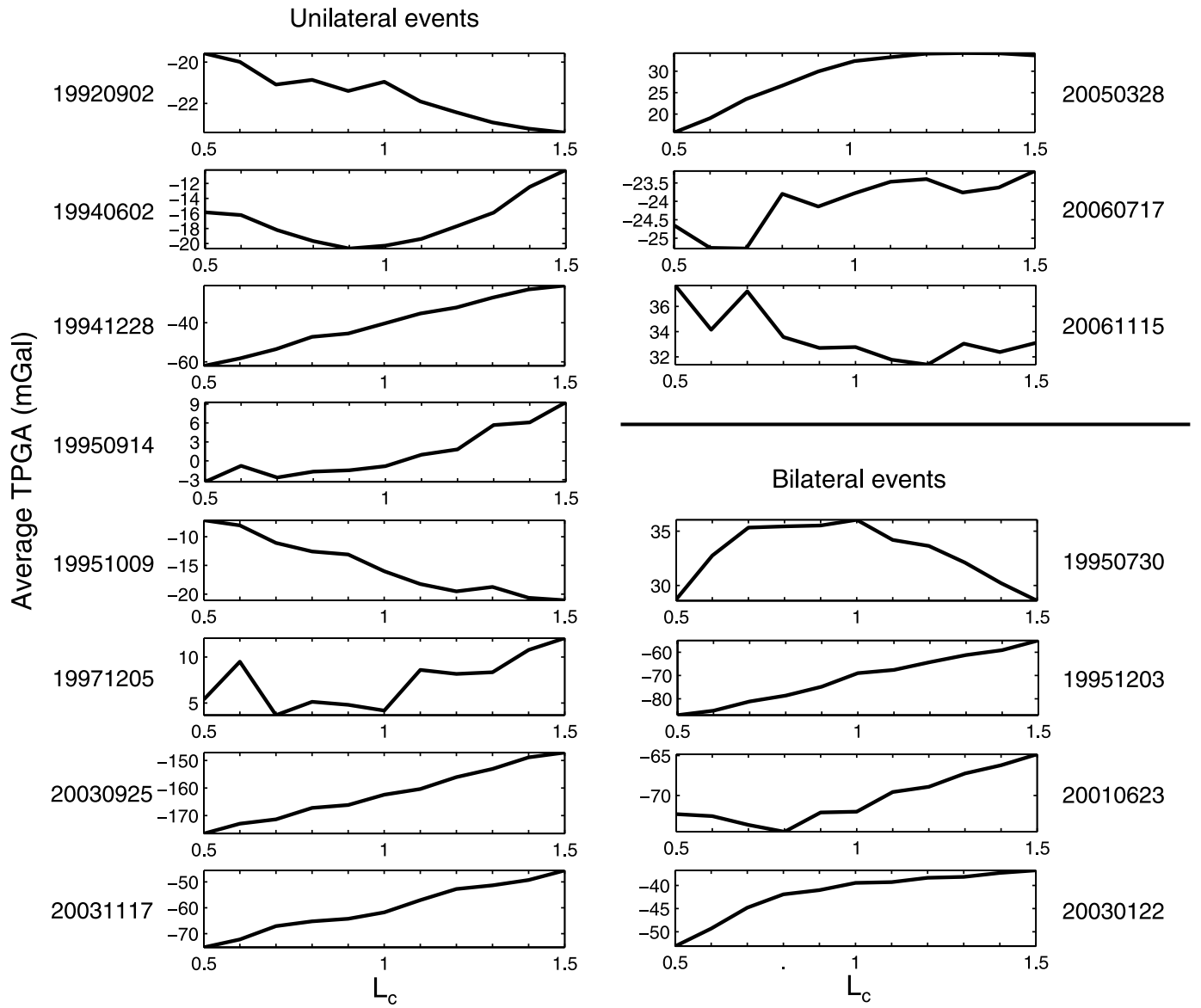

Figure 9. Average TPGA over rupture ellipses of varying $L_{c}$ for each event of the data set. In general, the average TPGA increases with $L_{c}$, indicating the centroid (reflected by the rupture ellipse of $0.5 L_{c}$ ) was located in a local TPGA minimum. The limits of the rupture ellipses which occur at $1 L_{c}$ generally coincide with increases or maxima in the TPGA.

than $\mathrm{M}_{\mathrm{w}} 7.7$ events (compare with measurements for a $\mathrm{M}_{\mathrm{w}} 7.5$ earthquake shown in Figure $4 \mathrm{a}$ and measurements for a $\mathrm{M}_{\mathrm{w}} 8.7$ shown in Figure B14). The inversion for the second moments resulted in a length $L_{c}$ of $108 \mathrm{~km}$, a duration $\tau_{c}$ of $55 \mathrm{~s}$, and an average instantaneous centroid velocity $\left|\mathbf{v}_{\mathbf{0}}\right|$ of $1.9 \mathrm{~km} / \mathrm{s}$. The characteristic rupture length, relatively long duration and directivity are consistent with other slip models for this event [Ammon et al., 2006; Fujii and Satake, 2006]. The duration is surprisingly long for an event of this magnitude; the duration for the $M_{w} 7.5$ Mexico earthquake was only $29 \mathrm{~s}$. The duration and moment for each event in this study are shown in Figure 6, fit with a line illustrating the scaling of duration as the cube root of moment. Both this event and the 1992 Nicaragua event have anomalously long durations considering their magnitudes. This shows these earthquakes belong to a class of slow tsunami earthquakes that radiate a large amount of low-frequency energy relative to their high-frequency radiation [e.g., Polet and Kanamori, 2000]. However, there is nothing obviously different about the TPGA profiles for these two events compared to the other events (e.g., Figure 4). Thus we find no evidence in this study to suggest a direct relationship between structure in the TPGA field and tsunamigenic potential.

[25] Figure 5b compares the characteristic rupture ellipse to the TPGA field. The centroid is again located in a negative TPGA region, and the limits of the rupture ellipse occur as the TPGA becomes increasingly positive (Figure 5c). When we consider the average TPGA over varying rupture dimensions, we find that the TPGA increases slightly near the edges of the rupture but is essentially flat. Hence the unilateral rupture propagation to the east appears to have been stopped near a local TPGA maximum (Figures $5 \mathrm{~b}$ and $5 \mathrm{c}$ ).

\subsection{The 1995 Chile Earthquake}

[26] $\mathrm{A} \mathrm{M}_{\mathrm{w}} 8.0$ earthquake occurred off the northern coast of Chile near the town of Antofagasta on 30 July 1995. This event has been the subject of a number of studies, which generally found that rupture initiated just south of the Mejillones peninsula and propagated unilaterally to the southwest [e.g., Delouis et al., 1997; Ihmlé and Ruegg, 1997; Carlo et al., 1999; Pritchard et al., 2006]. Our measurements and model fit are shown in Figure 7a. The inversion resulted in an $L_{c}$ of $121 \mathrm{~km}$, a $\tau_{\mathrm{c}}$ of $33 \mathrm{~s}$, and a 
(a)

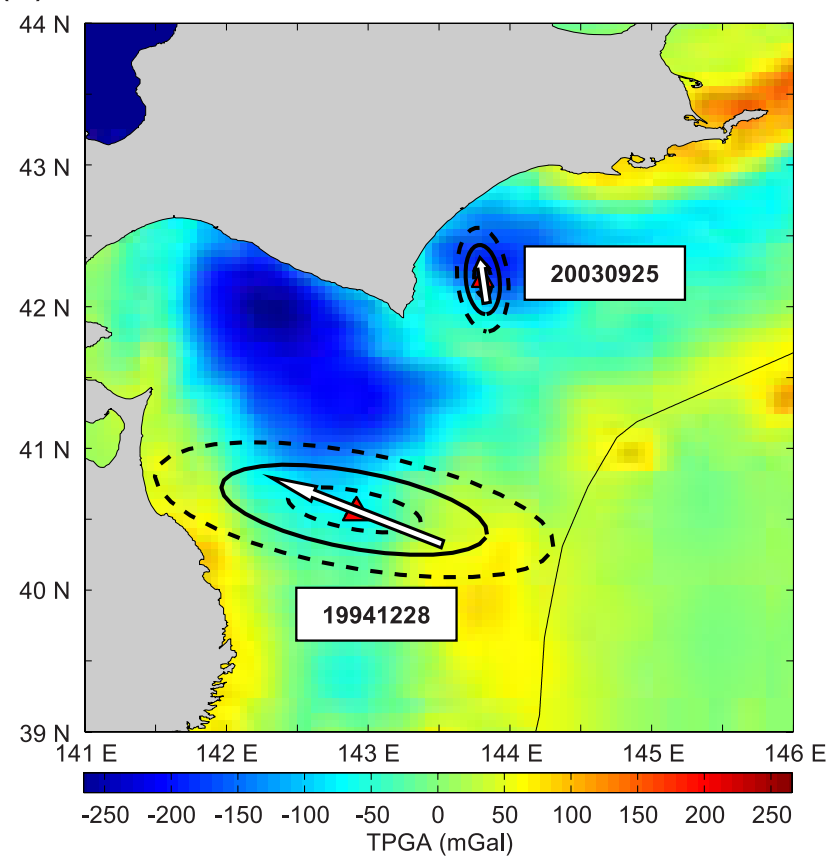

(b)
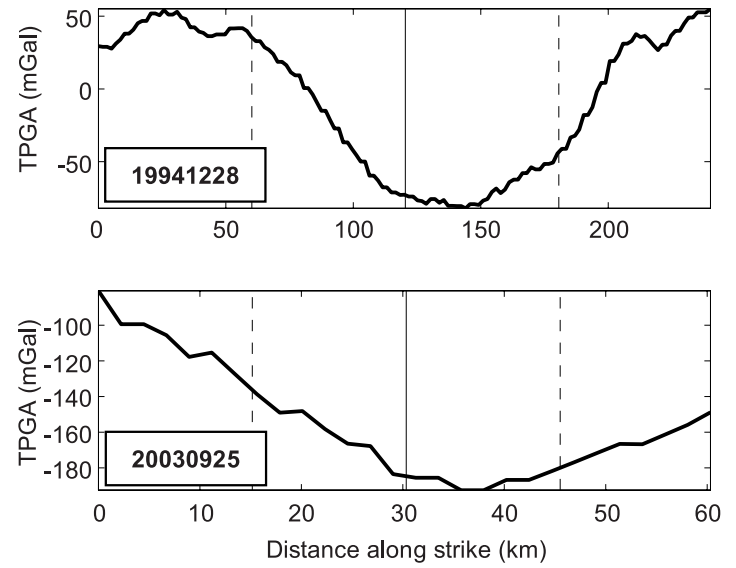

Figure 10. (a) Rupture ellipses for events 19941228 and 20030925 off the coast of northeastern Japan plotted on TPGA. See Figure 4 for symbol explanation. (b) Along-strike TPGA values for (top) 19941228 and (bottom) 20030925. Both events ruptured unilaterally, so rupture progresses from left to right. The $1 L_{c}$ limit in both cases correspond with a positive TPGA slope that can be qualitatively correlated with transitions from velocity-weakening to velocity-strengthening behavior shown in maps from Miyazaki et al. [2004b] and Nishimura et al. [2004].

directivity ratio of 0.33 , revealing a somewhat surprising bilateral component to the rupture. Our centroid location and rupture length are consistent with other slip models [Ihmlé and Ruegg, 1997; Pritchard et al., 2006], although the orientation of the moment release is slightly different. Where other slip models are oriented predominantly along strike, our rupture ellipse is oriented at around a $45^{\circ}$ angle to the trench. However, had our rupture ellipse been oriented more along strike, the overall shape of the TPGA profile would not change significantly, as the centroid is surrounded by higher TPGA regions along strike as well as updip and downdip (Figure $7 \mathrm{~b}$ ).

[27] The main moment release of this event, unlike most of the others in this study, was located in a positive TPGA region, although the centroid was located in a local TPGA minimum (Figure 7b). These higher TPGA regions are associated with the Mejillones Peninsula to the north and the Antofagasta Ridge to the west, both of which are thought to be tilted fault blocks [von Huene and Ranero, 2003]. The local TPGA minimum in which the centroid is located corresponds with a sediment-ponded basin behind the Antofagasta Ridge. The TPGA profiles show that the $1 L_{c}$ limit occurs near the high positive TPGA region denoting the Antofagasta Ridge (Figure 7c). However, had rupture continued beyond $1 L_{c}$, the TPGA would have decreased and so, unlike most of the other events in the data set, there is no obvious correlation between positive changes in the TPGA field and the termination of rupture.

\subsection{Evaluation of Bias From Unmodeled Propagation Effects}

[28] If inadequacies of the 3-D Earth models result in a significant bias in our estimates of rupture area, this bias should be shared by earthquakes within a given subduction zone owing to the very long wavelength nature of the R1 waves we utilize. Our data set consists of events from essentially four regions: the northwest Pacific (six events), the Middle American trench (four events), the Java trench (three events), and the Peru-Chile trench (two events). We have utilized two approaches to check for bias in our estimated rupture areas. First, many events have been compared to slip distributions derived from local geodetic data. For instance, our rupture areas agree well with geodetic inversions for both the 2003 Tokachi-oki [Miyazaki et al., 2004a] and 1995 Jalisco events [McGuire et al., 2001]. Moreover, there is considerable variability in the rupture directivity inferred for the various northwest Pacific earthquakes indicating that systematic biases are relatively unimportant for the majority of our events. As a further check to ensure that propagation effects do not bias the results, we compared our results to those obtained using an empirical Green's function (EGF) instead of point source synthetics to make amplitude measurements. In general, theoretical Green's functions (TGF) are preferable because of their superior signal-to-noise ratio at low frequencies and their true point source nature in time, but EGFs provide a useful way to check for consistency. Examples of EGF measure- 
(a)

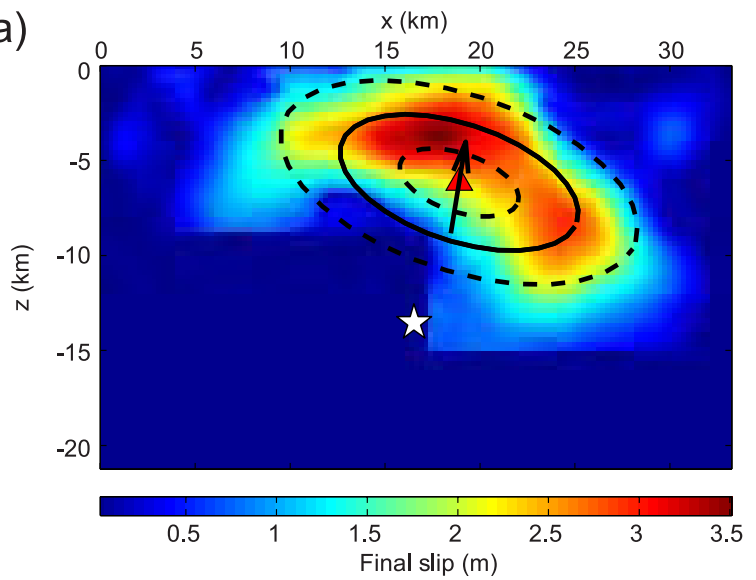

(c)

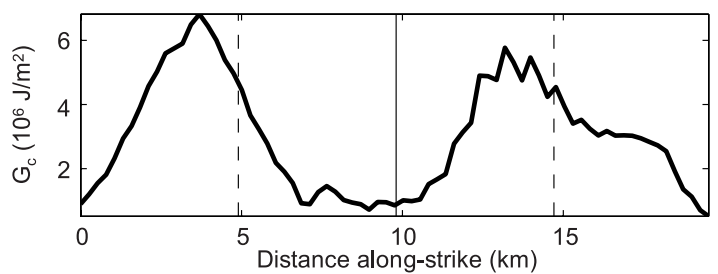

(b)

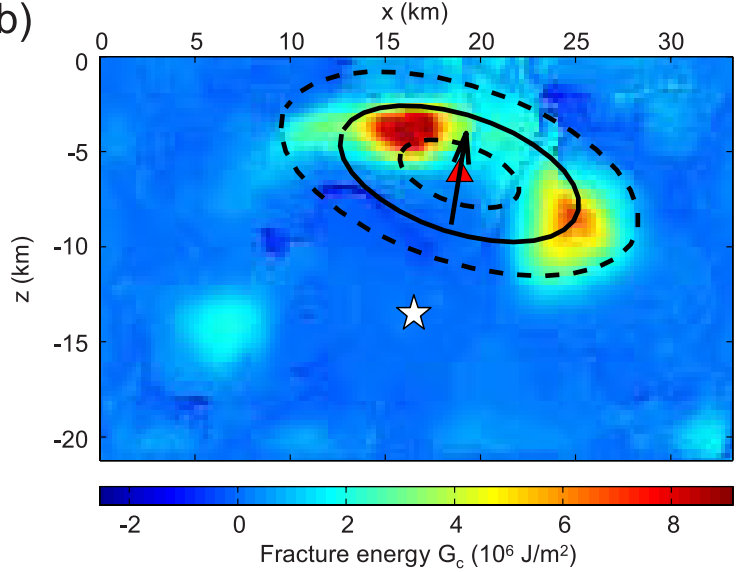

(d)

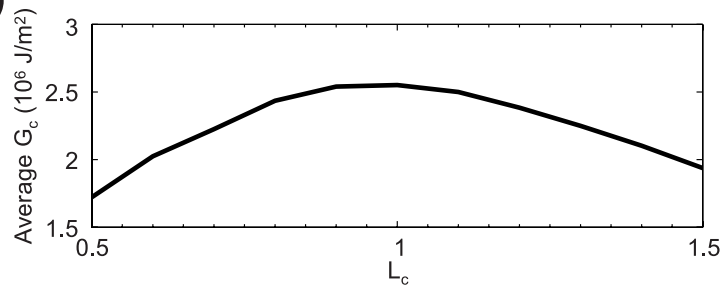

Figure 11. (a) Rupture ellipse (solid black ellipse) for the 2000 Tottori event plotted on the slip model of Iwata et al. [2000] from which it was determined. Ellipses of length 0.5 and $1.5 L_{c}$ are also shown (inner and outer dashed ellipses, respectively). Centroid location is marked by the red triangle. Directivity is indicated by the arrow. Hypocenter location marked by the white star. (b) Rupture ellipses and directivity plotted on top of fracture energy $G_{c}$ calculated by Dalguer et al. [2002]. (c) $G_{c}$ along the axis of the rupture ellipse. Maxima occur near the rupture ellipse limits (dashed lines). A minimum occurs at the centroid (solid black line). (d) Average $G_{c}$ over ellipses of varying $L_{c}$. Maximum occurs near $1 L_{c}$. Centroid occurs at a local minimum.

ments and inversion results for a northwest Pacific event and the two Peru-Chile trench events can be found in Appendix B (Figures B4, B5, and B11). The two PeruChile trench events have $\sim 15^{\circ}$ and $55^{\circ}$ rotations of their rupture ellipses when using EGFs versus TGFs, indicating that unmodeled effects may bias our estimates of rupture area for this subduction zone. We are not confident that the EGF results are better because of the large amount of scatter (e.g., poor SNR) at frequencies below $5 \mathrm{mHz}$ for these events (Figure B5a and B11a). The TPGA profile changes qualitatively for only the 2001 Peru event.

\subsection{Summary of Results}

[29] Our survey of 15 earthquakes indicates that TPGA increases as a rupture approaches the edge of its eventual rupture patch. Figures 8 and 9 summarize the along-strike TPGA and average TPGA profiles for all of the events. In 11 of the 15 events, the centroid was clearly located where the TPGA is a local minimum. In most cases this value was negative (e.g., events 19941228, 20030122), but in some cases it was positive (e.g., events 20050328, 19950730). The magnitude of TPGA variation over the rupture area also differs from event to event. In some cases, the average TPGA varied over a range of $\sim 2 \mathrm{mGal}$, while for others variations occurred over a range of $\sim 40 \mathrm{mGal}$ (see events 20060717 and 19941228 in Figure 9). This suggests that the relative rather than absolute values of TPGA may reflect rupture behavior more directly.

[30] Our results also show that in 11 of the 15 events, the limits of the rupture ellipses correspond with increasing TPGA (Figure 9). In 3 events, the TPGA is essentially flat between the centroid and the rupture edges. In one event (19951009), the limits correspond with decreasing TPGA, and so the reason for rupture to stop is not apparent in the TPGA field. If we exclude the South American events due to uncertainties in propagation effects, 9 of 13 events have increasing TPGA. Thus, in the majority of the events in our data set, the $1 L_{c}$ limit corresponds with a positive gradient in TPGA (Figure 9). This suggests that a relationship exists between the TPGA field and physical conditions on the plate interface that control the extent of individual ruptures.

\section{Discussion}

[31] In agreement with previous studies [Song and Simons, 2003; Wells et al., 2003], our results demonstrate that the areas of greatest seismic moment release for large subduction zone earthquakes tend to occur beneath local minima in the TPGA field. Typically these minima denote the presence of a fore-arc sedimentary basin. Additionally, we demonstrated that the limits of the two-dimensional rupture areas correlate with positive gradients of TPGA 

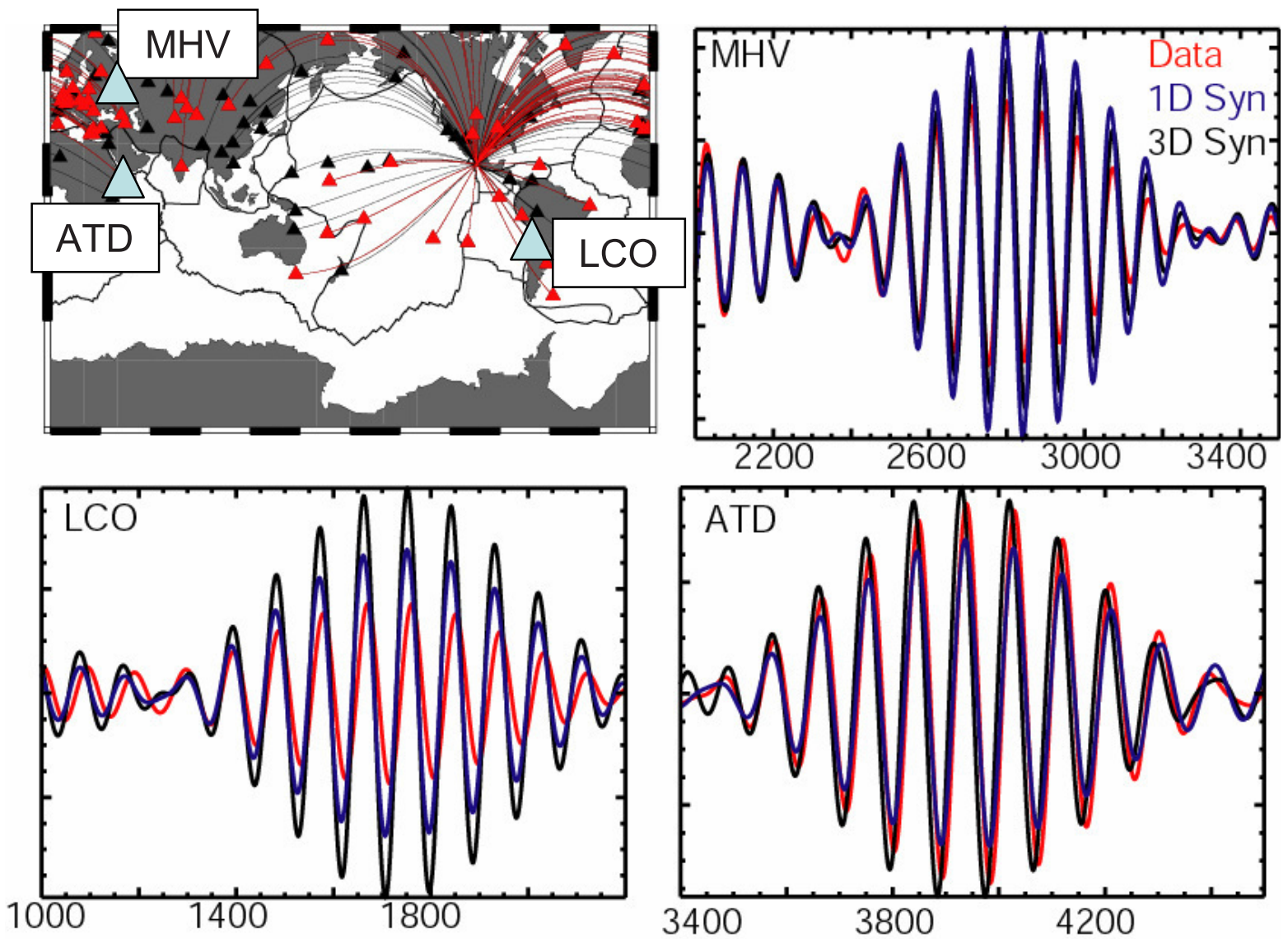

Figure A1. (top left) Map showing great circle paths from the source of the 2003 Mexico earthquake to stations. Red stations were used in the final inversion. Comparison of 1-D and 3-D synthetic waveforms at stations MHV, LCO, and ATD (blue triangles on the map) to actual data in the $10-12 \mathrm{mHz}$ band. The amplitude measurements are markedly different, especially at LCO.

(Figure 9). Our observations lead to two primary conclusions regarding the connection between TPGA and the frictional conditions on the plate interface. First, the relative rather than absolute values of TPGA have the greatest correlation to individual rupture behavior. Second, there appears to be a correlation between the resistance to rupture growth (either spatial variations in current shear stress level or material properties) and the edges of local TPGA minima. Although these minima often correlate with forearc basins, they do not identify them uniquely because of other variations in seafloor topography and density which contribute to the gravity field. However, Wells et al. [2003] demonstrated that the basin edges are spatially correlated with maxima in gravity gradient rather than absolute values of the free air gravity field, which they then correlate with updip and downdip frictional stability transitions. In this section, we further explore the potential mechanisms connecting the upper plate fore-arc basins reflected in the TPGA field and the resistance to rupture propagation observed to occur near the edges of these basins.

4.1. Fore-Arc Basin Formation and Wedge Mechanics

[32] A number of 2-D models have examined the link between fore-arc basin formation and conditions along the plate interface. Byrne et al. [1988] suggested that the presence of fore-arc basins indicates strong material at depth which causes a change in the critical taper angle of the wedge and allows backstops and outer-arc highs to form which trap sediments. Recent numerical work has explored the mechanics of the upper plate that allow the formation of fore-arc basins [Fuller et al., 2006; Wang and Hu, 2006]. Wang and Hu [2006] divide the fore arc into an undeforming inner wedge and an actively deforming outer wedge. The inner wedge provides a stable platform for fore-arc basins to form on and overlies the velocity-weakening seismogenic zone, while the outer wedge overlies the velocity-strengthening region updip of the seismogenic zone. Fuller et al. [2006] also suggest that fore-arc basins tend to form in stable wedges, and the lack of deformation in such wedges could mean that permeability is reduced in the direction normal to the plate interface, allowing processes such as thermal pressurization to generate elevated pore pressures that could significantly weaken the fault [Wibberley and Shimamoto, 2005]. Song and Simons [2003] infer that strongly negative TPGA values correlate with increases in the shear traction on the plate interface. Large shear tractions tend to result in more stick-slip behavior [Marone, 1998]. While the existing models are fairly simplistic, they 

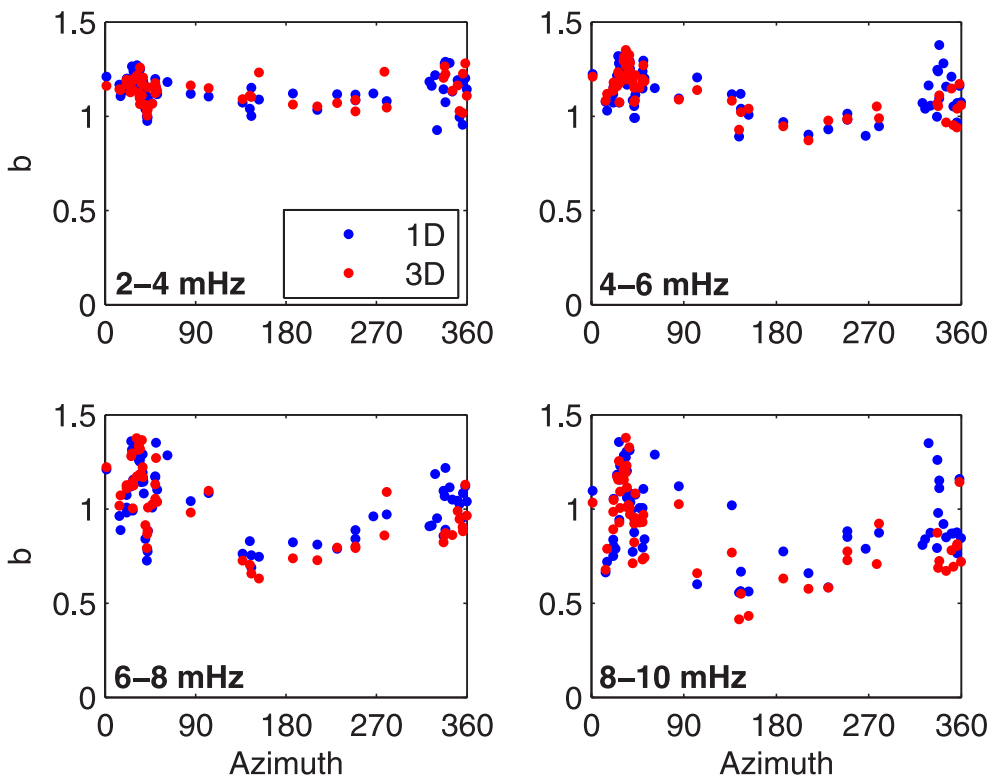

Figure A2. Amplitude measurements in different frequency bands made using 1-D synthetics (blue) and 3-D synthetics (red). At higher frequencies, the measurements become significantly different, particularly in northern azimuths. There is also more scatter in the 1-D synthetic measurements.

demonstrate mechanical reasons to expect fault strength and/or fluid pressure to be different under fore-arc basins than underneath adjacent areas. In general, these frictional differences do not appear to be related to variations in the thermal structure of the plate interface.

\subsection{How Great Earthquakes Stop: Dynamic Versus Quenched Heterogeneity}

[33] The resistance to rupture growth that causes earthquakes to stop can arise from along-strike variations in shear stress (dynamic heterogeneity) or along-strike variations in fault frictional properties (quenched heterogeneity) [Guatteri and Spudich, 2000; Shaw, 2000]. In numerical models, time-dependent, dynamic heterogeneities can produce complex earthquake sequences even on faults with uniform frictional properties owing to the low-stress regions leftover from past ruptures [Shaw, 2000]. However, the locations of these dynamic heterogeneities vary on the scale of an earthquake cycle (100 s of years). In contrast, the forearc basins (and associated TPGA anomalies) reflect the average stress state on the plate interface and within the wedge over timescales of basin formation (at least a million years) [Fuller et al., 2006]. Thus, if large ruptures are stopped simply by encountering the low-stress regions leftover from previous ruptures, as opposed to some longlived material heterogeneity, then averaging over many earthquake cycles (or equivalently many subduction zones) should remove any correlation with the TPGA field. Our observed correlation between TPGA variations and the boundaries of individual ruptures requires that long-lived, upper plate structural/geological heterogeneity is a firstorder control on along-strike rupture extent.

[34] One type of along-strike frictional heterogeneity on a fault that may prevent large throughgoing ruptures are patches of velocity-strengthening material that exist due to compositional or thermal anomalies. The correlation between positive TPGA gradients and a transition from velocity-weakening to velocity-strengthening behavior may be qualitatively assessed in a region such as northeastern Japan. Owing to the dense instrumentation network, a number of studies have mapped the long-term seismogenic behavior of the plate interface in this region [Miyazaki et al., 2004b; Nishimura et al., 2004; Yamanaka and Kikuchi, 2004]. Two earthquakes in our study occurred here: the 1994 $\mathrm{M}_{\mathrm{w}} 7.7$ Sanriku-oki earthquake off the coast of northern Honshu (19941228) and the $2003 \mathrm{M}_{\mathrm{w}} 8.3$ Tokachi-oki earthquake off the coast of Hokkaido (20030925). In their study of the 2003 earthquake, Miyazaki et al. [2004b] inferred that the afterslip of this event indicated velocitystrengthening behavior and found that it occurred in areas surrounding the greatest moment release (both along strike and updip). Significant afterslip also occurred in the areas surrounding the greatest coseismic slip of the 1994 Sanrikuoki earthquake [Nishimura et al., 2004].

[35] Our characteristic rupture ellipses for these two events are shown in Figure 10a. For 19941228, the limits of the rupture ellipse occur when the TPGA becomes positive. The positive TPGA regions correspond relatively well with the weak seismic coupling region shown by Nishimura et al. [2004]. This observation seems to suggest a correlation between positive TPGA values and velocitystrengthening behavior. However, the rupture ellipse for 20030925 shows that the rupture failed to fill the entire basin and stopped in a negative TPGA region. This suggests the presence of velocity-strengthening materials even though the TPGA remains negative. Instead, the transition from velocity-weakening to velocity-strengthening behavior seems to be correlated with positive TPGA gradients. Beyond the limits of the rupture ellipses for both events, 
(a)
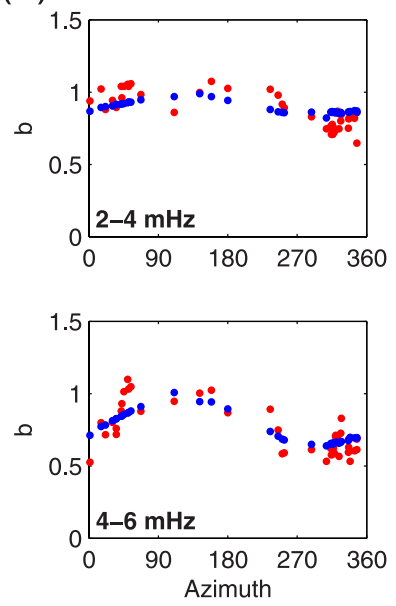
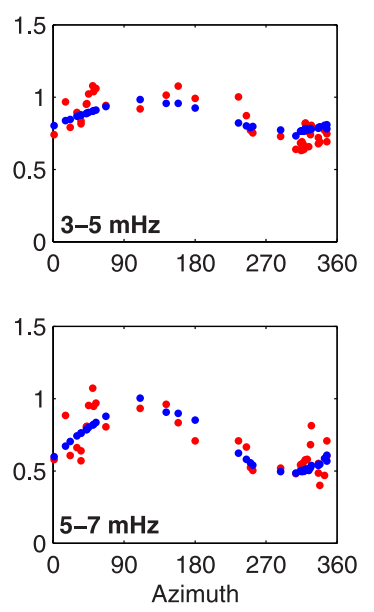

(c)
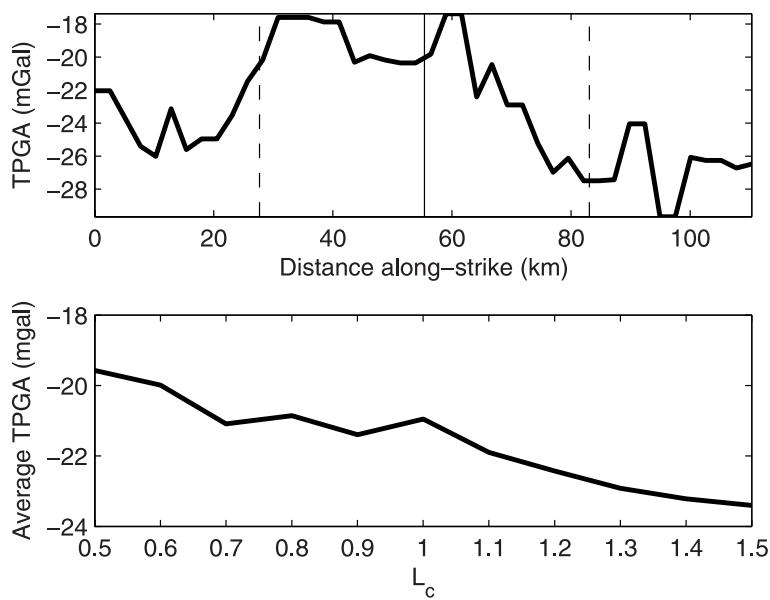

(b)

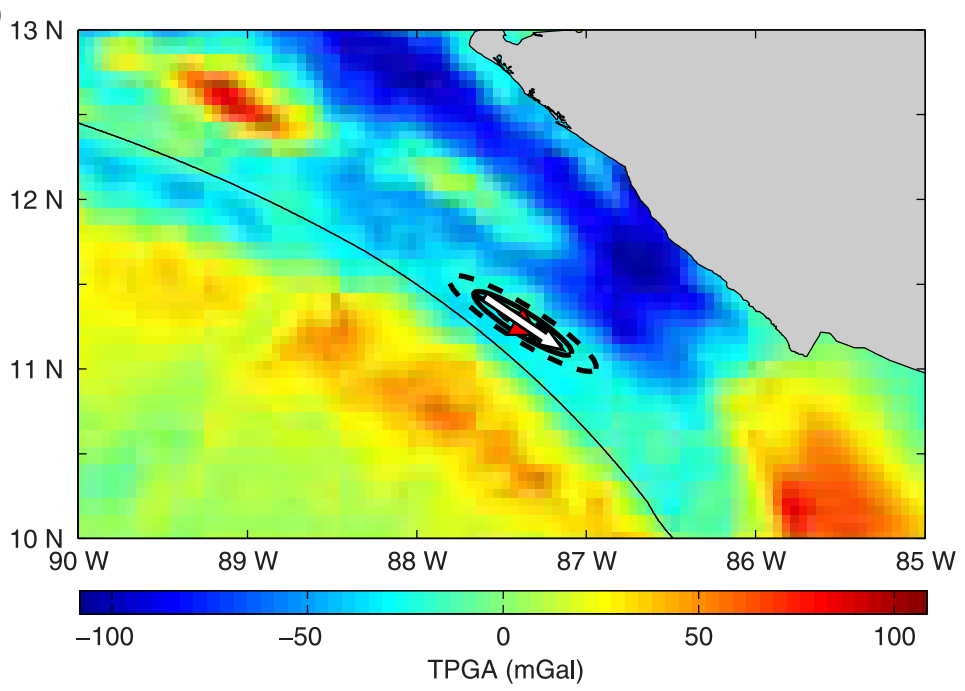

Figure B1. Measurements and results for unilateral event 19940602 in Java. See Figure 4 for symbol explanation.

the TPGA increases (Figure 10b). This change in the TPGA corresponds well in location with changes in the seismic coupling seen in maps drawn by Nishimura et al. [2004] and Miyazaki et al. [2004b] for the 1994 and 2003 earthquakes, respectively. At least in the Tokachi-oki region, there appears to be a link between increases in TPGA and transitions from velocity-weakening to velocity-strengthening behavior.

[36] A second type of frictional heterogeneity that can play a role in stopping earthquake rupture is regions of velocity weakening material with very high fracture energy. In subduction zones, this may represent areas of increased fault roughness due to the bathymetry of the incoming plate. Figure $11 \mathrm{~b}$ shows the characteristic rupture ellipse for the 2000 Tottori earthquake plotted on fracture energy calculated by Dalguer et al. [2002]. High fracture energies are associated with the limits of the rupture ellipse (Figures 11c and $11 \mathrm{~d}$ ) suggesting that the region near $1 L_{c}$ identifies the location of significant resistance to rupture propagation that was necessary to arrest a particular rupture. The fracture energy profiles in Figures $11 \mathrm{c}-11 \mathrm{~d}$ are remarkably similar to the typical TPGA profiles found in this study (Figures 8-9) despite being nominally unrelated variables. Thus the variations we observe in TPGA around the $1 L_{c}$ portion of the rupture zone may reflect a surprisingly direct connection between the edges of sedimentary basins and the variations in frictional properties of the plate interface.

[37] The primary difference between the fracture energy and frictional stability transitions as explanations for the boundaries of $\mathrm{M}_{\mathrm{w}} 8$ ruptures lies in the role of aseismic slip. In the fracture energy case, most of the plate motion would be expected to be made up by abundant smaller $\left(\mathrm{M}_{\mathrm{w}}<8\right)$ earthquakes, while in the stability transition explanation, much of the plate motion in these regions could occur aseismically, likely as afterslip. Thus distinguishing between these two types of frozen heterogeneity will require geodetic observations over multiple earthquake cycles, but 
(a)
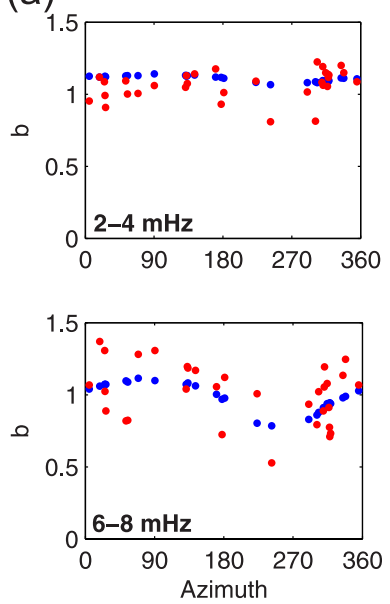

(c)
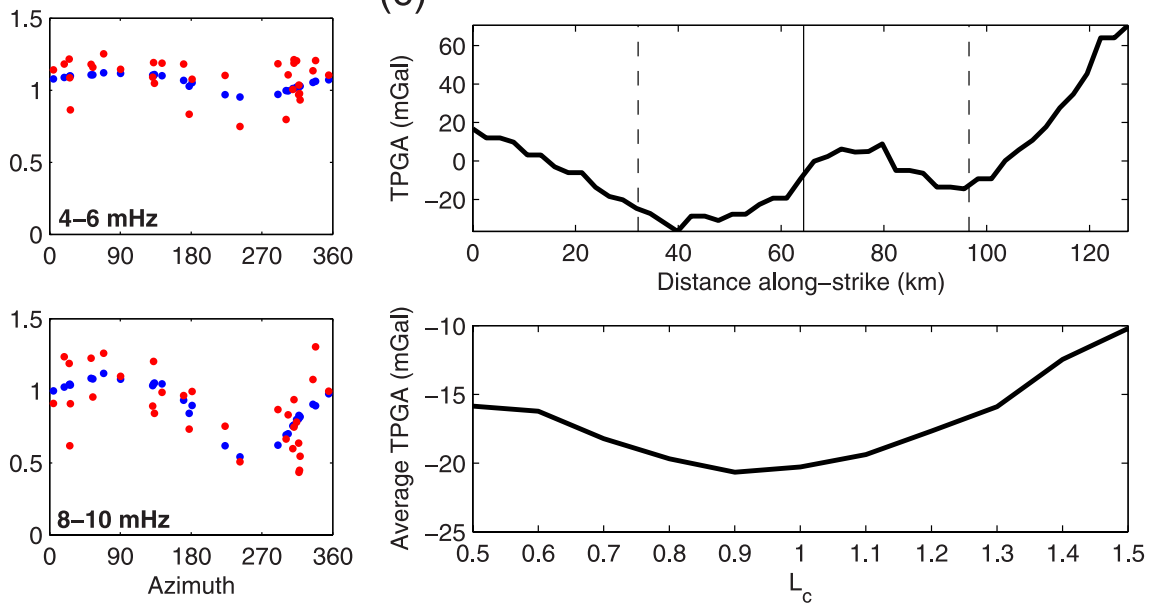

(b)

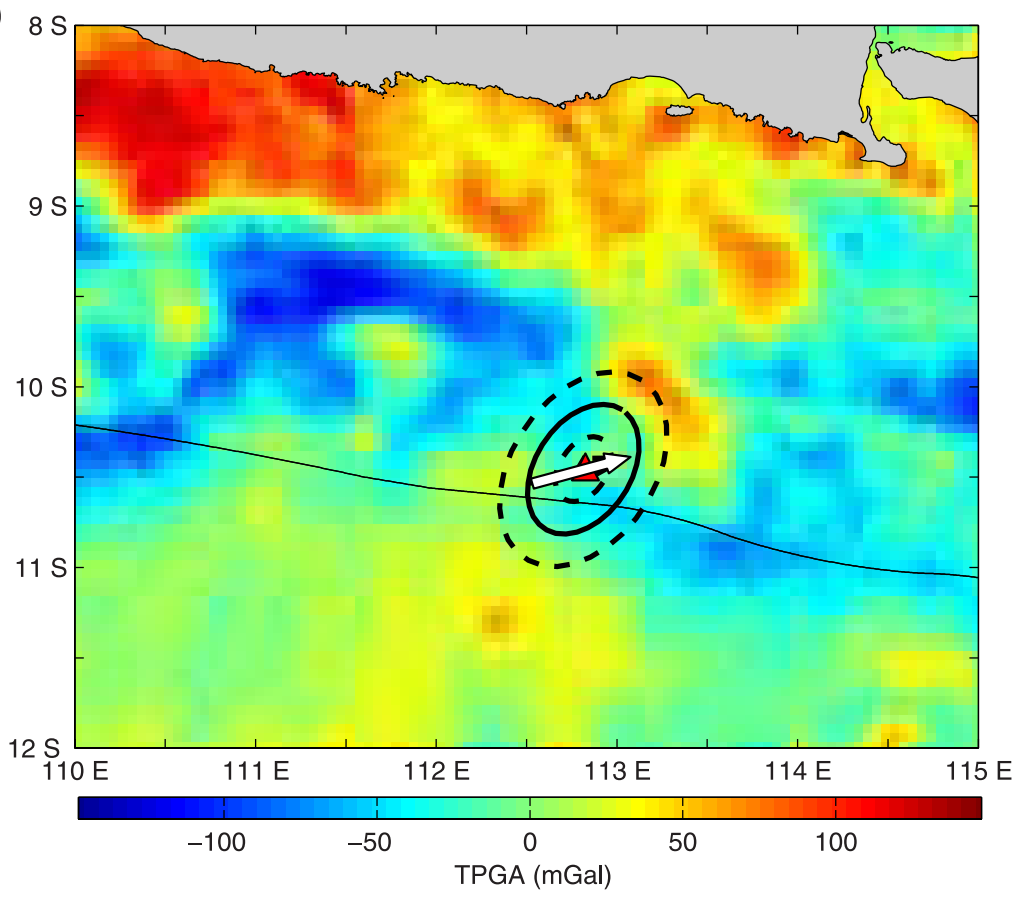

Figure B2. Measurements and results for unilateral event 19941228 in Japan. See Figure 4 for symbol explanation.

at least for the Tokachi-oki region, along-strike variations in frictional stability are important [Miyazaki et al., 2004b].

\section{Conclusion}

[38] The spatial heterogeneity of frictional properties which cause variations in seismogenic behavior along a subduction zone can be linked to variations in fore-arc TPGA and geological structure [Song and Simons, 2003]. To further investigate this relationship, we estimated the rupture characteristics of a global data set of large shallow subduction zone earthquakes and compared them with the TPGA field. The centroid locations typically correspond with local TPGA minima, and the limits of the areas of significant moment release correspond with positive TPGA gradients (Figure 9). These gradients appear to be linked to changes in the frictional properties along the plate interface that control rupture behavior. Owing to the inherently long timescales required for forearc basin formation, the correlation between the TPGA field and rupture termination regions indicates that longlived material heterogeneity rather than short timescale stress heterogeneities are responsible for arresting most great subduction zone ruptures. Variations in TPGA may therefore be used to not only determine the long-term seismogenic behavior along the strike of subduction zones but also to provide estimates of the boundaries of 
(a)
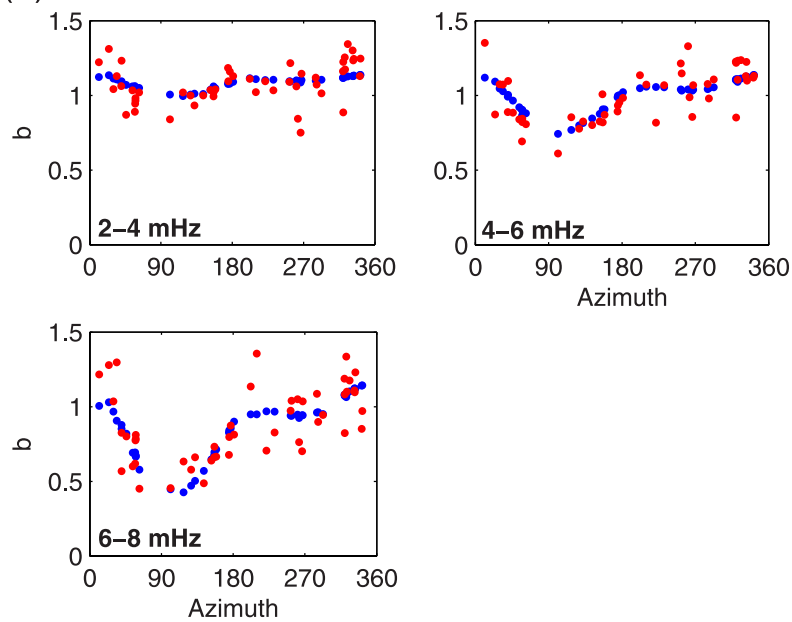

(c)
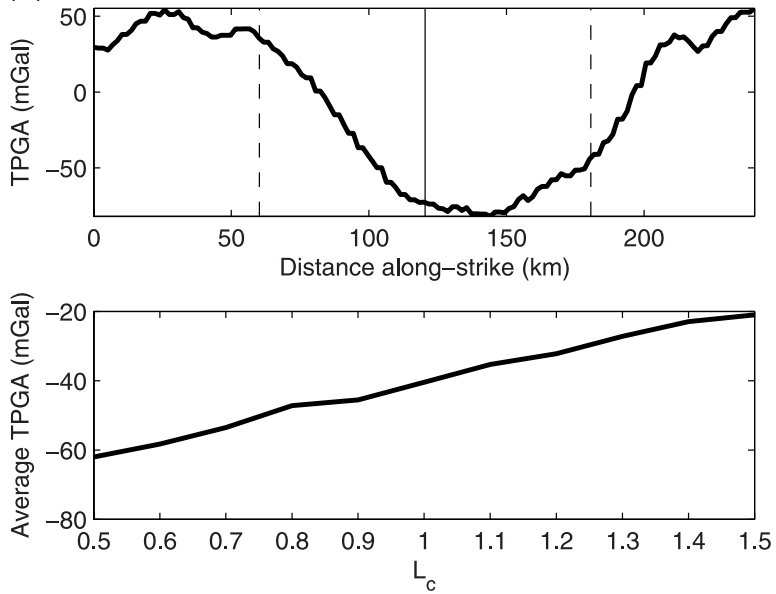

(b)

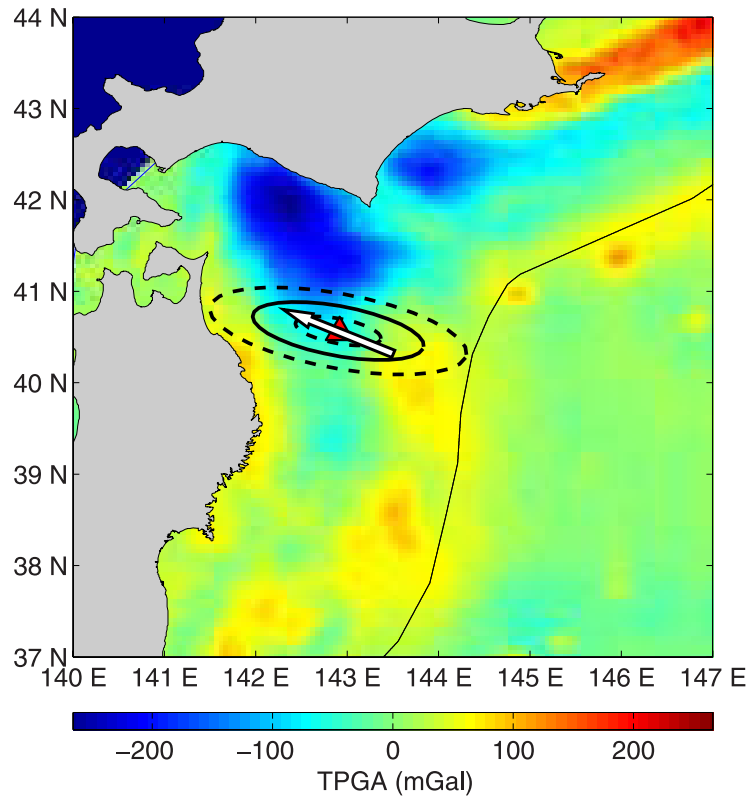

Figure B3. Measurements and results for unilateral event 19950914 in Mexico. See Figure 4 for symbol explanation.

individual future ruptures for probabilistic seismic hazard analysis.

\section{Appendix A: One-Dimensional Versus Three- Dimensional Synthetics}

[39] In this appendix, we discuss the reasons for using both 1-D and 3-D synthetic seismograms in this study. We use 1-D normal mode synthetic seismograms to calculate the partial derivatives used in the inversion and 3-D synthetics to make the actual amplitude measurements. The 1-D synthetics are much faster to compute than the 3 -D synthetics, which require a 64-processor Linux cluster, and so they are considerably more efficient to use for the numerical calculations of the partial derivatives of the Green's functions. The use of 3-D synthetics rather than 1-D synthetics to calculate the partial derivatives in (10) would make little difference in the inversion results. The partial derivatives are calculated from perturbations in source location, and so are more sensitive to source-station geometry than to the velocity model used to generate the synthetics. The results from a test event confirm that little is gained by using 3-D synthetics for the partial derivatives; therefore, because the 3-D synthetics require much more computational effort, we use the 1-D synthetics to calculate the partial derivatives.

[40] However, the 3-D synthetics produce more accurate R1 amplitude predictions at higher frequencies, so they are used to make the amplitude measurements. The difference in amplitude predictions can be seen by comparing the 1-D and 3-D synthetics with the seismograms observed at three stations at different azimuths for the $2003 \mathrm{M}_{\mathrm{w}} 7.5$ earthquake in Mexico (Figure A1). Amplitude measurements made using 1-D synthetics would have been lowest at station MHV $(\mathrm{az}=21)$. With the 3-D synthetics, the lowest measurement occurs at station LCO $(\mathrm{az}=145)$, which indicates a completely different direction of rupture directivity.

[41] The magnitude of amplitude anomaly measured with 1-D and 3-D synthetics can also be very different (see station LCO in Figure A1). Figure A2 compares the amplitude measurements made using 1-D and 3-D synthetics for 
(a)
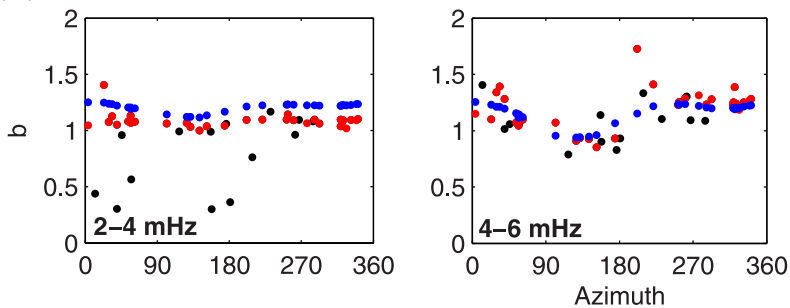

(b)

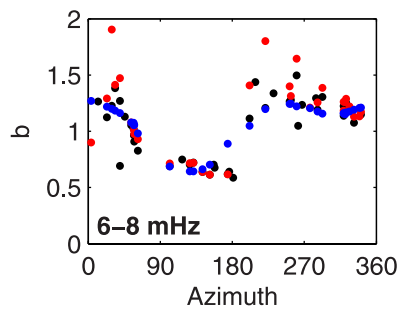

(c)
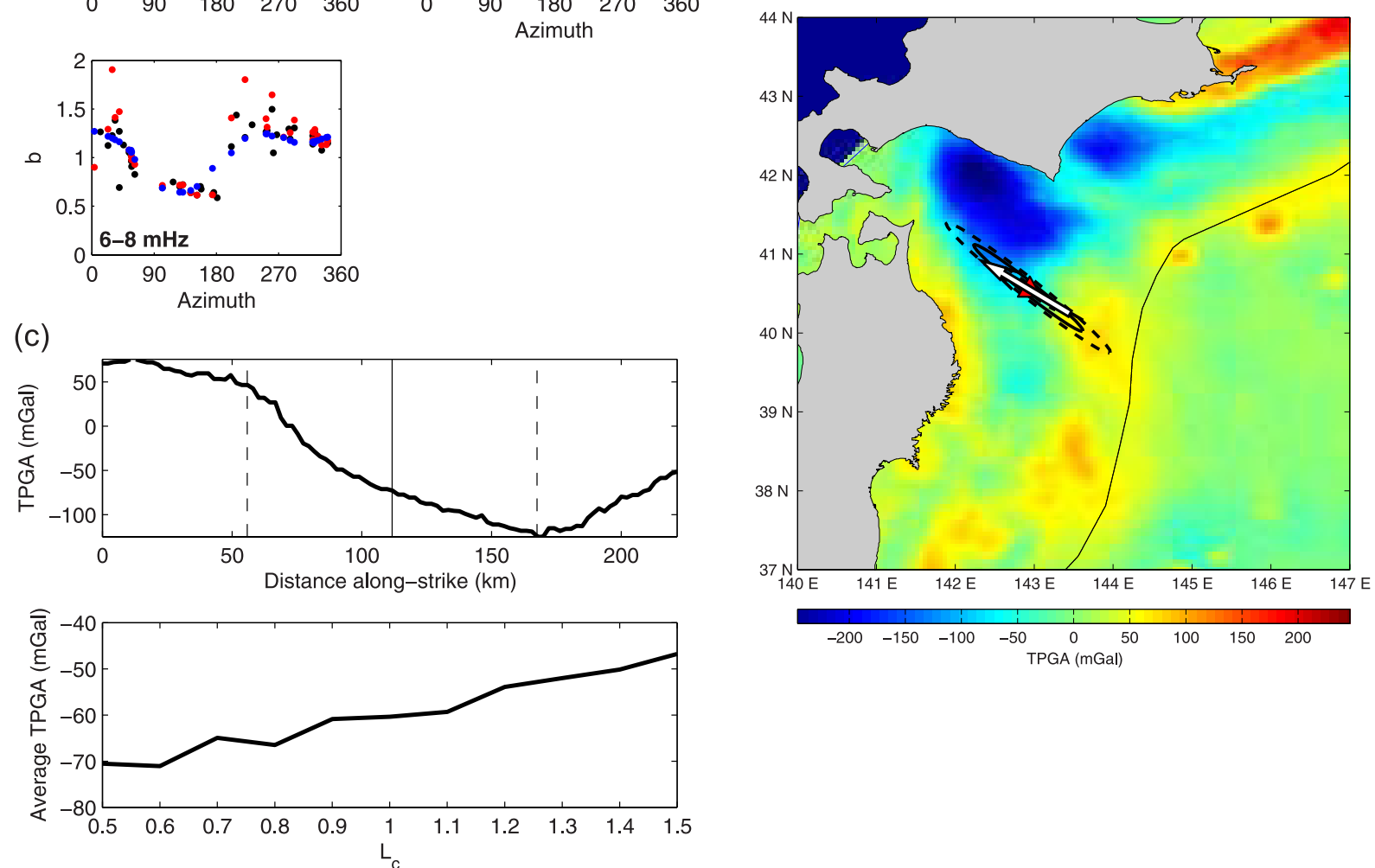

Figure B4. Measurements and results for event 19941228 in Japan made using a $\mathrm{M}_{\mathrm{w}} 6.7$ aftershock that occurred on 6 January 1995 as an empirical Green's function. (a) Amplitude measurements (red), fit from inversion (blue), and measurements from stations discarded in EGF due to poor SNR but retained in the original analysis (black). Note scatter in the lowest bandpass, as well as increase in amplitude with frequency due to differences in centroid depth of the EGF and the main shock. (b) See Figure 4 for symbol explanation. Compared to the original ellipse, this rupture ellipse has rotated by $\sim 28^{\circ}$, although the centroid location, rupture length, and directivity are similar. (c) See Figure 4 for symbol explanation. Qualitatively, these TPGA plots changed very little from the original analysis. 
(a)
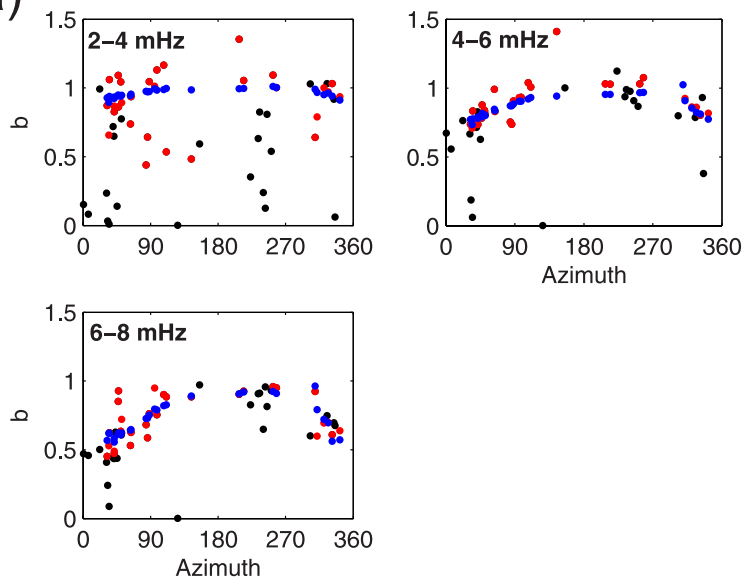

(c)
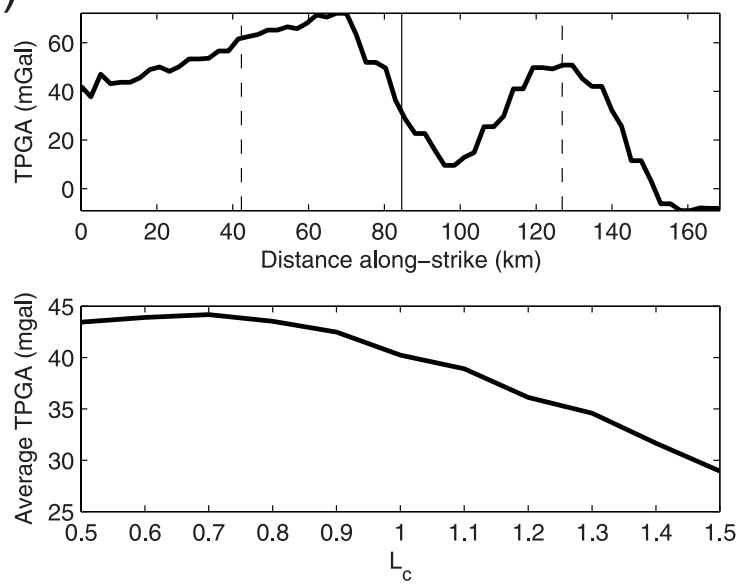

(b)

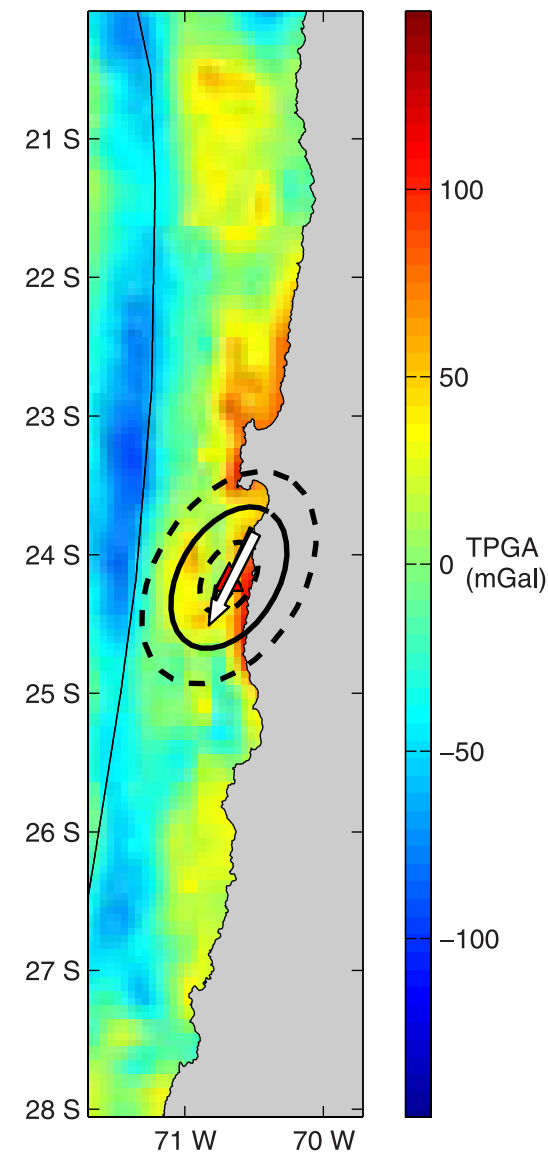

Figure B5. Measurements and results for event 19950730 in Chile using a $M_{w} 5.9$ aftershock that occurred on 3 August 1995 as an EGF. (a) See Figure B4 for symbol explanation. Note the large amount of scatter in the $2-4 \mathrm{mHz}$ band. (b) See Figure 4 for symbol explanation. Compared to the TGF results, the ellipse has rotated by $\sim 14^{\circ}$ but remains oblique to the strike of the trench. (c) See Figure 4 for symbol explanation. Although these plots have changed slightly from the original results, the overall conclusion remains the same qualitatively. 
(a)
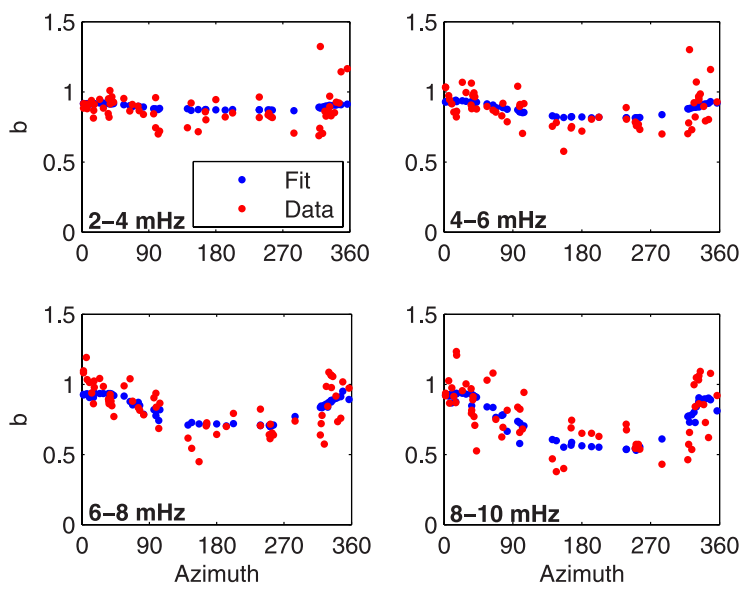

(c)
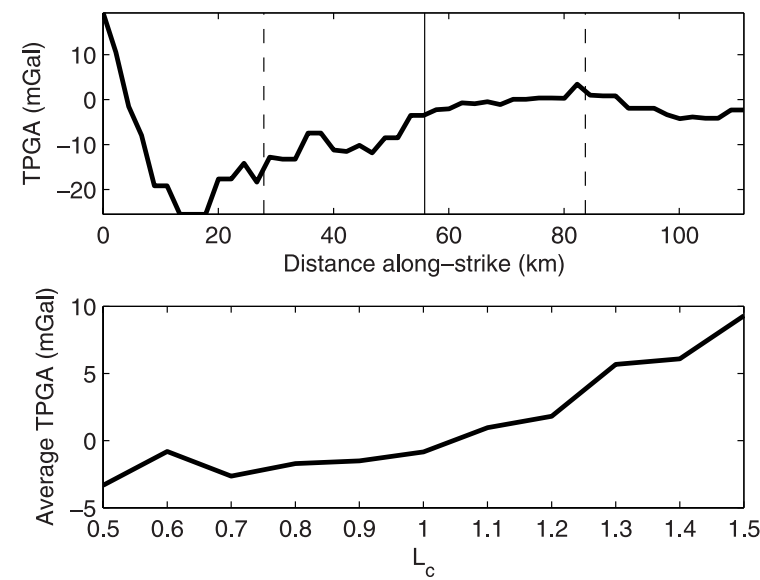

(b)

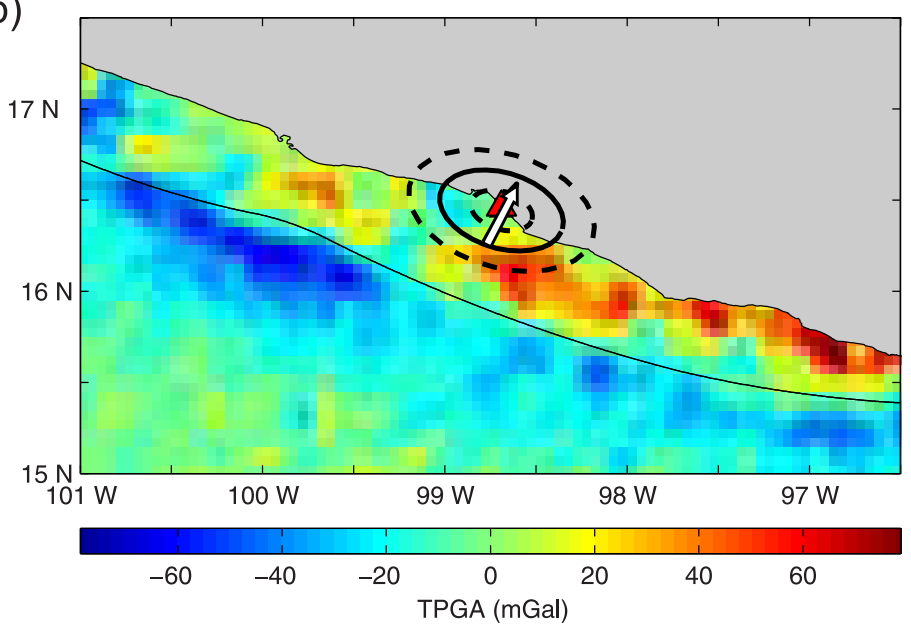

Figure B6. Measurements and results for unilateral event 19950914 in Mexico. See Figure 4 for symbol explanation. 
(a)
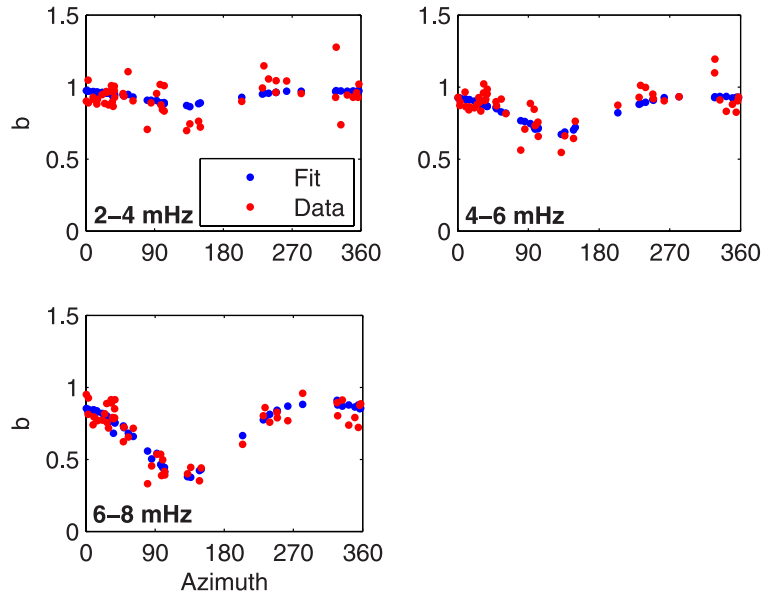

(c)
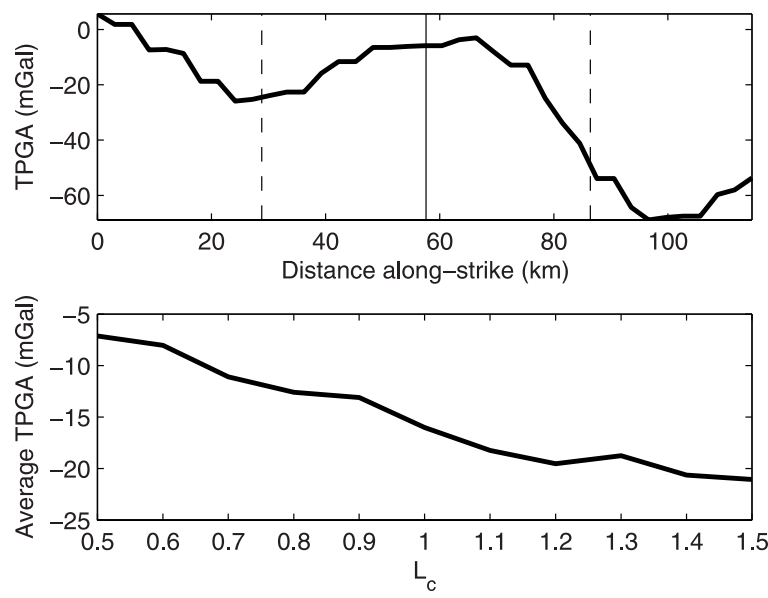

(b)

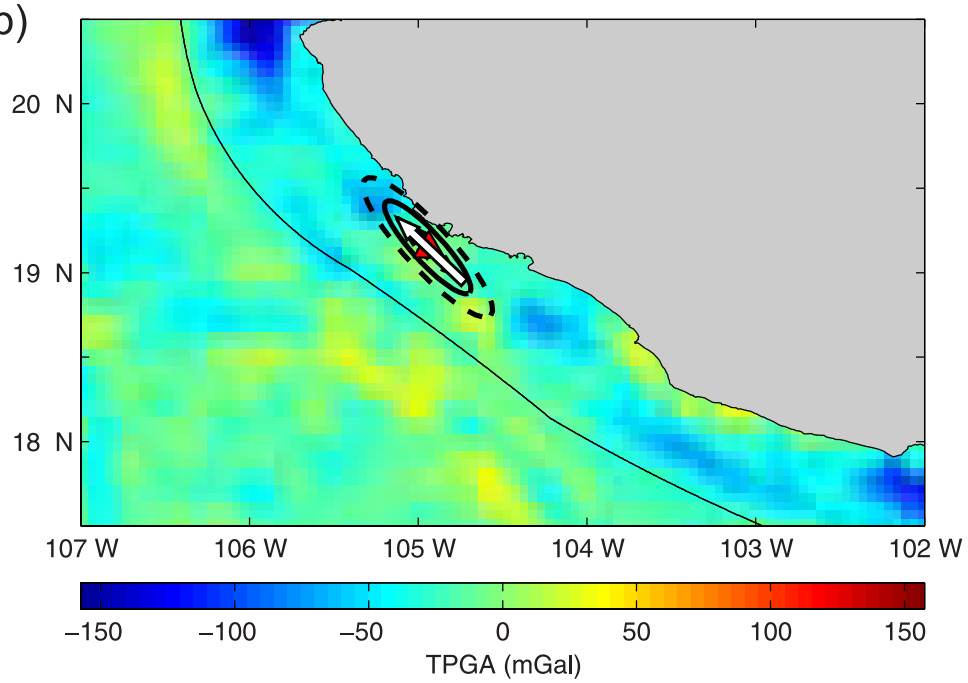

Figure B7. Measurements and results for unilateral event 19951009 in Mexico. See Figure 4 for symbol explanation. 
(a)
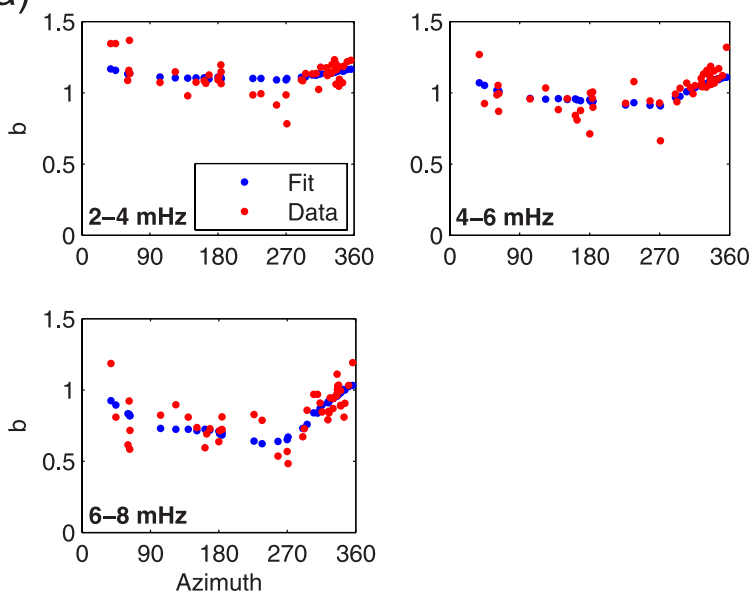

(c)
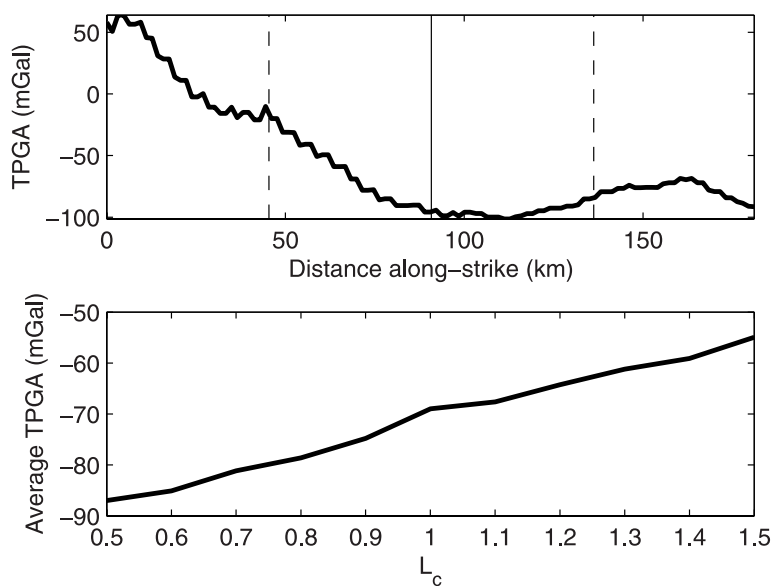

(b) $47 \mathrm{~N}$

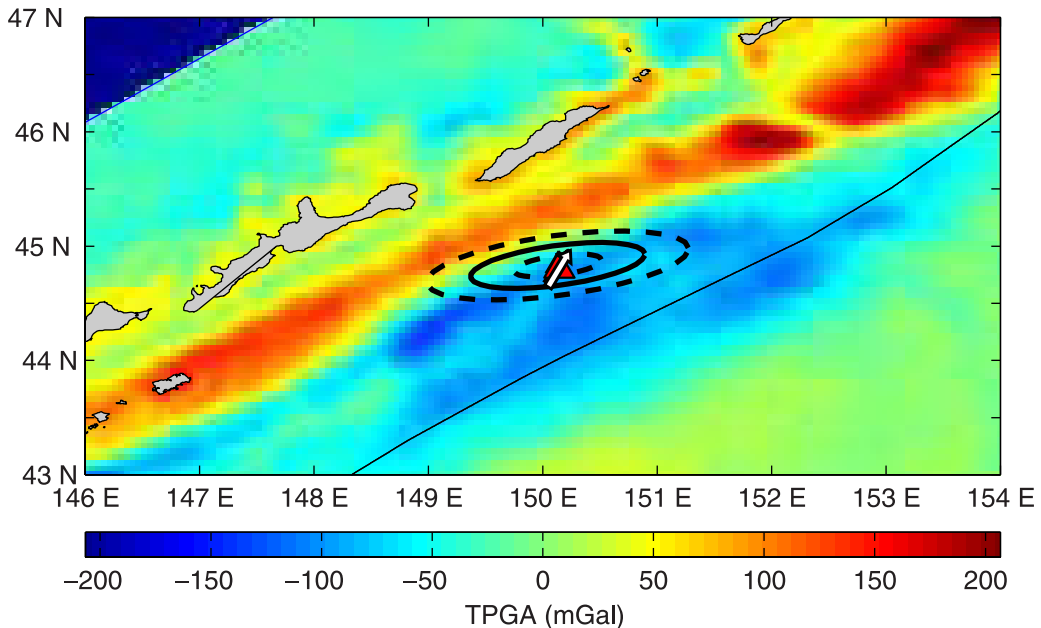

Figure B8. Measurements and results for bilateral event 19951203 in the Kurile Islands. See Figure 4 for symbol explanation. 
(a)
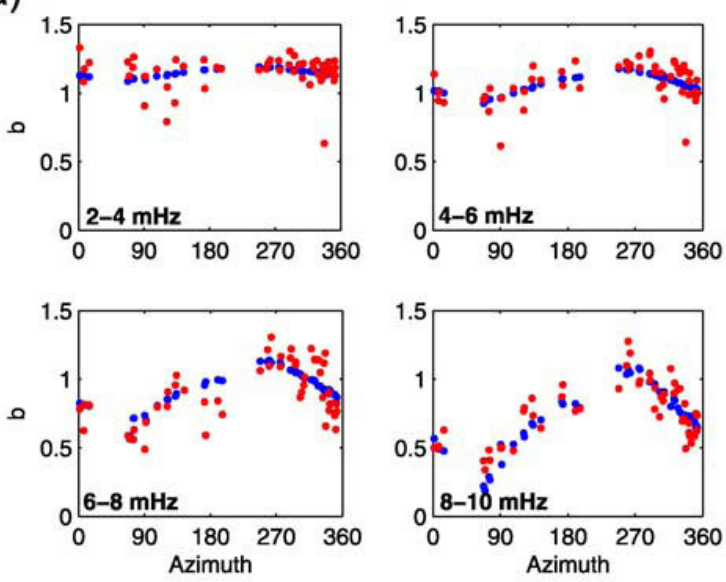

(c)
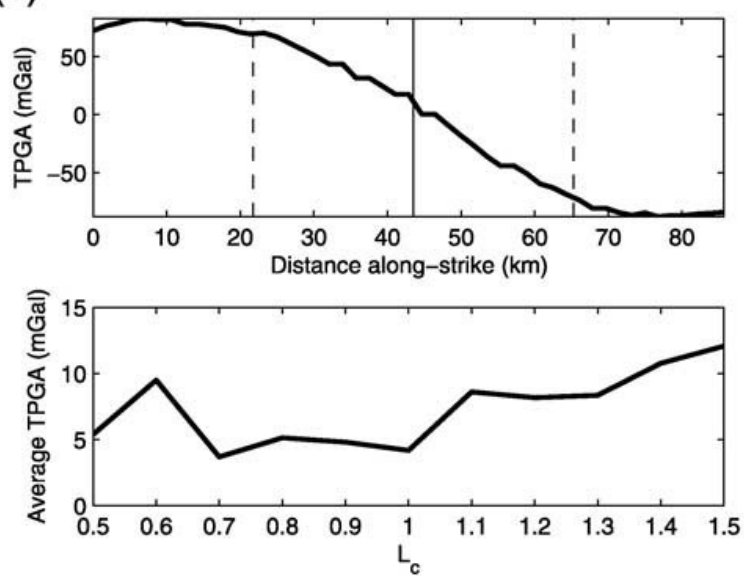

(b)

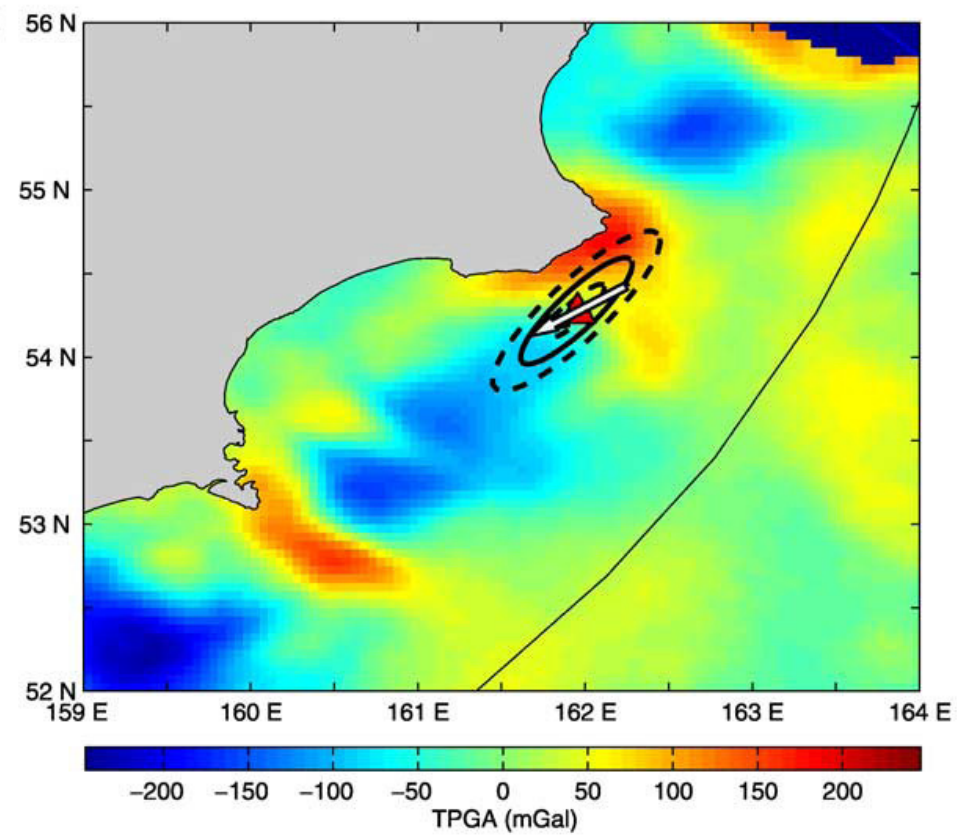

Figure B9. Measurements and results for unilateral event 19971205 in Kamchatka. See Figure 4 for symbol explanation. 
(a)
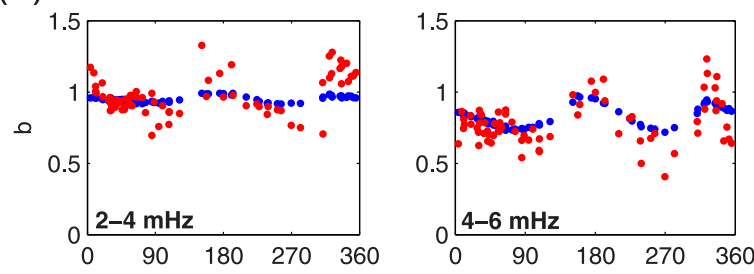

(b)

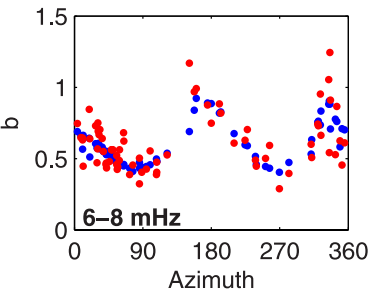

(c)
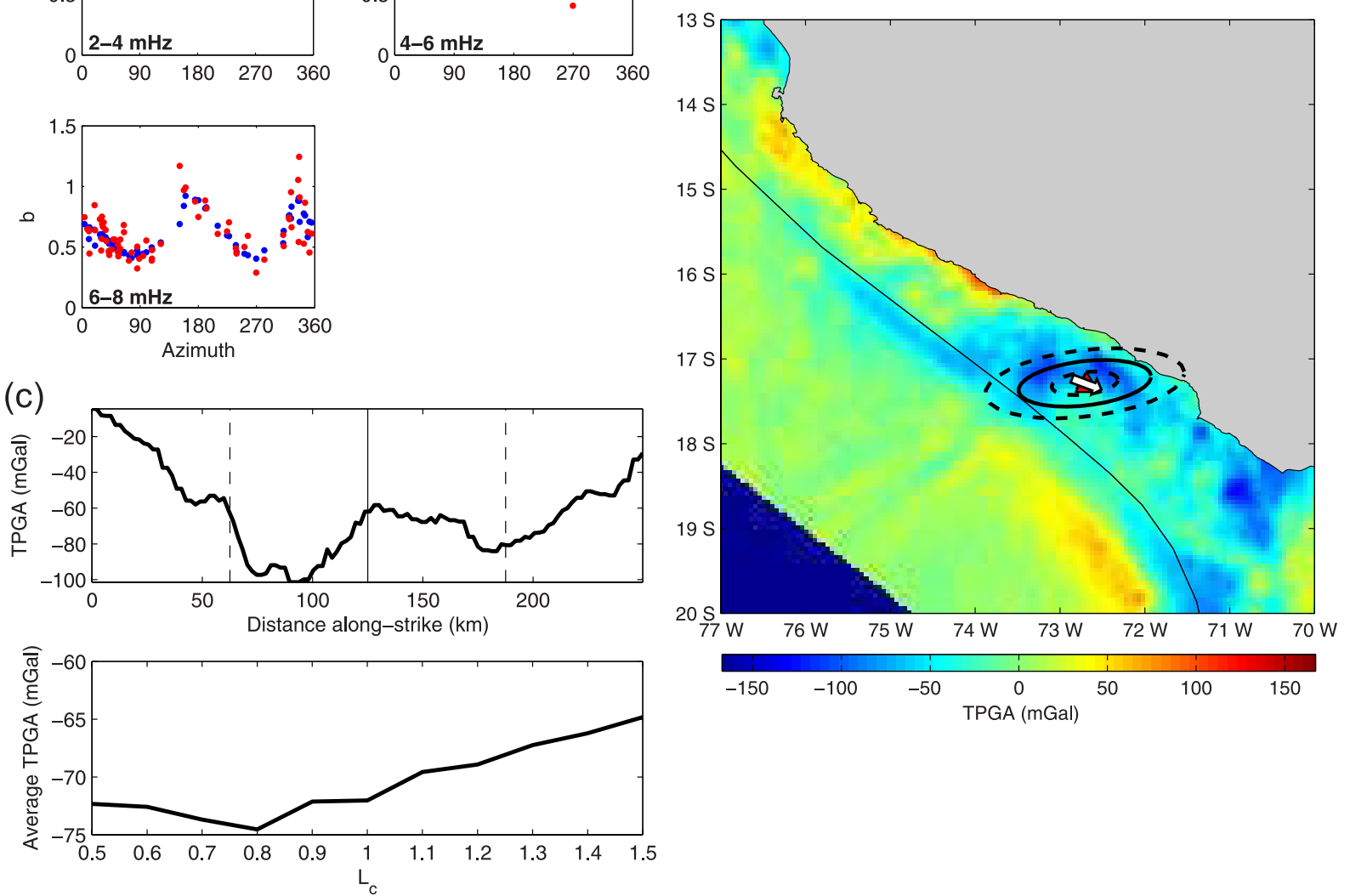

Figure B10. Measurements and results for bilateral event 20010623 in Peru. See Figure 4 for symbol explanation. 
(a)
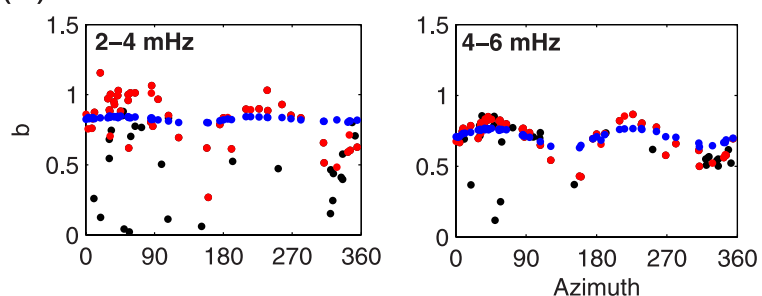

(b)

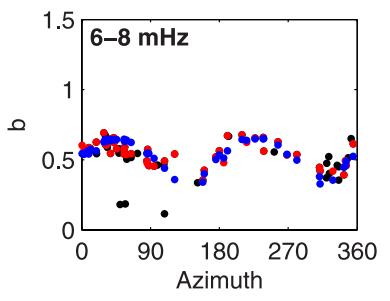

(c)
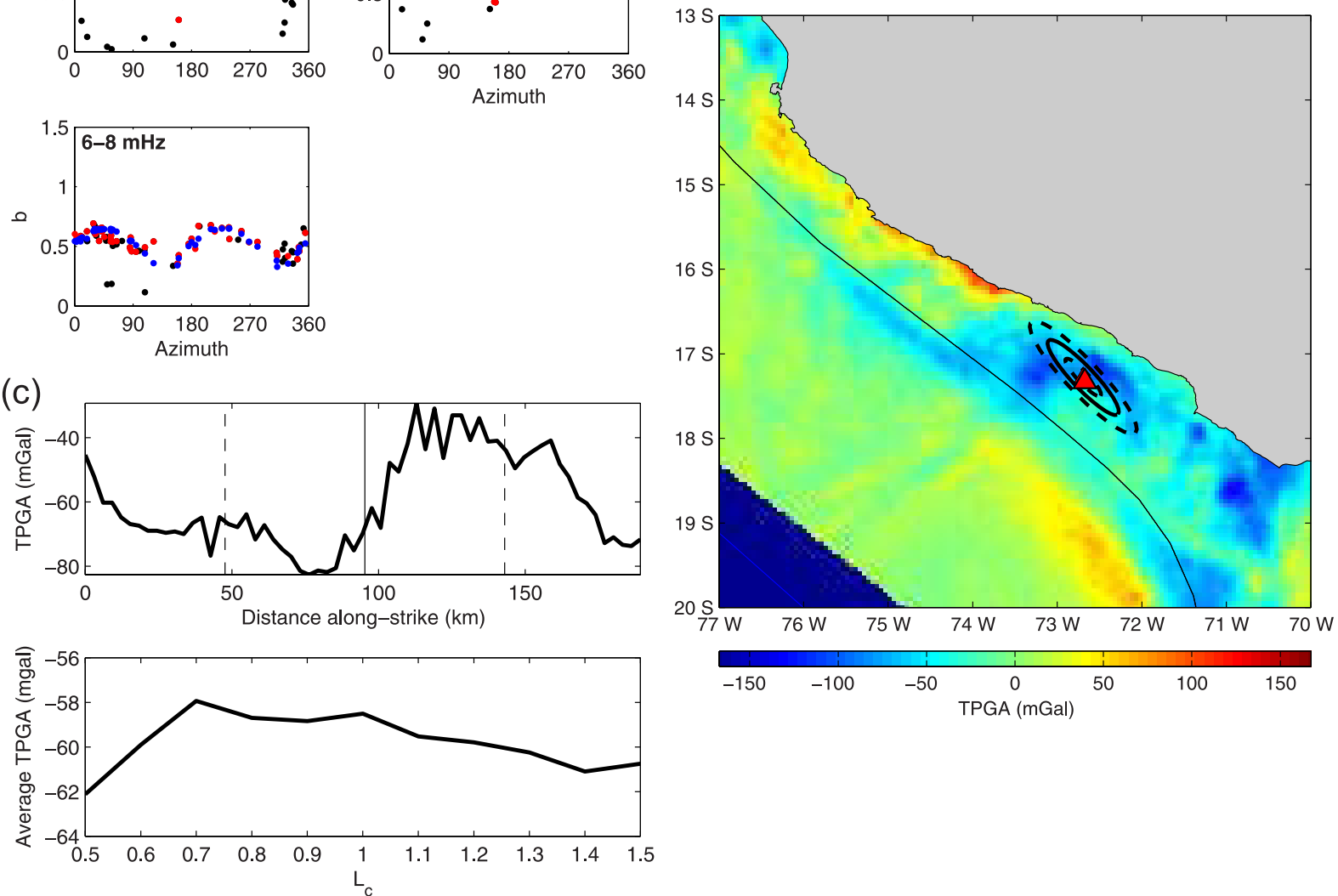

Figure B11. Measurements and results for event 20010623 in Peru, using a $M_{w} 6.7$ aftershock that occurred on 26 June 2001 as an EGF. (a) See Figure B4 for symbol explanation. Again, a large amount of scatter appears in the lowest frequency band. (b) See Figure 4 for symbol explanation. Compared to the TGF results, the ellipse has rotated by $\sim 54^{\circ}$; the orientation of the ellipse for this event is not well constrained, although the centroid location is. The directivity ratio remains very low. (c) See Figure 4 for symbol explanation. The rotation of the ellipse has caused these plots to change significantly. 
(a)
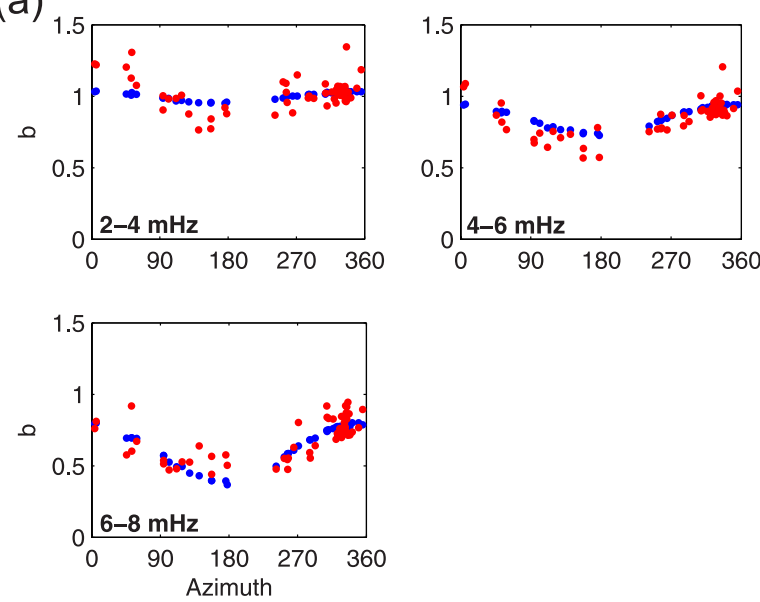

(c)
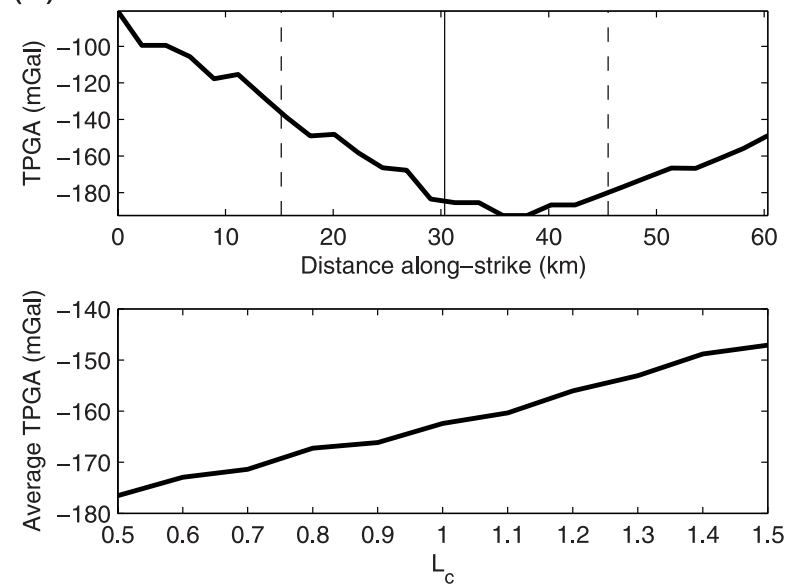

(b)

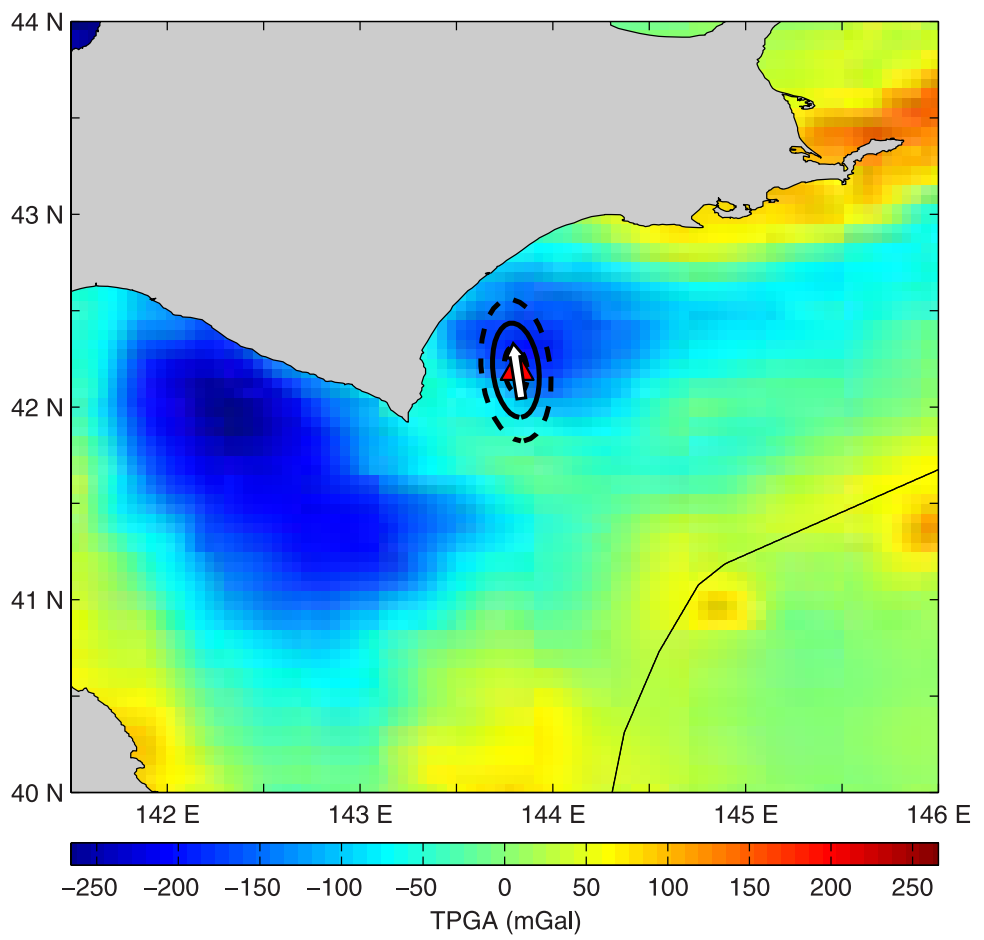

Figure B12. Measurements and results for unilateral event 20030925 in Japan. See Figure 4 for symbol explanation. 
(a)
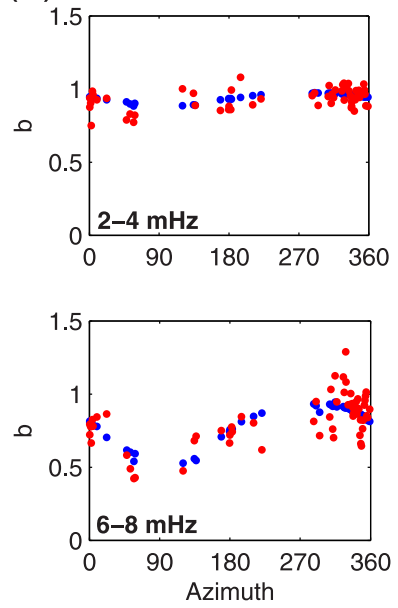

(c)
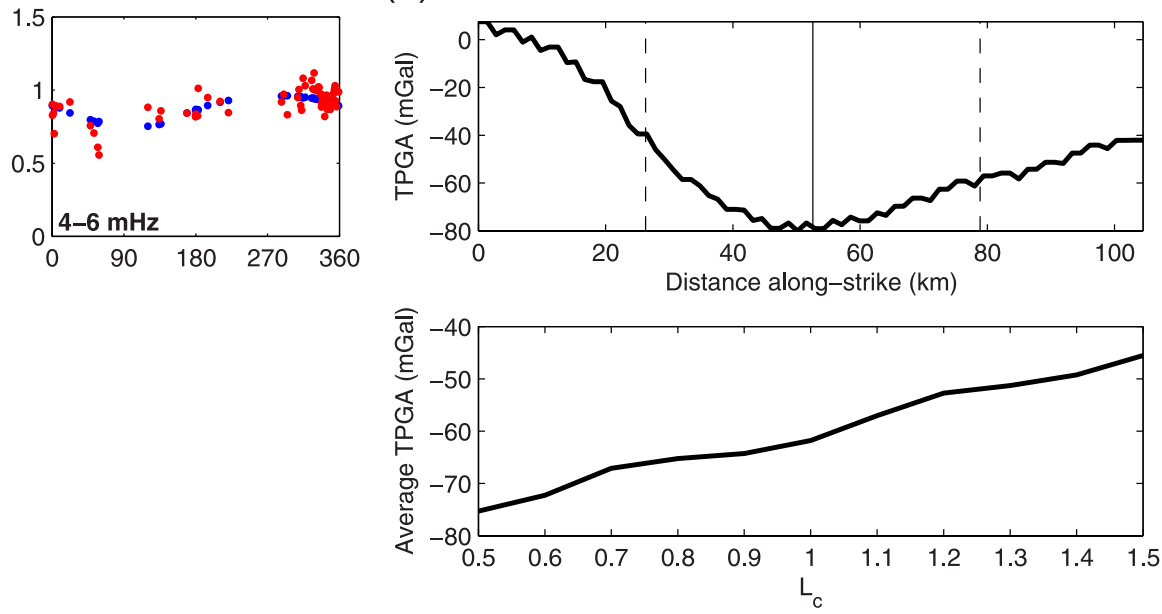

(b)

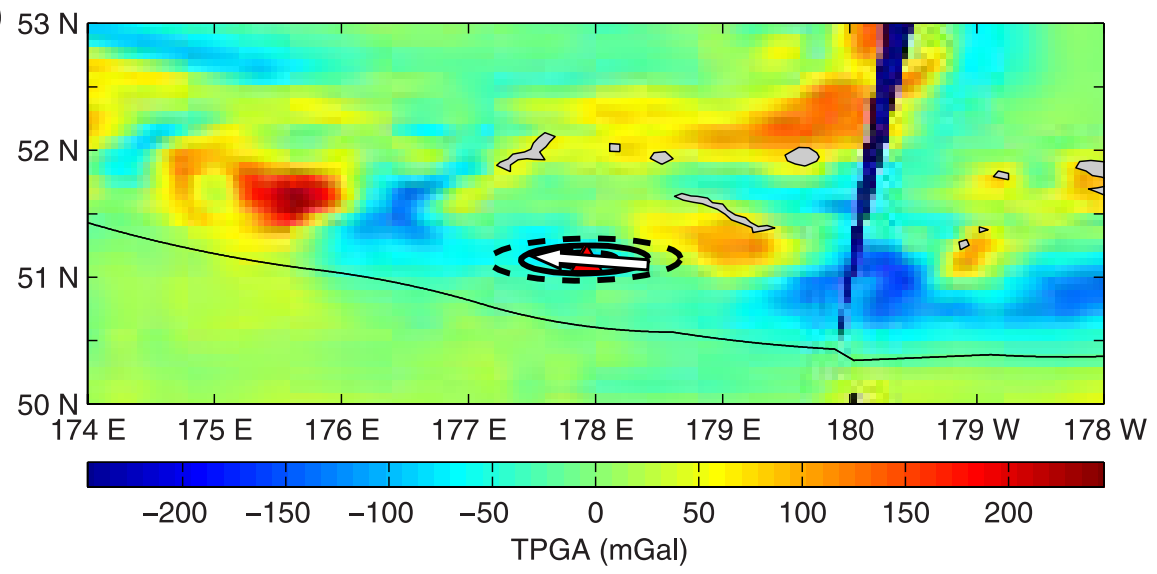

Figure B13. Measurements and results for unilateral event 20031117 in the Rat Islands. See Figure 4 for symbol explanation. 
(a)
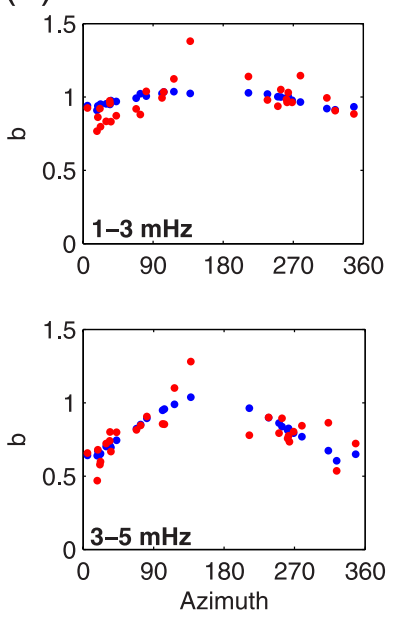

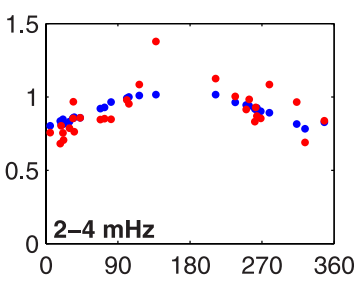

(c)
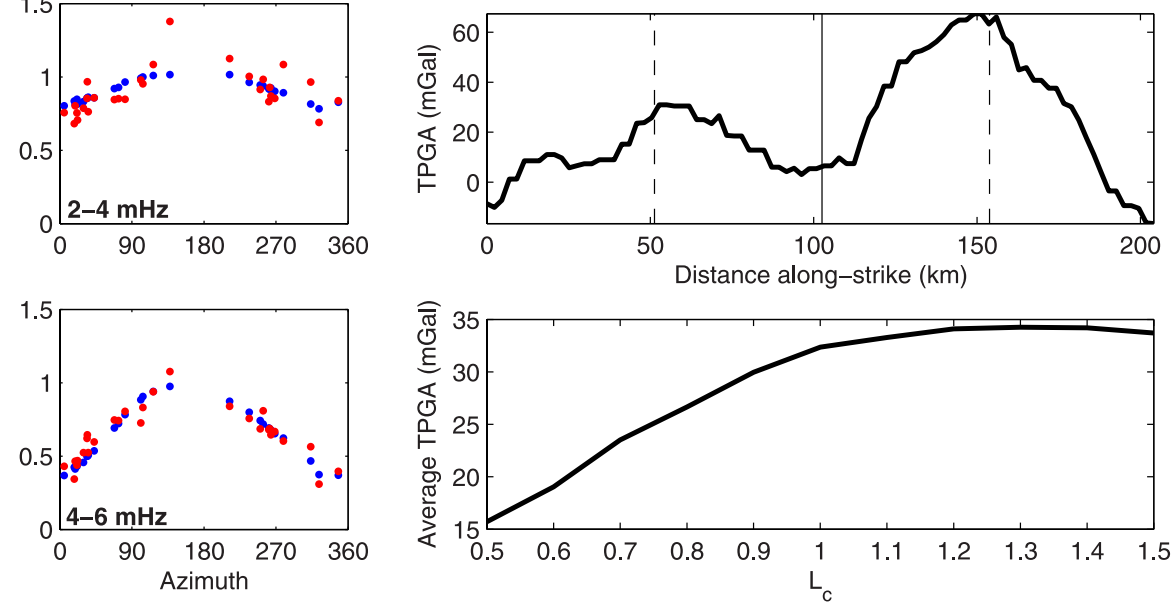

(b)

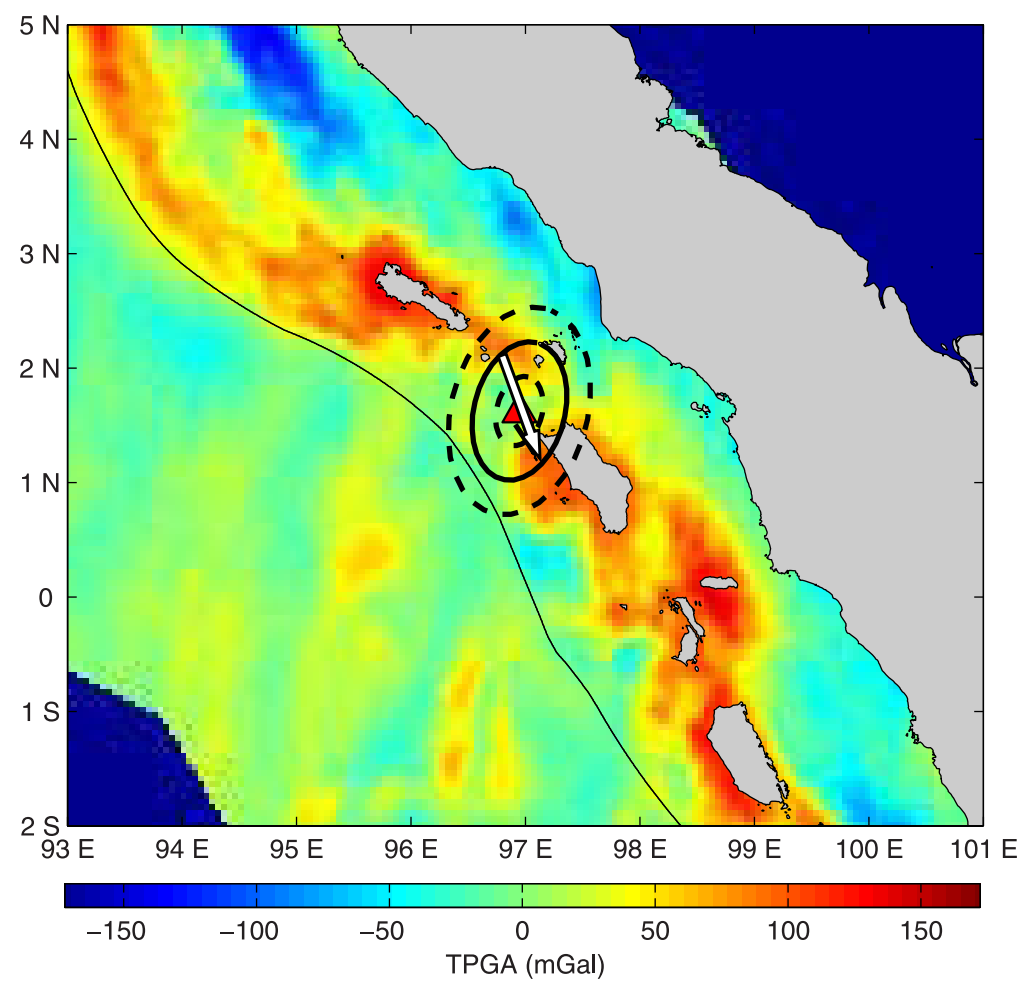

Figure B14. Measurements and results for unilateral event 20050328 in Sumatra. See Figure 4 for symbol explanation. 
(a)
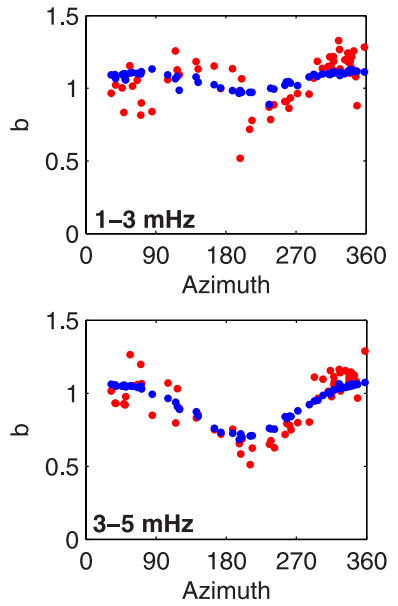

(c)
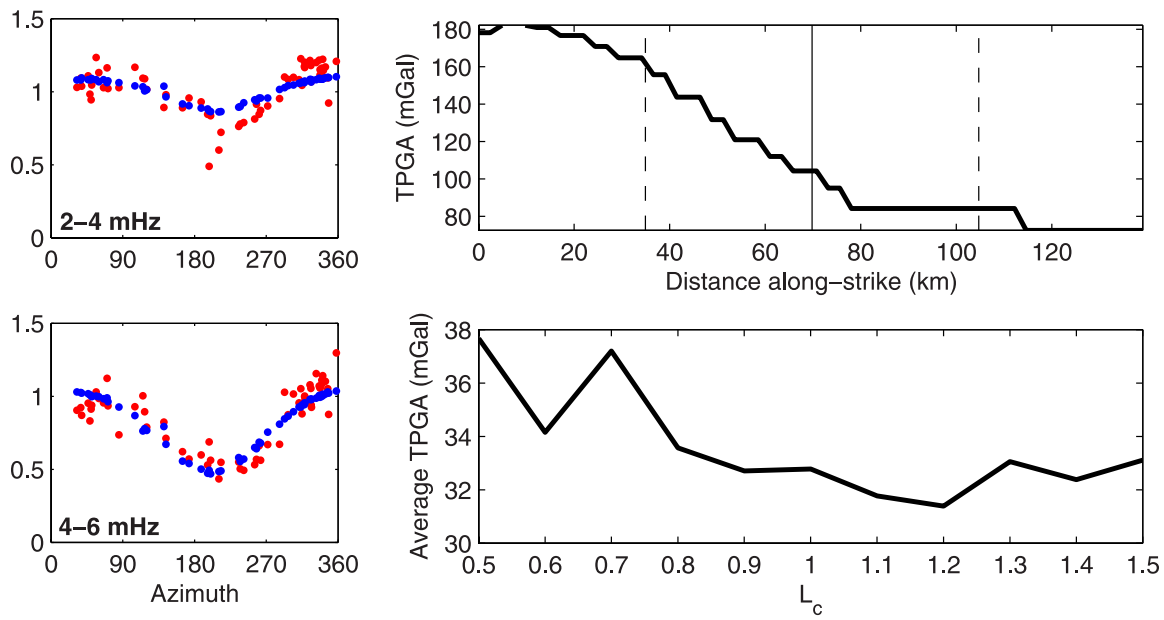

(b)

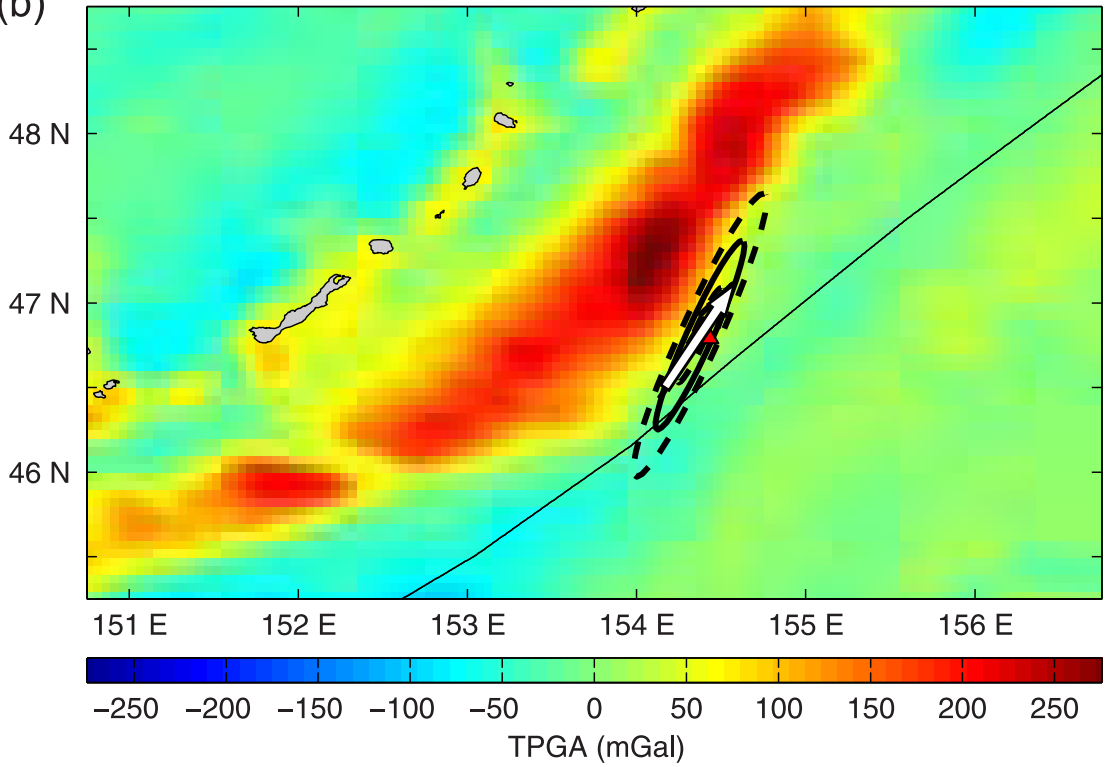

Figure B15. Measurements and results for unilateral event 20061115 in the Kurile Islands. See Figure 4 for symbol explanation. 
complete station sets. Significant differences in the measurements occur at northerly azimuths in the highest frequency band. These differences alter the results of the inversion. An inversion with the 1-D synthetics resulted in a rupture length of $51 \mathrm{~km}$. Using the 3-D synthetics in the inversion resulted in a rupture length of $92 \mathrm{~km}$. Therefore, because the improvement in propagation modeling is significant enough to affect the inversion results, we use 3-D synthetics for the amplitude measurements.

\section{Appendix B: Results for Additional Events}

[42] This section contains the results for each event in our data set (Figures B1-B15; see Table 1 for list of events). For each event, we show Rayleigh wave measurements, estimated rupture area plotted on a TPGA map, and TPGA profiles. For three events (19941228, 19950730, and 20010623), the results using measurements made with empirical Green's functions as described in section 3.4 are also shown (Figures B4, B5, and B11, respectively). These results can be directly compared with those obtained by using point source synthetics (theoretical Green's functions) as our analysis does (Figures B3, 7, and B10).

[43] Acknowledgments. We thank Mark Simons for help with the TPGA maps, Martin Mai for help with the Tottori slip model, and two anonymous reviewers for their helpful comments. Seismic data for all events were obtained from the IRIS, GEOFON, GEOSCOPE, MEDNET, and China Digital networks through the IRIS Data Management Center. Centroid moment tensor solutions were obtained from the Global CMT catalog. Some figures were prepared using the Generic Mapping Tools software freely distributed by Wessel and Smith [1998]. A. Llenos was supported by a National Defense Science and Engineering Graduate fellowship

\section{References}

Abercrombie, R. E., M. Antolik, K. Felzer, and G. Ekstrom (2001), The 1994 Java tsunami earthquake: Slip over a subducting seamount, J. Geophys. Res., 106, 6595-6607.

Ammon, C. J., H. Kanamori, T. Lay, and A. A. Velasco (2006), The 17 July 2006 Java tsunami earthquake, Geophys. Res. Lett., 33, L24308, doi:10.1029/2006GL028005.

Backus, G. E. (1977a), Interpreting the seismic glut moments of total degree two or less, Geophys. J. R. Astron. Soc., 51, 1-25.

Backus, G. E. (1977b), Seismic sources with observable glut moments of spatial degree two, Geophys. J. R. Astr. Soc., 51, 27-45.

Backus, G., and M. Mulcahy (1976a), Moment tensors and other phenomenological descriptions of seismic sources - I. Continuous displacements, Geophys. J. R. Astron. Soc., 46, 341-361.

Backus, G., and M. Mulcahy (1976b), Moment tensors and other phenomenological descriptions of seismic sources-II. Discontinuous displacements, Geophys. J. R. Astron. Soc., 47, 301-329.

Bassin, C., G. Laske, and G. Masters (2000), The current limits of resolution for surface wave tomography in North America, Eos Trans. $A G U$ 81(48), Fall Meet. Suppl., Abstract S12A-03.

Bevington, P. R., and D. K. Robinson (1992), Data Reduction and Error Analysis for the Physical Sciences, 2nd ed., 328 pp., McGraw-Hill, New York.

Byrne, D. E., D. M. Davis, and L. R. Sykes (1988), Loci and maximum size of thrust earthquakes and the mechanics of the shallow region of subduction zones, Tectonics, 7, 833-857.

Carlo, D. L., T. Lay, C. J. Ammon, and J. Zhang (1999), Rupture process of the 1995 Antofagasta subduction earthquake $\left(\mathrm{M}_{\mathrm{w}}=8.1\right)$, Pure Appl. Geophys., 154, 677-709.

Cloos, M. (1992), Thrust-type subduction-zone earthquakes and seamount asperities: A physical model for seismic rupture, Geology, 20, $601-604$

Dalguer, L. A., K. Irikura, W. Zhang, and J. D. Riera (2002), Distribution of Dynamic and Static Stress Changes during 2000 Tottori (Japan) Earthquake: Brief Interpretation of the Earthquake Sequences; Foreshocks, Mainshock and Aftershocks, Geophys. Res. Lett., 29(16), 1758, doi:10.1029/2001GL014333.
Das, S., and B. V. Kostrov (1997), Determination of the polynomial moments of the seismic moment rate density distributions with positivity constraints, Geophys. J. Int., 131, 115-126.

Delouis, B., et al. (1997), The $\mathrm{M}_{\mathrm{w}}=8.0$ Antofagasta (northern Chile) earthquake of 30 July 1995: A precursor to the end of the large 1877 gap, Bull. Seismol. Soc. Am., 87, 427-445.

Dziewonski, A. M., and D. L. Anderson (1981), Preliminary reference Earth model, Phys. Earth Planet. Inter., 25, 297-356.

Efron, B., and C. Stein (1981), The jackknife estimate of variance, Ann. Stat., 9, 586-596.

Ekstrom, G., J. Tromp, and E. W. F. Larson (1997), Measurements and global models of surface wave propagation, J. Geophys. Res., 102, $8137-8157$

Fuller, C. W., S. D. Willet, and M. T. Brandon (2006), Formation of forearc basins and their influence on subduction zone earthquakes, Geology, 34 $65-68$.

Fujii, Y., and K. Satake (2006), Source of the July 2006 West Java tsunami estimated from tide gauge records, Geophys. Res. Lett., 33, L24317, doi:10.1029/2006GL028049.

Guatteri, M., and P. Spudich (2000), What can strong-motion data tell us about slip-weakening fault-friction laws?, Bull. Seismol. Soc. Am., 90, $98-116$.

Honda, R., S. Aoi, N. Morikawa, H. Sekiguchi, T. Kunugi, and H. Fujiwara (2004), Ground motion and rupture process of the 2003 Tokachi-oki earthquake obtained from strong motion data of K-NET and KiK-net Earth Planets Space, 56, 317-322.

Hyndman, R. D., and K. Wang (1993), Thermal constraints on the zone of major thrust earthquake failure: The Cascadia subduction zone, J. Geophys. Res., 98, 2039-2060.

Ihmlé, P. F., and J.-C. Ruegg (1997), Source tomography by simulated annealing using broad-band surface waves and geodetic data: Application to the $\mathrm{M}_{\mathrm{w}}=8.1$ Chile 1995 event, Geophys. J. Int., 131, 146-158.

Iwata, T., H. Sekiguchi, Y. Matsumoto, H. Miyake, and K. Irikura (2000), Source process of the 2000 Western Tottori Prefecture earthquake and near-source strong ground motion, paper presented at the 2000 Fall Meeting, Seismol. Soc. of Jpn., Hokkaido, Japan.

Kelleher, J., and W. McCann (1976), Buoyant zones, great earthquakes, and unstable boundaries of subduction, J. Geophys. Res., 81, 4885-4896.

Kodaira, S., N. Takahashi, A. Nakanishi, S. Miura, and Y. Kaneda (2000), Subducted seamount imaged in the rupture zone of the 1946 Nankaido earthquake, Science, 289, 104-106.

Kodaira, S., E. Kurashimo, J.-O. Park, N. Takahashi, A. Nakanishi, S. Miura, T. Iwasaki, N. Hirata, K. Ito, and Y. Kaneda (2002), Structural factors controlling the rupture progress of a megathrust earthquake at the Nankai trough seismogenic zone, Geophys. J. Int., 149, 815-835.

Koketsu, K., K. Hikima, S. Miyazaki, and S. Ide (2004), Joint inversion of strong motion and geodetic data for the source process of the 2003 Tokachi-oki, Hokkaido, earthquake, Earth Planets Space, 56, 329334

Komatitsch, D., and J. Tromp (1999), Introduction to the spectral element method for three-dimensional seismic wave propagation, Geophys. J. Int. 139, 806-822.

Lay, T., and S. L. Bilek (2007), Anomalous earthquake ruptures at shallow depths on subduction zone megathrusts, in The Seismogenic Zone of Subduction Thrust Faults, edited by T. Dixon and C. Moore, Columbia Univ. Press, New York, in press.

Lay, T., and H. Kanamori (1981), An asperity model of great earthquake sequences, in Earthquake Prediction: An International Review, Maurice Ewing Ser., vol. 4, edited by D. Simpson and P. Richards, pp. 579-592, AGU, Washington, D. C.

Lay, T., H. Kanamori, and L. Ruff (1982), The asperity model and the nature of large subduction zone earthquakes, Earthquake Predict. Res., $1,3-71$.

Marone, C. (1998), Laboratory-derived friction laws and their application to seismic faulting, Annu. Rev. Earth Planet. Sci., 26, 643-696.

McCaffrey, R. (1993), On the role of the upper plate in great subduction zone earthquakes, $J$. Geophys. Res., 98, 11,953-11,966.

McGuire, J. J., L. Zhao, and T. H. Jordan (2001), Teleseismic inversion for the second-degree moments of earthquake space-time distributions, Geophys. J. Int., 145, 661-678.

McGuire, J. J., L. Zhao, and T. H. Jordan (2002), Predominance of unilateral rupture for a global catalog of large earthquakes, Bull. Seismol. Soc. Am., 92, 3309-3317.

Miyazaki, S., K. M. Larson, K. Choi, K Hikima, K. Koketsu, P. Bodin, J. Haase, G. Emore, and A. Yamagiwa (2004a), Modeling the rupture process of the 2003 September 25 Tokachi-Oki (Hokkaido) earthquake using 1-Hz GPS data, Geophys. Res. Lett., 31, L21603, doi:10.1029/ 2004 GL021457.

Miyazaki, S., P. Segall, J. Fukuda, and T. Kato (2004b), Space time distribution of afterslip following the 2003 Tokachi-oki earthquake: Impli- 
cations for variations in fault zone frictional properties, Geophys. Res. Lett., 31, L06623, doi:10.1029/2003GL019410.

Mogi, K. (1969), Relationship between the occurrence of great earthquakes and tectonic structures, Bull. Earthquake Res. Inst. Univ. Tokyo, 47, 429451 .

Nishimura, T., T. Hirasawa, S. Miyazaki, T. Sagiya, T. Tada, S. Miura, and K. Tanaka (2004), Temporal change of interplate coupling in northeastern Japan during 1995-2002 estimated from continuous GPS observations, Geophys. J. Int., 157, 901-916.

Oleskevich, D. A., R. D. Hyndman, and K. Wang (1999), The updip and downdip limits to great subduction earthquakes: Thermal and structural models of Cascadia, south Alaska, SW Japan, and Chile, J. Geophys Res., 104, 14,965-14,991.

Pacheco, J. F., L. R. Sykes, and C. H. Scholz (1993), Nature of seismic coupling along simple plate boundaries of the subduction type, J. Geophys. Res., 98, 14,133-14,159.

Polet, J., and H. Kanamori (2000), Shallow subduction zone earthquakes and their tsunamigenic potential, Geophys. J. Int., 142, 684-702.

Pritchard, M. E., C. Ji, and M. Simons (2006), Distribution of slip from $11 M_{w}>6$ earthquakes in the northern Chile subduction zone, J. Geophys. Res., 111, B10302, doi:10.1029/2005JB004013.

Pritchard, M. E., E. O. Norabuena, C. Ji, R. Boroschek, D. Comte, M. Simons, T. H. Dixon, and P. A. Rosen (2007), Geodetic, teleseismic, and strong motion constraints on slip from recent southern Peru subduction zone earthquakes, J. Geophys. Res., 112, B03307, doi:10.1029/ 2006JB004294.

Ritsema, J., and H. J. van Heijst (2000), Seismic imaging of structural heterogeneity in Earth's mantle: Evidence for large-scale mantle flow, Sci. Progr., 83, 243-259.

Ruff, L., and H. Kanamori (1980), Seismicity and the subduction process, Phys. Earth Planet. Inter., 23, 240-252.

Sandwell, D. T., and W. H. F. Smith (1997), Marine gravity anomaly from Geosat and ERS 1 satellite altimetry, J. Geophys. Res., 102, 10,03910,054 .

Scholz, C. H. (2002), The Mechanics of Earthquakes and Faulting, 2nd ed., 471 pp., Cambridge Univ. Press, New York.

Scholz, C. H., and J. Campos (1995), On the mechanism of seismic decoupling and back arc spreading at subduction zones, J. Geophys. Res., 100, $22,103-22,115$

Shaw, B. E. (2000), The edges of large earthquakes and the epicenters of future earthquakes: Stress-induced correlations in elastodynamic fault models, Pure Appl. Geophys., 157, 2149-2164.

Silver, P. (1983), Retrieval of source-extent parameters and the interpretation of corner frequency, Bull. Seismol. Soc. Am., 73, 1499-1511.

Silver, P. G., and T. H. Jordan (1983), Total-moment spectra of fourteen large earthquakes, J. Geophys. Res., 88, 3273-3293.
Song, T. A., and M. Simons (2003), Large trench-parallel gravity variations predict seismogenic behavior in subduction zones, Science, 301, 630633

Thatcher, W. (1989), Earthquake recurrence and risk assessment in circumPacific seismic gaps, Nature, 341, 432-434.

Tichelaar, B. W., and L. J. Ruff (1993), Depth of seismic coupling along subduction zones, J. Geophys. Res., 98, 2017-2037.

Tukey, J. W. (1984), The Collected Works of John W. Tukey, vol. 4, edited by L. Jones, Wadsworth and Brooks/Cole, Monterey, Calif.

Vandenberghe, L., and S. Boyd (1996), Semidefinite programming, SIAM Rev., 38, 49-95.

von Huene, R., and C. R. Ranero (2003), Subduction erosion and basal friction along the sediment-starved convergent margin off Antofagasta, Chile, J. Geophys. Res., 108(B2), 2079, doi:10.1029/2001JB001569.

Wang, K., and Y. Hu (2006), Accretionary prisms in subduction earthquake cycles: The theory of dynamic Coulomb wedge, J. Geophys. Res., 111, B06410, doi:10.1029/2005JB004094.

Wells, R. E., R. J. Blakely, Y. Sugiyama, D. W. Scholl, and P. A. Dinterman (2003), Basin-centered asperities in great subduction zone earthquakes: A link between slip, subsidence, and subduction erosion?, J. Geophys. Res., 108(B10), 2507, doi:10.1029/2002JB002072.

Wessel, P., and W. H. F. Smith (1998), New, improved version of Generic Mapping Tools released, Eos Trans. AGU, 79(47), 579.

Wibberley, C. A., and T. Shimamoto (2005), Earthquake slip weakening and asperities explained by thermal pressurization, Nature, 436 , doi:10.1038/nature03901.

Yagi, Y. (2004), Source rupture process of the 2003 Tokachi-oki earthquake determined by joint inversion of teleseismic body wave and strong ground motion data, Earth Planets Space, 56, 311-316.

Yagi, Y., T. Mikumo, J. Pacheco, and G. Reyes (2004), Source rupture process of the Tecoman, Colima, Mexico earthquake of 22 January 2003 , determined by joint inversion of teleseismic body-wave and near-source data, Bull. Seismol. Soc. Am., 94, 1795-1807.

Yamanaka, Y., and M. Kikuchi (2003), Source process of the recurrent Tokachi-oki earthquake on September 26, 2003, inferred from teleseismic body waves, Earth Planets Space, 55, 21-24.

Yamanaka, Y., and M. Kikuchi (2004), Asperity map along the subduction zone in northeastern Japan inferred from regional seismic data, J. Geophys. Res., 109, B07307, doi:10.1029/2003JB002683.

A. L. Llenos, MIT/WHOI Joint Program, 77 Massachusetts Avenue, 54-511, Cambridge, MA 02139, USA. (allenos@mit.edu)

J. J. McGuire, Department of Geology and Geophysics, Woods Hole Oceanographic Institution, MS 24, Woods Hole, MA 02543, USA. 


\title{
Chapter 3: Modeling seismic swarms triggered by aseismic transients
}

\begin{abstract}
The rate of earthquake occurrence varies by many orders of magnitude in a given region due to variations in the stress state of the crust. Our focus here is on variations in seismicity rate triggered by transient aseismic processes such as fluid flow, fault creep or magma intrusion. While these processes have been shown to trigger earthquakes, converting observed seismicity variations into estimates of stress rate variations has been challenging. Essentially aftershock sequences often obscure changes in the background seismicity rate resulting from aseismic processes. Two common approaches for estimating the time dependence of the underlying driving mechanisms are the stochastic Epidemic Type Aftershock Sequence model (ETAS) [Ogata, Y., (1988), Statistical models for earthquake occurrences and residual analysis for point processes, J. Am. Stat. Assoc., 83, 9-27.] and a physical approach based on the rate- and state-model of fault friction [Dieterich, J., (1994), A constitutive law for rate of earthquake production and its application to earthquake clustering, J. Geophys. Res., 99, 2601-2618.]. The models have different strengths that could be combined to allow more quantitative studies of earthquake triggering. To accomplish this, we identify the parameters that relate to one another in the two models and examine their dependence on stressing rate. A particular conflict arises because the rate-state model predicts that aftershock productivity scales with stressing rate while the ETAS model assumes that it is time independent. To resolve this issue, we estimate triggering parameters for 4 earthquake swarms contemporaneous with geodetically observed deformation transients in various tectonic environments. We find that stressing rate transients increase the background seismicity rate without affecting aftershock productivity. We then specify a combined model for seismicity rate variations that will allow future studies to invert seismicity catalogs for variations in aseismic stressing rates.
\end{abstract}

Published as A. L. Llenos, J. J. McGuire, and Y. Ogata, Modeling seismic swarms triggered by aseismic transients, Earth Planet. Sci. Lett., 281, 59-69, doi:10.1016/j.epsl.2009.02.011, 2009.

Reprinted with permission of Elsevier, 2009. 


\title{
Modeling seismic swarms triggered by aseismic transients
}

\author{
Andrea L. Llenos ${ }^{\mathrm{a}, *}$, Jeffrey J. McGuire ${ }^{\mathrm{b}}$, Yosihiko Ogata ${ }^{\mathrm{c}}$ \\ ${ }^{a}$ MIT/WHOI Joint Program, 77 Massachusetts Ave., 54-710, Cambridge, MA 02139, USA \\ b Woods Hole Oceanographic Institution, MS \#24, Woods Hole, MA 02543, USA

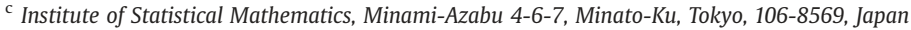

\section{A R T I C L E I N F O}

\section{Article history:}

Received 14 August 2008

Received in revised form 30 January 2009

Accepted 6 February 2009

Available online 9 March 2009

Editor: T.M. Harrison

\section{Keywords:}

earthquake swarms

aseismic deformation

ETAS model

rate-state model

triggering

\begin{abstract}
A B S T R A C T
The rate of earthquake occurrence varies by many orders of magnitude in a given region due to variations in the stress state of the crust. Our focus here is on variations in seismicity rate triggered by transient aseismic processes such as fluid flow, fault creep or magma intrusion. While these processes have been shown to trigger earthquakes, converting observed seismicity variations into estimates of stress rate variations has been challenging. Essentially aftershock sequences often obscure changes in the background seismicity rate resulting from aseismic processes. Two common approaches for estimating the time dependence of the underlying driving mechanisms are the stochastic Epidemic Type Aftershock Sequence model (ETAS) [Ogata, Y., (1988), Statistical models for earthquake occurrences and residual analysis for point processes, J. Am. Stat. Assoc., 83, 9-27.] and a physical approach based on the rate- and state-model of fault friction [Dieterich, J., (1994), A constitutive law for rate of earthquake production and its application to earthquake clustering, J. Geophys. Res., 99, 2601-2618.]. The models have different strengths that could be combined to allow more quantitative studies of earthquake triggering. To accomplish this, we identify the parameters that relate to one another in the two models and examine their dependence on stressing rate. A particular conflict arises because the rate-state model predicts that aftershock productivity scales with stressing rate while the ETAS model assumes that it is time independent. To resolve this issue, we estimate triggering parameters for 4 earthquake swarms contemporaneous with geodetically observed deformation transients in various tectonic environments. We find that stressing rate transients increase the background seismicity rate without affecting aftershock productivity. We then specify a combined model for seismicity rate variations that will allow future studies to invert seismicity catalogs for variations in aseismic stressing rates.
\end{abstract}

(c) 2009 Elsevier B.V. All rights reserved.

\section{Introduction}

Earthquake swarms are time periods of elevated seismicity rate that lack an obvious mainshock, and they are one of the clearest signals that many processes in the crust have variations on time scales of hours to days. The most common time periods of increased seismicity rate are the aftershock sequences that follow all large crustal earthquakes and generally decay away according to Omori's empirical law (Utsu, 1961). The term swarm has been used qualitatively by seismologists for nearly a century to describe temporal clusters of earthquakes that are not well described by Omori's law (Richter, 1958). Swarms are common in volcanic regions and have been explained as resulting from the stress perturbations during magma intrusions (e.g., Einarsson and Brandsdóttir, 1980; Dieterich et al., 2000; Smith et al., 2004) as well as from the movements of volatiles such as $\mathrm{CO}_{2}$ (e.g., Prejean et al., 2003; Hainzl

\footnotetext{
* Corresponding author. Tel.: +1 617324 3887; fax: +1 5084572150.

E-mail addresses: allenos@mit.edu (A.L. Llenos),jmcguire@whoi.edu (J.J. McGuire), ogata@ism.ac.jp (Y. Ogata).
}

and Ogata, 2005). Similarly, earthquake swarms are common in regions of aqueous fluid flow such as geothermal areas (Hill et al., 1975) and during hydrofracture experiments (Audigane et al., 2002; Shapiro et al., 2005; Bourouis and Bernard, 2007). Thus, a clear intuition has developed that swarms are driven by aseismic events that temporarily modify the stress state within the crust. Toda et al. (2002) recently formalized this hypothesis for a swarm of $\sim 7000$ earthquakes in the Izu islands that was associated with a large dike intrusion. They demonstrated that the seismicity rate varied spatially in proportion to the variations in the stress rate increase caused by the magmatic intrusion.

Recently a number of earthquake swarms have been found in association with times when a fault undergoes a large amount of slip without radiating seismic waves. These events are often termed slow earthquakes, silent earthquakes or creep events and require high quality geodetic data to detect owing to their lack of seismic radiation. Swarms triggered by such aseismic fault slip have been found in a number of tectonic regions. Ozawa et al. (2007) found swarms coincident with repeating slow earthquakes on the subduction zone thrust interface offshore of central Honshu. In these cases the slow event typically has a moment magnitude of $M_{\mathrm{w}} \sim 6.5$ while the largest 
earthquakes in the swarm are $M_{\mathrm{w}} \sim 4$, indicating that the vast majority of fault motion happens aseismically and only a few small patches fail seismically. A similar behavior was observed for a continental strikeslip fault by Lohman and McGuire (2007) in the Salton Trough region of California, where a swarm of $\sim 1000 M_{\mathrm{w}}<5.1$ earthquakes was triggered by a $M_{\mathrm{w}} 5.7$ slow event. Wolfe et al. (2007) found swarms of 10-50 earthquakes associated with slow events on a detachment fault beneath Kilauea's south flank. Similarly a swarm of $\sim 1700$ earthquakes in a volcanic region in Japan was also found to be associated with a much larger aseismic slip transient on reverse faults (Takada and Furuya, in review). Collectively these studies indicate that relatively modest earthquake swarms with events in the magnitude 4-5 range often result from much larger aseismic slip transients that generate microseismicity by loading neighboring regions of a fault system. Additionally, surveys of seismicity catalogs by Vidale et al. (2006) and Vidale and Shearer (2006) have found that swarms are widespread phenomena in California and Japan and often cover an unusually large area for their cumulative seismic moment, a property that corresponds well with the low stress drops observed for shallow aseismic creep events (Brodsky and Mori, 2007).

It is difficult to untangle the contribution of any time-dependent driving process from an earthquake catalog because of the preponderance of standard earthquake-earthquake triggering (e.g., aftershock sequences). Given a triggering model that utilizes an aftershock triggering exponent $\alpha$, the Gutenberg-Richter parameter $b$, and an offset $\Delta M_{\text {after }}$ describing the magnitude difference between a mainshock and its largest probable aftershock, the branching ratio $n=10^{-\alpha \Delta M_{\text {after }} b}$ / $(b-\alpha)$ describes the average fraction of a catalog consisting of triggered earthquakes (Helmstetter and Sornette, 2002; Boettcher and Jordan, 2004). Using values of $\alpha \approx 0.8, b \approx 1$ and $\Delta M_{\mathrm{after}} \approx 0.9$ that are consistent with southern California seismicity data (Helmstetter, 2003; Helmstetter and Sornette, 2003), up to roughly $90 \%$ of earthquakes in this region are triggered by other earthquakes. This number, however, is highly dependent on the value for $\alpha$, which is likely between 0.8 and 1 , and the parameter $\Delta M_{\text {after }}$ can also range from 0.9 to 1.2 (Helmstetter, 2003; Helmstetter and Sornette, 2003). Yet even with these ranges of values, around $60-90 \%$ of earthquakes in the catalog are aftershocks. Thus, even when some aseismic process is triggering an elevated rate of seismicity, that seismicity will generate its own aftershock sequences, which will ultimately comprise a significant fraction of the earthquake catalog. There are currently two main approaches to analyzing seismicity rate variations: stochastic models such as the Epidemic Type Aftershock Sequence (ETAS) model (Ogata, 1988), and physical models such as the rate- and statedependent friction model (Dieterich, 1994).

The ETAS stochastic model is an effective way to detect anomalous seismicity rates. By modeling earthquake occurrence as a point process described by just a few optimizable parameters, the model can detect time periods that are not well described by a stationary stochastic process (McGuire et al., 2005). Recently, studies have utilized a space-time version of ETAS to relate non-stationary seismicity rates to regional stress changes (Ogata, 1998, 2004, 2005). The difficulty with this approach is that it lacks a quantitative relationship between seismicity rate variations and stress/stressingrate variations. However, it has been used to resolve time dependence of the background triggering rate by binning unusually large earthquake swarms into smaller (moving window) time periods that are assumed to have a stationary background rate within the time window (Hainzl and Ogata, 2005).

An alternative approach that is being utilized to map seismicity rate variations directly into stressing rate variations is a physical model based on rate- and state-dependent friction (Dieterich, 1994; Dieterich et al., 2000). This model incorporates several properties of laboratory friction measurements including an Omori-like response to a step change in stress-level. It has had several successful applications including retrieving the magnitude of stress steps using laboratory derived friction parameters (Dieterich et al., 2000) and predicting the spatial distribution of seismicity rate changes and aftershock sequence durations based on a geodetically derived model of stressing rate transients (Toda et al., 2002). However, both these applications occurred in volcanic regions where aftershock sequences are often subdued due to high geothermal gradients (Kisslinger and Jones, 1991; Ben-Zion and Lyakhovsky, 2006). In contrast, Toda and Matsumura (2006) used this method to estimate spatio-temporal stress changes from seismicity rate changes during a $M_{\mathrm{w}} 7.0$ slow subduction zone earthquake in Tokai, Japan. Despite the extremely large magnitude of the slow event, the stressing rate changes retrieved by the rate-state inversion were not clearly distinguishable from other variations in the area. Some of this lack of resolution likely results from the contamination of moderate aftershock sequences in the stress vs. time curves produced by the rate-state inversion algorithm.

We seek to combine the strengths of the ETAS and rate-state approaches to develop an effective tool to detect anomalous seismicity rates and relate them to changes in stressing rates caused by physical processes. There have been recent attempts to combine the two models of seismicity rate for different purposes. For example, Console et al. $(2006,2007)$ combine the two models in order to produce a new model of earthquake clustering that incorporates physical constraints with a minimum number of free parameters. However, a combined ETAS/rate-state model that can be used in a single algorithm to detect anomalous stressing rates from seismicity rates has not been developed yet. Ogata (2005) demonstrated that even small changes in stress can cause anomalies in seismicity rate, and so a combined ETAS/rate-state model of seismicity rate has the potential to be a highly sensitive detector of transient deformation.

To develop such a combined model of seismicity rate, we first identify parameters that are related between the two models and examine their dependence on stressing rate. To clarify the stressing rate dependence of the aftershock parameters, we analyze data from 4 different earthquake swarms in various tectonic settings. We then specify a functional form for the seismicity rate in a combined ETAS/ rate-state model, in which aseismically-triggered and coseismicallytriggered components of seismicity rate are independent of one another. This suggests that an aseismically-triggered seismicity rate can be isolated from a catalog and used to directly estimate stressing rate changes associated with transient deformation.

\section{Models}

In general, the seismicity rate $R$ in a catalog is a function of the stressing rate $\dot{S}$ acting on a fault (Dieterich, 1994). Earthquake catalogs contain seismicity triggered by different underlying mechanisms, such as earthquake-earthquake interactions, aseismic deformation, or background plate tectonic motion. Therefore, in our model, we consider three primary contributions to $R$ :

$R(x, t)=f(\dot{S})=f\left(R_{\mathrm{A}}, R_{\mathrm{C}}, R_{\mathrm{T}}\right)$

where $R_{\mathrm{A}}$ represents the seismicity rate triggered by aseismic processes such as slow slip or dike intrusion, $R_{\mathrm{C}}$ reflects seismicity triggered by other earthquakes (e.g., aftershock sequences), and $R_{\mathrm{T}}$ is triggered by long-term tectonic loading. Because the tectonic component $R_{\mathrm{T}}$ is presumably small if aseismic processes are occurring, we simply combine it with $R_{\mathrm{A}}$, so that $R(x, t) \approx f\left(R_{\mathrm{A}}, R_{\mathrm{C}}\right)$.

In order to develop a model that can quantitatively relate stressing rates to seismicity rates, we need to know the stressing rate dependence of each of the components of $R$. Toda et al. (2002) and Lohman and McGuire (2007) showed that seismicity rates clearly increase during periods of increased stressing rate caused by aseismic processes. Both studies found that the increase in earthquake rate was approximately equal to the increase in stressing rate so $R_{\mathrm{A}}$ likely scales linearly with stressing rate as predicted by the rate-state model. 
(a)

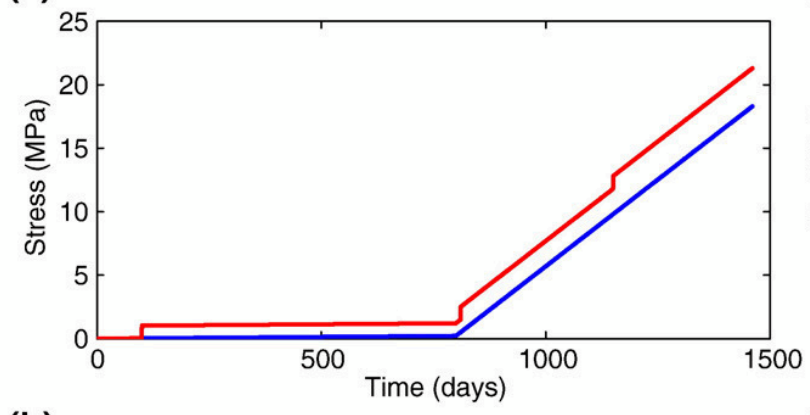

(b)

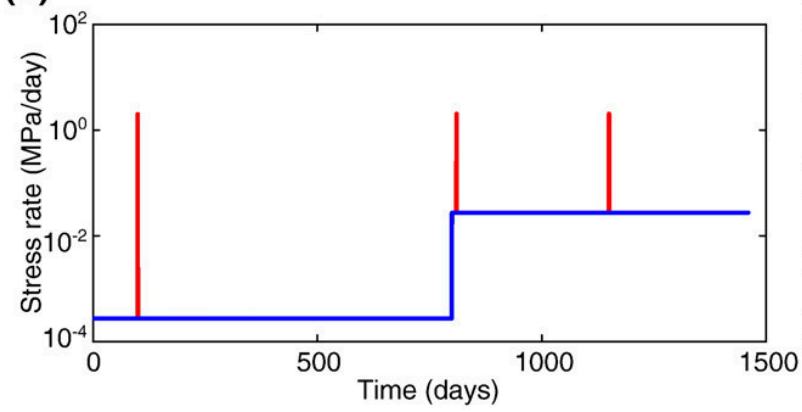

(c)

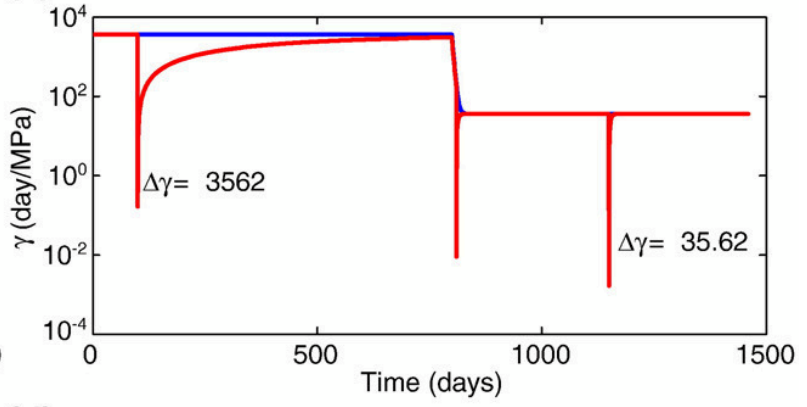

(d)

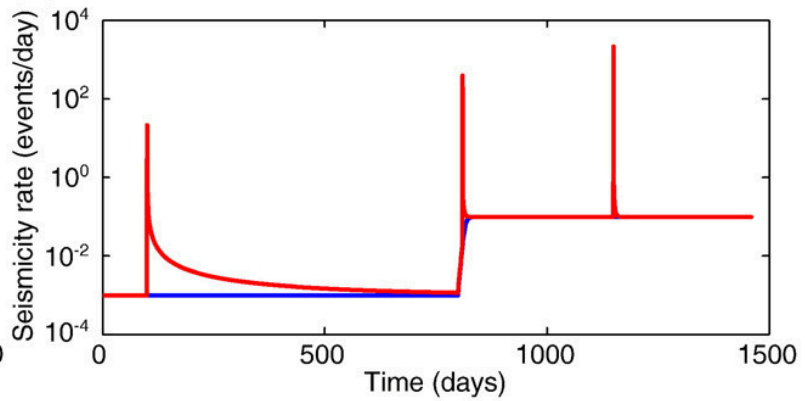

Fig. 1. Calculation of seismicity rates using forward simulation of rate-state model equations for two different stress histories, with $A \sigma=0.1 \mathrm{MPa}$. a) Stress histories for two cases: i) increase in stressing rate by 2 orders of magnitude (blue), and ii) increase in stressing rate by 2 orders of magnitude plus sudden stress changes (earthquakes) (red). b) Stressing rate histories for both cases. c) Evolution of $\gamma$ from using Eqs. (3) and (4). d) Seismicity rate estimates obtained from stressing rates using Eq. (2).

The stressing rate dependence of $R_{\mathrm{C}}$ is less certain. The two main approaches to modeling the change in seismicity rate following an earthquake (i.e., $R_{\mathrm{C}}$ ) are the stochastic Epidemic Type Aftershock Sequence (ETAS) model (Ogata, 1988), which is based on Omori's law (Omori, 1894), and the physically based rate-state friction model, which reproduces Omori's law following a sudden stress change (Dieterich, 1994). In this section we summarize the two models and compare how they predict $R_{\mathrm{C}}$ changes with stressing rate.

\subsection{ETAS model}

The ETAS model is a point process model that generalizes the modified Omori law (Omori, 1894; Utsu, 1961; Ogata, 1988). In this model, every aftershock has some probability of generating its own aftershocks. Therefore, the seismicity rate at some time $t$ can be obtained by summing the aftershock sequences produced by each event that has occurred prior to time $t$ plus a background seismicity rate $\mu$ :

$R(t)=\mu+\sum_{t_{\mathrm{i}} \leq t} \frac{K e^{\alpha\left(M_{\mathrm{i}}-M_{\mathrm{c}}\right)}}{\left(t-t_{\mathrm{i}}+c\right)^{p}}$

where $c$ and $p$ are the Omori decay parameters, $\alpha$ is related to the efficiency of an earthquake of a given magnitude at generating aftershocks, and $K$ reflects the aftershock productivity of a mainshock. These parameters are generally obtained using maximum likelihood estimation from the observed times $t_{\mathrm{i}}$ and magnitudes $M_{\mathrm{i}}$ of earthquakes in a catalog, given the magnitude of completeness $M_{c}$ of the catalog (Ogata, 1988). The summation in Eq. (1) is essentially the coseismic component of seismicity rate $\left(R_{\mathrm{C}}\right)$, as it contains all the aftershock sequences in the catalog. Because the ETAS parameters are not explicitly related to stressing rate, $R_{\mathrm{C}}$ also is independent of stressing rate in the ETAS model.

\subsection{Rate- and state-dependent friction model}

In the rate-state model, the seismicity rate $R$ for a given magnitude interval observed on a population of faults governed by rate- and state-dependent friction can be linked to a stressing rate $\dot{S}$ through the following equations that assume normal stress is constant (Dieterich, 1994):

$$
\begin{aligned}
& R=\frac{r}{\gamma \dot{S}_{\mathrm{r}}} \\
& \mathrm{d} \gamma=\frac{\mathrm{d} t}{A \sigma}(1-\gamma \dot{S})
\end{aligned}
$$

where $r$ is the steady-state seismicity rate for the same magnitude interval associated with a reference stressing rate $\dot{S}_{\mathrm{r}}, S$ is a modified Coulomb stress function, $\gamma$ is a state variable, and $A$ is a fault constitutive parameter. We assume that the normal stress $\sigma$ remains constant, and as a result treat $A \sigma$ as a constant frictional parameter and $\dot{S}$ as a shear stressing rate.

Using this formulation, given some knowledge of regional background seismicity and $A \sigma$, the stressing rate can be obtained from an observed seismicity rate simply by integrating Eqs. (2) and (3) (Dieterich et al., 2000). Fig. 1 illustrates the relationship between stressing rate and seismicity rate in the rate-state model. Given a stress history that involves a change in stressing rate by two orders of magnitude (Fig. 1a-b, blue), Eq. (3) can be used to calculate the related change in $\gamma$ (Fig. 1c, blue), which can then be used in Eq. (2) to obtain the change in seismicity rate. Fig. 1d demonstrates that following a change in stressing rate by a factor of 100 , a similar change in seismicity rate occurs after a time lag that is related to the parameter $A \sigma$.

Now consider a stress history that includes the same change in stressing rate as well as earthquakes (sudden stress steps) (Fig. 1a-b, red). Dieterich (1994) derived a solution for $\gamma$ given a sudden stress change (Eq. B11 in the 1994 paper):

$\gamma=\gamma_{0} \exp \left[\frac{-\Delta S}{A \sigma}\right]$ 
Using both Eqs. (3) and (4), the evolution of $\gamma$ associated with this stress history can also be determined (Fig. 1c, red) and Eq. (2) used to obtain the seismicity rate (Fig. 1d, red).

This simple case shows that the rate-state model predicts that certain parameters describing aftershock decay change with stressing rate. For example, consider two of the sudden stress steps (earthquakes) shown in Fig. 1b, the first (at time $t=100$ ) which occurs prior to the stressing rate change and the third (at time $t=1150$ ) which occurs well after the stressing rate change. The seismicity rate following the first earthquake, which occurs during low stressing rates, takes longer to decay to the background rate than that following the second earthquake, which occurs during high stressing rates (Fig. 1d); thus, this characteristic relaxation time, $t_{\mathrm{a}}$, depends on stressing rate as seen in the Miyake-Jima swarm (Toda et al., 2002).

This case also demonstrates that the change in seismicity rate immediately following the stress step also varies with stressing rate. Although the first and second earthquakes both had the same stress change, the peak seismicity rate is higher for the second earthquake than for the first. Because the change in seismicity rate $\Delta R$ due to the stress change depends on the change in $\gamma$, this is a direct consequence of Eq. (4). If we define $\Delta \gamma$ to be the change in $\gamma$ due to the stress step (i.e., $\Delta \gamma=\gamma-\gamma_{0}$ ), it is easy to see from Eq. (4) that $\Delta \gamma$ will be a function of $\gamma_{0}$ (i.e., the value of $\gamma$ prior to the stress step). Since the second earthquake occurs during the higher stressing rate, it has a lower $\gamma_{0}$, and therefore a smaller $\Delta \gamma$ and a larger $\Delta R$ than the first earthquake (Fig. 1c). Thus the seismicity rate immediately following a stress step depends on the stressing rate.

This prediction of the rate-state model can also be shown with a second simulation. Assuming a constant stressing rate following a stress step and steady-state seismicity rate prior to a stress step, Dieterich (1994) used Eqs. (2)-(4) to express the seismicity rate following a stress step as:

$R(t)=\frac{r \frac{\dot{S}}{S_{\mathrm{r}}}}{\left[\frac{\dot{S}}{S_{\mathrm{r}}} \exp \left(\frac{-\Delta S}{A \sigma}\right)-1\right] \exp \left[\frac{-t}{t_{\mathrm{a}}}\right]+1}, \quad \dot{S} \neq 0$

where

$t_{\mathrm{a}}=A \sigma / \dot{S}$

is the characteristic relaxation time related to the time it takes for the seismicity rate to return to background levels. This takes the form of Omori's law for $t<t_{\mathrm{a}}$.

Eq. (5) can be used to compare the seismicity rate change due to a uniform stress step during different magnitudes of stressing rate. Because Eq. (5) is only valid when the seismicity rate prior to the stress step is at steady-state, we assume that the reference seismicity rate $r$ (i.e., the seismicity rate prior to the stress step) has already achieved a steady-state value at each of the stressing rate levels. Therefore, $r$ will have a different value at each stressing rate (Fig. 2a, dashed lines), because as Eqs. (2) and (3) demonstrate, the steady-state seismicity rate scales with stressing rate (Fig. 1). Furthermore, we assume that the stressing rate before and after the stress step remains constant (i.e., $\dot{S}_{\mathrm{r}}=\dot{S}$ ). Given these assumptions, we can use Eq. (5) to predict the

Fig. 2. a) Seismicity rate $R$ calculated with Eq. (5) at different magnitudes of stressing rate $\dot{S}$ relative to a background stressing rate $\dot{S}_{\mathrm{b}}=0.1 \mathrm{MPa} / \mathrm{yr}$ (solid lines), using $\Delta S=0.1 \mathrm{MPa}$ and $A \sigma=0.01 \mathrm{MPa}$. Colors indicate the stressing rate. Steady-state seismicity rate $r$ for each stressing rate is also shown (dashed lines). As stressing rate increases, $R$ increases while $t_{a}$ decreases. b) Cumulative number of events over time obtained by integrating curves in Fig. 2a. The difference between solid and dashed lines of similar color represents aftershocks due to the sudden stress change that is present in the solid curves. c) Number of aftershocks $N$ produced by the uniform stress change at each of the relative stressing rate values $\dot{S} / \dot{S}_{\mathrm{b}}$, relative to number $N_{\mathrm{b}}$ produced at the background stressing rate. The least-squares fit shows that as stressing rate increases, the number of aftershocks also increases, indicating that the parameter $K$ is dependent on stressing rate. seismicity rate $R$ following a uniform stress step at different magnitudes of stressing rate relative to some background stressing rate $\dot{S}_{\mathrm{b}}$, ranging from 1 to 1000 (Fig. 2a, solid lines). In agreement with the first simulation, the results show that as the stressing rate increases, the seismicity rate increases, while $t_{\mathrm{a}}$ decreases.
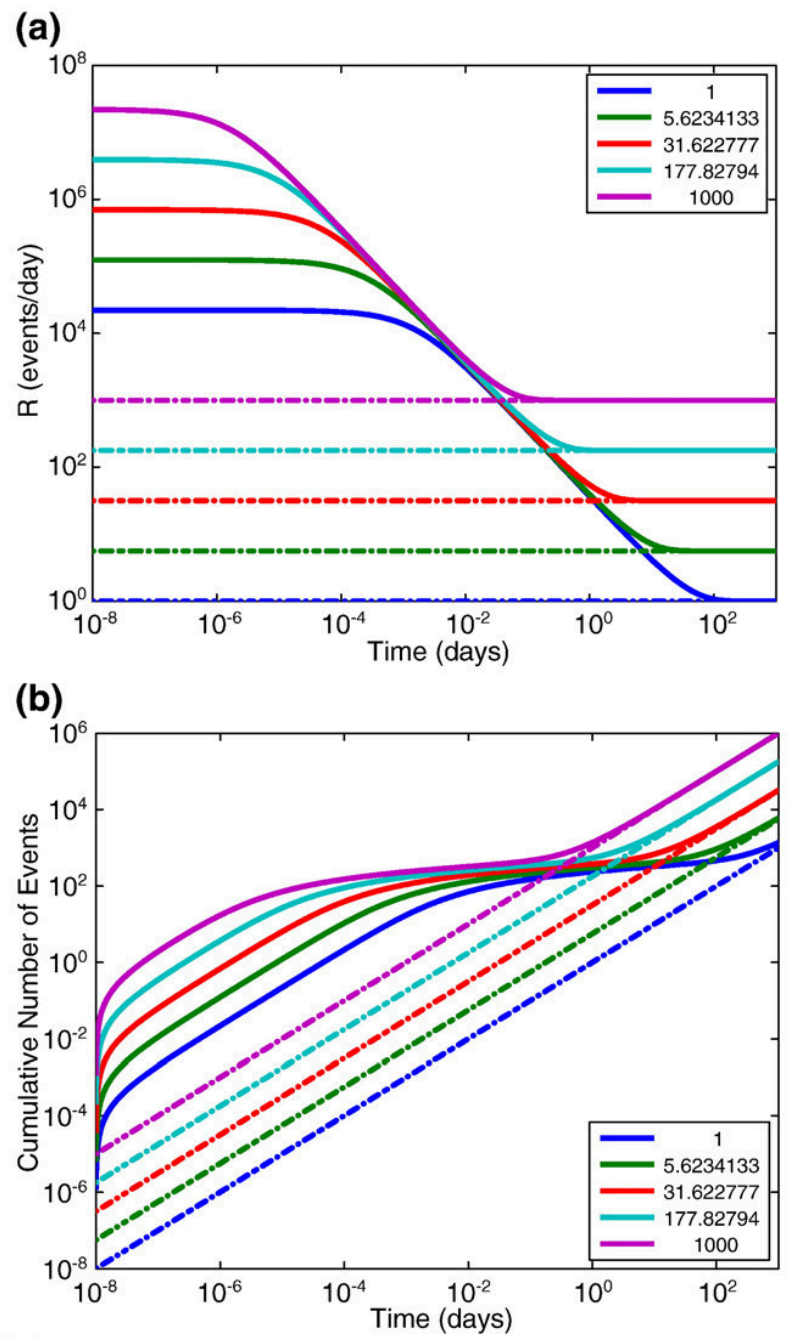

(c)

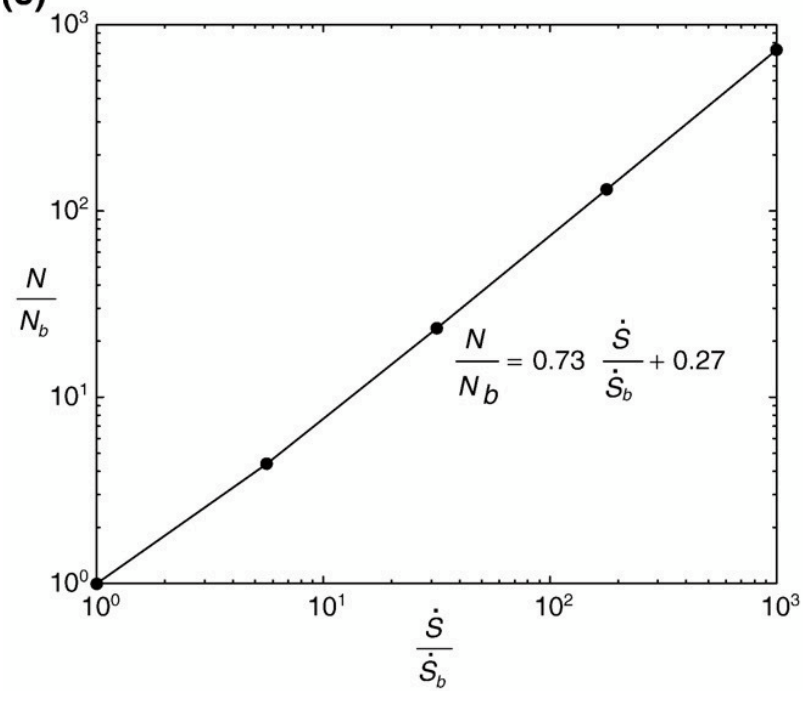




\subsection{Combining the ETAS and rate-state models}

To combine the ETAS and rate-state models into a single model appropriately, we now examine the relationships between parameters of both models and their dependence on stressing rate. The parameters we will consider are the ETAS parameters $\alpha, p, c, K$, and $\mu$. The dependence of these parameters on stressing rate will determine the dependence of $R_{\mathrm{C}}$ on stressing rate, which in turn will determine the functional form of $R$ that we seek to establish.

The ETAS parameter $\alpha$ describes the efficiency of an earthquake of a given magnitude at generating aftershocks. It has no direct equivalent in the rate-state model, which incorporates no magnitude dependence in its equations. However, there is an implicit magnitude dependence in the rate-state model, in that larger earthquakes increase the stress-levels in a greater volume of the crust than small ones. Therefore, we assume that $\alpha$ is related to the spatial extent of a stress step and independent of stressing rate.

Simulations using Eq. (5) show that the ETAS parameter $p$ is essentially 1 and independent of stressing rate in the rate-state model. Both theoretical and observational studies also suggest that this Omori decay parameter is more influenced by factors that are relatively stressing rate independent, such as heterogeneity in temperature/heat flow or structure (e.g., Mogi, 1962, 1967; Kisslinger and Jones, 1991; Utsu et al., 1995). Recently, Helmstetter and Shaw (2006) have also shown that $p$ can be related to the rate- state parameter $A \sigma$ and the spatial distribution of the stress field on a fault. Therefore, as $p$ seems to be more sensitive to longer-term heterogeneities on a fault, in our model we consider $p$ independent of stressing rate.

In the rate-state model, the ETAS parameter $c$ can be analytically related to rate-state parameters and stressing rate (Dieterich, 1994). In reality, it is difficult to obtain an accurate measurement of $c$ because of the incomplete detection of early aftershocks (Utsu et al., 1995). Therefore, any dependence that $c$ may have on stressing rate will most likely be obscured by this effect, and so we consider $c$ independent of stressing rate.

The last two ETAS parameters ( $K$ and $\mu$ ) do not have as straightforward a relationship with stressing rate. The rate-state model predicts that background seismicity rate (i.e., seismicity not triggered by an earthquake) depends on stressing rate. As the stressing rate increases, so does the background seismicity rate (blue lines in Fig. 1, dashed lines in Fig. 2). The ETAS model on the other hand assumes that background seismicity rate $\mu$ is constant in a particular time interval.

The ETAS model also assumes that aftershock productivity $K$ is independent of stressing rate. On the other hand, the rate-state model predicts that $K$ increases with stressing rate. Therefore, an earthquake with a given stress drop that occurs during a time of lower stressing rate will produce fewer aftershocks than if it had occurred during a time of higher stressing rate.

(a)

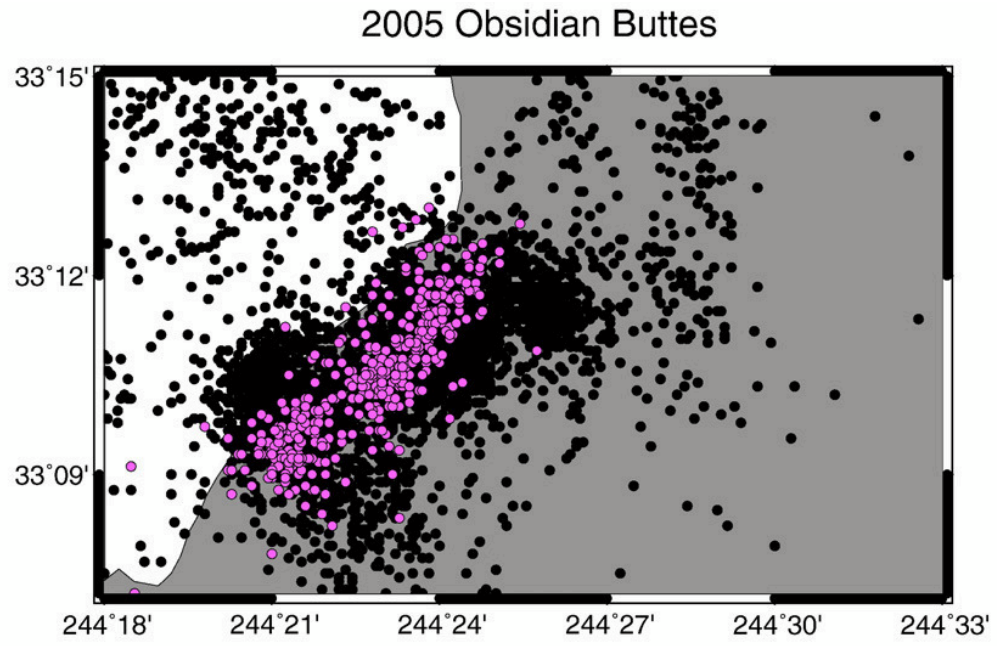

(b)

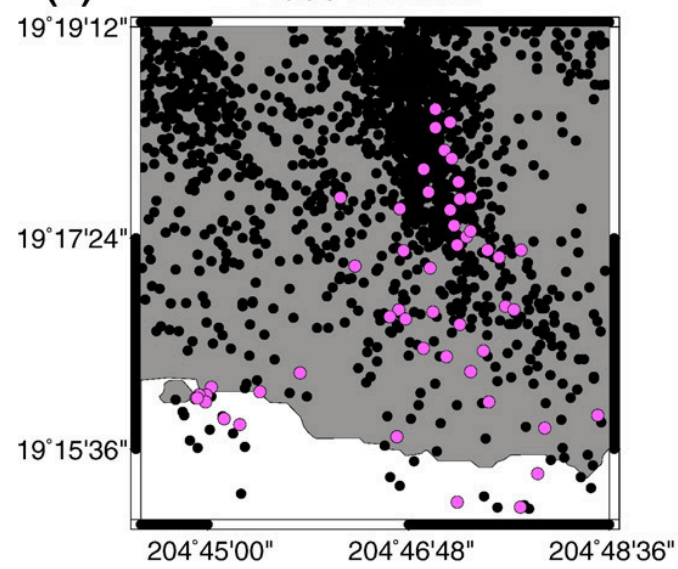

(c) 2002 and 2007 Boso

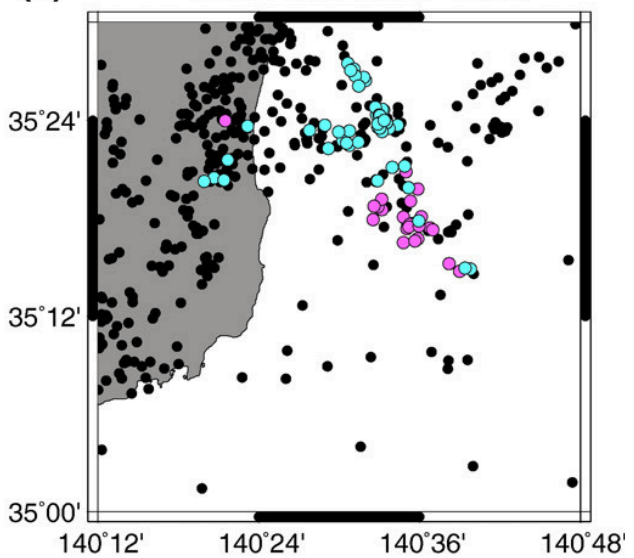

Fig. 3. Maps of seismicity used in analysis. a) $M \geq 1.9$ events in the Obsidian Buttes region from 1985-2005. Events in the 2005 swarm are shown in magenta. b) $M \geq 1.5$ events in the Kilauea region from 2001-2007. Events in the 2005 swarm are shown in magenta. c) $M \geq 2$ events in the Boso region from 1992 to 2007 . Events in the 2002 swarm are shown in magenta, events in the 2007 swarm are shown in cyan. 
The simulations using Eq. (5) demonstrate this behavior. The seismicity rates associated with the five different stressing rates in Fig. 2a are integrated to determine the cumulative number of events for each stressing rate (Fig. 2b). When comparing the case with a stress step (solid lines) to the case with no stress step (dashed lines), the difference between the two curves at a given stressing rate is due to the aftershocks produced by the stress step. We can then compare the number of aftershocks $N$ produced by uniform stress changes at the five different stressing rates to the number of aftershocks $N_{\mathrm{b}}$ produced by the same stress change at the background stressing rate (Fig. 2c). As the stressing rate increases, the number of aftershocks produced also increases. For example, an earthquake that occurs at a stressing rate 1000 times higher than the background stressing rate produces $\sim 700$ times more aftershocks than a similar sized earthquake occurring at the background stressing rate when $A \sigma=0.01 \mathrm{MPa}$. The ratio $\mathrm{N} / \mathrm{N}_{\mathrm{b}}$ thus reflects the increase in aftershock productivity $K$ predicted by the rate-state model due to the increase in stressing rate unlike the ETAS model, in which $K$ is not related to stressing rate. Therefore, the main issues that need to be resolved in order to build a consistent combined model of seismicity rate involves ascertaining the dependence of $K$ and background seismicity rate $\mu$ on stressing rate.

\section{Data analysis}

Many studies suggest that swarms are a response to geodetically observed increases in stressing rate (e.g., Lohman and McGuire, 2007; Ozawa et al., 2007). Therefore, by analyzing swarms, we can establish whether the ETAS parameters $K$ and $\mu$ change during periods of high stressing rates. We use three types of analyses: first, we fit the ETAS model to a catalog containing a swarm to determine if the triggering behavior is non-stationary during swarms. Second, we divide the catalog into pre-swarm and swarm portions, fit the ETAS model to each and compare the parameter estimates to determine how they change during swarms. Finally, we compare aftershock counts of a moderate-sized earthquake that occurred during a stressing rate transient to aftershock counts of other earthquakes in the catalog to test the rate-state model prediction that aftershock productivity $K$ scales with stressing rate.

We examine 4 earthquake swarms that geodetic studies have linked to changes in stressing rate: the 2005 Obsidian Buttes swarm (Lohman and McGuire, 2007), the 2005 Kilauea swarm (Wolfe et al., 2007), and the 2002 and 2007 Boso swarms (Ozawa et al., 2003, 2007). Catalogs for these swarms were obtained from the Southern California Earthquake Data Center, the Advanced National Seismic System, and the Japan Meteorological Agency respectively.

\subsection{Detection of anomalous seismicity rates}

The ETAS model when used as a diagnostic tool can identify time periods when seismicity rates do not behave as typical aftershock sequences (Ogata, 1988; McGuire et al., 2005). We apply the method described in Ogata (2005) by fitting the ETAS model to a catalog that includes a swarm. We then employ a transformation described in Ogata (1988) which utilizes the following theoretical cumulative function:

$\Lambda(t)=\int_{0}^{t} R(s) \mathrm{d} s$

where $R$ is the seismicity rate predicted by the ETAS model (Eq. (1)). The occurrence times $t_{\mathrm{i}}$ in the catalog are transformed into $\tau_{\mathrm{i}}=\Lambda\left(t_{\mathrm{i}}\right)$. If the earthquakes in the catalog are described well by the ETAS model, then $t_{\mathrm{i}}$ will be distributed according to a stationary Poisson process, and a plot of the actual cumulative number of events vs. the theoretical number of events (i.e., the transformed time $\tau$ ) will be linear. Anomalous seismicity that the ETAS model cannot explain will appear as deviations from this trend.

\subsubsection{Obsidian Buttes swarm}

In August 2005, an earthquake swarm occurred over the course of two weeks on a continental strike-slip fault in the Salton Trough in
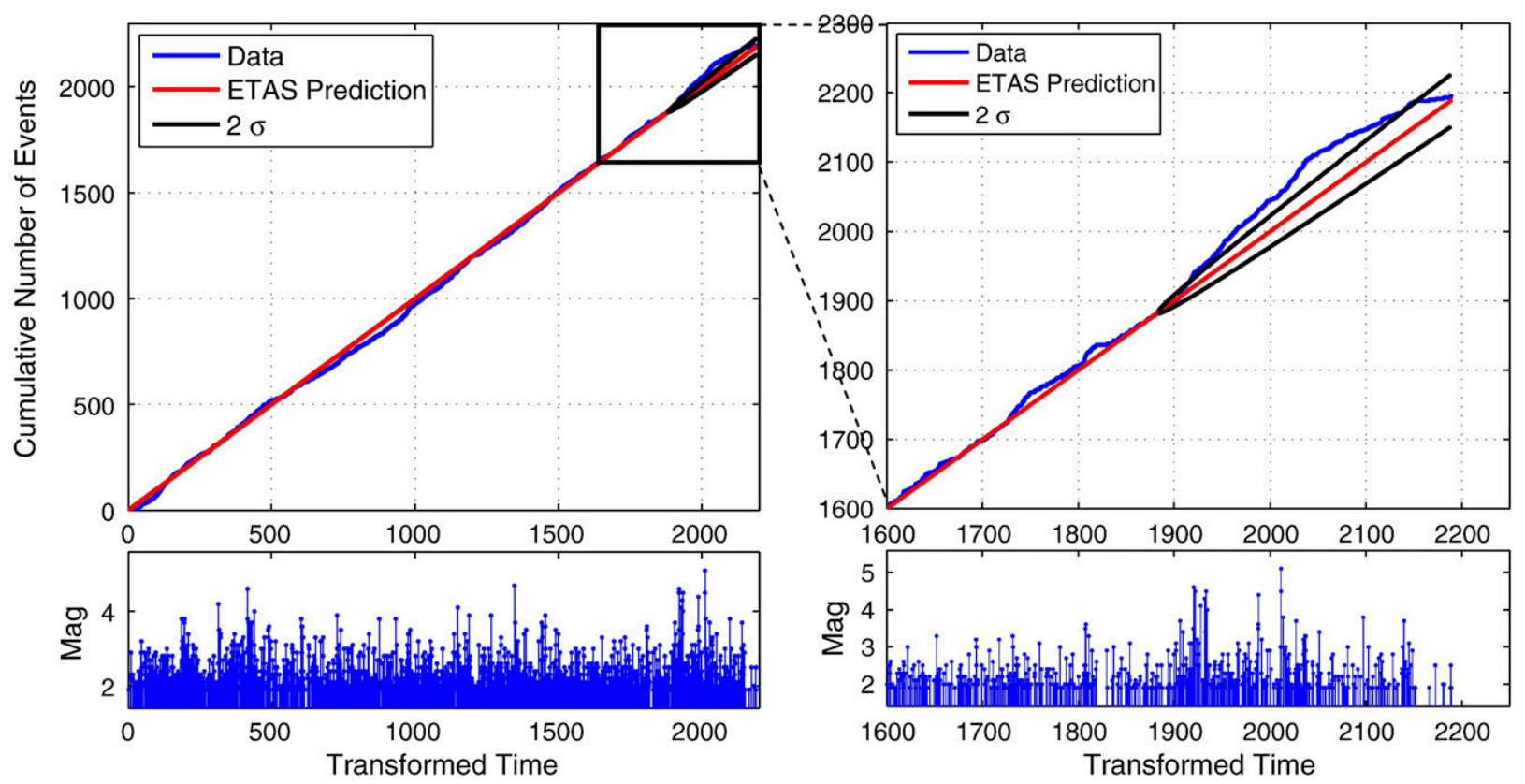

Fig. 4. Results of optimization of the ETAS model for the 2005 Obsidian Buttes catalog, comparing the cumulative number of events to the transformed time (ETAS predicted number of events). The observed data are shown in blue and the ETAS prediction in red. Bottom panels show the magnitudes of the events in the swarm. The ETAS model is optimized until just prior to the swarm and extrapolated for the remainder of the catalog. Black lines signify the $2 \sigma$ bounds of the extrapolation. A significant deviation from the ETAS prediction occurs near the beginning of the swarm. (for interpretation of the references to colour in this figure legend, the reader is referred to the web version of this article.) 


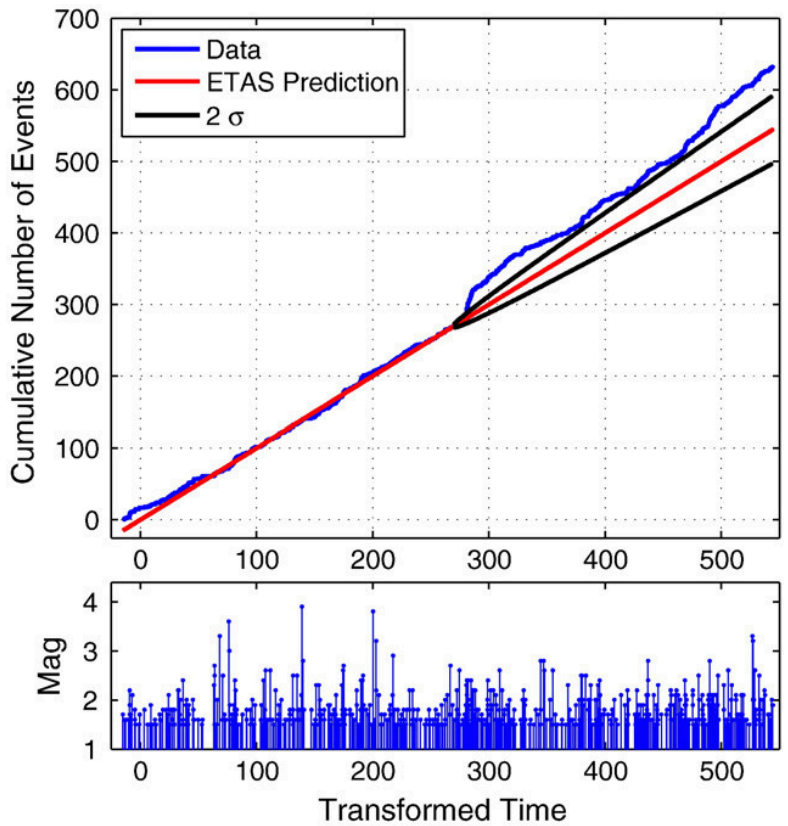

Fig. 5. Results of ETAS model optimization for the 2005 Kilauea catalog. See Fig. 4 for symbol explanation. The ETAS model ceases to adequately fit the catalog early in the swarm.

southern California. Lohman and McGuire (2007) concluded that the swarm was triggered primarily by aseismic fault creep that released moment equivalent to a $M_{\mathrm{w}} 5.7$ earthquake and increased the stressing rate (and seismicity rate) by about a factor of 1000 .
The earthquake catalog used in our analysis consists of events from 1985-2005, with a magnitude of completeness $M_{\mathrm{c}}=1.9$ (Fig. 3a). The ETAS model was optimized through 2005 until just prior to the swarm and then extrapolated until 2006. The transformed time plot shows that a significant deviation from the ETAS predicted trend occurs at the time of the swarm (Fig. 4). More events occurred during the swarm than the ETAS model can explain with the parameters that best fit the preceding catalog. This suggests that at least one of the ETAS parameters changes during periods of high stressing rate.

\subsubsection{Kilauea swarm}

Slow earthquakes that trigger microseismicity periodically occur on the south flank of Kilauea Volcano in Hawaii (Cervelli et al., 2002; Brooks et al., 2006; Segall et al., 2006; Wolfe et al., 2007). In this study, we focus on a slow earthquake that occurred on 26 January 2005 and released moment equivalent to a $M_{\mathrm{w}} 5.8$ earthquake over the course of hours to days (Brooks et al., 2006; Wolfe et al., 2007).

The catalog we analyze consists of events occurring from 20012007, with a catalog completeness of $M_{\mathrm{c}}=1.5$ (Fig. 3b). We optimize the ETAS model from 2001-2005 and extrapolate through the remainder of the catalog. Again, the results show that a significant deviation from typical aftershock behavior occurs at the time of the swarm (blue curve above the black confidence limits in Fig. 5), suggesting a stressing rate dependence of one or more parameters.

\subsubsection{2 and 2007 Boso swarms}

The Boso peninsula in central Japan has been the site of recurring slow slip events on the subduction thrust interface in 1996, 2002 and 2007 (Ozawa et al., 2003; Sagiya, 2004; Ozawa et al., 2007). These events, detected by GPS instruments, lasted on the order of a week and were accompanied by earthquake swarm activity. Ozawa et al. (2007) suggest that the slow slip events are the primary driving process

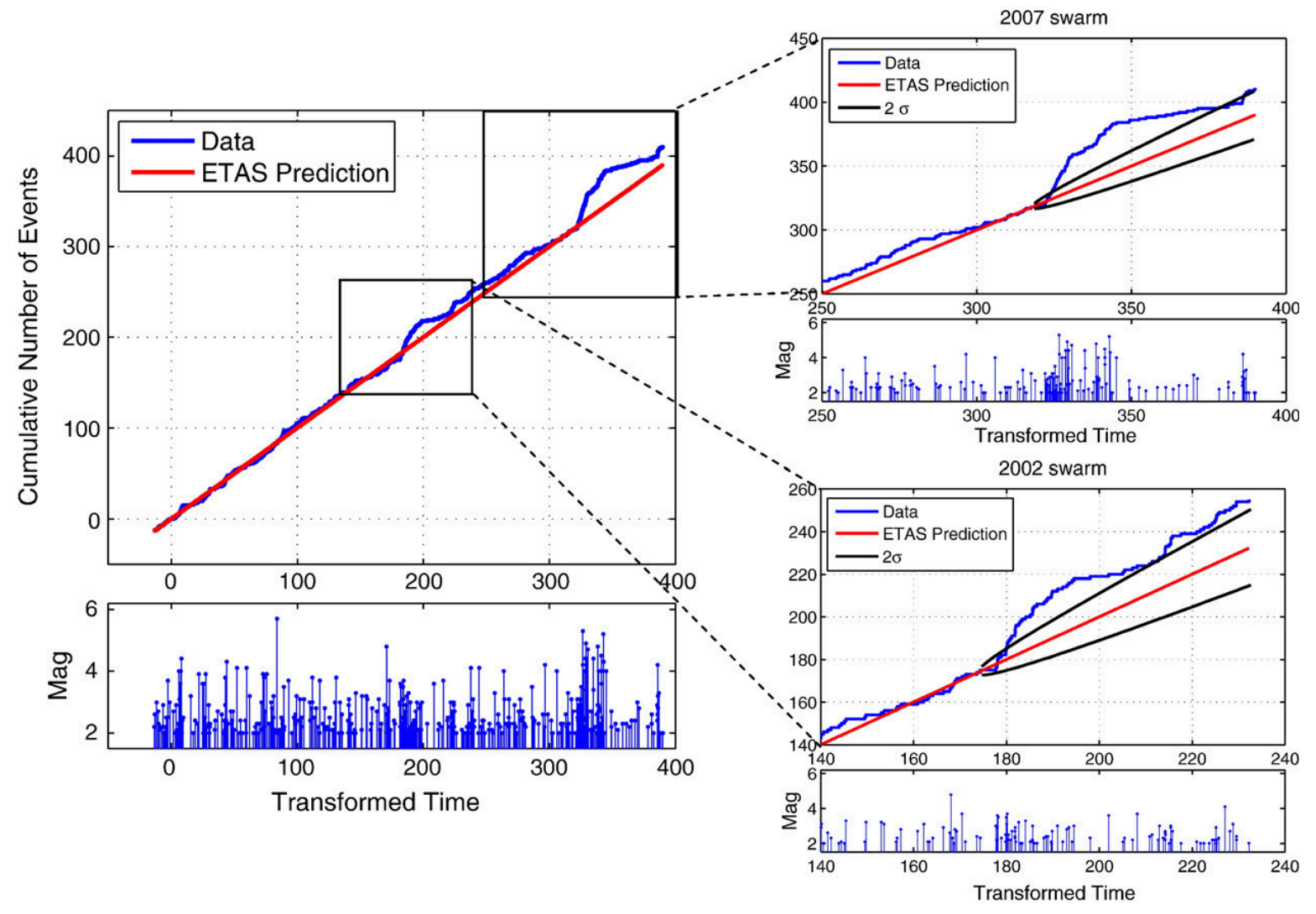

Fig. 6. Results of ETAS model optimization for the 2002 and 2007 Boso swarms. See Fig. 4 for symbol explanation. For both swarms, the ETAS model again fails to explain the amount of seismicity that occurs during the swarms, indicating that the ETAS parameters that best fit the catalog prior to the swarms no longer fit during the swarms. 
Table 1

Comparison of maximum likelihood estimates of ETAS parameters before and during each swarm.

\begin{tabular}{lll}
\hline Swarm & Pre-swarm MLE $(K, \mu, \alpha, p, c)$ & Swarm MLE $(K, \mu, \alpha, p, c)$ \\
\hline 2002 Boso & $0.13,0.022,0.56,1.11,0.096$ & $0.07,2.09,0.09,1.0,0.0005$ \\
2005 Kilauea & $0.28,0.16,1.24,1.21,0.002$ & $0.96,0.89,0.61,0.92,0.003$ \\
2005 Obsidian Buttes & $0.61,0.031,0.88,1.1,0.001$ & $1.4,225,1.05,1.0,0.001$ \\
2007 Boso & $0.20,0.013,0.55,0.88,0.0004$ & $0.61,2.4,1.37,1.0,0.0008$ \\
\hline
\end{tabular}

triggering the swarms, similar to the Obsidian Buttes swarm (Lohman and McGuire, 2007).

Our catalog consists of $M \geq 2$ events from 1992 to 2007 (Fig. 3c). To obtain the best-fitting parameter estimates for the catalog as a whole, the

\section{(a)}

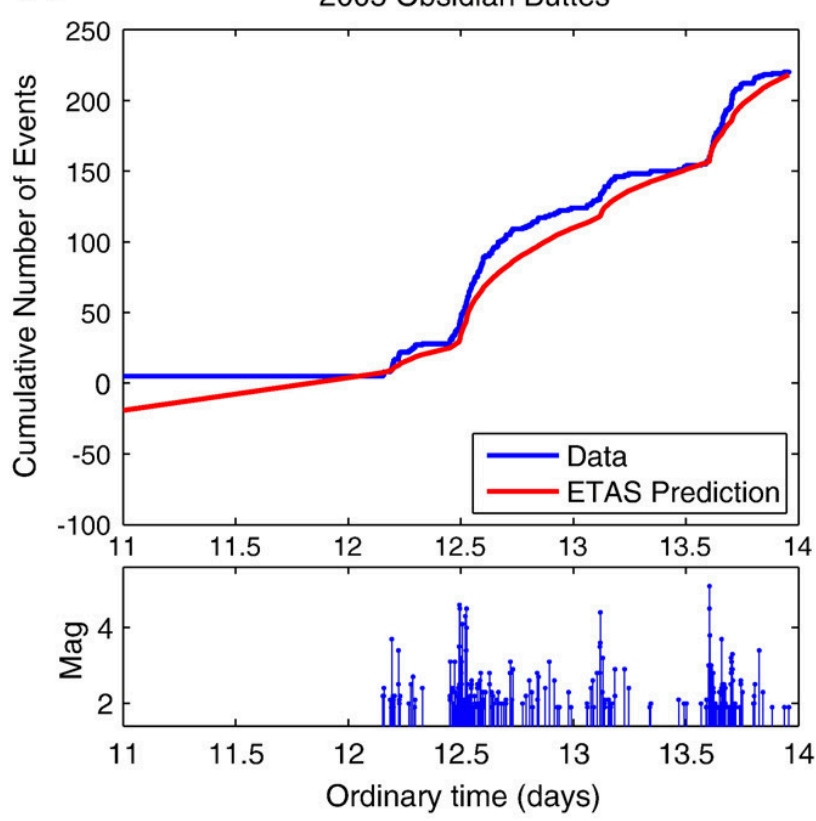

(c)
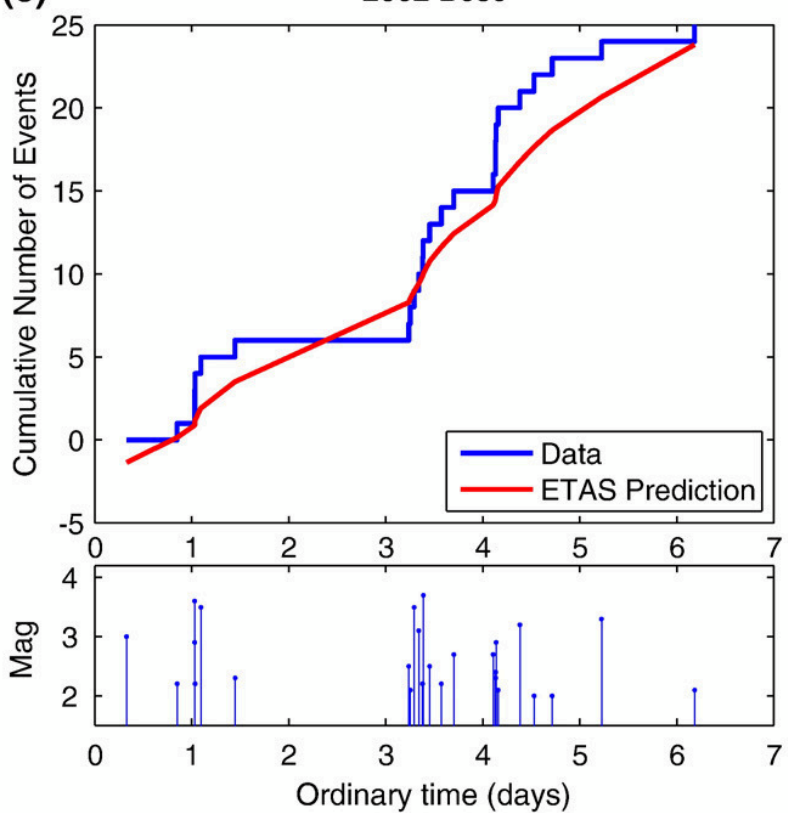

ETAS model is optimized from 1992 to February 2007 and extrapolated through 2008. Due to the short duration of the 2002 swarm, it should have very little effect on the parameter estimates. The results indicate that anomalous seismicity rates occur during the slow slip events in 2002 and 2007 that cannot be explained by the ETAS model (Fig. 6). Again, this suggests that at least one ETAS parameter depends on stressing rate.

\subsection{Fitting ETAS to earthquake swarms}

One way to determine which ETAS parameters change during swarms (i.e., high stressing rate periods) is to fit the ETAS model to the pre-swarm portion of the catalog and compare it to ETAS fit to the swarm alone. Table 1 shows the pre-swarm and swarm estimates of

(b)
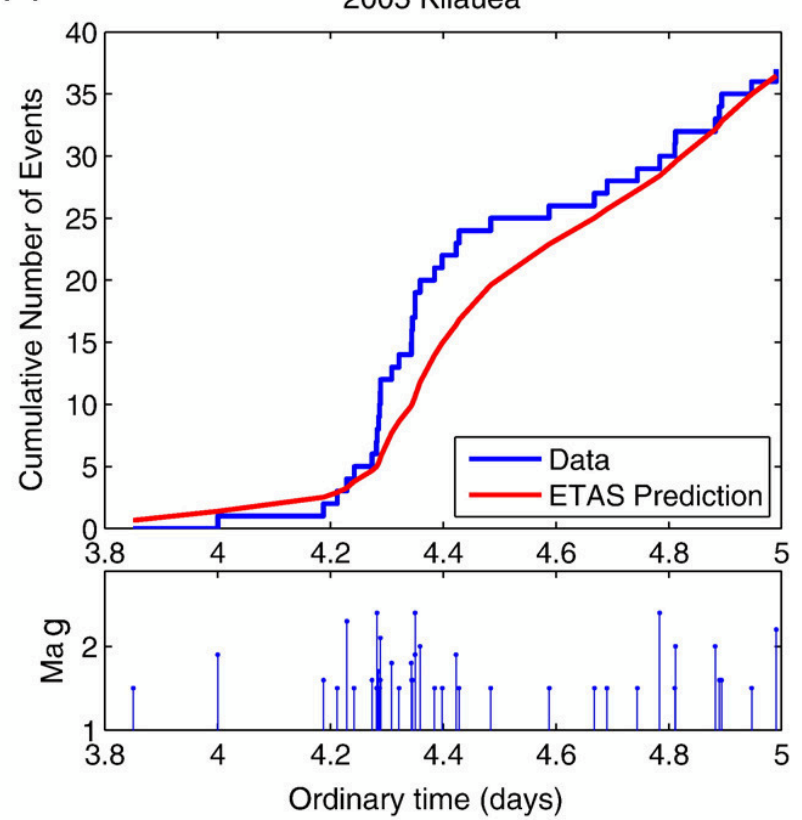

(d)
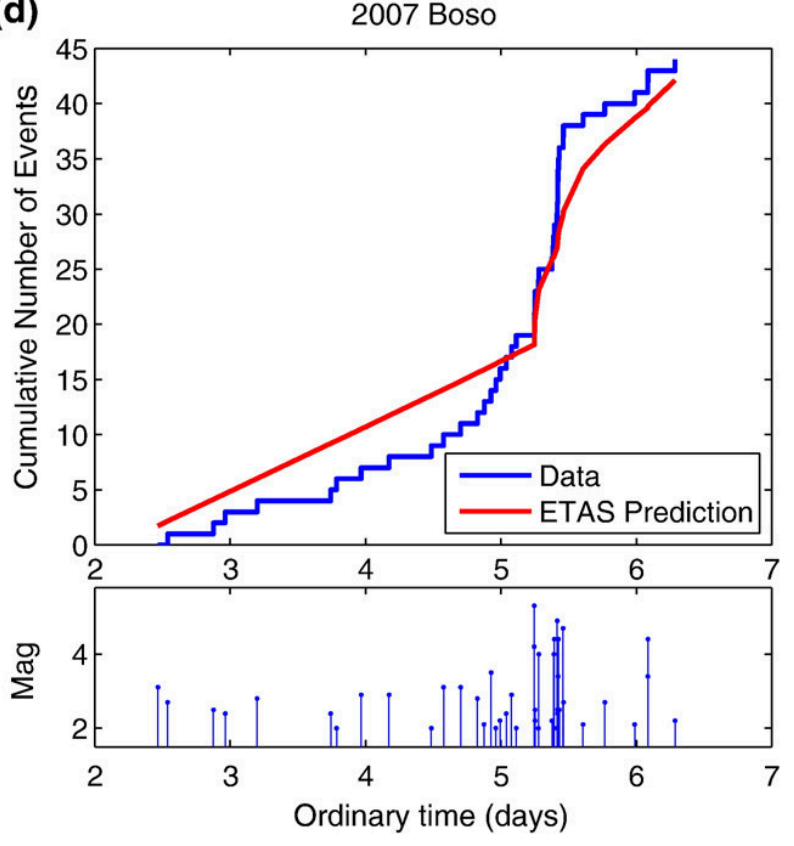

Fig. 7. Results of applying the ETAS model only on swarm seismicity from a) the 2005 Obsidian Buttes catalog, b) the 2005 Kilauea catalog, c) the 2002 Boso catalog, and d) the 2007 Boso catalog. In all 4 cases, the ETAS model requires increases in $K$ and $\mu$ compared to pre-swarm estimates in order to adequately fit the data during the swarm. 
the ETAS parameters for each swarm. In most cases, in order for the model to converge, $p$ was held fixed at 1.0. The observed and predicted cumulative numbers of events for each swarm are shown in Fig. 7a-d. The poorer quality of the fits could suggest that a time-dependent $\mu$ may be necessary to more accurately fit the data. For all of the swarms, the ETAS model finds changes in $K$ by factors of $2-4$. However, the parameter $\mu$ increases by $1-3$ orders of magnitude during the swarms. Therefore, with the ETAS model, stressing rate transients appear to primarily increase the background seismicity rate without increasing aftershock productivity substantially.

\subsection{Comparison of rate-state predictions with observations}

A final way to test the stressing rate dependence of $K$ is to look at moderate sized earthquakes that occur during a swarm. By counting the number of aftershocks following these earthquakes (in narrow space-time windows) and comparing to the number of aftershocks produced by other earthquakes in the catalog (during low stressing rate periods), we can test the hypothesis that $K$ is stressing rate dependent. Assuming that the ETAS parameters $\alpha, p$, and $c$ remain constant over time, the average number of aftershocks following an earthquake of magnitude $M$ can be expressed as:

$N=\frac{K}{1-n} 10^{\alpha\left(M-M_{c}\right)}$

where the branching ratio $n=K b /(b-\alpha)$ (Helmstetter and Sornette, 2003; McGuire et al., 2005). Therefore, if the ETAS and GutenbergRichter parameters are assumed to remain constant throughout the catalog, $N$ is primarily a function of the difference between mainshock magnitude $M$ and catalog completeness threshold $M_{\mathrm{c}}$, and a plot of the logarithm of aftershock counts of mainshocks in the catalog will be linear with respect to the mainshock magnitudes (McGuire et al., 2005). In contrast, the rate-state equations predict a greater productivity (larger $K$ ) during the transient and Eq. (8) will not describe the data well.

Fig. 8 shows the aftershock productivity for the Obsidian Buttes catalog. Aftershocks in a 1-day time window were counted for

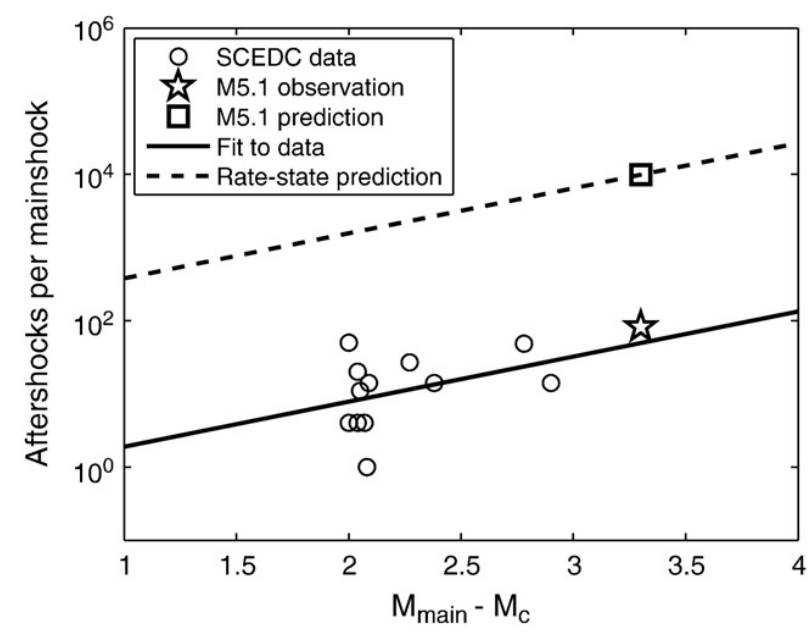

Fig. 8. Aftershocks per mainshock vs. difference between mainshock magnitude and magnitude of completeness $M_{\mathrm{c}}=1.9$ for events of $M_{\text {main }} \geq 4$ in the Obsidian Buttes catalog from 1985-2005 (circles). Aftershocks for each event were counted within a 1 day window. Lines depict lines of constant aftershock parameters, where number of aftershocks depends on $M_{\text {main }}-M_{\mathrm{c}}$. Solid line shows least-squares fit to data; dashed line shows increase in aftershock productivity predicted by rate-state model for a stressing rate of 1000 times background stressing rate. The actual number of aftershocks following the M5.1 mainshock (star) is much less than the number predicted by the rate-state model (square) and falls on a line consistent with other mainshocks in the catalog, suggesting that $K$ (i.e., aftershock productivity) is not stressing rate dependent. mainshocks with $M \geq 4$, occurring sufficiently apart in time so as not to interact with one another. During the swarm, Lohman and McGuire (2007) estimated that a stressing rate transient of $\sim 1000$ times the background stressing rate occurred. Therefore, the rate-state model equations predict that the M5.1 earthquake that occurred during the swarm should produce almost 1000 times more aftershocks than a similar sized earthquake occurring at typical stressing rates (Fig. 2c). However, the actual number of aftershocks observed following the earthquake was not that large (star in Fig. 8). The aftershock count for this event in fact plots on the same constant line as the other events in the catalog, suggesting that $K$ is independent of stressing rate. A concern is that the lack of increase in $K$ could be due to the incomplete detection of early aftershocks. However, we have carefully taken the magnitude of completeness $M_{c}$ into account for each of the catalogs in our analysis. Moreover, the rate-state model equations and thus predictions are defined for a given magnitude interval that we assume to be $M \geq M_{\mathrm{c}}$ (Dieterich, 1994). Therefore, undetected aftershocks are unlikely to be the primary reason for the lack of an increase in $K$.

\subsection{Summary}

We have analyzed 4 different earthquake swarms to examine the dependence of the ETAS parameters $K$ and $\mu$ on stressing rate. The ETAS model identified the swarms as anomalous seismicity that cannot be fit with the same parameters as the rest of the catalog, suggesting that at least one of the parameters changes with stressing rate. However, when the ETAS model was fit to the swarms alone, estimates for $K$ changed very little compared to the pre-swarm fit while the estimates for $\mu$ increased by several orders of magnitude. Finally, the aftershock count following the M5.1 Obsidian Buttes earthquake revealed no substantial increase in $K$ during the heightened stressing rate associated with the swarm. Together these results suggest that stressing rate transients increase the background seismicity rate $\mu$ without causing a substantial increase in aftershock productivity $K$.

\section{Discussion and conclusion}

The primary conflict between the ETAS and rate-state models of seismicity rate lies in the dependence of aftershock productivity on stressing rate. Our results suggest that, contrary to rate-state model predictions, the aftershock productivity is unaffected during stressing rate transients, which instead increase the background seismicity rate. The key to this discrepancy lies in the evolution of the rate-state variable $\gamma$. In the rate-state model, an increase in seismicity rate implies that $\gamma$ has evolved to a new steady-state value (Eq. (2)). Our simulations show that with this increase in seismicity rate comes an increase in aftershock productivity (Fig. 2). Therefore, the lack of an increase in productivity suggests that the state variable $\gamma$ has not evolved. Thus, there is a fundamental conflict between the heightened seismicity rate and the unchanged aftershock productivity we have observed in our analysis of swarms.

An additional complication is that the evolution of $\gamma$ also depends on the frictional parameter $A \sigma$ (see Eq. (3)). This parameter controls how quickly $\gamma$ evolves in response to changes in stressing rate, and therefore ultimately affects the aftershock productivity of a stress step. We can again use Eqs. (2)-(4) to explore in detail how the change in aftershock productivity with stressing rate varies with $A \sigma$. We compare two stress histories, one in which an earthquake $(\Delta S=1 \mathrm{MPa}$ ) occurs during a background stressing rate of $0.2 \mathrm{MPa}$ / $\mathrm{yr}$, and one in which a similar stress step occurs three days after a stressing rate transient begins. We use Eqs. (3) and (4) to calculate $\gamma$ for each stress history and Eq. (2) to obtain seismicity rates that can then be integrated to estimate the number of aftershocks produced by each earthquake. Fig. 9 compares the number of aftershocks $\mathrm{N}_{2}$ produced by an earthquake that occurs three days after a stressing rate 


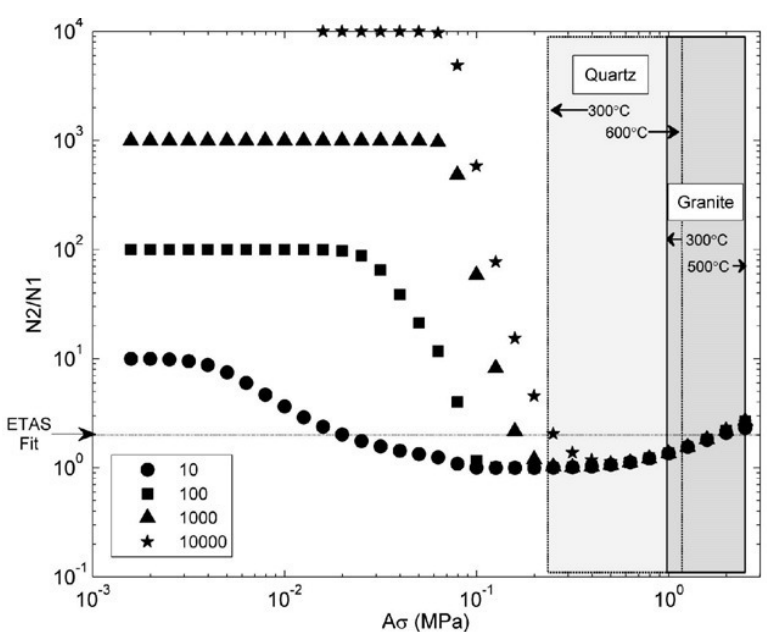

Fig. 9. Change in aftershock productivity $N_{2} / N_{1}$ vs. A $\sigma$ following various magnitudes of stressing rate jumps relative to the background stressing rate of $0.2 \mathrm{MPa} / \mathrm{yr}$ (symbols), for an earthquake with $\Delta S=1 \mathrm{MPa}$. The ratio predicted by the ETAS fits in Table 1 for the Obsidian Buttes swarm is indicated. Values for $A \sigma$ are also shown, given laboratory values of $A$ for quartz (Chester and Higgs, 1992) and granite (Blanpied et al., 1998) in hydrostatic conditions at a depth of $4 \mathrm{~km}$ for temperatures ranging from $300{ }^{\circ} \mathrm{C}$ to $600{ }^{\circ} \mathrm{C}$. For any given range of $A \sigma$, the rate-state model cannot satisfy both the increase in seismicity/stressing rate and the lack of change in aftershock productivity observed during the Obsidian Buttes swarm.

transient begins to the number of aftershocks $N_{1}$ produced by an earthquake that occurs during the background stressing rate, using different values of $A \sigma$ ranging from $10^{-3}$ to $3 \mathrm{MPa}$. The ratio $N_{2} / N_{1}$ essentially gives the expected increase in aftershock productivity $K$ during a stressing rate transient. Fig. 9 demonstrates that the predicted change in aftershock productivity is highly dependent on the value of $A \sigma$ used in the rate-state equations.

Catalli et al. (2008) recently examined the role of $A \sigma$ in modeling seismicity rate variations and found that it controlled the total number of aftershocks triggered by an earthquake primarily in two ways. First, $A \sigma$ controls the instantaneous change in $\gamma$ (and therefore seismicity

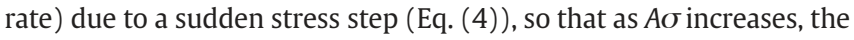
instantaneous change in seismicity rate decreases. Second, the duration of aftershock sequences, $t_{\mathrm{a}}$, also depends on $A \sigma$; as $A \sigma$ increases, $t_{\mathrm{a}}$ increases (Eq. (6)). The simulations in this study demonstrate that these two effects are also dependent on stressing rate (Figs. 1-2). As stressing rate increases, the change in seismicity rate due to a stress step increases, but the aftershock duration $t_{\mathrm{a}}$ decreases. Therefore, the range of aftershock productivity behavior seen in Fig. 9 reflects the tradeoffs in how these two effects are controlled by both $A \sigma$ and stressing rate.

To compare this predicted behavior with a real-life example, for the 2005 Obsidian Buttes M5.1 earthquake, which occurred three days after an increase in stressing rate of almost three orders of magnitude, we found $N_{2} / N_{1} \sim 1$ from aftershock counts (Fig. 8). Additionally, the ETAS model fitting resulted in an increase in background seismicity rate by over three orders of magnitude (Table 1 ), which agrees with the observed increase in seismicity rate. Fig. 9 shows that the ratestate model cannot satisfy all of these observations in a small range of $A \sigma$. Typical estimates of $A \sigma$ from earthquake catalogs range from $10^{-3}$ to $10^{-1} \mathrm{MPa}$ (e. g., Gross and Kisslinger, 1997; Harris and Simpson, 1998; Toda et al., 1998; Belardinelli et al., 1999; Console et al., 2007). In this range of $A \sigma, \gamma$ evolves quickly, so that jumps in stressing rate cause jumps in seismicity rate, but also cause jumps in $N_{2} / N_{1}$ (i.e., aftershock productivity). Laboratory measurements of $A$ for quartz and granite (Chester and Higgs, 1992; Blanpied et al., 1998) result in higher values of $A \sigma\left(10^{-1}\right.$ to $\left.1 \mathrm{MPa}\right)$ for faults under hydrostatic pore pressure at a depth of $4 \mathrm{~km}$. At these values of $A \sigma$, although aftershock productivity does not change with the jump in stressing rate, neither does the seismicity rate, because $\gamma$ has not evolved to any great extent. We find that the increase in seismicity rate and the lack of change in aftershock productivity observed in the Obsidian Buttes swarm cannot both be satisfied simultaneously using the rate-state model, because the two observations imply fundamentally different things about whether $\gamma$ has evolved or not. Therefore, some caution is necessary when applying the rate-state inversion algorithm to obtain stressingrate changes from earthquake catalogs.

Given our observations of the dependence of the ETAS parameters on stressing rate, we can now specify a combined ETAS/rate-state model of seismicity rate to detect stressing rate transients from earthquake catalogs. As described earlier, the seismicity rate $R$ in a catalog is a function of an aseismically-triggered component $R_{\mathrm{A}}$ and an earthquake-earthquake triggered component $R_{\mathrm{C}}$. While $R_{\mathrm{A}}$ is clearly related to stressing rate, the relationship between $R_{\mathrm{C}}$ and stressing rate was unclear. Our results suggest that $K$ is independent of stressing rate for a particular region, and so $R_{\mathrm{C}}$ is independent of stressing rate. $R$ can then essentially be separated into the aseismic component $R_{\mathrm{A}}$ and the coseismic component $R_{\mathrm{C}}$ (represented by the ETAS model):

$R=R_{\mathrm{A}}+R_{\mathrm{C}}=R_{\mathrm{A}}+\sum_{t_{\mathrm{i}} \leq t} \frac{K e^{\alpha\left(M_{\mathrm{i}}-M_{\mathrm{c}}\right)}}{\left(t-t_{\mathrm{i}}+c\right)^{p}}$

Then $R_{\mathrm{A}}$ is effectively a time dependent version of the ETAS parameter $\mu$ (see Eq. (1)), and to obtain it, one can simply subtract the ETAS-predicted $R_{\mathrm{C}}$ from the observed rate $R$. The residual $R_{\mathrm{A}}$ can then be directly related to a stressing rate $\dot{S}_{\mathrm{A}}$ caused by aseismic deformation through the rate-state model equations:

$R_{\mathrm{A}}=R-R_{\mathrm{C}}=R-\sum_{t_{\mathrm{i}} \leq t} \frac{K e^{\alpha\left(M_{\mathrm{i}}-M_{\mathrm{c}}\right)}}{\left(t-t_{\mathrm{i}}+c\right)^{p}}=\frac{r}{\dot{S}_{\mathrm{r}} \gamma}$

$\mathrm{d} \gamma=\frac{\mathrm{d} t}{A \sigma}\left[1-\gamma\left(\dot{S}_{\mathrm{A}}+\dot{S}_{\mathrm{b}}\right)\right]$

where $\dot{S}_{\mathrm{b}}$ is the background tectonic stressing rate. The use of the ETAS model to estimate $R_{\mathrm{C}}$ reduces the impact of aftershock sequences on the estimation of the aseismically-triggered seismicity rate, while the rate-state model establishes the relationship between aseismicallytriggered seismicity rates and stressing rates.

There are a number of caveats to keep in mind about this model. First, a fundamental assumption this model makes is that the ETAS parameters $K, \alpha, c$ and $p$ are constant in space and time and can describe all coseismically-triggered seismicity in a catalog completely. These parameters can in fact vary from sequence to sequence, as well as place to place (Ogata, 1998). However, our data analysis suggests that at least within relatively small and homogeneous regions, these parameters will remain constant, and therefore changes in the observed seismicity rate will be primarily mapped into changes in $R_{\mathrm{A}}$. Second, practical applications of this model will have to be careful about catalog completeness, to ensure that undetected events such as early aftershocks do not affect the results. An additional point to bear in mind is the need to smooth the seismicity rates over some time window. Currently there is no way to estimate $R_{\mathrm{A}}$ at arbitrarily fine time scales, so algorithms will need to be developed to smooth these estimates in an optimal way. These issues will need to be considered when this model is implemented in an algorithm to invert for stressing rate variations, but the studies of Toda et al. (2002) and Lohman and McGuire (2007) suggest that our model is correct at least at the order of magnitude level. To verify the rate-state equations for background rate at a higher level of precision would require high sample-rate geodetic measurements (e.g., strain- or tiltmeters). However, to first order, our model provides a simple and direct way to quantitatively relate aseismic stressing rate transients to seismicity 
data and will allow future studies to invert seismicity catalogs to detect stressing rate variations caused by transient aseismic processes.

\section{Acknowledgments}

We thank R. Stein, S. Toda, and J. Dieterich for helpful discussions that increased our understanding of the rate-state model, and three anonymous reviewers whose comments improved the paper. Earthquake catalogs were obtained from the Advanced National Seismic System, Japan Meteorological Agency, and the Southern California Earthquake Data Center. Map figures were prepared using the Generic Mapping Tools software freely distributed by Wessel and Smith (1998). This work was supported by NSF EAR grant \#0738641 (McGuire and Llenos) and a National Defense Science and Engineering Graduate Fellowship (Llenos).

\section{References}

Audigane, P., Royer, J.J., Kaieda, H., 2002. Permeability characterization of the Soultz and Ogachi large-scale reservoir using induced microseismicity. Geophysics 67, 204-211. doi:10.1190/1.1451573.

Belardinelli, M.E., Cocco, M., Coutant, O., Cotton, F., 1999. Redistribution of dynamic stress during coseismic ruptures: evidence for fault interaction and earthquake triggering. J. Geophys. Res. 104, 14925-14945.

Ben-Zion, Y., Lyakhovsky, V., 2006. Analysis of aftershocks in a lithospheric model with seismogenic zone governed by damage rheology. Geophys. J. Int. 165, 197-210. doi:10.1111/j.1365-246X.2006.02878.X.

Blanpied, M.L., Marone, C.J., Lockner, D.A., Byerlee, J.D., King, D.P., 1998. Quantitative measure of the variation in fault rheology due to fluid-rock interactions. J. Geophys. Res. 103, 9691-9712.

Boettcher, M.S., Jordan, T.H., 2004. Earthquake scaling relations for mid-ocean ridge transform faults. J. Geophys. Res. 109, B12302. doi:10.1029/2004JB003110.

Bourouis, S., Bernard, P., 2007. Evidence for coupled seismic and aseismic fault slip during water injection in the geothermal site of Soultz (France), and implications for seismogenic transients. Geophys. J. Int. 169, 723-732. doi:10.1111/j.1365-246X.2006. 03325.x.

Brodsky, E.E., Mori, J., 2007. Creep events slip less than ordinary earthquakes. Geophys. Res. Lett. 34, L16309. doi:10.1029/2007GL030917.

Brooks, B.A., Foster, J.H., Bevis, M., Frazer, L.N., Wolfe, C.J., Behn, M., 2006. Periodic slow earthquakes on the flank of Kilauea volcano, Hawai i, Earth Planet. Sci. Lett. 246 , 207-216. doi:10.1016/j.epsl.2006.03.035.

Catalli, F., Cocco, M., Console, R., Chiaraluce, L., 2008. Modeling seismicity rate changes during the 1997 Umbria-Marche sequence (central Italy) through a rate- and statedependent model. J. Geophys. Res. 113, B11301. doi:10.1029/2007JB005356.

Cervelli, P., Segall, P., Johnson, K., Lisowski, M., Miklius, A., 2002. Sudden aseismic fault slip on the south flank of Kilauea volcano. Nature 415, 1014-1018.

Chester, F.M., Higgs, N.G., 1992. Multimechanism friction constitutive model fo ultrafine quartz gouge at hypocentral conditions. J. Geophys. Res. 97, 1859-1870.

Console, R., Murru, M., Catalli, F., 2006. Physical and stochastic models of earthquake clustering. Tectonophysics 417, 141-153. doi:10.1016/j.tecto.2005.05.052.

Console, R., Murru, M., Catalli, F., Falcone, G., 2007. Real time forecasts through an earthquake clustering model constrained by the rate-and-state constitutive law: comparison with a purely stochastic ETAS model. Seis. Res. Lett. 78, 49-56.

Dieterich, J., 1994. A constitutive law for rate of earthquake production and its application to earthquake clustering. J. Geophys. Res. 99, 2601-2618.

Dieterich, J., Cayol, V., Okubo, P., 2000. The use of earthquake rate changes as a stress meter at Kilauea volcano. Nature 408, 457-460.

Einarsson, P., Brandsdóttir, B., 1980. Seismological evidence for lateral magma intrusion during the July 1978 deflation of the Krafla volcano in NE-Iceland. J. Geophys. 47, 160-165.

Gross, S., Kisslinger, C., 1997. Estimating tectonic stress rate and state with Landers aftershocks. J. Geophys. Res. 102, 7603-7612.

Hainzl, S., Ogata, Y., 2005. Detecting fluid signals in seismicity data through statistical earthquake modeling. J. Geophys. Res. 110. doi:10.1029/2004JB003247.

Harris, R.A., Simpson, R.W., 1998. Suppression of large earthquakes by stress shadows: comparison of Coulomb and rate-and-state failure. J. Geophys. Res. 103, 24439-24451.

Helmstetter, A., 2003. Is earthquake triggering driven by small earthquakes? Phys. Rev. Lett. 91. doi:10.1103/PhysRevLett.91.058501.

Helmstetter, A., Sornette, D., 2002. Subcritical and supercritical regimes in epidemic models of earthquake aftershocks. J. Geophys. Res. 107 (B10), 2237. doi:10.1029/ 2001JB001580.
Helmstetter, A., Sornette, D., 2003. Bath's law derived from the Gutenberg-Richter law and from aftershock properties. Geophys. Res. Lett. 30. doi:10.1029/2003GL018186.

Helmstetter, A., Shaw, B.E., 2006. Relation between stress heterogeneity and aftershock rate in the rate-and-state model. J. Geophys. Res. 111, B07304. doi:10.1029/ 2005JB004077.

Hill, D.P., Mowinckel, P., Peake, L.G., 1975. Earthquakes, active faults and geothermal areas in the Imperial Valley, California. Science 188, 1306-1308.

Kisslinger, C., Jones, L.M. 1991. Properties of aftershock sequences in southern California. J. Geophys. Res. 96, 11,947-11,958.

Lohman, R.B., McGuire, J.J., 2007. Earthquake swarms driven by aseismic creep in the Salton Trough, California. J. Geophys. Res. 112, B04405. doi:10.1029/2006JB004596.

McGuire, J.J., Boettcher, M.S., Jordan, T.H., 2005. Foreshock sequences and short-term earthquake predictability on East Pacific Rise transform faults. Nature 434 doi:10.1038/nature03377.

Mogi, K., 1962. Study of elastic shocks caused by the fracture of heterogeneous materials and its relation to earthquake phenomena. Bull. Earthquake Res. Inst. Univ. Tokyo 40, 125-173.

Mogi, K., 1967. Regional variation of aftershock activity. Bull. Earthquake Res. Inst. Univ. Tokyo 45, 711-726.

Ogata, Y., 1988. Statistical models for earthquake occurrences and residual analysis for point processes. J. Am. Stat. Assoc. 83, 9-27.

Ogata, Y., 1998. Space-time point-process models for earthquake occurrences. Ann. Inst. Statist. Math. 50, 379-402.

Ogata, Y., 2004. Space-time model for regional seismicity and detection of crustal stress changes. J. Geophys. Res. 109, B03308. doi:10.1029/2003JB002621.

Ogata, Y., 2005. Detection of anomalous seismicity as stress change sensor. J. Geophys. Res. 110, B05S06. doi:10.1029/2004JB003245.

Omori, F., 1894. On the aftershocks of earthquakes. J. Coll. Sci. Imp. Univ. Tokyo 7, $111-200$

Ozawa, S., Miyazaki, S., Hatanaka, Y., Imakiire, T., Kaidzu, M., Murakami, M., 2003. Characteristic silent earthquakes in the eastern part of the Boso peninsula, Central Japan. Geophys. Res. Lett. 30 (6), 1283. doi:10.1029/2002GL016665.

Ozawa, S., Suito, H., Tobita, M., 2007. Occurrence of quasi-periodic slow-slip off the east coast of the Boso peninsula, Central Japan. Earth Planets Space 59, 1241-1245.

Prejean, S., Stork, A., Ellsworth, W., Hill, D., Julian, B., 2003. High precision earthquake locations reveal seismogenic structure beneath Mammoth Mountain, California. Geophys. Res. Lett. 30 (24), 2247. doi:10.1029/2003GL018334.

Richter, C.F., 1958. Elementary Seismology. W.H. Freeman, San Francisco.

Sagiya, T., 2004. Interplate coupling in the Kanto district, central Japan, and the Boso peninsula silent earthquake in May 1996. Pure Appl. Geophys. 161. doi:10.1007/ s00024-004-2566-6.

Segall, P., Desmarais, E.K., Shelly, D., Miklius, A., Cervelli, P., 2006. Earthquakes triggered by silent slip events on Kilauea volcano, Hawaii. Nature 442. doi:10.1038/nature04938.

Shapiro, S.A., Rentsch, S., Rothert, E., 2005. Characterization of hydraulic properties of rocks using probability of fluid-induced microearthquakes. Geophysics 70, F27-F33. doi:10.1190/1.1897030.

Smith, K.D., von Seggern, D., Blewitt, G., Preston, L., Anderson, J.G., Wernicke, B.P., Davis, J.L., 2004. Evidence for deep magma injection beneath Lake Tahoe, NevadaCalifornia. Science 305. doi:10.1126/science.1101304.

Takada, Y., and Furuya, M., in review, Aseismic slip during the 1996 earthquake swarm in and around the Onikobe geothermal area, NE Japan, Earth Planet. Sci. Lett.

Toda, S., Matsumura, S., 2006. Spatio-temporal stress states estimated from seismicity rate changes in the Tokai region, central Japan. Tectonophysics 417, 53-68. doi:10.1016/j.tecto.2005.08.030

Toda, S., Stein, R.S., Reasenberg, P.A., Dieterich, J.H., 1998. Stress transferred by the Mw $=6.5$ Kobe, Japan, shock: effect on aftershocks and future earthquake probabilities. J. Geophys. Res. 103, 24,543-24,565.

Toda, S., Stein, R.S., Sagiya, T., 2002. Evidence from the AD 2000 Izu islands earthquake swarm that stressing rate governs seismicity. Nature 419, 58-61.

Utsu, T., 1961. A statistical study on the occurrence of aftershocks. Geophys. Mag. 30, 521-605.

Utsu, T., Ogata, Y., Matsu'ura, R.S., 1995. The centenary of the Omori formula for a decay law of aftershock activity. J. Phys. Earth 43, 1-33.

Vidale, J.E., Shearer, P.M., 2006. A survey of 71 earthquake bursts across southern California: exploring the role of pore fluid pressure fluctuations and aseismic slip as drivers. J. Geophys. Res. 111, B05312. doi:10.1029/2005JB004034.

Vidale, J.E., Boyle, K.L., Shearer, P.M., 2006. Crustal earthquake bursts in California and Japan: their patterns and relation to volcanoes. Geophys. Res. Lett. 33, L20313. doi:10.1029/2006GL027723.

Wessel, P., Smith, W.H.F., 1998. New, improved version of generic mapping tools released. Eos Trans. AGU 79 (47), 579.

Wolfe, C.J., Brooks, B.A., Foster, J.H., Okubo, P.G., 2007. Microearthquake streaks and seismicity triggered by slow earthquakes on the mobile south flank of Kilauea Volcano, Hawai i. Geophys. Res. Lett. 34, L23306. doi:10.1029/2007GL031625. 


\title{
Chapter 4: Detecting Aseismic Strain Transients From Seismicity Data
}

\begin{abstract}
Aseismic deformation transients such as fluid flow, magma migration, and slow slip can trigger changes in seismicity rate [e.g., Dieterich et al., 2000; Toda et al., 2002; Hainzl and Ogata, 2005; Lohman and McGuire, 2007; Ozawa et al., 2007]. We present a method that can detect these seismicity rate variations and associate these anomalies with underlying variations in stressing rate. Because ordinary aftershock sequences often obscure changes in the background seismicity caused by aseismic processes, we combine the stochastic Epidemic Type Aftershock Sequence model [Ogata, 1988; Ogata, 1998] that describes aftershock sequences well and the physically based rate- and statedependent friction seismicity model [Dieterich, 1994] into a single seismicity rate model that models both aftershock activity and changes in background seismicity rate. We implement this model into a data assimilation algorithm that inverts seismicity catalogs to estimate space-time variations in stressing rate. We evaluate the method using a synthetic catalog, and then apply it to a catalog of $\mathrm{M} \geq 1.5$ events that occur in the Salton Trough from 1990-2009. We validate our stressing rate estimates by comparing them to estimates from a geodetically-derived slip model for a large creep event on the Obsidian Buttes fault [Lohman and McGuire, 2007]. The results demonstrate that our approach can identify large aseismic deformation transients in a multi-decade long earthquake catalog and roughly constrain the absolute magnitude of the stressing rate transients.
\end{abstract}




\section{Introduction}

Transient aseismic processes such as fluid flow, magmatic intrusions, or slow slip events can alter the stress state and trigger seismicity in a variety of tectonic environments. For example, earthquake swarms associated with aseismic deformation have been observed in subduction zones such as Japan and New Zealand [Ozawa et al., 2007; Delahaye et al., 2009], continental strike-slip faults [Lohman and McGuire, 2007], and volcanic regions [Dieterich et al., 2000; Toda et al., 2002; Segall et al., 2006; Wolfe et al., 2007; Montgomery-Brown et al., 2009]. However, there is not a straightforward relationship between the magnitude of the aseismic transient and the amount of seismicity triggered. In the Salton Trough of California, a $\mathrm{M}_{\mathrm{w}} 5.7$ creep event triggered a swarm of $\sim 1000 \mathrm{M} \leq 5.1$ earthquakes [Lohman and McGuire, 2007], whereas offshore of central Honshu, Japan, recurrent $\mathrm{M}_{\mathrm{w}} \sim 6.5$ slow earthquakes on the plate interface typically trigger swarms of $\sim 10 \mathrm{~s}$ of $\mathrm{M} \leq 5$ earthquakes [Ozawa et al., 2007]. Moreover, a $\mathrm{M}_{\mathrm{w}} 4.7$ creep event detected on the Superstition Hills fault in southern California did not trigger any earthquakes [Wei et al., 2009]. There is evidence, however, that the seismicity rate varies in proportion to the stressing rate increase caused by the aseismic transient [Toda et al., 2002; Segall et al., 2006; Lohman and McGuire, 2007]. Although this is likely complicated by a dependence on ambient stress conditions such as the timing within a fault's seismic cycle, there appears to be a possibility of utilizing seismicity rate variations observed in earthquake catalogs to detect when and where aseismic processes are occurring on some faults, which would ordinarily require high-quality geodetic data to resolve. Moreover, the variations in earthquake triggering observed during aseismic deformation transients suggest an opportunity to learn about the physics of earthquake triggering, and to constrain the extent to which seismicity is triggered by potentially observable geophysical processes, such as slow slip, and hence may be forecastable in a probabilistic sense.

The rate- and state-dependent friction model [Dieterich, 1994; Dieterich et al., 2000] is one approach for mapping seismicity rate variations to underlying stressing rate variations. This model has been used to estimate stress changes caused by a dike 
intrusion [Dieterich et al., 2000] and slow slip events [Segall et al., 2006; MontgomeryBrown et al., 2009] on Kilauea volcano as well as a large intrusion in the Izu islands [Toda et al., 2002]. Oftentimes, however, the background seismicity rate changes due to aseismic processes can be obscured by the aftershock sequences in a catalog, particularly in regions such as southern California that are characterized by high aftershock productivity [Helmstetter, 2003; Helmstetter and Sornette, 2003a]. In such cases, the stressing rate changes estimated by the rate-state inversion will be a combination of those due to the underlying aseismic process and those due to the static stress changes resulting from the seismicity itself. Moreover, the rate-state equations predict that changes in stressing rate due to aseismic processes should cause many orders of magnitude changes in aftershock productivity, but this was not observed in earthquake swarms triggered by aseismic fault slip in a variety of tectonic environments [Llenos et al., 2009]. For these reasons, the rate-state inversion should be used with caution.

The stochastic Epidemic Type Aftershock Sequence (ETAS) model [Ogata, 1988] is an alternative approach used to estimate the time-dependence of underlying driving mechanisms. Earthquake occurrence is modeled as a point process and characterized by a background rate and a set of parameters associated with Omori's law that can be optimized to fit a particular catalog. The ETAS model is effective at detecting when anomalous seismicity is being triggered by an external process [Hainzl and Ogata, 2005; Ogata, 2004; Ogata, 2005; McGuire et al., 2005]. However, ETAS lacks a procedure for estimating smooth variations in the background earthquake rate and a quantitative way to relate these directly to stressing rate variations.

The rate-state model and the ETAS model have complementary strengths which, when combined, can provide an effective tool for detecting seismicity rate anomalies and relating them to underlying stress fields. In a previous study, we combined these two models into a single seismicity rate model that explains both aftershock activity as well as variations in background seismicity occurring in a region [Llenos et al., 2009]. In this model, the observed seismicity rate $R$ in a catalog is approximately a linear combination of an aseismically-triggered component (reflecting seismicity triggered by long-term 
tectonic loading and aseismic processes) and an earthquake-earthquake triggered component (reflecting aftershock sequences). This is in contrast to the pure rate-state model where aftershock productivity is proportional to the stressing rate, which was not observed in our previous study of slow slip events, preventing us from using it for the coseismically-triggered component [Llenos et al., 2009]. We instead use the ETAS model to estimate the coseismically-triggered component of seismicity rate and subtract it from the observed (binned) catalog rate. We then relate the residual seismicity rate directly to an aseismic stressing rate using the rate-state model.

We implement this combined model in a data assimilation algorithm that uses seismicity catalogs to estimate stressing rate variations. We incorporate the rate-state equations into a state-space model and use an extended Kalman filter to estimate spatial and temporal variations in stressing rate. We evaluate this method with a synthetic test, and apply it to a catalog of events from the Salton Trough in southern California in which a geodetically-detected aseismic transient occurred. To validate our approach, we compare the estimated stressing rate peak during this aseismic slip event to that obtained from a slip inversion of geodetic data [Lohman and McGuire, 2007]. The results suggest that our seismicity inversion method provides an accurate way to detect and locate transient deformation strictly from seismicity catalogs and may provide a means to constrain the absolute magnitude of stressing rate variations.

\section{Method}

The seismicity rate $R$ observed in a catalog is in general a function of the stressing rate acting on the population of faults in a region [Dieterich, 1994]. We assume that the seismicity in a catalog is primarily triggered by three mechanisms: earthquake-earthquake interactions (i.e., as aftershocks), transient changes to the stress field from aseismic processes such as fluid flow or slow slip, and long-term tectonic loading. Therefore, $R(t, x)=f(\dot{S})=f\left(R_{A}, R_{C}, R_{T}\right)$, where $R_{A}$ reflects seismicity triggered by aseismic processes, $R_{C}$ represents a coseismically-triggered component (i.e., earthquakes triggered by other earthquakes), and $R_{T}$ is triggered by long-term tectonic loading. We assume that 
$R_{T}$ is small relative to $R_{A}$ if an aseismic deformation/fluid-flow transient is occurring and therefore combine it with $R_{A}$, so that $R(t, x) \approx f\left(R_{A}, R_{C}\right)$. In previous studies, the ETAS model and the rate-state model have each been used to investigate both $R_{A}$ and $R_{C}$.

\subsection{ETAS model}

The space-time ETAS model is a point process model that represents the seismicity rate $R(t, x, y)$ as a summation of the aftershock sequences produced by each event prior to time $t$ plus a time-independent background seismicity rate $\mu$ [Ogata, 1998; Zhuang et al., 2005; Ogata and Zhuang, 2006]:

$R(t, x, y)=\mu(x, y)+\sum_{i: t_{i}<t} \kappa\left(M_{i}\right) \cdot \psi\left(t-t_{i}\right) \cdot f\left(x-x_{i}, y-y_{i} ; M_{i}\right)$

where

$$
\begin{aligned}
& \kappa(M)=K e^{\alpha\left(M-M_{c}\right)} \\
& \psi(t)=\frac{p-1}{c}\left(1+\frac{t}{c}\right)^{-p} \\
& f(x, y ; M)=\frac{q-1}{\pi d e^{\eta\left(M-M_{c}\right)}}\left(1+\frac{x^{2}+y^{2}}{d e^{\eta\left(M-M_{c}\right)}}\right)^{-q}
\end{aligned}
$$

The function $\kappa(M)$ is the expected number of events triggered by an earthquake of magnitude $M$ and involves the aftershock productivity $K$ and scaling parameter $\alpha$, the function $\psi(t)$ is the probability density function form of the modified Omori law and is specified by the Omori decay parameters $c$ and $p$ [Omori, 1894; Utsu, 1961], and the function $f(x, y ; M)$ describes the spatial distribution of the events triggered by an earthquake of magnitude $M$, specified by the parameters $d, q$, and scaling parameter $\eta$. The ETAS parameters $\mu, K, c, p, \alpha, d, q$, and $\eta$ are generally obtained using maximum likelihood estimation from the observed occurrence times $t_{i}$ and magnitudes $M_{i}$ of earthquakes in a catalog with a magnitude of completeness $M_{c}$ [Ogata and Zhuang, 2006]. 


\subsection{Rate- and state-dependent friction model}

In the rate- and state-dependent friction model, the seismicity rate $R$ is a function of the stressing rate $\dot{S}$ acting on a population of faults governed by rate- and statedependent friction [Dieterich, 1994]:

$$
\begin{aligned}
& R=\frac{r}{\gamma \dot{S}_{r}} \\
& d \gamma=\frac{d t}{A \sigma}(1-\dot{S})
\end{aligned}
$$

where $r$ is a steady-state reference seismicity rate associated with a reference stressing rate $\dot{S}_{r}, \dot{S}$ is the modified Coulomb stressing rate, $\gamma$ is a state variable, and $A$ is a fault constitutive parameter. We assume the normal stress $\sigma$ and therefore the frictional parameter $A \sigma$ remain constant.

\subsection{Combined ETAS/rate-state model}

By examining how the ETAS and rate-state model parameters changed during periods of high stressing rate, Llenos et al. [2009] determined that aseismic transients primarily increase the background seismicity rate (i.e., ETAS parameter $\mu$ ) while other aftershock parameters such as productivity $K$ remain relatively unaffected by the increase in stressing rate. The seismicity rate $R$ can then be (approximately) modeled as a linear combination of the aseismically-triggered component $R_{A}$ and the coseismically-triggered component $R_{C}$ :

$$
R(t)=R_{A}(t)+R_{C}(t) \approx R_{A}(t)+\sum_{t_{i} \leq t} \frac{K e^{\alpha\left(M_{i}-M_{c}\right)}}{\left(t-t_{i}+c\right)^{p}}
$$

where $R_{C}$ is represented by the ETAS model, and $R_{A}$ is essentially a time-dependent version of $\mu$ that will reflect the variations in seismicity rate triggered by transients. We approximate $R_{A}$ by subtracting out an ETAS-predicted rate from the observed rate $R$ in a catalog. We then directly relate our estimate of $R_{A}$ to an aseismic stressing rate $\dot{S}_{A}$ through the rate-state model equations. We utilize the space-time version of the ETAS model [Ogata and Zhuang, 2006], so that the model becomes: 


$$
\begin{aligned}
& R_{A}(t, x, y)=R(t, x, y)-R_{C}(t, x, y)=R(t, x, y)- \\
& \sum_{i: t_{i}<t} K e^{\alpha\left(M_{i}-M_{c}\right)} \cdot \frac{p-1}{c}\left(1+\frac{t-t_{i}}{c}\right)^{-p} \cdot \frac{q-1}{\pi d e^{\eta\left(M_{i}-M_{c}\right)}}\left(1+\frac{\left(x-x_{i}\right)^{2}+\left(y-y_{i}\right)^{2}}{d e^{\eta\left(M_{i}-M_{c}\right)}}\right)^{-q}=\frac{r}{\dot{S}_{r} \gamma} \\
& d \gamma=\frac{d t}{A \sigma}\left[1-\gamma\left(\dot{S}_{A}+\dot{S}_{p}\right)\right]
\end{aligned}
$$

where $\dot{S}_{p}$ is the background plate tectonic stressing rate. This combined model of seismicity rate now reduces the impact of aftershock sequences on the estimation of $R_{A}$ by using ETAS to model $R_{C}$ and provides a way to quantitatively relate seismicity rate variations to stressing rate variations.

\subsection{Extended Kalman filter algorithm}

We incorporate the aseismically-triggered rate $R_{A}$ into a state-space model, which describes a system using a state vector that evolves over time and can be related to observable data. Our state-space model consists of a non-linear measurement equation that relates the observations $\mathbf{d}_{k}$ to the state vector $\mathbf{x}_{k}$ at each time step $k$ :

$\mathbf{d}_{k}=\mathbf{h}_{k}\left(\mathbf{x}_{k}\right)+\omega_{k}, \omega_{k} \sim N\left(0, \mathbf{R}_{k}\right)$

and a non-linear state transition equation that describes how the state vector evolves over time:

$\mathbf{x}_{k+1}=\mathbf{t}\left(\mathbf{x}_{k}\right)+\delta_{k+1}, \quad \delta_{k+1} \sim N\left(0, \mathbf{Q}_{k+1}\right)$

Our state variables $\mathbf{x}_{k}$ consist of the long-term tectonic loading rate $\dot{S}_{p}$, the aseismic stressing rate $\dot{S}_{A}$, and the logarithm of the rate-state seismicity state variable $\gamma$ to ensure positivity. We also divide the region up into $N$ spatial boxes and estimate the state variables in each one, so that the full state vector is:

$$
\begin{gathered}
\mathbf{x}_{k}=\left[\dot{S}_{p_{1}}\left(t_{k}\right), \dot{S}_{A_{1}}\left(t_{k}\right), \ln \gamma_{1}\left(t_{k}\right), \dot{S}_{p_{2}}\left(t_{k}\right), \dot{S}_{A_{2}}\left(t_{k}\right), \ln \gamma_{2}\left(t_{k}\right), \ldots\right. \\
\left.\dot{S}_{p_{N}}\left(t_{k}\right), \dot{S}_{A_{N}}\left(t_{k}\right), \ln \gamma_{N}\left(t_{k}\right)\right]
\end{gathered}
$$

The variables $\dot{S}_{A}$ and $\ln (\gamma)$ are modeled as random walk processes with scale parameters of $\tau$ and $\varepsilon$ respectively. The data vector $\mathbf{d}_{k}$ consists of the aseismically-triggered rate $R_{A}$ estimated in each spatial box and is related to the state variables through the measurement 
matrix $\mathbf{h}_{k}$, which is based on the rate-state model (Eq. 5). The measurement and process noises $\omega_{k}$ and $\delta_{k+1}$ are assumed to be Gaussian and described by the data and process covariance matrices $\mathbf{R}_{k}$ and $\mathbf{Q}_{k+1}$ respectively. The data covariance matrix $\mathbf{R}_{k}$ is assumed to be known only up to a scalar multiplier $\xi$, such that $\mathbf{R}_{k}=\xi^{2} \Sigma_{k}$, where $\Sigma_{k}$ is a matrix that contains any known correlations between the spatial cells and components [Segall and Matthews, 1997]. In our case, we assume $\xi \sim 1$ and estimate $\Sigma_{k}$ a priori based on the variance of the data vector during stable time periods.

The system is solved using an extended Kalman filter algorithm [e.g., Gelb, 1974; Anderson and Moore, 2005]. We first make a priori estimates of the state vector $\mathbf{x}_{010}$ and covariance $\Sigma_{0 \mid 0}$ and update them with the first observations to obtain $\mathbf{x}_{1 \mid 1}$ and $\Sigma_{1 \mid 1}$. We then use the filter prediction equations to estimate the state vector and covariance at the next time step $k+1$ :

$\mathbf{x}_{k+1 \mid k}=\mathbf{t}\left(\mathbf{x}_{k \mid k}\right)+\delta_{k+1}, \quad \delta_{k+1} \sim N\left(0, \mathbf{Q}_{k+1}\right)$

$\boldsymbol{\Sigma}_{k+1 \mid k}=\mathbf{T}_{k} \boldsymbol{\Sigma}_{k \mid k} \mathbf{T}_{k}^{T}+\mathbf{Q}_{k+1}$

where $\mathbf{T}$ is the Jacobian of the non-linear state transition model $\mathbf{t}$, which incorporates the rate-state evolution equation (Eq. 6):

$\mathbf{T}_{k}=\left.\frac{\partial \mathbf{t}(\mathbf{x})}{\partial \mathbf{x}}\right|_{\mathbf{x}_{k}}$

and the elements of the $3 N \times 3 N$ process covariance matrix $\mathbf{Q}_{k+1}$ are determined by the properties of the random walks used to model the state variables $\dot{S}_{A}$ and $\ln (\gamma)$ :

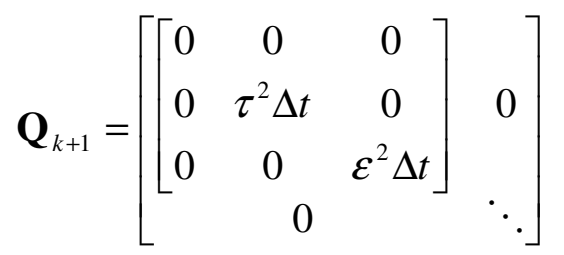

The predictions are then compared with the observations at the current time step and updated using the filter update equations:

$$
\begin{aligned}
& \left.\mathbf{x}_{k+11 k+1}=\mathbf{x}_{k+11 k}+\mathbf{g}_{k+1} \mid \mathbf{d}_{k+1}-\mathbf{h}\left(\mathbf{x}_{k+11 k}\right)\right] \\
& \boldsymbol{\Sigma}_{k+11 k+1}=\left[\mathbf{I}-\mathbf{g}_{k+1} \mathbf{H}_{k+1}\right] \boldsymbol{\Sigma}_{k+11 k}
\end{aligned}
$$


where the Kalman gain $\mathbf{g}$ is computed by:

$$
\mathbf{g}_{k+1}=\boldsymbol{\Sigma}_{k+11 k} \mathbf{H}_{k+1}^{T}\left[\mathbf{H}_{k+1} \boldsymbol{\Sigma}_{k+11 k} \mathbf{H}_{k+1}^{T}+\mathbf{R}_{k+1}\right]^{-1}
$$

and $\mathbf{H}$ is the Jacobian of the non-linear measurement matrix $\mathbf{h}$, which incorporates the rate-state model equation (Eq. 5):

$$
\mathbf{H}_{k}=\left.\frac{\partial \mathbf{h}(\mathbf{x})}{\partial \mathbf{x}}\right|_{\mathbf{x}_{k}}
$$

These prediction and update steps are iterated forward through the entire data set, resulting in estimates of the state variables $\mathbf{x}_{k \mid k}$ at each time step $k$ given the data up to time step $k$. The filter can be run backwards in time in a process known as smoothing to obtain a backsmoothed estimate of the state variables (i.e., $\mathbf{x}_{k \mid N}$, or estimates of $\mathbf{x}$ at time step $k$ given the entire data set).

\subsection{Likelihood calculations}

There are a total of 11 time-independent parameters in our model, seven of which are the space-time ETAS parameters $(K, c, p, \alpha, d, q$, and $\eta)$, two of which are rate-state parameters $(A \sigma$ and $r$ ), and two of which are filter hyper-parameters ( $\tau$ and $\varepsilon$ ). We first optimize the model over the set of ETAS parameters $\phi$ given a history of occurrence $H_{t}$ using a point process likelihood function [Ogata, 1998; Daley and Vere-Jones, 2002]:

$$
\ln L\left(\phi \mid H_{t}\right)=\sum_{i=1}^{n} \ln R\left(t_{i}, x_{i}, y_{i} \mid H_{t}\right)-\int_{0}^{T} \iint_{A} R\left(t, x, y \mid H_{t}\right) d A d t
$$

While this likelihood computation works well to estimate the ETAS parameters, it is relatively insensitive to changes in the non-ETAS parameters. Based on synthetic tests, it is preferable to optimize the set of non-ETAS parameters $\theta$ by computing a likelihood based on prediction-error decomposition [Harvey, 1989; Segall and Matthews, 1997]. For Gaussian data, the likelihood can be expressed as:

$$
\log L(\theta)=-\frac{1}{2}\left(N_{d}-N_{d} \log N_{d}\right)-\frac{1}{2} \sum_{k=1}^{N_{e}} \log \left|\mathbf{V}_{k}\right|-\frac{1}{2} N_{d} \log \left[\sum_{k=1}^{N_{e}} \mathbf{v}_{k}^{T} \mathbf{V}_{k}^{-1} \mathbf{v}_{k}\right]
$$

where $N_{d}$ is the total number of observations, $\boldsymbol{v}_{k}$ is the innovation at each time step $k$ : 
$\mathbf{v}_{k}=\mathbf{d}_{k}-\hat{\mathbf{d}}_{k \mid k-1}=\mathbf{d}_{k}-\mathbf{h}\left(\mathbf{x}_{k \mid k-1}\right)$

and $\mathbf{V}_{k}$ is the variance of the $k^{\text {th }}$ innovation:

$$
\mathbf{V}_{k}=\mathbf{H}_{k} \boldsymbol{\Sigma}_{k \mid k-1} \mathbf{H}_{k}^{T}+\mathbf{R}_{k}
$$

This likelihood function also employs a maximum likelihood estimate for the data covariance scalar multiplier $\xi$ :

$\hat{\xi}^{2}=\frac{1}{N_{d}} \sum \mathbf{v}_{k}^{T} \mathbf{V}_{k}^{-1} \mathbf{v}_{k}$

With these equations, we then grid-search over multiple non-ETAS parameter sets to determine their maximum likelihood estimate, with initial grid sizes of a factor of 10 for each parameter. A fundamental assumption we have made in this initial implementation is that the data and errors are Gaussian distributed, which is likely incorrect in that earthquake statistics typically involve non-Gaussian distributions. Future implementations could incorporate non-Gaussian error distributions by utilizing particle filter methods [e.g., Fukuda and Johnson, 2008; Werner, 2008; Werner et al., 2009].

\subsection{Summary}

Our complete algorithm can be summarized as follows:

0. Determine magnitude of completeness for the catalog.

1. Optimize the ETAS parameters for the catalog using a space-time ETAS algorithm [Zhuang et al., 2005; Ogata and Zhuang, 2006].

2. Calculate $R_{A}$ to be used as the data vector for the filter by subtracting the ETASpredicted rate from the observed (binned) seismicity rate in each of $N$ spatial boxes.

3. Given a set of non-ETAS parameters, run the extended Kalman filter to obtain the time history of the state variables.

4. Compute the Gaussian likelihood associated with the set of non-ETAS parameters.

5. Repeat steps 3 and 4 as a grid-search for different parameter sets to obtain maximum likelihood estimates of the non-ETAS parameters. 


\section{Synthetic test}

To test the validity of our algorithm, we generate a synthetic catalog of events using known model parameters and a stressing rate history that we will attempt to recover. We subdivide a $30 \mathrm{~km}$ by $30 \mathrm{~km}$ region into 9 spatial boxes (Fig. 1a) and impose a factor of 10 increase in stressing rate above a background rate of $0.1 \mathrm{MPa} / \mathrm{yr}$ in the center box (Box 5). The stressing rate in the other boxes remains constant at the background rate (Fig. 2a). Given these stressing rate histories, we use the rate-state equations (Eq. 5-6) to calculate associated background seismicity rate histories, which are used in an ETAS simulator [Felzer et al., 2002; Helmstetter and Sornette, 2002, 2003b] to generate a synthetic catalog with a magnitude of completeness $M_{C}=0$. Fig. 1 shows the catalog event locations, magnitudes and times of occurrence. Occurrence times were binned in time windows of 1 day to obtain seismicity rates. The seismicity rate variations in both space and time due to the transient are not easily seen because the catalog is dominated by the aftershocks of the largest events (Fig. 2b). The anomalous seismicity triggered by the transient only becomes readily apparent following the removal of the ETAS-predicted rate (Fig. 2c).

\subsection{Parameter estimation}

We estimate the best-fitting ETAS parameters using the space-time algorithm of Ogata and Zhuang [2006]. The parameters used in the simulator were $K=4.5 \mathrm{e}-4$ events/day $/ \mathrm{deg}^{2}, \alpha=0.8, p=1.2, c=0.0001$ days, $d=0.001 \mathrm{deg}^{2}, q=3$, and $\eta=0.3$. The estimates of these parameters from the Ogata and Zhuang [2006] algorithm were $K=$ 0.15 events/day $/ \mathrm{deg}^{2}, \alpha=1.8, p=1.2, c=0.0001$ days, $d=0.5 \mathrm{e}-8 \mathrm{deg}^{2}, q=1.35$, and $\eta=$ 0.58. A different form for the cluster size factor $\kappa(M)$ (Eq. 2) is used to generate the synthetic catalog [Felzer et al., 2002; Helmstetter and Sornette, 2003b] than the form utilized in the Ogata and Zhuang [2006] algorithm, resulting in differences between the true and estimated values of the parameters $K$ and $\alpha$. Differences in the estimates of the spatial scaling parameters $d, q$, and $\eta$ are due to the fact that the spatial probability density function (Eq. 4) used by the simulator also has a slightly different form than that 
used by the Ogata and Zhuang [2006] estimation algorithm. However, both the simulation and estimation algorithms employed the same temporal function (Eq. 3) based on the modified Omori law, and the true values for $p$ and $c$ are recovered by the estimation algorithm even though the assumption of constant background seismicity rate is violated. Thus, the space-time ETAS parameters appear to be well resolved by the estimation algorithm.

The ETAS-predicted seismicity rate is subtracted from the binned seismicity rate to obtain the data vector (Eq. 8, 10), which is the input for the extended Kalman filter. We ran the filter with a number of different values for the non-ETAS parameters $(r, A \sigma$, $\tau$, and $\varepsilon$ ) and calculated the Gaussian likelihood for each filter run (Eq. 22). Again, the fundamental assumption made here is that the data and errors are Gaussian distributed (see Section 2.5). While the reference seismicity rate $r$ was well-resolved by this gridsearch procedure, we observed a trade-off in likelihood between the parameters $A \sigma$ and $\tau$, suggesting there is little constraint in $A \sigma$. Therefore, we fixed $A \sigma$ to be the true value $(0.001 \mathrm{MPa})$ and grid-searched over $\tau$ and $\varepsilon$, the scaling parameters for the random walk processes used to model $\dot{S}_{A}$ and $\ln (\gamma)$ respectively.

There are two further constraints that we employ to select appropriate values for $\tau$ and $\varepsilon$. The first constraint comes from enforcing consistency between the filter's estimates of the state variables $\dot{S}_{A}$ and $\ln (\gamma)$. Because they are modeled as stochastic processes with noise specified by covariance matrix $\mathbf{Q}_{k}$ (Eq. 11), they do not have to strictly obey Equations 5-6. Thus, the filter estimate of total stressing rate $\dot{S}$ (the sum of the estimates of $\dot{S}_{A}$ and $\dot{S}_{p}$ ) can be integrated using the rate-state equations (Eq. 5-6) to produce an estimate of $\gamma$ that is not identical to the filter estimate for $\gamma$. These two estimates of $\gamma$ ideally should closely agree with one another. This places a constraint on the value of $\tau$ (i.e., the temporal smoothing of $\dot{S}_{A}$ ), since it must be large enough to allow enough variation in $\dot{S}$ for it to integrate to $\gamma$. However, if $\tau$ is too large (i.e., $\dot{S}_{A}$ too 
rough), the error covariance matrix $\Sigma$ becomes non-positive semi-definite, and the prediction step (Eq. 14) can no longer be computed.

A second constraint is employed to help choose a value for $\varepsilon$. Fig. 3 shows the Gaussian likelihood and maximum likelihood estimate of the data covariance multiplier $\hat{\xi}^{2}$ for various values of $\varepsilon$, calculated using Eq. 22 and 25. The maximum likelihood occurs when $\varepsilon=0.79$ (Fig. 3a); however, at this value of $\varepsilon, \hat{\xi}^{2}$ is significantly less than 1 (Fig. 3b). Because we estimate $\mathbf{R}_{k}$ a priori based on the variance of the data vector, $\hat{\xi}^{2}$ should be $\sim 1$. Values other than 1 will over-fit or under-fit the data. Therefore, we choose $\varepsilon$ such that $\hat{\xi}^{2} \sim 1$. Moreover, at higher values of $\varepsilon$, the filter estimate for $\dot{S}$ fails to integrate to match the filter estimate for $\gamma$ as well as at smaller values of $\varepsilon$ because the stressing rate estimate cannot vary enough to match the variance in $\gamma$ (Fig. 4a). Additionally, higher values of $\varepsilon$ ultimately over-fit the data (Fig. 4b). While the filter fits the smaller peaks in the data vector well, it over-predicts the largest peak. Smaller values of $\varepsilon$ smooth out the smaller peaks in seismicity rate but end up fitting the largest peak well. Therefore, our preferred value for $\varepsilon$ is 0.16 , for which $\hat{\xi}^{2} \sim 1$, rather than the MLE of 0.79 . The stressing rate estimate results show that the estimate for $\dot{S}$ with $\varepsilon=0.16$ actually comes closer to recovering the true $\dot{S}$ than the MLE value of $\varepsilon$ (Fig. 4c).

To summarize, of the 11 model parameters used in our algorithm, the seven space-time ETAS parameters are well-resolved by maximizing the point process likelihood function used in the Ogata and Zhuang [2006] algorithm. The two random walk scaling parameters $\tau$ and $\varepsilon$ can be optimized using a Gaussian likelihood function subject to constraints. The rate-state parameters $r$ and $A \sigma$ however are not well constrained by either likelihood function and thus should be fixed a priori.

\subsection{Synthetic test results}

Fig. 5 shows the resulting filter estimates of $\dot{S}$ for each box using $\varepsilon=0.16$. The transient is clearly identifiable in Box 5, in both the forward and backsmoothed filter 
estimates. Although the filter-estimated peak stressing rate is not quite as large as the true stressing rate, it is still within a factor of 2-3. The forward filter estimate of the onset of the transient is also delayed compared to the true onset, although the backsmoothed estimate mitigates this effect somewhat. Clearly, the filter is able to detect when and in which region the transient is occurring (Fig. 6). This is an encouraging result because the jump in stressing rate was only a factor of 10 while the stressing rate jumps over the plate tectonic rate that occur during slow earthquakes and magma intrusions are likely to be many orders of magnitude [Thatcher, 2001; Toda et al., 2002; Lohman and McGuire, 2007].

\section{Data Analysis: Salton Trough}

We next apply our algorithm to real earthquake data from the Salton Trough in southern California. In the Salton Trough, a transition occurs from a divergent plate boundary setting in the Gulf of California to the south, to the San Andreas strike-slip fault system to the north. The region is characterized by high heat flow [Kisslinger and Jones, 1991], which potentially acts to subdue aftershock activity [Ben-Zion and Lyakhovsky, 2006]. A high rate of earthquake swarm activity has been observed [e.g., Richter, 1958; Brune and Allen, 1967; Hill et al., 1975; Johnson and Hadley, 1976; Lohman and McGuire, 2007; Roland and McGuire, 2009], possibly driven by magmatic intrusion [Hill, 1977] or aseismic fault creep [Lohman and McGuire, 2007; Roland and McGuire, 2009]. A number of aseismic transients have also been geodetically detected in this region, including afterslip following the 1987 M6.6 Superstition Hills earthquake [Williams and Magistrale, 1989], creep events on the Superstition Hills fault [Wei et al., 2009], and aseismic creep on the Obsidian Buttes fault [Lohman and McGuire, 2007].

\subsection{Data binning}

We analyze a catalog of $M \geq 1.5$ earthquakes that occurred in the Salton Trough from February 1990 to August 2009. Because of the partial derivatives involved in setting up the state-space model equations (e.g., Eq. 15 and 20), we need to be able to 
resolve the background seismicity rate in each space-time window. Therefore we divide the region up into 4 spatial boxes (Fig. 7) and bin the occurrence times into time windows of 20 days to obtain seismicity rates in each box. This time window is necessary to obtain enough earthquakes in each bin to resolve the background rate.

\subsection{Parameter estimation}

We first fit the space-time ETAS model to the 2005 M5.1 Obsidian Buttes earthquake using the Ogata and Zhuang [2006] algorithm, in an attempt to account for as much of the aftershock behavior as possible. From the Ogata and Zhuang [2006] algorithm, the MLE for the ETAS parameters are $K=0.53$ events $/$ day $/ \mathrm{deg}^{2}, \alpha=0.92, p=$ 1.3, $c=0.01$ days, $d=4.8 \mathrm{e}-5 \mathrm{deg}^{2}, q=2.63$, and $\eta=0.23$. However, the data vector formed using these parameters resulted in a number of negative seismicity rate values, primarily due to the estimate of $p$, which can lead to instabilities in the filter due to the assumption of a Gaussian error distribution. Therefore, we instead use the ordinary-time ETAS parameters ( $K=0.61$ events/day/deg ${ }^{2}, \alpha=0.88, p=1.1$, and $c=0.001$ days).

The ETAS-predicted rate is subtracted from the observed seismicity rate to form the data vector, and the data covariance $\mathbf{R}_{\mathrm{k}}$ is estimated. Again because of the tradeoff between the parameters $\tau$ and $A \sigma$, we fix $A \sigma$ to $1 \mathrm{MPa}$, which is roughly consistent with faults under hydrostatic conditions at a depth of $\sim 4 \mathrm{~km}$, the depth at which the Obsidian Buttes swarm occurred [Chester and Higgs, 1992; Blanpied et al., 1998; Lohman and McGuire, 2007]. We then grid-search over values of $\tau$ and $\varepsilon$. Using the constraint that the integral of the filter estimate of stressing rate must be consistent with the filter estimate of $\gamma$, we choose a value of $\tau=2.5 \mathrm{e}-4$, and maximize the likelihood over values of $\varepsilon$ (Fig. 8). The maximum likelihood estimate occurs when $\varepsilon=0.5$ (Fig. 8a) but again, as in the synthetic test, at this value the data covariance multiplier $\hat{\xi}^{2}$ is significantly less than 1 (Fig. 8b), and the filter over-fits the data. Our preferred value is $\varepsilon=0.04$, for which $\hat{\xi}^{2} \sim 1$, and the largest peaks in the data are better fit. 


\section{$\underline{4.3 \text { Results }}$}

The stressing rate estimates for each box using $\varepsilon=0.04$ are shown in Figure 9. Figure 10 plots the forward stressing rate estimate for each box on top of one another, illustrating the filter's ability to detect when and in which box the largest transient in the region occurs. The largest anomaly occurs in Box 2 and can be associated with a geodetically-observed 2005 shallow aseismic creep event on the Obsidian Buttes fault that triggered an earthquake swarm [Lohman and McGuire, 2007]. The peak forward estimate of stressing rate is $0.042 \pm 0.004 \mathrm{MPa} /$ day and the backsmoothed estimate is $0.022 \pm 0.006 \mathrm{MPa} / \mathrm{day}$, roughly two orders of magnitude above tectonic loading.

The second largest signal also occurred in Box 2 and is related to the Bombay Beach earthquake swarm that occurred in March 2009. The swarm consisted of $\sim 100$ s of events, the largest of which was a M4.8 that occurred three days after the swarm initiated. Other small anomalies in Boxes 2 and 4 in May 2003 may be related to an earthquake swarm that occurred in the Imperial fault zone (located near the boundary of the two boxes) [Roland and McGuire, 2009]. Smaller peaks in Box 2 also can be associated with earthquake swarms that occurred in the Brawley seismic zone in 1996, 1998, and 2008 [Southern California Earthquake Center, http://www.data.scec.org/monthly/index.php].

\section{Discussion}

Our results highlight the need for a time-dependent background seismicity rate to account for variations in seismicity rate due to aseismic processes. Fig. 11 compares the observed cumulative number of events in the Salton Trough catalog with the predicted number of events from optimizing the space-time ETAS model to the part of the catalog that occurred prior to the 2005 Obsidian Buttes swarm and the predicted number of events from the filter estimate of seismicity rate. We transform the occurrence times $t_{i}$ of the events in the catalog with the theoretical cumulative function $\tau_{i}=\int_{0}^{i} \lambda(s) d s$, where $\lambda$ is the predicted seismicity rate from either ETAS or the filter [Ogata, 1988, 2005]. A plot of the cumulative number of events vs. transformed time should be linear if the seismicity in the catalog is well described by a particular model. Positive (or negative) 
deviations from this trend indicate that the model is under-predicting (or over-predicting) the amount of seismicity. Fig. 11 shows that with the ETAS model, a significant positive deviation from this trend occurs near the beginning of the Obsidian Buttes swarm, suggesting that anomalous seismicity is occurring that cannot be explained by the ETAS model alone. The filter prediction however is able to match the observed seismicity well. Therefore, the seismicity rate anomalies that appear with respect to the space-time ETAS model, which utilizes a time-independent background seismicity rate, can be accounted for by the time-dependent background seismicity rate produced by our filter algorithm.

To validate the estimates of $\dot{S}$ obtained from these seismicity rate variations, we can compare our peak stressing rate estimate for the 2005 Obsidian Buttes aseismic transient to an estimate based on a geodetically-derived slip model of the deformation inverted from InSAR data [Lohman and McGuire, 2007]. The seismicity triggered by this transient occurred primarily in the depth range of 4-6 km. We calculate the Coulomb stress change [King et al., 1994; Lin and Stein, 2004; Toda et al., 2005] at this depth range due to aseismic slip on the shallow part of the fault (Fig. 12). The average total Coulomb stress change on this part of the fault is 0.6 MPa. Based on GPS line-length change data, the transient lasted 1-10 days [Lohman and McGuire, 2007]. Using this range of durations, the average stressing rate during the transient then becomes $\sim 0.06-0.6$ $\mathrm{MPa} /$ day. For a duration of 5 days (which appears to best describe the GPS data), the average stressing rate is $0.12 \mathrm{MPa} /$ day. From our filter estimate, we obtain a peak stressing rate of $\sim 0.04 \mathrm{MPa} /$ day (in the forward filter) and $\sim 0.02 \mathrm{MPa} /$ day (in the backsmoothed filter) (Fig. 9). Our estimates from inverting the seismicity catalog are within a factor of 5 of the average stressing rate derived from the geodetic data. If we take the duration of the transient to match the time step in our filter (20 days) then the estimates agree extremely well (0.03 MPa/day vs. 0.02-0.04 MPa/day). Given that stressing rate increases are likely to be many orders of magnitude over background plate tectonic rates [Thatcher, 2001; Toda et al., 2002; Lohman and McGuire, 2007], the Salton Trough example demonstrates the feasibility of utilizing our approach to both detect and constrain the magnitude of stressing rate transients. 


\section{Conclusion}

We have developed a technique to detect aseismic transients in time and space from earthquake catalog data by combining the ETAS and rate-state models of seismicity rate into a single data assimilation algorithm to invert catalogs for stressing rate variations. We applied it to a synthetic test and successfully detected an aseismic transient that involved a factor of 10 increase in stressing rate. We then applied it to a catalog from the Salton Trough in California, and successfully detected the onset and constrained the absolute magnitude of the largest aseismic transient in a 20 year catalog to within a factor of five of the stressing rate estimated with geodetic data.

Overall, the synthetic test and Salton Trough results suggest that our algorithm is a feasible way to detect aseismic stressing rate transients strictly from seismicity catalog data. This method may ultimately enable aseismic transient detection in regions lacking good geodetic data resolution, such as the (offshore) updip part of subduction zone faults, and in time periods prior to the widespread availability of geodetic data. Additionally, a seismicity based approach may be more sensitive to small (M4-5) and/or shallow slowslip transients that are not detected by even dense geodetic networks such as the Plate Boundary Observatory [Wei et al., 2009]. The results suggest that our seismicity inversion method provides an accurate way to detect and locate transient deformation strictly from seismicity catalogs and can constrain the absolute magnitude of stressing rate variations.

\section{Acknowledgments}

We thank Y. Ogata and J. Zhuang for help with the ETAS modeling, R. Lohman for help with the Obsidian Buttes slip model, and J. Lin for help with the Coulomb calculations. The earthquake catalog was obtained from the Southern California Earthquake Data Center. Map figures were prepared using the Generic Mapping Tools software freely distributed by Wessel and Smith [1998]. This work was supported by NSF EAR grant \#0738641. 


\section{References}

Anderson, B. D. O., and J. B. Moore (2005), Optimal Filtering, Dover, Mineola, NY.

Ben-Zion, Y., and V. Lyakhovsky (2006), Analysis of aftershocks in a lithospheric model with seismogenic zone governed by damage rheology, Geophys. J. Int., 165, 197-210, doi:10.1111/j.1365-246X.2006.02878.x.

Blanpied, M. L., C. J. Marone, D. A. Lockner, J. D. Byerlee, and D. P. King (1998), Quantitative measure of the variation in fault rheology due to fluid-rock interactions, $J$. Geophys. Res., 103, 9691-9712.

Brune, J. N., and C. R. Allen (1967), A low-stress-drop, low-magnitude earthquake with surface faulting: The Imperial, California, earthquake of March 4, 1966, Bull. Seis. Soc. Am., 57, 501-514.

Chester, F. M., and N. G. Higgs (1992), Multimechanism friction constitutive model for ultrafine quartz gouge at hypocentral conditions, J. Geophys. Res., 97, 1859-1870.

Daley, D. J., and D. Vere-Jones (2002), An Introduction to the Theory of Point Processes, vol. $1,2^{\text {nd }}$ ed., Springer-Verlag, New York.

Delahaye, E. J., J. Townend, M. E. Reyners, and G. Rogers (2009), Microseismicity but no tremor accompanying slow slip in the Hikurangi subduction zone, New Zealand, Earth Planet. Sci. Lett., 277, 21-28, doi:10.1016/j.eps1.2008.09.038.

Dieterich, J. (1994), A constitutive law for rate of earthquake production and its application to earthquake clustering, J. Geophys. Res., 99, 2601-2618.

Dieterich, J., V. Cayol, and P. Okubo (2000), The use of earthquake rate changes as a stress meter at Kilauea volcano, Nature, 408, 457-460.

Felzer, K. R., T. W. Becker, R. E. Abercrombie, G. Ekström, and J. R. Rice (2002), Triggering of the $1999 \mathrm{M}_{\mathrm{W}} 7.1$ Hector Mine earthquake by aftershocks of the $1992 \mathrm{M}_{\mathrm{W}}$ 7.3 Landers earthquake, J. Geophys. Res., 107(B9), 2190, doi:10.1029/2001JB000911.

Fukuda, J., and K. M. Johnson (2008), A fully Bayesian inversion for spatial distribution of fault slip with objective smoothing, Bull. Seis. Soc. Am., 98, 1128-1146, doi:10.1785/0120070194.

Gelb, A. (1974), Applied Optimal Estimation, MIT Press, Cambridge, MA.

Hainzl, S., and Y. Ogata (2005), Detecting fluid signals in seismicity data through statistical earthquake modeling, J. Geophys. Res., 110, doi:10.1029/2004JB003247. 
Harvey, A. C. (1989), Forecasting, Structural Time Series Models and the Kalman Filter, Cambridge Univ Press, New York.

Helmstetter, A. (2003), Is earthquake triggering driven by small earthquakes?, Phys. Rev. Lett., 91, doi:10.1103/PhysRevLett.91.058501.

Helmstetter, A., and D. Sornette (2002), Subcritical and supercritical regimes in epidemic models of earthquake aftershocks, J. Geophys. Res., 107(B10), 2237, doi: $10.1029 / 2001$ JB001580.

Helmstetter, A., and D. Sornette (2003a), Båth's law derived from the Gutenberg-Richter law and from aftershock properties, Geophys. Res. Lett., 30, doi:10.1029/2003GL018186.

Helmstetter, A., and D. Sornette (2003b), Importance of direct and indirect triggered seismicity in the ETAS model of seismicity, Geophys. Res. Lett., 30(11), 1576, doi:10.1029/2003GL017670.

Hill, D. P. (1977), A model for earthquake swarms, J. Geophys. Res., 82, 1347-1352.

Hill, D. P., P. Mowinckel, and L. G. Peake (1975), Earthquakes, active faults and geothermal areas in the Imperial Valley, California, Science, 188, 1306-1308.

Johnson, C. E., and D. M. Hadley (1976), Tectonic implications of the Brawley earthquake swarm, Imperial Valley, California, January 1975, Bull. Seis. Soc. Am., 66, 1133-1144.

King, G. C. P., R. S. Stein, and J. Lin (1994), Static stress changes and the triggering of earthquakes, Bull. Seis. Soc. Am., 84, 935-953.

Kisslinger, C., and L. M. Jones (1991), Properties of aftershock sequences in southern California, J. Geophys. Res., 96, 11,947-11,958.

Lin, J. and R.S. Stein (2004), Stress triggering in thrust and subduction earthquakes, and stress interaction between the southern San Andreas and nearby thrust and strike-slip faults, J. Geophys. Res., 109, B02303, doi:10.1029/2003JB002607.

Llenos, A. L., J. J. McGuire, and Y. Ogata (2009), Modeling seismic swarms triggered by aseismic transients, Earth Planet. Sci. Lett., 281, 59-69, doi:10.1016/j.eps1.2009.02.011.

Lohman, R. B., and J. J. McGuire (2007), Earthquake swarms driven by aseismic creep in the Salton Trough, California, J. Geophys. Res., 112, B04405, doi:10.1029/2006JB004596. 
McGuire, J. J., M. S. Boettcher, and T. H. Jordan (2005), Foreshock sequences and shortterm earthquake predictability on East Pacific Rise transform faults, Nature, 434, doi:10.1038/nature03377.

Montgomery-Brown, E. K., P. Segall, and A. Miklius (2009), Kilauea slow slip events: Identification, source inversions, and relation to seismicity, J. Geophys. Res., 114, B00A03, doi:10.1029/2008JB006074.

Ogata, Y. (1988), Statistical models for earthquake occurrences and residual analysis for point processes, J. Am. Stat. Assoc., 83, 9-27.

Ogata, Y. (1998), Space-time point process models for earthquake occurrences, Ann. Inst. Statist. Math., 50, 379-402.

Ogata, Y. (2004), Space-time model for regional seismicity and detection of crustal stress changes, J. Geophys. Res., 109, B03308, doi:10.1029/2003JB002621.

Ogata, Y. (2005), Detection of anomalous seismicity as stress change sensor, J. Geophys. Res., 110, B05S06, doi:10.1029/2004JB003245.

Ogata, Y., and J. Zhuang (2006), Space-time ETAS models and an improved extension, Tectonophysics, 413, doi:10.1016/j.tecto.2005.10.016.

Omori, F. (1894), On the aftershocks of earthquakes, J. Coll. Sci. Imp. Univ. Tokyo, 7, 111-200.

Ozawa, S., H. Suito, and M. Tobita (2007), Occurrence of quasi-periodic slow-slip off the east coast of the Boso peninsula, Central Japan, Earth Planets Space, 59, 1241-1245.

Richter, C. F. (1958), Elementary Seismology, W. H. Freeman, San Francisco.

Roland, E., and J. J. McGuire (2009), Earthquake swarms on transform faults, Geophys. J. Int., 178, 1677-1690, doi:10.1111/j.1365-246X.2009.04214.X.

Segall, P., and M. Matthews (1997), Time dependent inversion of geodetic data, $J$. Geophys. Res., 102, 22,391-22,409.

Segall, P., E. K. Desmarais, D. Shelly, A. Miklius, and P. Cervelli (2006), Earthquakes triggered by silent slip events on Kilauea volcano, Hawaii, Nature, 442, doi:10.1038/nature04938.

Thatcher, W. (2001), Silent slip on the Cascadia subduction interface, Science, 292, doi:10.1126/science.1061770. 
Toda, S., R. S. Stein, and T. Sagiya (2002), Evidence from the AD 2000 Izu islands earthquake swarm that stressing rate governs seismicity, Nature, 419, 58-61.

Toda, S., R. S. Stein, K. Richards-Dinger and S. Bozkurt (2005), Forecasting the evolution of seismicity in southern California: Animations built on earthquake stress transfer, J. Geophys. Res., 110, B05S16, doi:10.1029/2004JB003415.

Utsu, T. (1961), A statistical study on the occurrence of aftershocks, Geophys. Mag., 30, 521-605.

Wei, M., D. Sandwell, and Y. Fialko (2009), A silent $M_{w} 4.7$ slip event of October 2006 on the Superstition Hills fault, southern California, J. Geophys. Res., 114, B07402, doi:10.1029/2008JB006135.

Wessel, P., and W. H. F. Smith (1998), New, improved version of generic mapping tools released, Eos Trans. AGU, 79(47), 579

Werner, M. J. (2008), On the fluctuations of seismicity and uncertainties in earthquake catalogs: Implications and methods for hypothesis testing, Ph.D. thesis, 308 pp., Univ. of Calif. Los Angeles, Los Angeles.

Werner, M. J., K. Ide, and D. Sornette (2009), Earthquake forecasting based on data assimilation: Sequential Monte Carlo methods for renewal processes, arXiv:0908.1516 [physics.geo-ph].

Williams, P. L., and H. W. Magistrale (1989), Slip along the Superstition Hills fault associated with the 24 November 1987 Superstition Hills, California, earthquake, Bull. Seis. Soc. Am., 79, 390-410.

Wolfe, C. J., B. A. Brooks, J. H. Foster, and P. G. Okubo (2007), Microearthquake streaks and seismicity triggered by slow earthquakes on the mobile south flank of Kilauea Volcano, Hawai'I, Geophys. Res. Lett., 34, L23306, doi:10.1029/2007GL031625.

Zhuang, J., C.-P. Chang, Y. Ogata, and Y.-I. Chen (2005), A study on the background and clustering seismicity in the Taiwan region by using point process models, $J$. Geophys. Res., 110, B05S18, doi:10.1029/2004JB003157. 

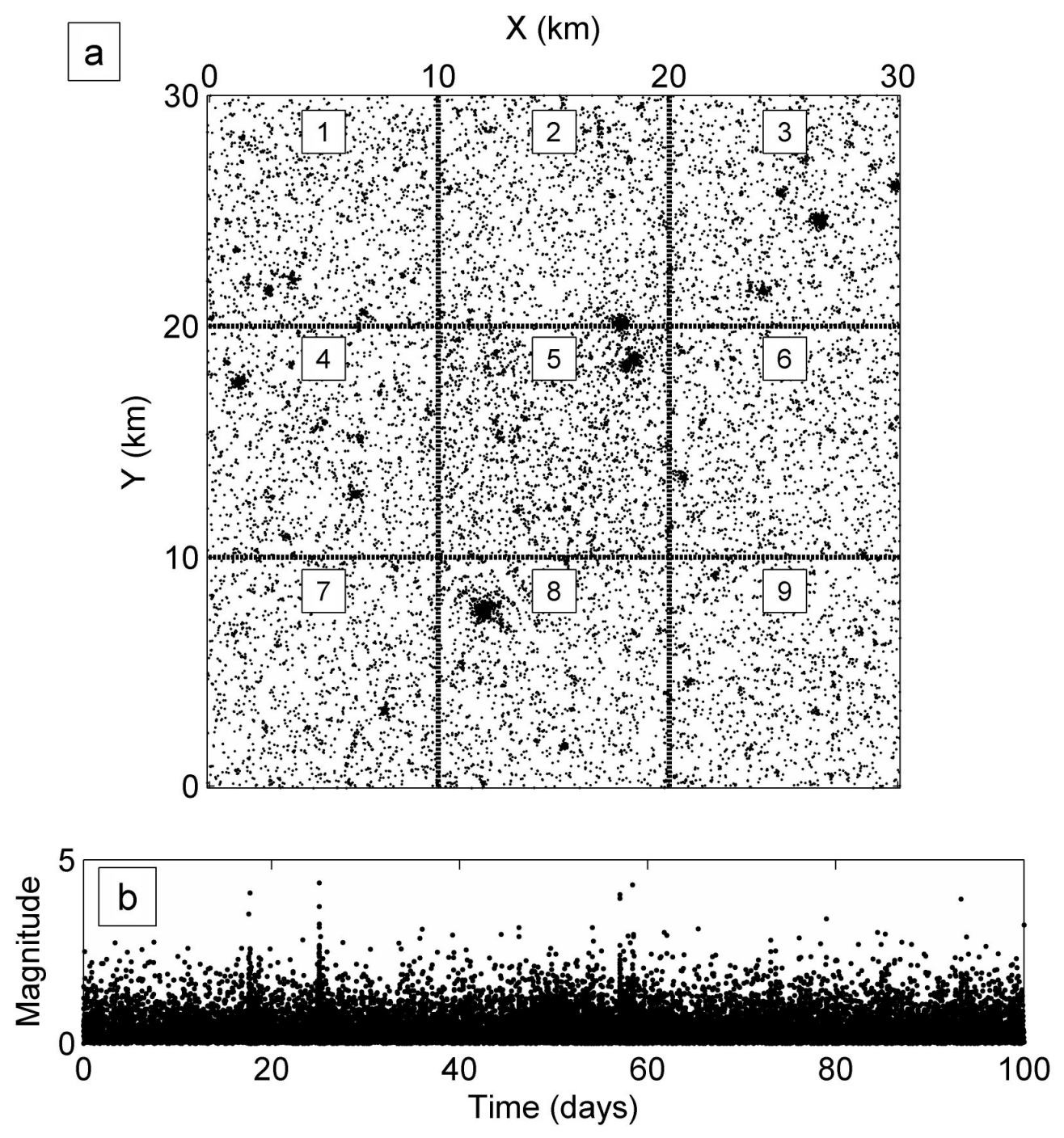

Figure 1. a) Synthetic catalog locations and boxes used in analysis. Parameters used to generate the catalog are $K=4.5 \mathrm{e}-4$ events $/ \mathrm{day} / \mathrm{deg}^{2}, \alpha=0.8, p=1.2, c=0.0001$ days, $d=$ $0.001 \mathrm{deg}^{2}, q=3, \eta=0.3, r=10$ events/day, and $A \sigma=0.001 \mathrm{MPa}$. b) Synthetic catalog earthquake magnitudes and occurrence times. Anomalous seismicity triggered by the transient is not readily apparent in either the map or the magnitude-time history, which are dominated by the aftershock sequences of the largest events in the catalog. 

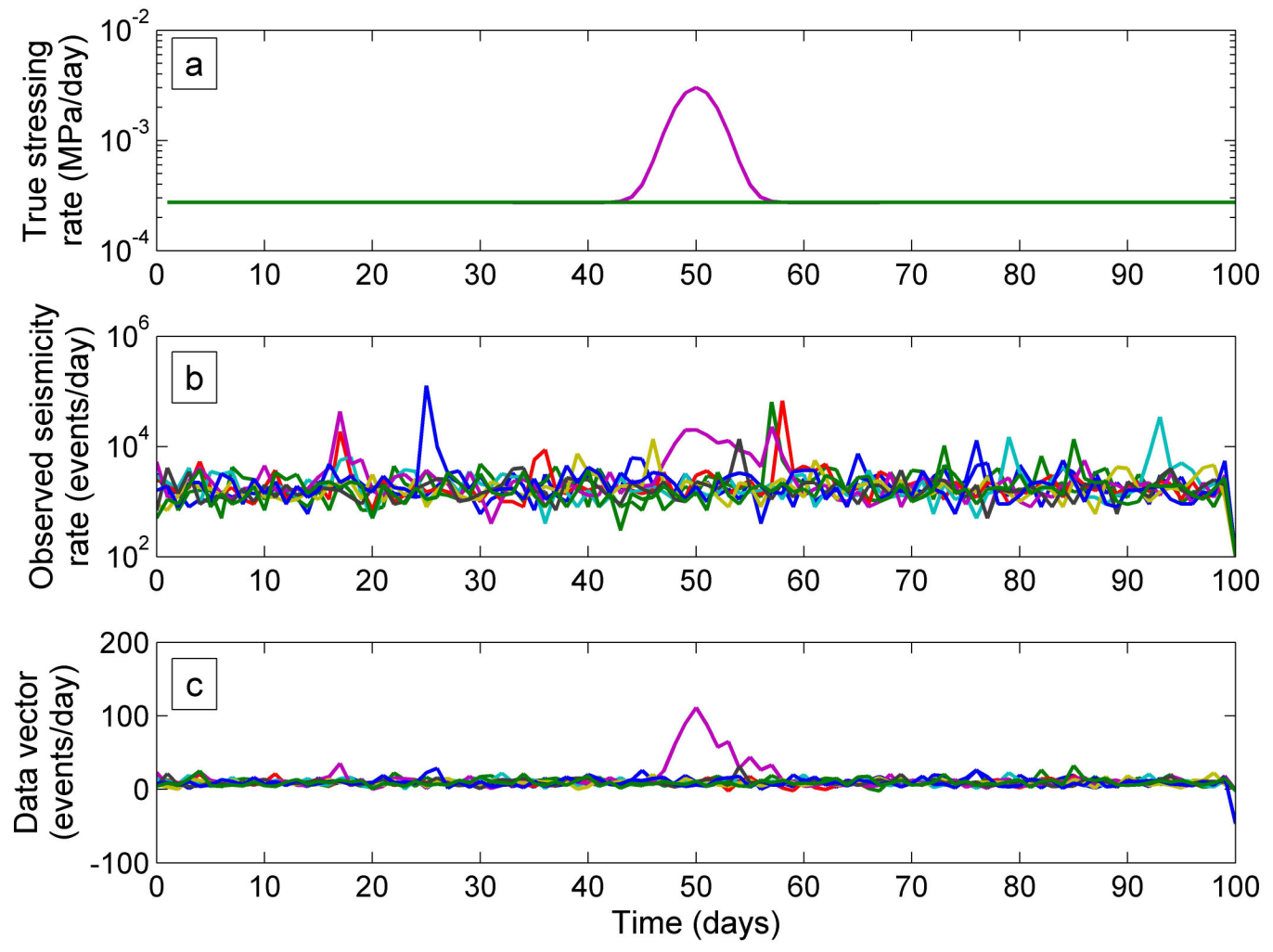

Figure 2. a) True stressing rate $\dot{S}$ used in each spatial box for the synthetic test. A transient rate is imposed in Box 5 (purple), involving an increase in $\dot{S}$ by a factor of 10 over the background rate of $0.1 \mathrm{MPa} / \mathrm{yr}$ imposed in the other boxes (green). b) Observed seismicity rates in each spatial box (colors) obtained by binning occurrence times in time bins of 1 day. The anomalous seismicity rate due to the transient in Box 5 (purple) is overshadowed by jumps in rate due to aftershock sequences, therefore the stressing rate estimate from a straightforward rate-state inversion will primarily reflect changes due to these larger peaks. c) Data vectors (i.e., the aseismically-triggered seismicity rate $R_{A}$ ) in each box obtained by subtracting out the ETAS-predicted rate. The anomalous seismicity in Box 5 (purple) due to the transient is now much more visible. 

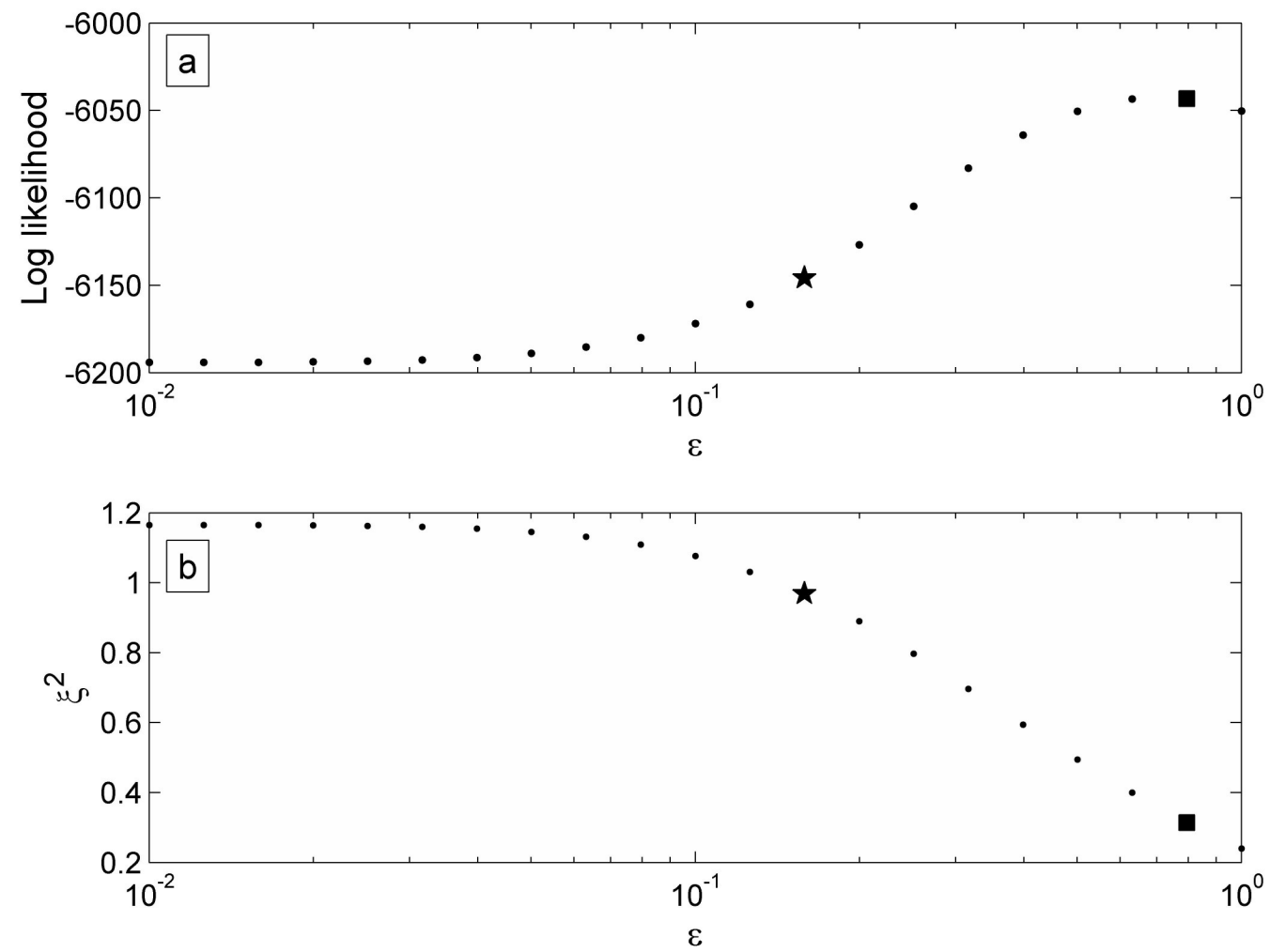

Figure 3. a) Log likelihood vs. smoothing parameter $\varepsilon$. b) Data covariance multiplier $\hat{\xi}^{2}$ vs. $\varepsilon$. Ideally $\hat{\xi}^{2}$ should be close to 1 , because the data covariance $\mathbf{R}_{k}$ is estimated $a$ priori. The maximum likelihood estimate of $\varepsilon$ is indicated by a square; our preferred value for $\mathcal{E}$, for which $\hat{\xi}^{2} \sim 1$, is indicated by a star. 

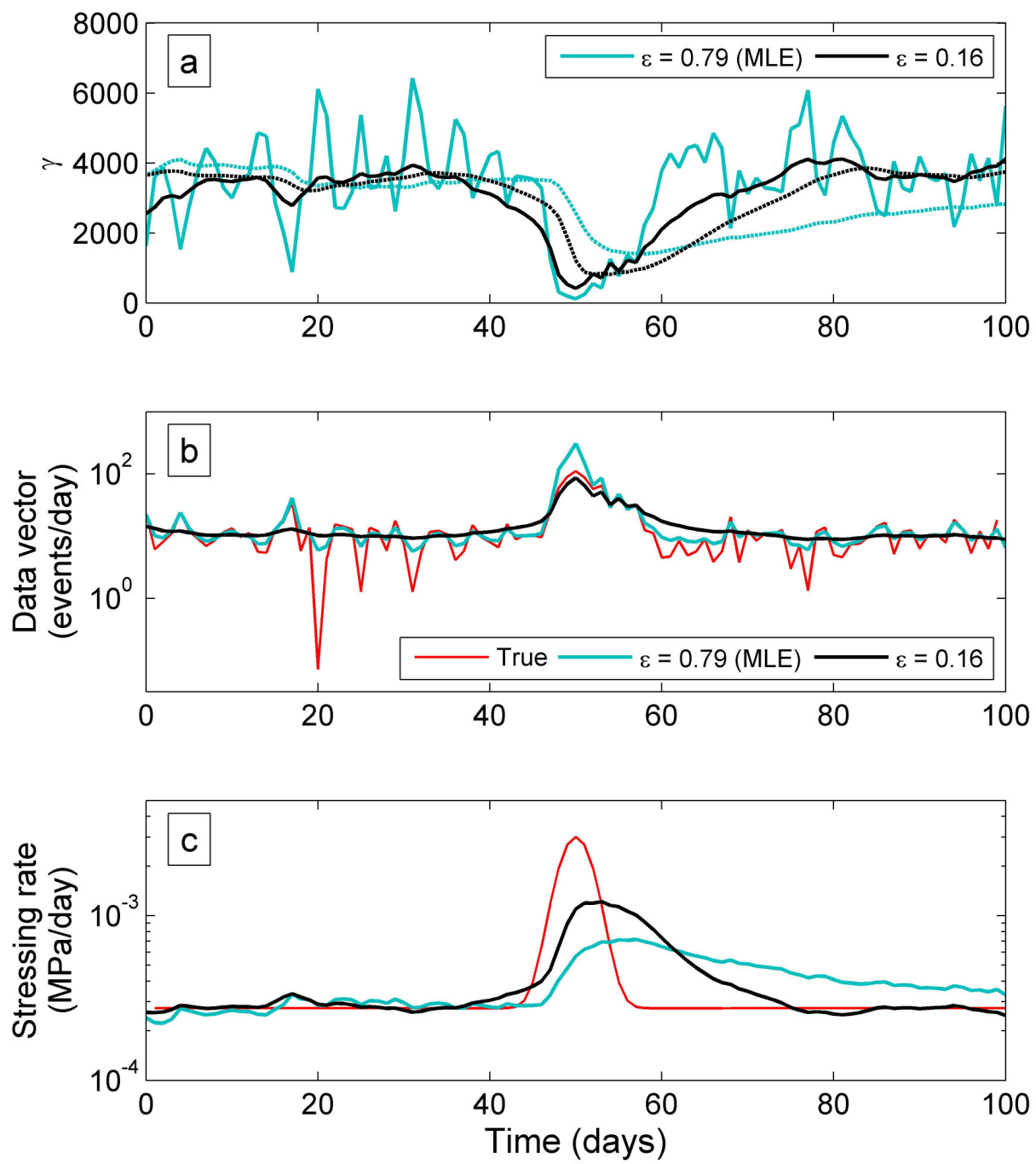

Figure 4. Comparison of backsmoothed filter results in Box 5 for different values of $\varepsilon$. a) Estimates for the rate-state seismicity state variable $\gamma$ for the MLE, $\varepsilon=0.79$ (teal), and our preferred value of $\varepsilon=0.16$ (black). Also shown are the estimates for $\gamma$ directly derived from the filter (solid lines) and estimates for $\gamma$ integrated from the filter estimate of $\dot{S}$ using the rate-state model (Eq. 5-6) (dashed lines). Ideally the two estimates at a given value of $\varepsilon$ should agree with each other, which is better achieved when $\varepsilon=0.16$. b) Fit to the observed data vector in Box 5 (red) by each value of $\varepsilon$. For the MLE (teal), the filter clearly over-fits the data. The $\varepsilon=0.16$ case (black) better fits the largest peak. c) Forward filter estimates for $\dot{S}$ in Box 5 with $\varepsilon=0.79$ (teal) and $\varepsilon=0.16$ (black), compared to the true $\dot{S}$ (red). The $\varepsilon=0.16$ estimate comes closer to recovering the true stressing rate. 

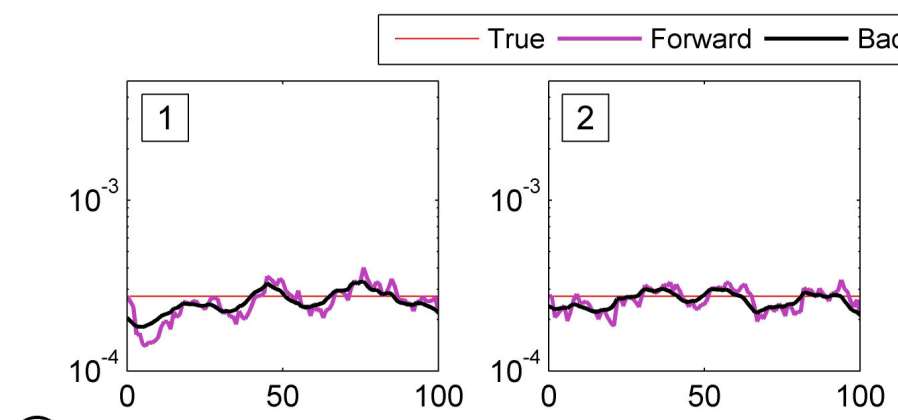

Backsmoothed
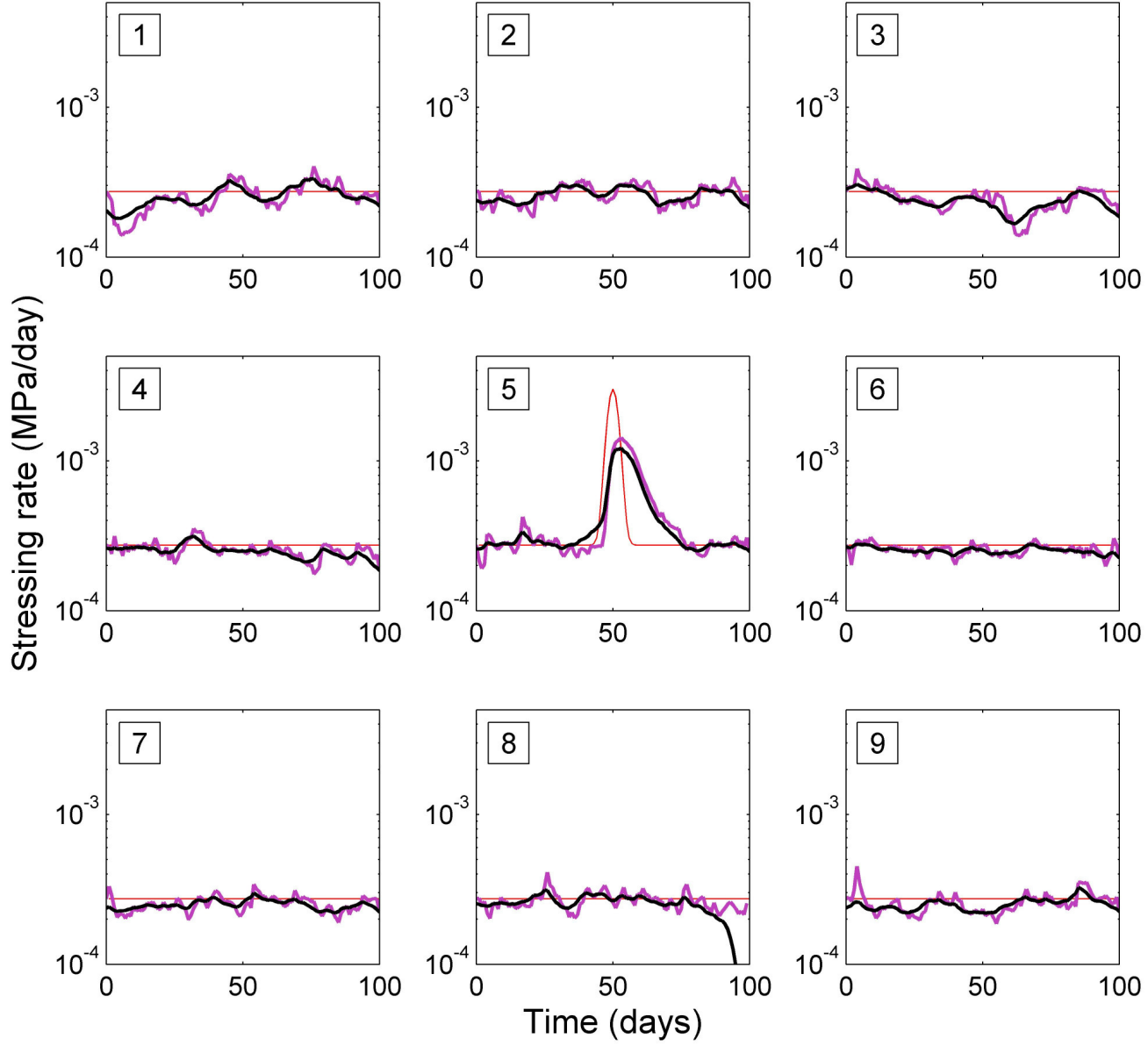

Figure 5. Filter estimates of stressing rate $\dot{S}$ in each box. True stressing rate is shown by the red line, the forward estimate by the purple line, and the backsmoothed estimate by the black line. Both the forward and backsmoothed results clearly identify in which box the transient is located, and produce estimates of the peak stressing rate of the transient that are within a factor of 2-3 of the actual peak. 


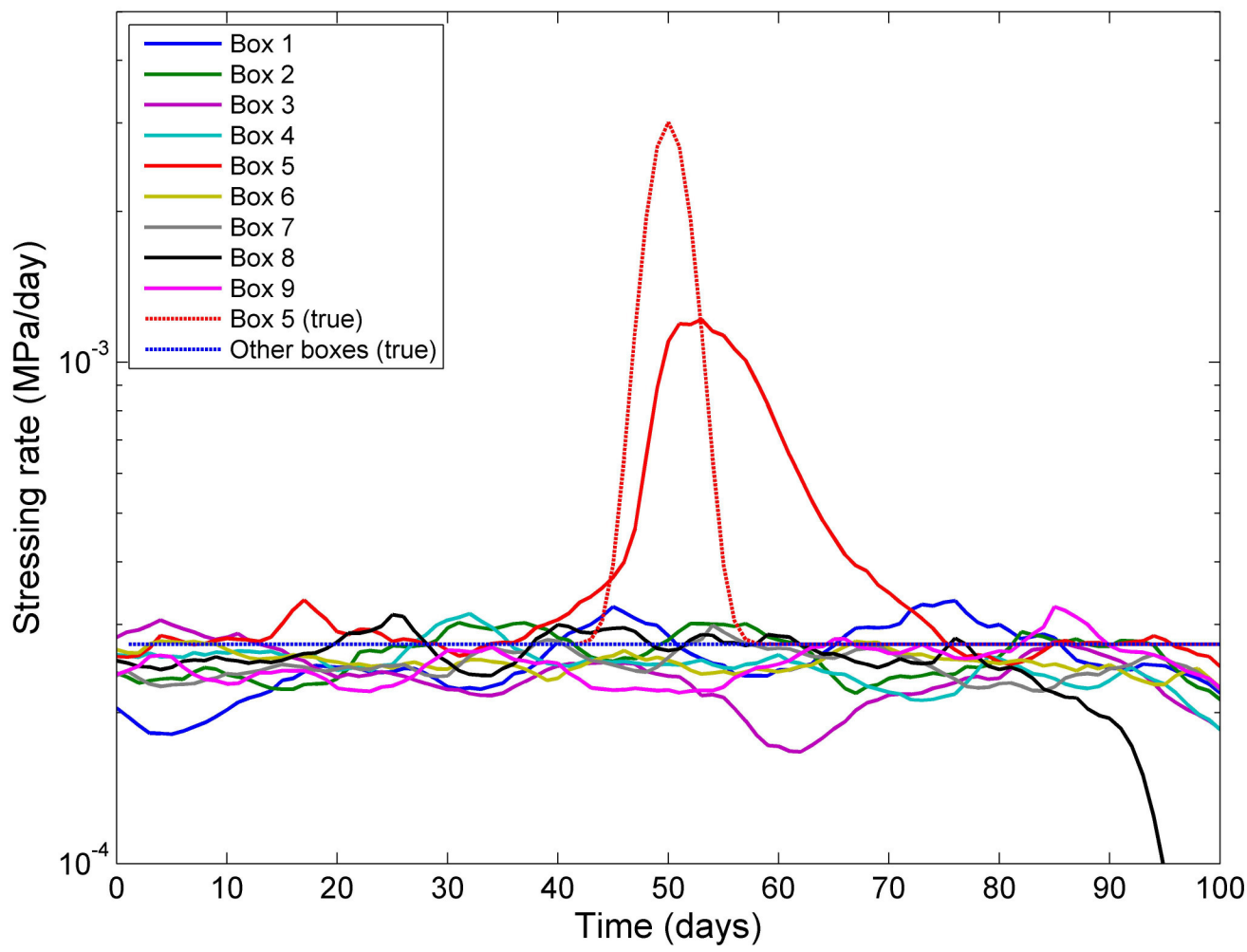

Figure 6. Overlay of backsmoothed filter estimates of $\dot{S}$ in each box (solid colors). The true stressing rates are shown by the dashed lines. This emphasizes that the filter is able to correctly identify the box in which the transient occurs and estimates the peak stressing rate to within a factor of 2-3 of the true peak. 

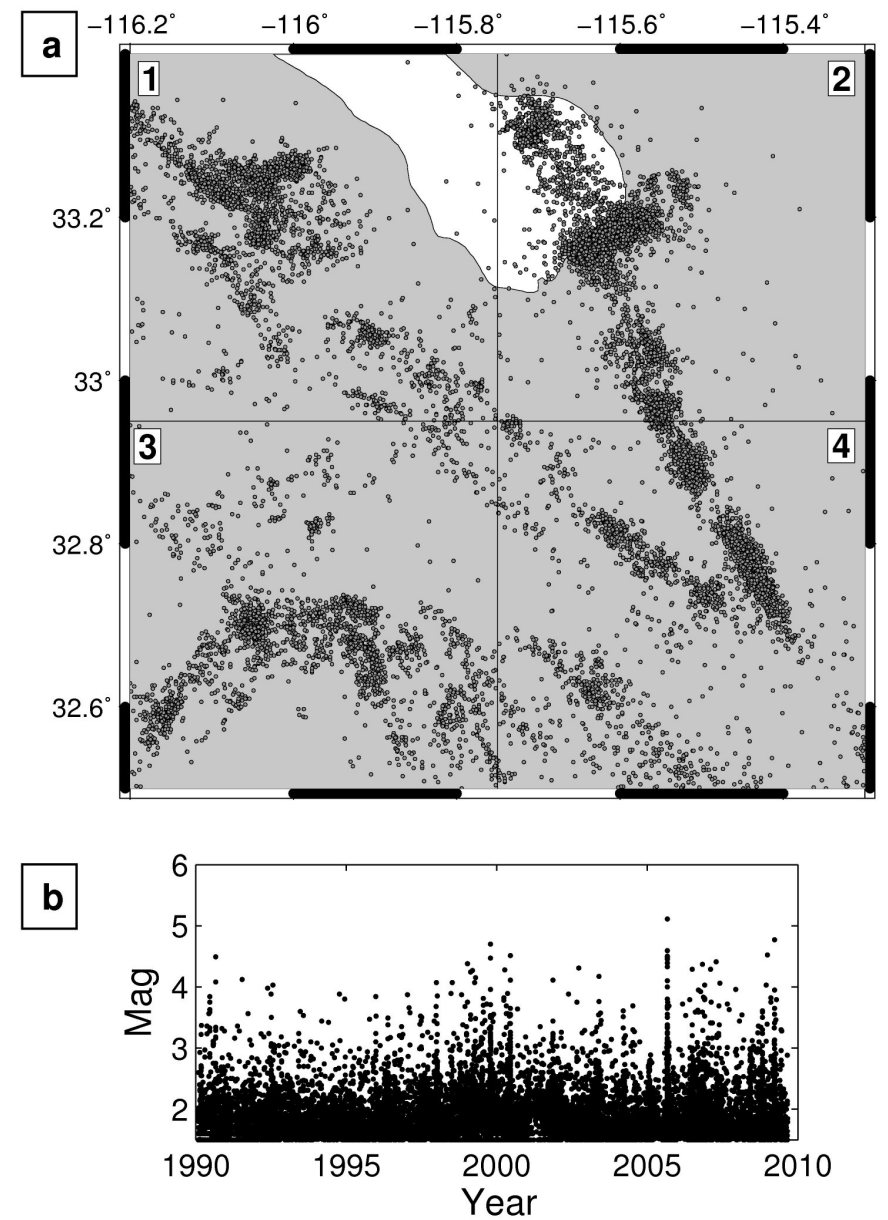

Figure 7. a) Map of the Salton Trough region in California showing $M \geq 1.5$ seismicity occurring from February 1990-August 2009, obtained from the Southern California Earthquake Data Center. For our analysis, the region is divided up into the 4 boxes indicated. b) Magnitude-time history of the Salton Trough catalog. 

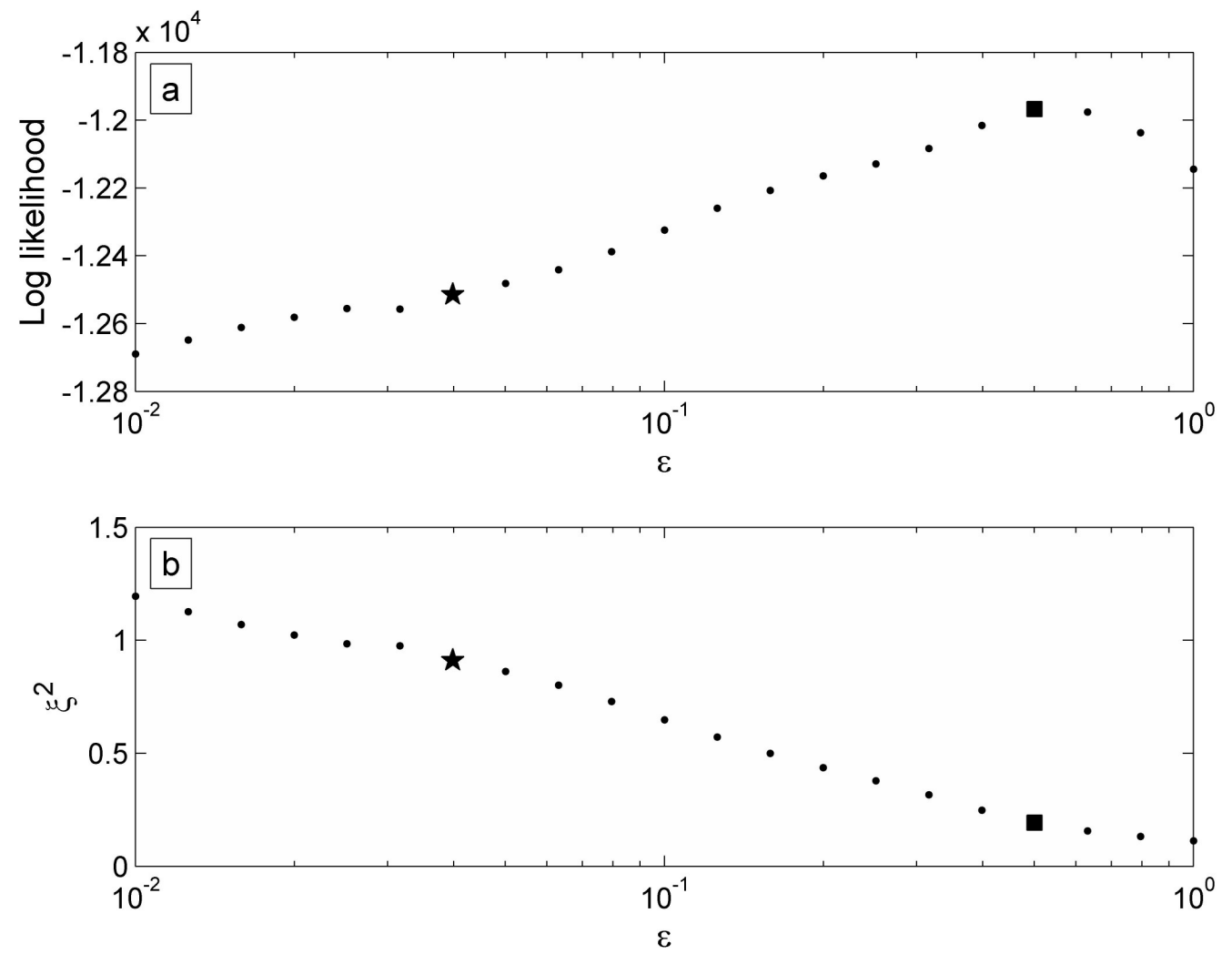

Figure 8. a) Loglikelihood vs. $\varepsilon$ for the Salton Trough data set. b) Data covariance multiplier $\hat{\xi}^{2}$ vs. $\varepsilon$. Again the maximum likelihood estimate of $\varepsilon$ (square) differs from our preferred value for $\varepsilon$ (star), for which $\hat{\xi}^{2} \sim 1$. As in the synthetic test, the MLE value of $\varepsilon(0.5)$ overfits the data, while the preferred value of $\varepsilon(0.04)$ fits the largest peaks better and also results in better agreement between the direct and integrated filter estimates of $\gamma$. 

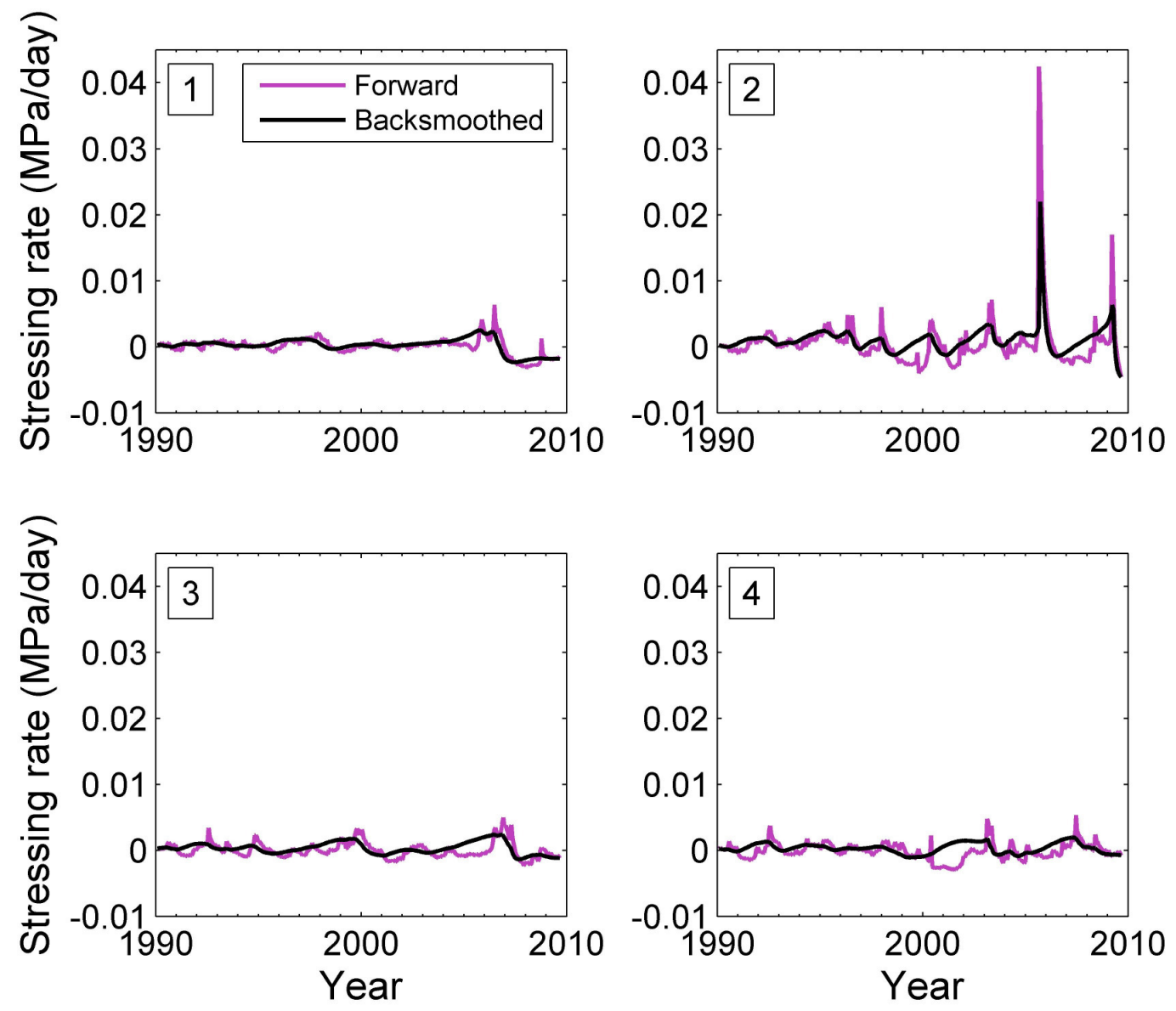

Figure 9. Filter estimates of $\dot{S}$ in each spatial box for the Salton Trough. The forward estimate is shown by the purple line, and the backsmoothed estimate by the black line. The largest signal, in Box 2, can be associated with a geodetically-observed aseismic transient in the Obsidian Buttes in 2005 [Lohman and McGuire, 2007]. The next largest signal, also in Box 2, can be associated with the 2009 Bombay Beach earthquake swarm. 


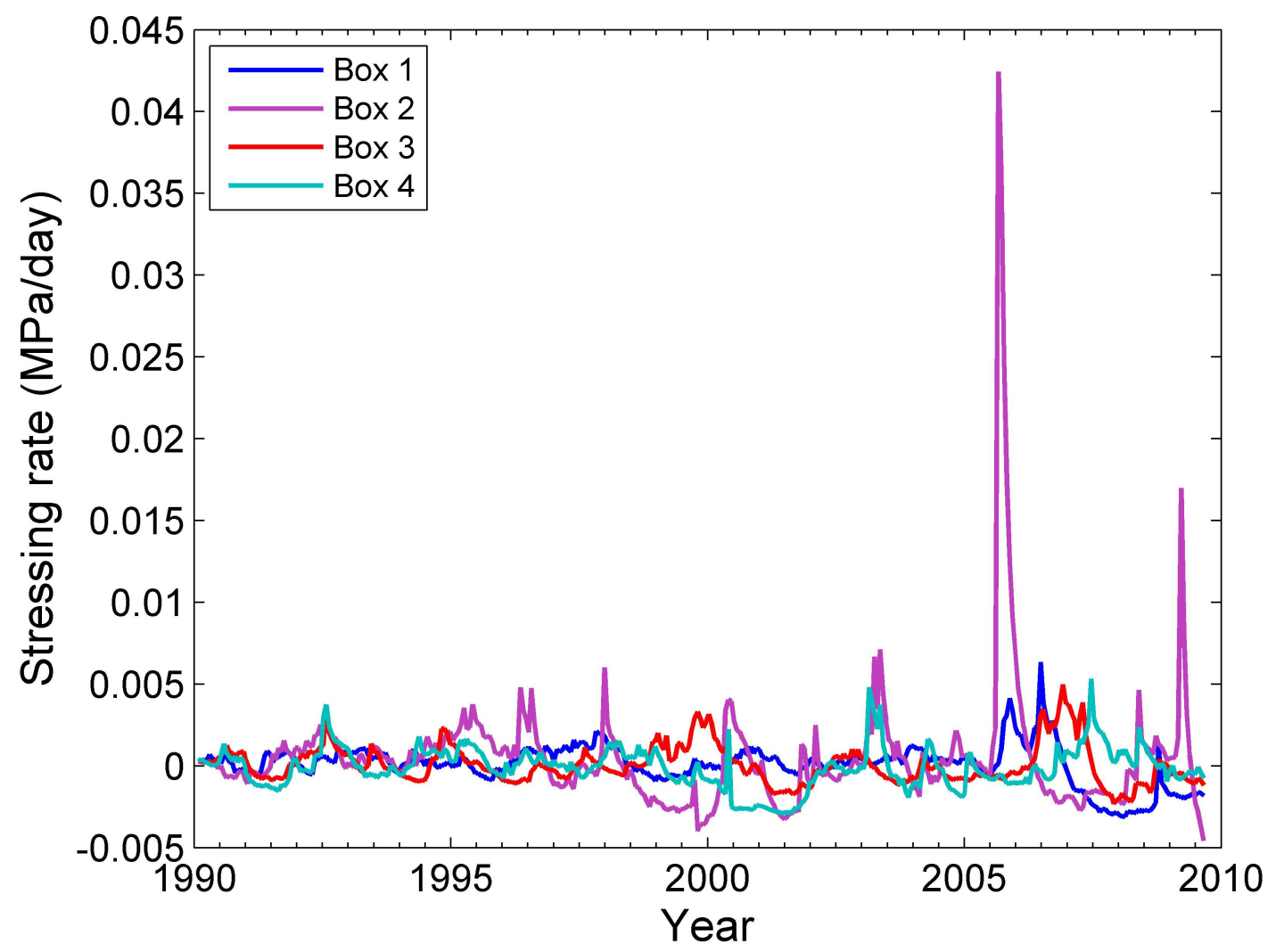

Figure 10. Overlay of forward filter estimates of stressing rate in each box (solid colors). This emphasizes that the filter is able to detect the largest geodetically-observed transient that has occurred in the region (the Obsidian Buttes aseismic creep event in 2005). Other smaller anomalies may be related to an earthquake swarm on the Imperial Fault in 2003 [Roland and McGuire, 2009] in Boxes 2 and 4, earthquake swarms in the Brawley seismic zone in 1996, 1998, and 2008 in Box 2, and the 2009 Bombay Beach swarm in Box 2. 


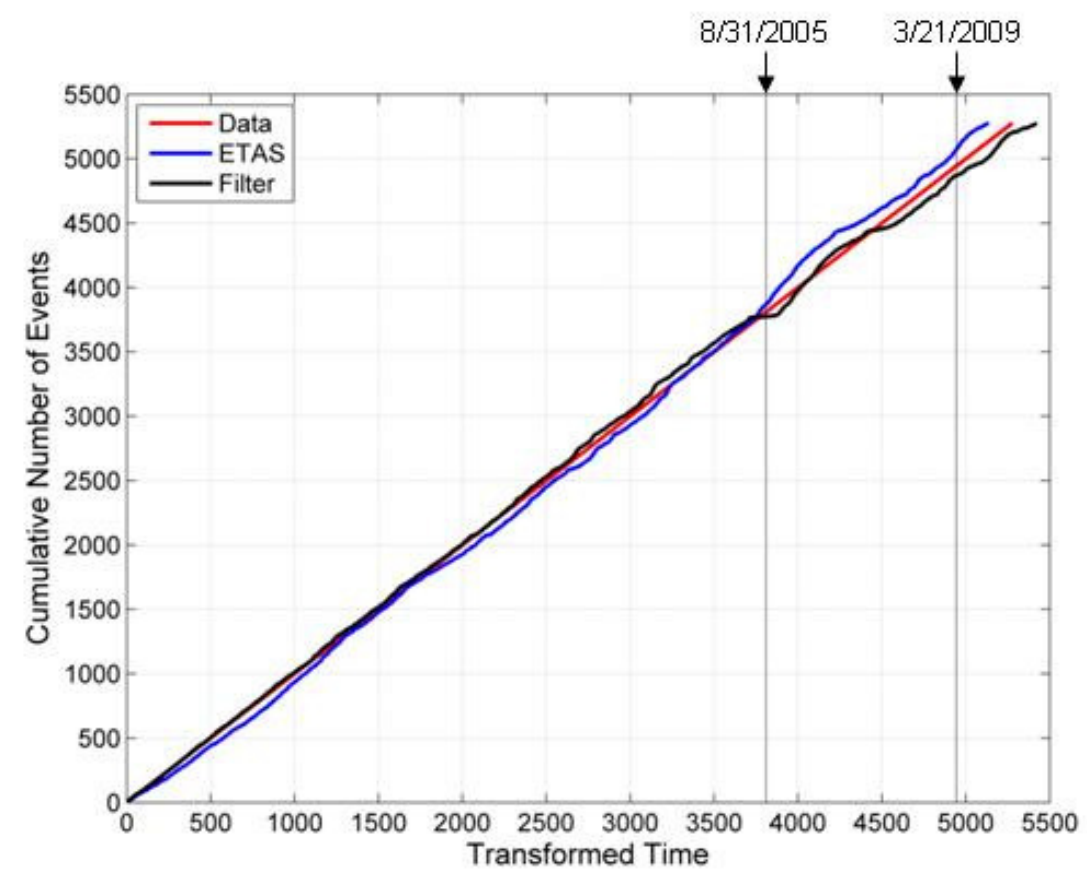

Figure 11. Cumulative number of events vs. transformed time (i.e., predicted cumulative number of events). The red line is a one-to-one line indicating a perfect fit to the observed data. ETAS transformed times are calculated using seismicity rates estimated from the space-time ETAS model optimized to just prior to the 2005 Obsidian Buttes earthquake swarm (event 3779) and extrapolated for the remainder of the catalog (blue line). Transformed times are also calculated using the filter estimate of seismicity rate (black line). The significant deviation of the blue line from the data shows that the ETAS model (with its time-independent background rate) underpredicts the amount of seismicity, particularly during the 2005 swarm. The filter estimate (with a timedependent background rate) provides a better fit to the observed cumulative number of events. 

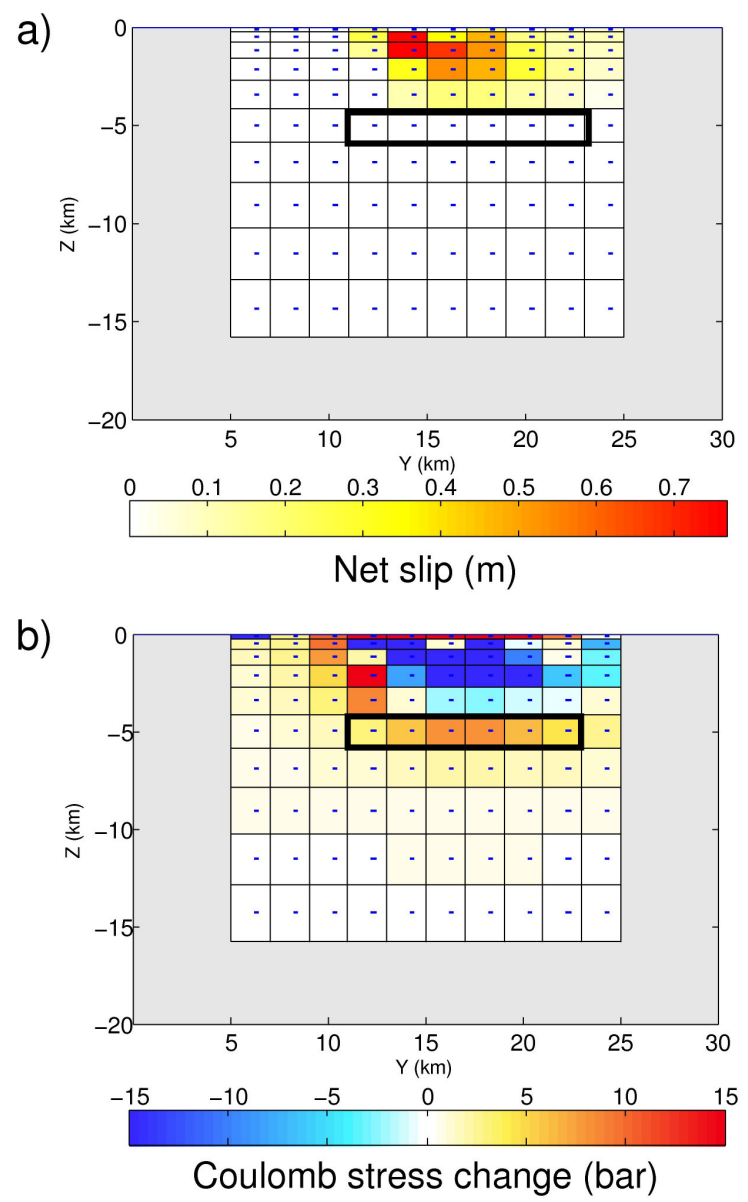

Figure 12. a) Slip model of shallow aseismic creep on the Obsidian Buttes fault inverted from InSAR data [Lohman and McGuire, 2007]. Black box indicates depth at which microseismicity triggered by the transient occurred. b) Calculated Coulomb stress change on the fault due to the shallow aseismic slip. The Coulomb stress change averaged over the outlined boxes is used to calculate an average stressing rate for the transient $(\sim 0.06-$ $0.6 \mathrm{MPa}$ /day for transient durations of 1-10 days). 


\title{
Chapter 5: Detecting Aseismic Transients in the Hokkaido Corner
}

\begin{abstract}
Transient aseismic processes alter the stress state of a region and can cause seismicity rate anomalies in space and time relative to commonly used aftershock models. The presence of such anomalies in subduction zones can therefore indicate stress changes occurring due to processes such as fluid flow, afterslip or slow earthquakes. Therefore, mapping these anomalies can lead to a better understanding of where and how stress accumulates on the megathrust. We have developed a method to invert seismicity catalogs for stressing rate variations in time and space. We apply this technique to a catalog of events occurring in the Hokkaido corner from 1985-2009. This area consists of asperities that rupture in great earthquakes such as the 2003 M8.0 Tokachi-oki earthquake. Our initial results identify seismicity anomalies that can be related to geodetically-observed afterslip following major interplate earthquakes in the catalog, as well as a possible precursory transient before the 1994 M7.6 earthquake.
\end{abstract}




\section{Introduction}

Transient aseismic deformation in subduction zones, such as afterslip following major interplate earthquakes or slow slip events on the plate interface, alter the stress state of a region and can trigger seismicity [e.g., Hsu et al., 2006; Ozawa et al., 2007; Delahaye et al., 2009]. This seismicity often does not decay in time or space as quickly as typical aftershock sequences, and so appear as seismicity rate anomalies relative to models, such as the Epidemic Type Aftershock Sequence (ETAS) model [Ogata, 1988], that are based on the empirical laws describing aftershock behavior (e.g., Omori's law, Bath's law, and the Gutenberg-Richter magnitude frequency distribution) [Llenos et al., 2009]. The presence of these seismicity rate anomalies in subduction zones can therefore indicate that stress changes are occurring due to processes such as afterslip or slow slip events, and identifying regions in which they occur can lead to a better understanding of stress accumulation on the megathrust, which has important implications for seismic hazard assessment. Moreover, detecting these anomalies could provide a way to map the frictional properties of the plate interface by identifying velocity-strengthening regions where stress is being released stably through aseismic fault slip as opposed to velocityweakening regions where stress is released through recurrent major earthquakes.

The Hokkaido corner in northeastern Japan, where the Pacific plate subducts along the Kurile and Japan trenches at rates of $\sim 8-9 \mathrm{~cm} / \mathrm{yr}$ [DeMets et al., 1990], consists of several fixed asperities that rupture in great earthquakes such as the 1994 M7.6 Sanriku-oki earthquake and the 2003 M8.0 Tokachi-oki earthquake [e.g., Yamanaka and Kikuchi, 2004]. The areas of the plate interface surrounding the asperities release stress primarily through aseismic slip [Yamanaka and Kikuchi, 2004; Miyazaki et al., 2004a]. A large quantity of both seismic and geodetic data is available in Japan, making it a good region to investigate seismicity rate anomalies and their relationship to aseismic deformation.

In Chapter 4, we developed a method that can detect seismicity rate anomalies in an earthquake catalog and map them to underlying stressing rate variations. We implemented a seismicity rate model [Llenos et al., 2009] that combined both the ETAS 
model and the rate- and state-dependent friction model [Dieterich, 1994] into a data assimilation algorithm that inverts seismicity catalogs for stressing rate variations, resulting in space-time estimates of the state variables in our model (background stressing rate, aseismic stressing rate, and rate-state variable $\gamma$ ). We now apply this technique to a catalog of events occurring in the Hokkaido corner from 1985-2009 to detect seismicity anomalies and explore how they are related to spatial and temporal variations in stress on the megathrust.

\section{Method}

We apply the method described in Chapter 4 to analyze the catalog of events from northeastern Japan for aseismic stressing rate variations. We assume that the seismicity rate $R$ observed in a catalog can be approximated as a linear combination of a component $R_{A}$ (reflecting seismicity triggered by aseismic processes, including long-term tectonic loading) and a coseismically-triggered component $R_{C}$ (representing aftershock sequences)

The component $R_{C}$ is estimated with the stochastic space-time ETAS model [Ogata, 1998; Ogata and Zhuang, 2006]. The ETAS model is a point process model that represents the seismicity rate $R(t, x, y)$ as a summation of the Omori-like aftershock sequences produced by each event prior to time $t$ plus a time-independent background seismicity rate $\mu$ [Ogata, 1998; Ogata and Zhuang, 2006]:

$$
R(t, x, y)=\mu(x, y)+\sum_{i: t_{i}<t} \kappa\left(M_{i}\right) \cdot \psi\left(t-t_{i}\right) \cdot f\left(x-x_{i}, y-y_{i} ; M_{i}\right)
$$

where

$$
\begin{aligned}
& \kappa(M)=K e^{\alpha\left(M-M_{c}\right)} \\
& \psi(t)=\frac{p-1}{c}\left(1+\frac{t}{c}\right)^{-p} \\
& f(x, y ; M)=\frac{q-1}{\pi d e^{\eta\left(M-M_{c}\right)}}\left(1+\frac{x^{2}+y^{2}}{d e^{\eta\left(M-M_{c}\right)}}\right)^{-q}
\end{aligned}
$$

The summation in Eq. 1 representing the aftershock sequences in the catalog is essentially $R_{C}$. The function $\kappa(M)$ is the expected number of events triggered by an 
earthquake of magnitude $M$ given an aftershock productivity $K$ and scaling parameter $\alpha$, the function $\psi(t)$ is the probability density function form of the modified Omori law and is specified by the Omori decay parameters $c$ and $p$ [Omori, 1894; Utsu, 1961], and the function $f(x, y ; M)$ describes the spatial distribution of the events triggered by an earthquake of magnitude $M$, specified by the parameters $d, q$, and scaling parameter $\eta$.

We divide the catalog into a number of spatial boxes, bin the occurrence times in each box to obtain seismicity rates in time and space, and subtract the ETAS-predicted $R_{C}$ from the observed rate $R$ in each box to obtain a first-order estimate of a time-dependent background seismicity rate $R_{A}$ that contains variations due to aseismic processes. This seismicity rate can be related to a stressing rate on a population of faults in the region through the use of the rate- and state-dependent friction model [Dieterich, 1994]:

$$
\begin{aligned}
& R=\frac{r}{\gamma \dot{S}_{r}} \\
& d \gamma=\frac{d t}{A \sigma}(1-\dot{S})
\end{aligned}
$$

where $r$ is a steady-state reference seismicity rate associated with a reference stressing rate $\dot{S}_{r}, \dot{S}$ is the modified Coulomb stressing rate, $\gamma$ is a state variable, and $A$ is a fault constitutive parameter. We assume the normal stress $\sigma$ and therefore the frictional parameter $A \sigma$ remain constant.

We incorporate the rate-state equations into an underlying state-space model. The time-dependent state variables used to describe the system are background stressing rate $\dot{S}_{p}$, aseismic stressing rate $\dot{S}_{A}$, and the rate-state variable $\gamma$ in each spatial box. A number of time-independent model parameters also must be optimized. Seven of these parameters come from the space-time ETAS model, and are optimized using the algorithm of Ogata and Zhuang [2006]. Two of the parameters ( $r$ and A $\sigma)$ come from the rate-state model equations and are estimated a priori. The final two parameters ( $\tau$ and $\varepsilon)$ are the scaling parameters for the random walk processes used to model aseismic stressing rate and $\gamma$ respectively and are optimized using a Gaussian likelihood function [Harvey, 1989; Segall and Matthews, 1997] subject to the constraints discussed in 
Chapter 4. We solve the system using an extended Kalman filter algorithm [e.g., Gelb, 1974; Segall and Matthews, 1997; McGuire and Segall, 2003], which results in time histories of the stressing rate in each spatial box.

\section{Data analysis and results}

We apply our method to a catalog of $M \geq 3$ earthquakes that occurred in northeastern Japan from 1985-2009, obtained from the Japan Meteorological Agency (Fig. 1). During this time period, four major interplate earthquakes occurred, three of which were off Sanriku (1989 M7.1, 1992 M6.9, and 1994 M7.6) and one of which was off Tokachi (2003 M8.0). We divide the region up into 6 spatial boxes and bin the occurrence times into time windows of 30 days to obtain the seismicity rate in each box. The length of the time step is necessary in order for enough seismicity to occur to allow the background rate to be resolved in most of the time steps. We set the rate-state frictional parameter $A \sigma$ to be $0.4 \mathrm{MPa}$, in agreement with the estimate of Fukuda et al. [2009] inferred from GPS data following the Tokachi-oki earthquake, and, following Toda and Matsumara [2006] and Ghimire et al. [2009], assume a value for the reference stressing rate $\dot{S}_{r}$ of $0.2 \mathrm{MPa} / \mathrm{yr}$, which corresponds to a stress drop of $10 \mathrm{MPa}$ with a 50 year recurrence interval under full plate coupling [Yamanaka and Kikuchi, 2004; Miyazaki et al., 2004a; Yagi, 2004].

\subsection{ETAS fitting to aftershock sequences}

To explore how well the ETAS model parameters describe the seismicity in the catalog, we first fit the ordinary and space-time ETAS models [Ogata, 1988; Ogata and Zhuang, 2006] to the aftershock sequences of the four major interplate earthquakes. The results suggest that either variations in background rate or in the ETAS parameters over time, space and from sequence to sequence could be significant and cause the sequences to appear as anomalies from the rest of the catalog.

Table 1 summarizes the space-time ETAS model parameters that best fit the first 100 days of aftershocks of the four major interplate earthquakes. These results indicate 
that the ETAS parameters can vary both in space and in time. The parameters for the first two events (1989 M7.1 and 1992 M6.9), which occur in the southern part of the catalog, are relatively similar, but the parameters for the 1994 M7.6 and 2003 M8.0 are quite different. While the background seismicity rate $\mu$ appears to be relatively constant in time and space, this may be due to the general insensitivity of the ETAS model to background seismicity when fitting individual aftershock sequences [Ogata, 2006]. In fact, $\mu$ can vary by several orders of magnitude in both space and time [Ogata et al., 2003; Hainzl and Ogata, 2005; Llenos et al., 2009].

For both the 1994 and 2003 events, the ETAS model cannot fit both the early ( 510 days) aftershocks and the late aftershocks (200 days) with the same set of parameters (Table 2). We further demonstrate this for the Tokachi-oki earthquake by optimizing the ordinary ETAS model to the first 5 days of aftershocks and extrapolating the fit to a yearlong catalog of aftershocks. We transform the occurrence times $t_{i}$ of the events using the theoretical cumulative function $\tau_{i}=\int_{0}^{i} \lambda(s) d s$, where $\lambda$ is the seismicity rate predicted by the optimized ETAS parameters [Ogata, 1988, 2005]. A plot of the cumulative number of events in the year-long catalog versus transformed time (i.e., theoretical cumulative number) should be linear if the ETAS parameters optimized from the first 5 days fit the catalog well. Fig. 2 demonstrates that this is not the case for the 2003 Tokachi-oki earthquake. Significantly less earthquakes occur in the later part of the aftershock sequence than is predicted by the fit to the earlier part, which suggests that the temporal decay in seismicity following the mainshock cannot be well explained by a single set of ETAS parameters.

The space-time ETAS model also has difficulty modeling the spatial decay in seismicity in the first month following the 2003 Tokachi-oki event. The ETAS model utilizes a spatial probability density function that predicts a power-law decay in mainshock-aftershock distance (Eq. 4). However, a histogram of the distances of the Tokachi-oki aftershocks reveals that the ETAS model that best fits this sequence does not match the observed decay of seismicity in space (Fig. 3). The number of aftershocks in fact peaks at distances of $\sim 0.2-0.3 \mathrm{deg}$ in the first month after the mainshock. This 
roughly corresponds with the location of the peak of the 30-day afterslip of this event, modeled from GPS data [Miyazaki et al., 2004a] (Fig. 1).

Taken together, the results of fitting both the ordinary and space-time ETAS models to various space-time windows of the catalog show that a single set of ETAS parameters alone cannot explain the space-time distribution of seismicity following the largest earthquakes in the catalog. Seismicity rate anomalies may arise due to the inability of a given set of parameters to model either the spatial or temporal decay in aftershocks. This suggests that other triggering mechanisms besides earthquake interactions may be responsible for these variations.

\subsection{Filter results}

To form the data vector for the filter, we fit the space-time ETAS model to the 100-day aftershock sequence of the 2003 Tokachi-oki earthquake in order to account for as much of the aftershocks following this event as possible. We then subtract this ETASpredicted rate from the observed rate to estimate the aseismically-triggered seismicity rate $R_{A}$. This residual thus represents a time-dependent background seismicity rate, and becomes the input of the extended Kalman filter. The filter results in estimates of background stressing rate $\dot{S}_{p}$, aseismic stressing rate $\dot{S}_{A}$, and rate-state variable $\gamma$. As a check, the estimate of $\dot{S}_{A}$ can be forward propagated using the rate-state equations (Eq. 5-6) to obtain the filter's prediction of seismicity rate $R_{A}$. This quantity can be combined with the ETAS-predicted $R_{C}$ and integrated to obtain a filter prediction of the cumulative number of events in the catalog over time, which can be compared to the observed cumulative number of events (Fig. 4). While the filter under-predicts the total number of events (possibly due to smoothing), it accounts for more of the catalog than the ETAS model optimized to the entire catalog alone. This demonstrates that the inclusion of a time-dependent background seismicity rate $\left(R_{A}\right)$ is necessary to account for the cumulative number of events in the catalog.

The filter estimates of total stressing rate $\dot{S}$ (the sum of $\dot{S}_{A}$ and $\dot{S}_{p}$ ) for each box are shown in Fig. 5a. The largest signals are clearly due to afterslip following the four 
interplate earthquakes, which has been observed geodetically. However, two smaller anomalies are also detected that were not observed geodetically. In the following sections, we will explore these signals in greater detail.

\subsubsection{Afterslip of the 1989 M7.1 and 1992 M6.9 Sanriku-oki earthquakes}

The 2 November 1989 M7.1 and the 18 July 1992 M6.9 thrust earthquakes occurred off the coast of Sanriku in northern Honshu (Fig. 1). The first two large signals detected by the filter appear to be spatially and temporally coincident with the afterslip associated with these events (Fig. 5b). Although these events occurred prior to the establishment of the GEONET continuous GPS network in Japan, significant postseismic deformation following each was observed in extensometer data [Miura et al., 1993; Kawasaki et al., 1995, 2001]. Despite the 1989 earthquake having a larger magnitude than the 1992 earthquake, slightly more aseismic moment release occurred for the second event [Kawasaki et al., 1995, 2001], which agrees well with the relative sizes of the stressing rate peaks we obtain for these two events.

\subsubsection{Afterslip of the 1994 M7.6 Sanriku-oki earthquake}

A M7.6 earthquake occurred off Sanriku on 12 December 1994 (Fig. 1), with rupture propagating westward and the majority of the seismic moment release occurring downdip of the epicenter [e.g., Sato et al., 1996; Yagi et al., 2003; Llenos and McGuire, 2007]. Significant afterslip following this earthquake was detected from both GPS and extensometer data [Heki et al., 1997; Kawasaki et al., 2001]. Postseismic slip models suggest that the afterslip occurred both in the rupture zone and downdip [Nishimura et al., 2000; Yagi et al., 2003].

The filter detects large stressing rate anomalies in both Box 4 (downdip of the epicenter) and Box 5 (Fig. 5c) that occur following the 1994 earthquake. These transients involve peak stressing rates that are $\sim 1-2$ orders of magnitude above the tectonic rate. Contrary to many of the afterslip models of this event, the transient in Box 5 has a larger amplitude and longer duration than the transient detected in Box 4. 
A particularly interesting anomaly is detected in Box 6, located updip of the epicenter near the trench. An increase in stressing rate begins near the start of 1994 that peaks 1-2 months prior to the occurrence of the 1994 earthquake (Fig. 5c). This peak stressing rate is a factor of $\sim 10$ above the tectonic rate. Compared to the other anomalies detected by the filter, this signal is quite small, but represents a large jump in stressing rate for the box it is observed in. While not observed geodetically, perhaps because of low resolution so far offshore, pre-seismic slip in this region beginning $\sim 8$ months prior to the 1994 Sanriku-oki earthquake has been inferred by repeating earthquake analysis [Uchida et al., 2004]. Repeating earthquakes are assumed to rupture the same small asperity, which is surrounded by stable sliding areas; therefore the cumulative slip released by the repeating events reflect the aseismic slip release in the surrounding regions [Nadeau and Johnson, 1998; Igarashi et al., 2003]. The onset of the increased stressing rate detected by our filter agrees remarkably well with the accelerated slip detected through repeating earthquake analysis.

\subsubsection{Afterslip of the 2003 M8.0 Tokachi-oki earthquake}

A M8.0 earthquake occurred offshore of Hokkaido on 25 September 2003 (Fig. 1). The abundance of high quality seismic and geodetic data for that event have led to the development of detailed coseismic and postseismic slip models [e.g., Yamanaka and Kikuchi, 2003; Miyazaki et al., 2004a,b; Yagi, 2004]. The majority of the seismic moment release occurred downdip to the northwest of the earthquake's hypocenter. Afterslip occurred primarily on the parts of the fault surrounding the coseismic rupture, both updip and along-strike [Miyazaki et al., 2004a; Baba et al., 2006]. While the afterslip updip of the rupture is not particularly well resolved in land-based geodetic models, its occurrence is supported by offshore pressure gauge data [Baba et al., 2006] and repeating earthquake analysis [Matsubara et al., 2005].

The filter detects stressing rate transients in Boxes 2 and 3 (Fig. 5d). However, the transient is much larger in Box 3, where the majority of the afterslip occurred, than in 
Box 2 where the majority of the coseismic slip occurred (Fig. 1). This agrees well with the geodetically-derived afterslip models of this event.

\subsubsection{Afterslip following moderate earthquakes}

Besides the large anomalies associated with afterslip of the major interplate thrust events, we have also detected two smaller anomalies in Box 5 that correspond with two smaller thrust events: a M6.5 earthquake that occurred on 8 April 1994 and a M6.3 that occurred on 31 May 1998 (Fig. 5b). Afterslip following these events has not been found by geodetic data analyses, however repeating earthquake analyses detected accelerations in quasi-static slip following both events [Uchida et al., 2003]. The 8 April 1994 event is particularly interesting, in that it was located between the hypocenter of the M7.6 that occurred later that year (downdip to the west) and the region near the trench (updip to the east) where we detected a possible precursory rate change that began in JanuaryFebruary and repeating earthquake analysis detected pre-seismic slow slip [Uchida et al., 2004]. This supports the idea that aseismic transient deformation initiated near the trench in the beginning of 1994 and migrated downdip over the course of the year, culminating in a stress concentration around the asperity of the M7.6 that led to the rupture of that asperity in December of that year [Uchida et al., 2004].

\section{Discussion}

Our results suggest that transient aseismic deformation in subduction zones can be detected solely from earthquake catalog data. Besides the examples of afterslip we have detected in northeastern Japan, recurrent $\mathrm{M}_{\mathrm{w}} \sim 6.5$ slow slip events offshore of the Boso peninsula in central Japan have also triggered seismicity anomalies [Ozawa et al., 2007; Llenos et al., 2009]. Other examples of deformation in subduction zones driving seismicity are afterslip following the $2005 \mathrm{M}_{\mathrm{w}} 8.7$ Nias earthquake [Hsu et al., 2006], and a slow slip event in the Hikurangi trough in New Zealand that triggered microseismicity but no discernible tremor [Delahaye et al., 2009]. These findings clearly suggest that 
aseismic deformation can trigger seismicity, which may therefore provide a means to detect it.

Our technique may also be useful for mapping spatial variations in frictional conditions on the plate interface. For the 2003 Tokachi-oki event, coseismic slip and postseismic slip occurred on adjacent patches (Fig. 1), which Miyazaki et al. [2004a] inferred was an indication of spatial heterogeneity in the frictional stability of the plate interface. The rupture of the mainshock, which occurs on a velocity-weakening patch, loads the adjacent velocity-strengthening patches, which releases the stress stably as afterslip. This hypothesis is supported by modeling of GPS data that suggests the timing of the early afterslip ( $\sim 5$ hours after the mainshock) is controlled by the stress change due to the mainshock and the frictional properties of the megathrust [Fukuda et al., 2009].

In our analysis for the Tokachi-oki event, we divided the region such that the majority of the coseismic slip occurred in Box 2, while the peak afterslip occurred in Box 3 (Fig. 1). Although a small transient occurs in Box 2 at the time of the earthquake, the transient signal in Box 3 is larger by a factor of $\sim 5$ (Fig. $5 \mathrm{~d}$ ). Thus we are clearly able to identify the spatial region where the peak afterslip occurred, and distinguish between areas that are more velocity-weakening (Box 2) and those that are more velocitystrengthening (Box 3). With increased spatial resolution (i.e., lower magnitude of completeness in the catalog), our technique could provide a way to map the frictional conditions on the plate interface simply from earthquake catalog data.

Finally, we have demonstrated that our method, which relies solely on seismicity data, can successfully detect and locate aseismic transients in subduction zones. The repeating earthquake analyses off the coast of Hokkaido and Honshu, which also utilize seismicity data but are based on entirely different physical models and assumptions, have also detected accelerations in quasi-static slip due to aseismic transients [e.g., Igarashi et al., 2003; Uchida et al., 2003, 2004]. These results together suggest that seismicity rate histories can provide an alternative way to detect and monitor aseismic deformation in areas where land-based geodetic resolution is poor and seafloor geodesy impractical if not impossible, such as the offshore updip part of subduction megathrusts. 


\section{Conclusion}

We applied the method developed in Chapter 4 to invert earthquake catalogs for stressing rate variations to a catalog of events from northeastern Japan. We successfully detected afterslip following four major interplate earthquakes as well as two moderate interplate earthquakes. For the 2003 Tokachi-oki event, we were able to spatially distinguish between parts of the fault that were velocity-weakening and parts of the fault that were velocity-strengthening. We also detected possible precursory aseismic slip prior to the 1994 M7.6 Sanriku-oki earthquake that initiated near the trench and migrated downdip, ultimately potentially triggering the rupture of that asperity. Our results suggest the following: 1) transient deformation in subduction zones triggers seismicity anomalies relative to the ETAS model; 2) our method can successfully detect these anomalies in space and time simply from seismic data, which can enable the observation of near-trench aseismic deformation; and 3) this method can also be used to map the spatial distribution of frictional heterogeneities on the plate interface.

\section{Acknowledgments}

We thank Y. Ogata and J. Zhuang for their help with the ETAS models. The seismicity catalog was obtained from the Japan Meteorological Agency. Map figures were prepared using the Generic Mapping Tools software freely distributed by Wessel and Smith [1998]. This work was funded by NSF EAR grant \#0738641. 


\section{References}

Baba, T., K. Hirata, T. Hori, and H. Sakaguchi (2006), Offshore geodetic data conducive to the estimation of the afterslip distribution following the 2003 Tokachi-oki earthquake, Earth Planet. Sci. Lett., 241, 281-292, doi:10.1016/j.eps1.2005.10.019.

Delahaye, E. J., J. Townend, M. E. Reyners, and G. Rogers (2009), Microseismicity but no tremor accompanying slow slip in the Hikurangi subduction zone, New Zealand, Earth Planet. Sci. Lett., 277, 21-28, doi:10.1016/j.epsl.2008.09.038.

DeMets, C., R. Gordon, D. Argus, and S. Stein (1990), Current plate motion, Geophys. J. Int., 101, 425-478.

Dieterich, J. (1994), A constitutive law for rate of earthquake production and its application to earthquake clustering, J. Geophys. Res., 99, 2601-2618.

Fukuda, J., K. M. Johnson, K. M. Larson, and S. Miyazaki (2009), Fault friction parameters inferred from the early stages of afterslip following the 2003 Tokachi-oki earthquake, J. Geophys. Res., 114, B04412, doi:10.1029/2008JB006166.

Gelb, A. (1974), Applied Optimal Estimation, MIT Press, Cambridge, MA.

Ghimire, S., K. Katsumata, and M. Kasahara (2008), Spatio-temporal evolution of Coulomb stress in the Pacific slab inverted from the seismicity rate change and its tectonic interpretation in Hokkaido, northern Japan, Tectonophysics, 455, 25-42, doi:10.1016/j.tecto.2008.04.017.

Hainzl, S., and Y. Ogata (2005), Detecting fluid signals in seismicity data through statistical earthquake modeling, J. Geophys. Res., 110, doi:10.1029/2004JB003247.

Harvey, A. C. (1989), Forecasting, Structural Time Series Models and the Kalman Filter, Cambridge Univ Press, New York.

Heki, K., S. Miyazaki, and H. Tsuji (1997), Silent fault slip following an interplate thrust earthquake at the Japan trench, Nature, 386, 595-598.

Hsu, Y.-J., M. Simons, J.-P. Avouac, J. Galetzka, K. Sieh, M. Chlieh, D. Natawidjaja, L. Prawirodirdjo, and Y. Bock (2006), Frictional afterslip following the 2005 Nias-Simeulue earthquakes, Sumatra, Science, 312, 1921-1926, doi:10.1126/science.1126960.

Igarashi, T., T. Matsuzawa, and A. Hasegawa (2003), Repeating earthquakes and interplate aseismic slip in the northeastern Japan subduction zone, J. Geophys. Res., 108, doi:10.1029/2002JB001920. 
Kawasaki, I., Y. Asai, Y. Tamura, T. Sagiya, N. Mikami, Y. Okada, M. Sakata, and M. Kasahara (1995), The 1992 Sanriku-Oki, Japan, ultra-slow earthquake, J. Phys. Earth, 43, 105-116.

Kawasaki, I., Y. Asai, and Y. Tamura (2001), Space-time distribution of interplate moment release including slow earthquakes and the seismo-geodetic coupling in the Sanriku-oki region along the Japan trench, Tectonophysics, 330, 267-283.

Llenos, A. L., and J. J. McGuire (2007), Influence of fore-arc structure on the extent of great subduction zone earthquakes, J. Geophys. Res., 112, B09301, doi:10.1029/2007JB004944.

Llenos, A. L., J. J. McGuire, and Y. Ogata (2009), Modeling seismic swarms triggered by aseismic transients, Earth Planet. Sci. Lett., 281, 59-69, doi:10.1016/j.eps1.2009.02.011.

Matsubara, M., Y. Yagi, and K. Obara (2005), Plate boundary slip associated with the 2003 Off-Tokachi earthquake based on small repeating earthquake data, Geophys. Res. Lett., 32, L08316, doi:10.1029/2004GL022310.

McGuire, J. J., and P. Segall (2003), Imaging of aseismic fault slip transients recorded by dense geodetic networks, Geophys. J. Int., 155, 778-788.

Miura, S., K. Tachibana, T. Sato, K. Hashimoto, M. Mishina, N. Kato, and T. Hirasawa (1993). Postseismic slip events following interplate thrust earthquakes occurring in subduction zone, Proceedings of CRCM '93, Geodetic Society of Japan, 83-84.

Miyazaki, S., P. Segall, J. Fukuda, and T. Kato (2004a), Space time distribution of afterslip following the 2003 Tokachi-oki earthquake: Implications for variations in fault zone frictional properties, Geophys. Res. Lett., 31, L06623, doi:10.1029/2003GL019410.

Miyazaki, S., K. M. Larson, K. Choi, K. Hikima, K. Koketsu, P. Bodin, J. Haase, G. Emore, and A. Yamagiwa (2004b), Modeling the rupture process of the 2003 September 25 Tokachi-Oki (Hokkaido) earthquake using 1-Hz GPS data, Geophys. Res. Lett., 31, L21603, doi:10.1029/2004GL021457.

Nadeau, R. M., and L. R. Johnson (1998), Seismological studies at Parkfield VI: Moment release rates and estimates of source parameters for small repeating earthquakes, Bull. Seismol. Soc. Am., 87, 1463-1472.

Nishimura, T., S. Miura, K. Tachibaba, K. Hashimoto, T. Sato, S. Hori, E. Murakami, T. Kono, K. Nida, M. Mishina, T. Hirasawa, and S. Miyazaki, Distribution of seismic coupling on the subducting plate boundary in northeastern Japan inferred from GPS observations, Tectonophysics, 323, 217-238. 
Ogata, Y. (1988), Statistical models for earthquake occurrences and residual analysis for point processes, J. Am. Stat. Assoc., 83, 9-27.

Ogata, Y. (1998), Space-time point process models for earthquake occurrences, Ann. Inst. Statist. Math., 50, 379-402.

Ogata, Y. (2005), Detection of anomalous seismicity as stress change sensor, J. Geophys. Res., 110, B05S06, doi:10.1029/2004JB003245.

Ogata, Y. (2006), Statistical Analysis of Seismicity - Updated Version (SASeis2006), Computer Science Monograph, No.33, pp.1-28, The Institute of Statistical Mathematics, Tokyo, Japan.

Ogata, Y., and J. Zhuang (2006), Space-time ETAS models and an improved extension, Tectonophysics, 413, doi:10.1016/j.tecto.2005.10.016.

Ogata, Y., K. Katsura, and M. Tanemura (2003), Modelling heterogeneous space-time occurrences of earthquakes and its residual analysis, Appl. Statist., 52, 499-509.

Ozawa, S., H. Suito, and M. Tobita (2007), Occurrence of quasi-periodic slow-slip off the east coast of the Boso peninsula, Central Japan, Earth Planets Space, 59, 1241-1245.

Sato, T., K. Imanishi, and M. Kosuga (1996), Three-stage rupture process of the 28 December 1994 Sanriku-Oki earthquake, Geophys. Res. Lett., 23, 33-36.

Segall, P., and M. Matthews (1997), Time dependent inversion of geodetic data, J. Geophys. Res., 102, 22,391-22,409.

Toda, S., and S. Matsumura (2006), Spatio-temporal stress states estimated from seismicity rate changes in the Tokai region, central Japan, Tectonophysics, 417, 53-68, doi:10.1016/j.tecto.2005.08.030.

Uchida, N., T. Matsuzawa, and A. Hasegawa (2003), Interplate quasi-static slip off Sanriku, NE Japan, estimated from repeating earthquakes, Geophys. Res. Lett., 30(15), 1801, doi:10.1029/2003GL017452.

Uchida, N., A. Hasegawa, T. Matsuzawa, and T. Igarashi (2004), Pre- and post-seismic slow slip on the plate boundary off Sanriku, NE Japan associated with three interplate earthquakes as estimated from small repeating earthquake data, Tectonophysics, 385, 115, doi:10.1016/j.tecto.2004.04.015.

Wessel, P., and W. H. F. Smith (1998), New, improved version of generic mapping tools released, Eos Trans. AGU, 79(47), 579. 
Yagi, Y. (2004), Source rupture process of the 2003 Tokachi-oki earthquake determined by joint inversion of teleseismic body wave and strong ground motion data, Earth Planets Space, 56, 311-316.

Yagi, Y., M. Kikuchi, and T. Nishimura (2003), Co-seismic slip, post-seismic slip, and largest aftershock associated with the 1994 Sanriku-haruka-oki, Japan, earthquake, Geophys. Res. Lett., 30(22), 2177, doi:10.1029/2003GL018189.

Yamanaka, Y., and M. Kikuchi (2003), Source processes of the recurrent Tokachi-oki earthquake on September 26, 2003, inferred from teleseismic body waves, Earth Planets Space, 55, 21-24.

Yamanaka, Y., and M. Kikuchi (2004), Asperity map along the subduction zone in northeastern Japan inferred from regional seismic data, J. Geophys. Res., 109, B07307, doi:10.1029/2003JB002683. 


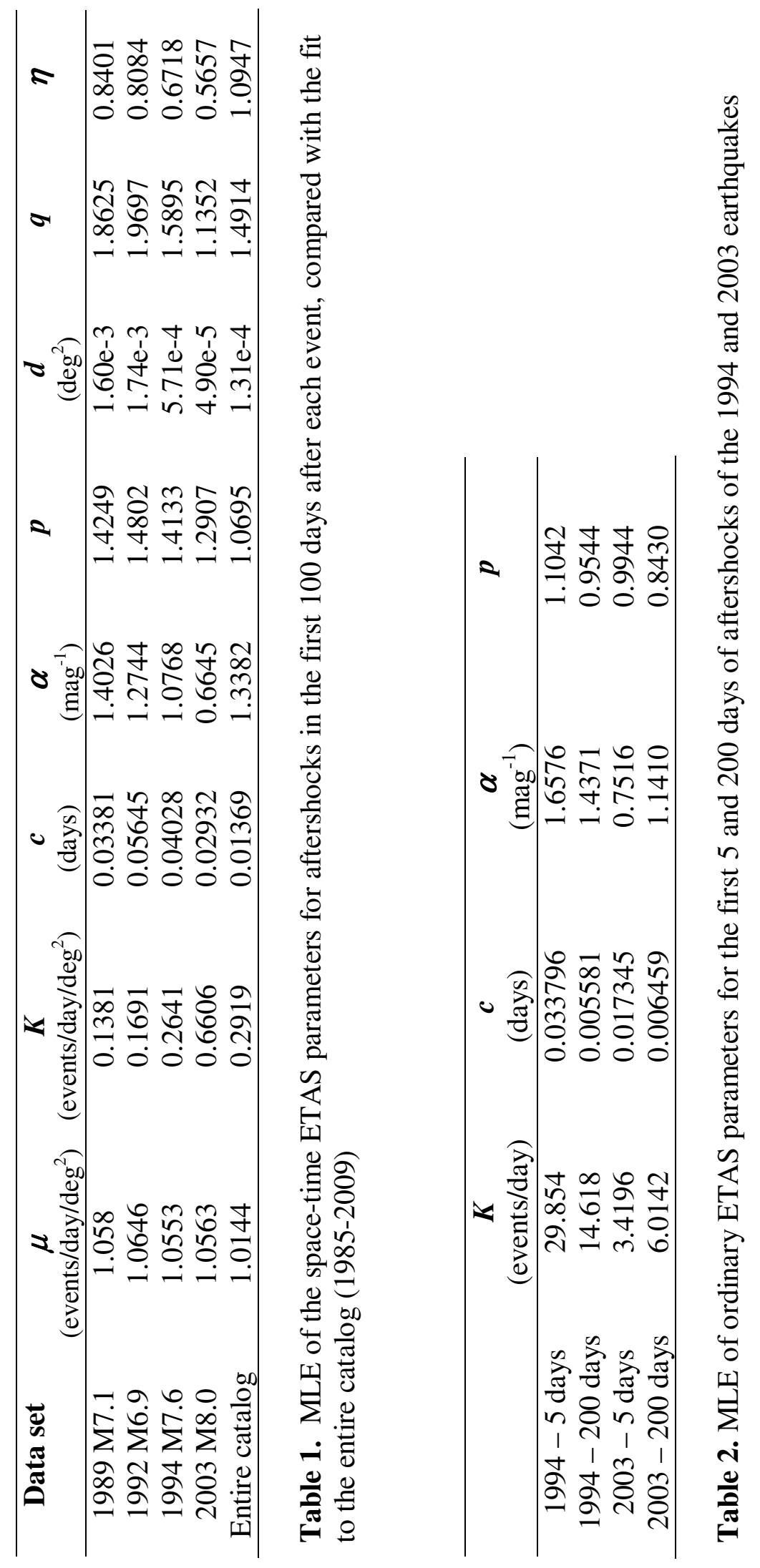




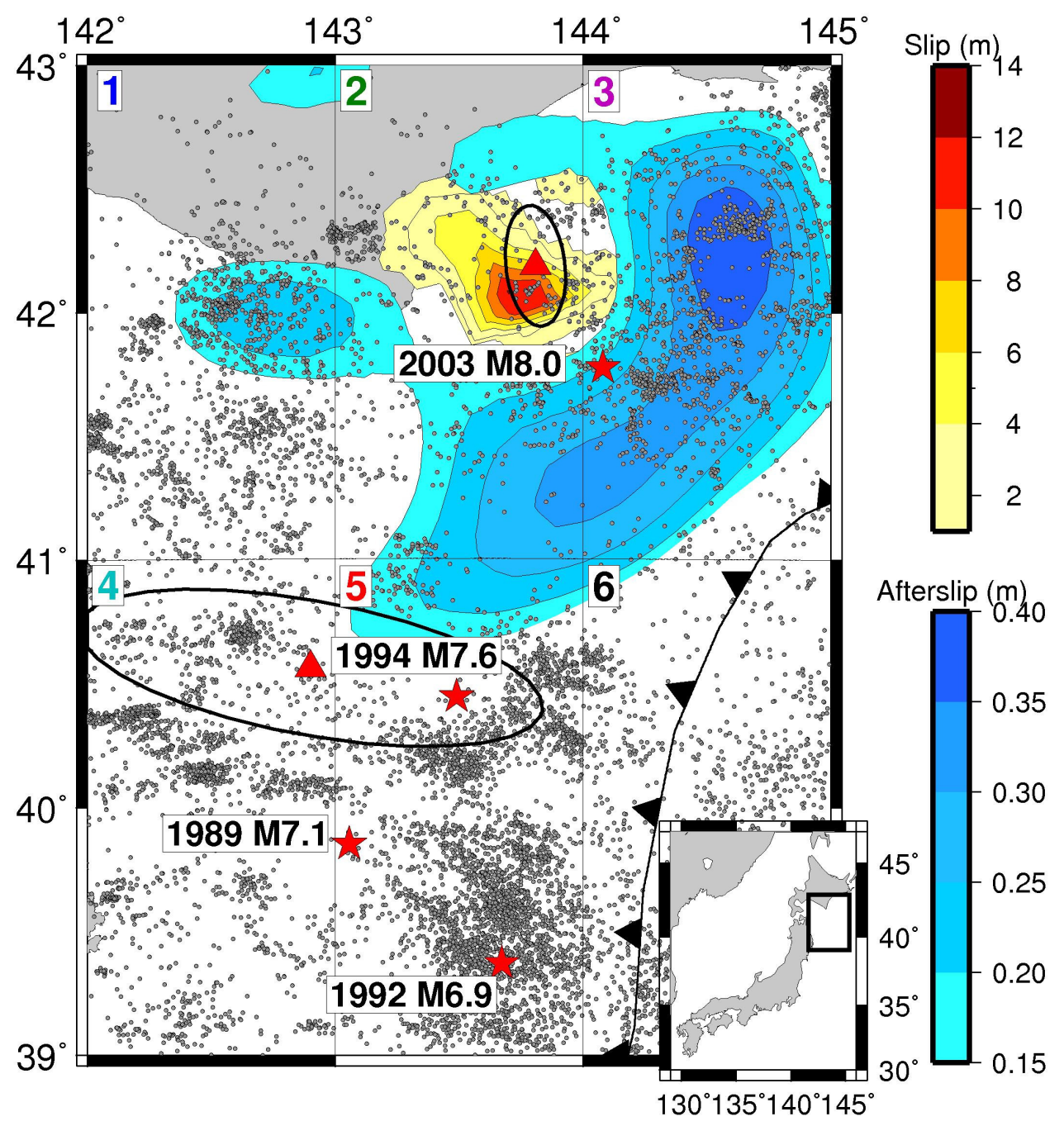

Figure 1. Map of the Hokkaido corner showing $M \geq 3$ seismicity occurring from 19852009, obtained from the Japan Meteorological Agency (black dots). Hypocenters of the 4 largest interplate events are indicated by red stars. Centroids from the Global Centroid Moment Tensor catalog for the 1994 M7.6 Sanriku-oki and 2003 M8.0 Tokachi-oki earthquakes are indicated by red triangles. Also shown for these two events are ellipses representing the part of the fault where the majority of the coseismic moment release occurred [Llenos and McGuire, 2007]. For the 2003 Tokachi-oki event, a coseismic slip model (red contours) [Miyazaki et al., 2004b] and 30-day afterslip model (blue contours) [Miyazaki et al., 2004a] estimated from GPS are also shown. For the filter inversion the region is divided up into the 6 boxes indicated by the colored numbers. 

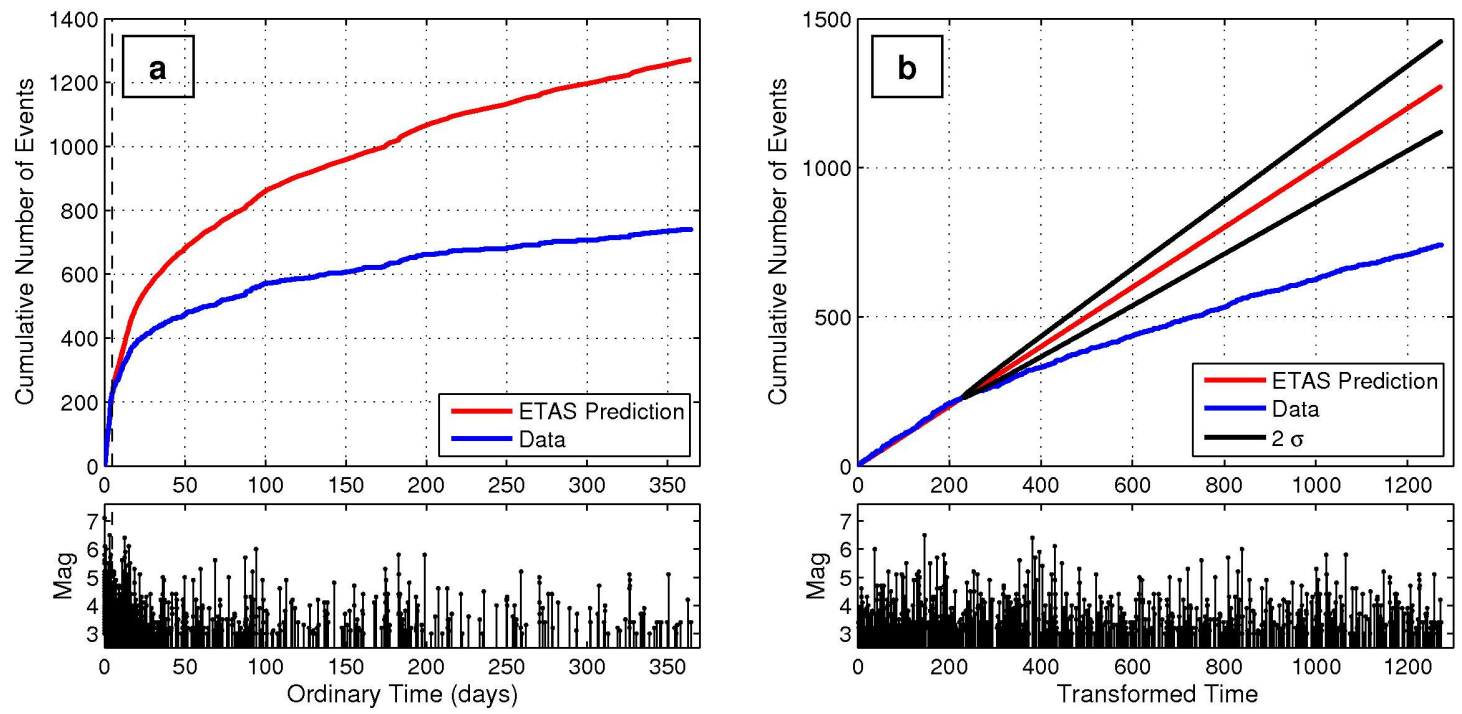

Figure 2. Results of optimizing the ETAS model to fit the first 5 days of the Tokachi-oki aftershocks and extrapolated for a year following the earthquake. Bottom panels show the magnitudes of the events. a) Observed cumulative number of events in the year following the earthquake (blue) compared with the ETAS prediction (red) based on fitting the first 5 days (dashed line). b) Cumulative number of events versus ETAS transformed time (predicted cumulative number of events). The ETAS prediction is shown by the red line and observed data in blue. Black lines signify the $2 \sigma$ bounds of the extrapolation. There are significantly less earthquakes in the later part of the sequence than is predicted by the parameters that fit the earlier part, suggesting that the same set of parameters cannot be used to describe both the early and late parts of the aftershock sequence. 


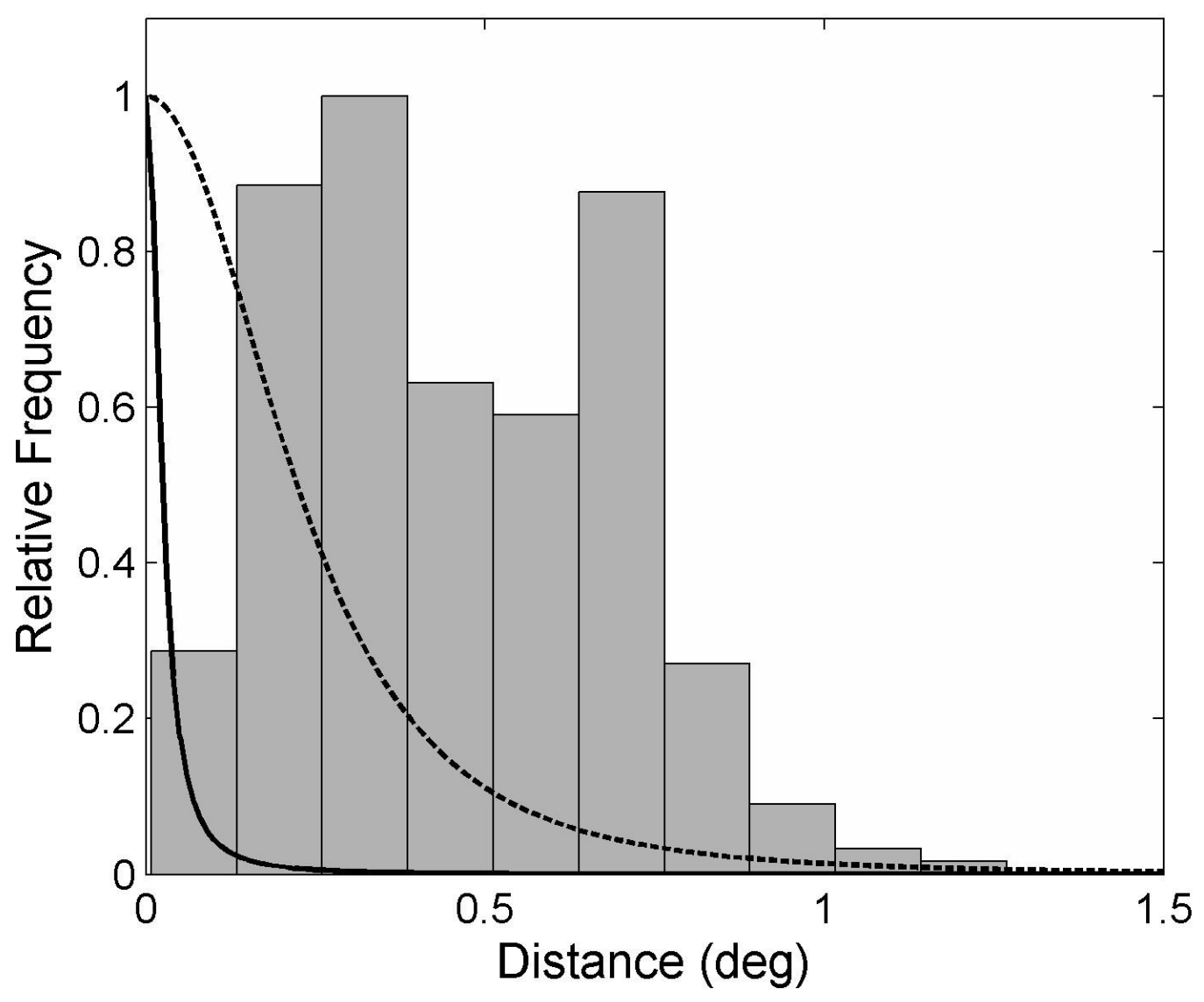

Figure 3. Histogram of mainshock-aftershock distances for aftershocks in Boxes 2 and 3 in the first month following the 2003 M8.0 Tokachi-oki earthquake, scaled such that the peak occurs at a value of 1 . Also shown is the decay predicted by the spatial PDF used in the ETAS model (Eq. 4) with parameters estimated for the 2003 earthquake (solid black line) and for the 1989 M7.1 event (dashed black line) as a comparison (see Table 1 for parameter values). The aftershocks do not decay as quickly with distance as predicted by the ETAS model fit to either of the events. 


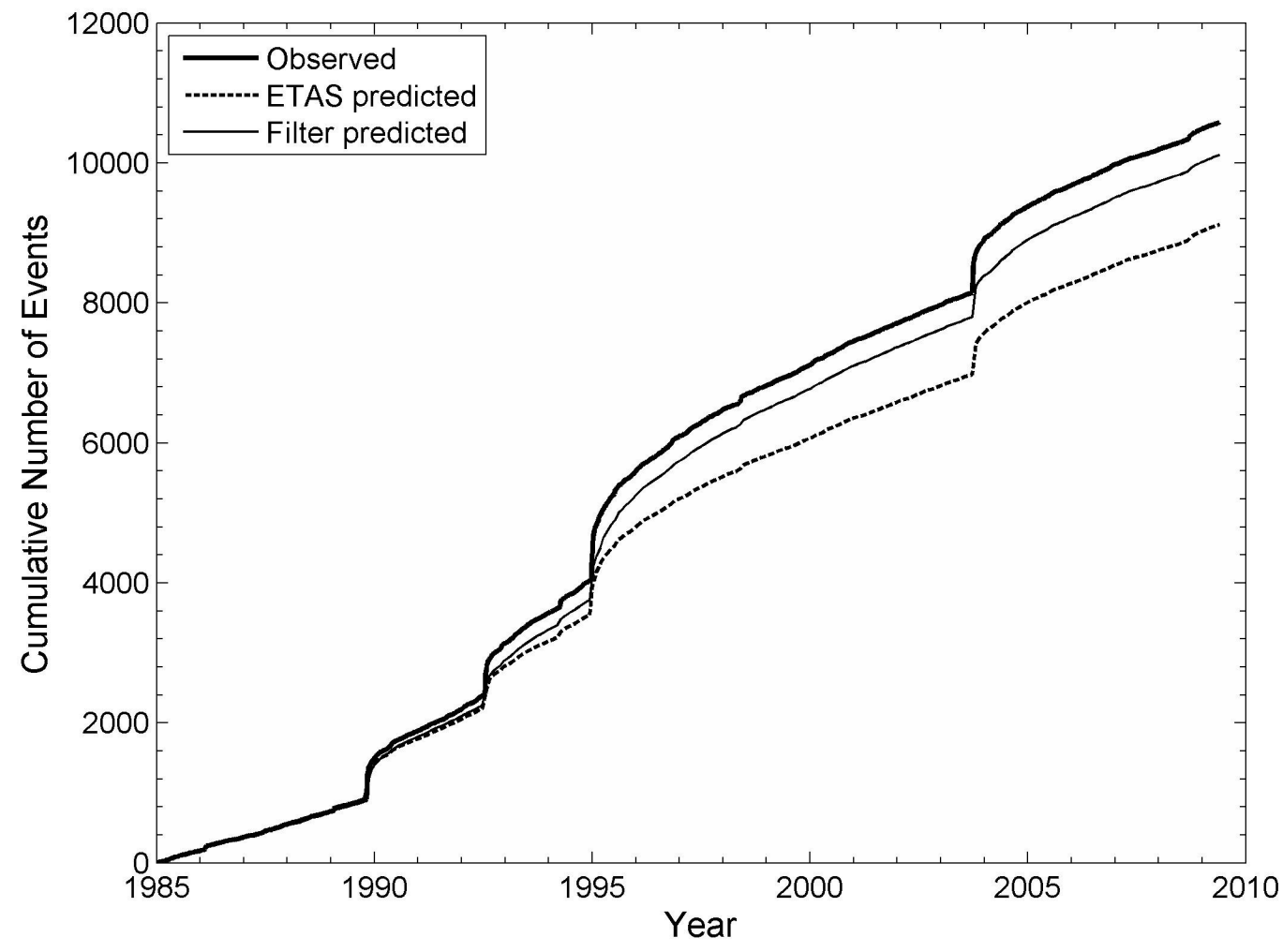

Figure 4. Cumulative number of events vs. time observed in the catalog (heavy line), compared with the number of events predicted from the ETAS model alone (dashed line), and from the filter estimate of stressing rate (thin line). While still under-predicting the total number of events, the filter estimate which utilizes a time-dependent background seismicity rate does a better job at fitting the observations than the ETAS model which utilizes a time-independent background rate. 

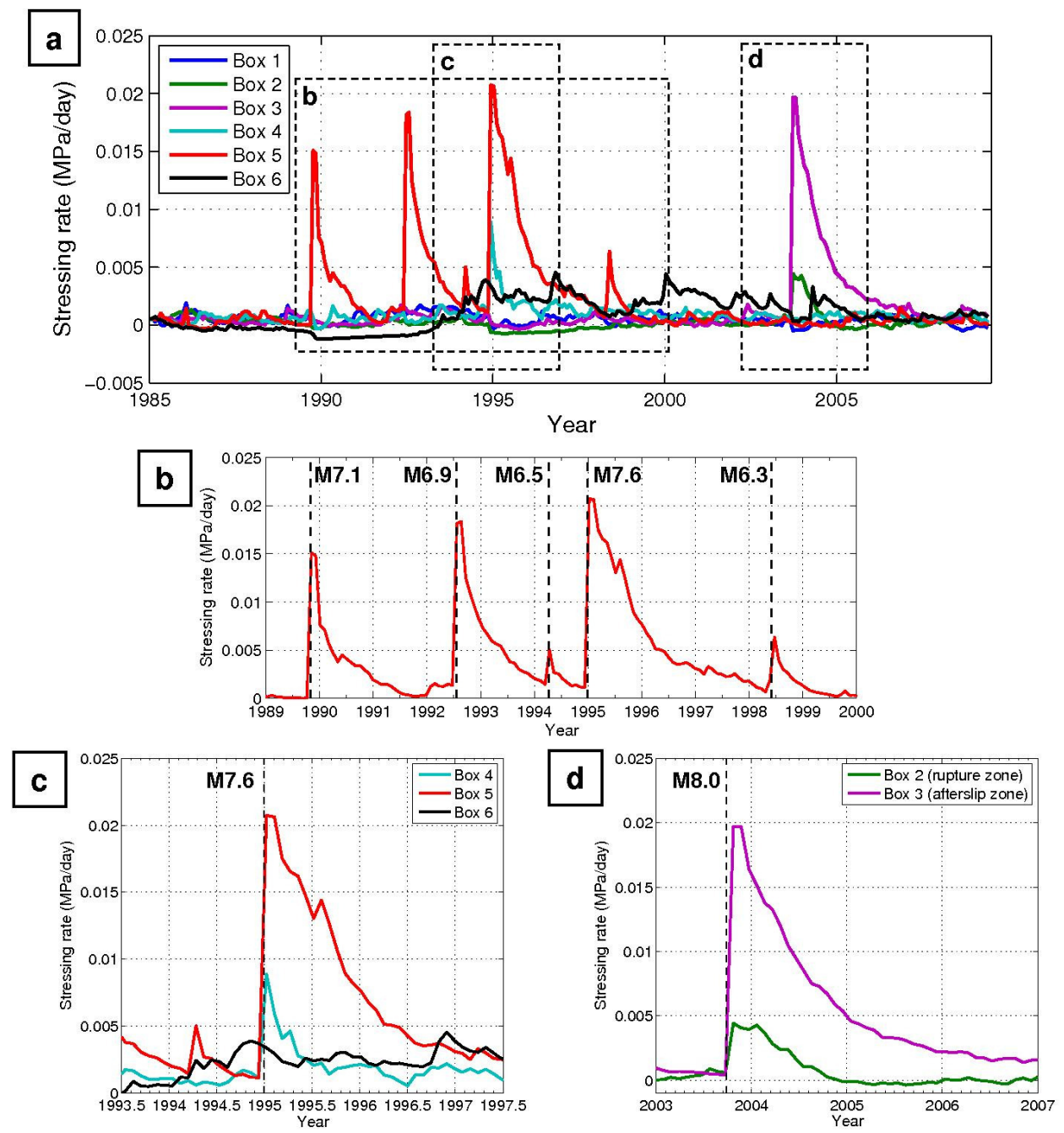

Figure 5. a) Forward filter estimates of stressing rate $\dot{S}$ in each of the spatial boxes indicated in Fig. 1. The largest signals detected are associated with geodeticallyobserved afterslip following major interplate earthquakes in 1989 (M7.1), 1992 (M6.9), 1994 (M7.6) and 2003 (M8.0). b) Results for Box 5, showing geodetically-observed afterslip following the 1989, 1992, and 1994 off-Sanriku earthquakes, as well as afterslip following a 1994 M6.5 and 1998 M6.3 event, which has been inferred from repeating earthquake analyses [Uchida et al., 2003; Uchida et al., 2004]. c) Filter estimates of $\dot{S}$ for the updip (Box 6), downdip (Box 4), and hypocentral (Box 5) areas of the 1994 M7.6 Sanriku-oki earthquake. Afterslip is concentrated in Box 4-5. A possible preseismic transient begins in early 1994 updip of the rupture (Box 6) and peaks $\sim 2$ months before the rupture. d) Results for the 2003 M8.0 Tokachi-oki event. A larger signal occurs in Box 3 (where the peak afterslip occurred [Miyazaki et al., 2004a]) than in Box 2 (where the coseismic slip occurred [Miyazaki et al., 2004b]). 